Cochrane Database of Systematic Reviews

\title{
Risperidone for psychosis-induced aggression or agitation (rapid tranquillisation) (Review)
}

Ostinelli EG, Hussein M, Ahmed U, Rehman FU, Miramontes K, Adams CE

Ostinelli EG, Hussein M, Ahmed U, Rehman FU, Miramontes K, Adams CE.

Risperidone for psychosis-induced aggression or agitation (rapid tranquillisation).

Cochrane Database of Systematic Reviews 2018, Issue 4. Art. No.: CD009412.

DOI: 10.1002/14651858.CD009412.pub2.

www.cochranelibrary.com 
TABLE OF CONTENTS

HEADER

ABSTRACT

PLAIN LANGUAGE SUMMARY

SUMMARY OF FINDINGS

BACKGROUND

Figure 1.

OBJECTIVES

METHODS

RESULTS

Figure 2.

Figure 3.

Figure 4.

DISCUSSION

AUTHORS' CONCLUSIONS

ACKNOWLEDGEMENTS

REFERENCES

CHARACTERISTICS OF STUDIES

DATA AND ANALYSES

Analysis 1.1. Comparison 1 RISPERIDONE vs OTHER ANTIPSYCHOTIC: a. HALOPERIDOL, Outcome 1 Specific behaviour: 1 . Agitation - Various measures.

Analysis 1.2. Comparison 1 RISPERIDONE vs OTHER ANTIPSYCHOTIC: a. HALOPERIDOL, Outcome 2 Specific behaviour: $1 b$.

Agitation - Average scores - i. up to 2 hours.

Analysis 1.3. Comparison 1 RISPERIDONE vs OTHER ANTIPSYCHOTIC: a. HALOPERIDOL, Outcome 3 Specific behaviour: $1 \mathrm{c}$. Agitation - Average scores - ii. up to 24 hours.

Analysis 1.4. Comparison 1 RISPERIDONE vs OTHER ANTIPSYCHOTIC: a. HALOPERIDOL, Outcome 4 Specific behaviour: $1 \mathrm{~d}$. Agitation - Average scores - iii. over 24 hours.

Analysis 1.5. Comparison 1 RISPERIDONE vs OTHER ANTIPSYCHOTIC: a. HALOPERIDOL, Outcome 5 Global outcome: 1a. General - Need for additional measures.

Analysis 1.6. Comparison 1 RISPERIDONE vs OTHER ANTIPSYCHOTIC: a. HALOPERIDOL, Outcome 6 Global outcome: 1 b. General - Need for additional medication (skewed data).

Analysis 1.7. Comparison 1 RISPERIDONE vs OTHER ANTIPSYCHOTIC: a. HALOPERIDOL, Outcome 7 Adverse effects: 1. General.

Analysis 1.8. Comparison 1 RISPERIDONE vs OTHER ANTIPSYCHOTIC: a. HALOPERIDOL, Outcome 8 Adverse effects: 2a. Specific - Arousal level.

Analysis 1.9. Comparison 1 RISPERIDONE vs OTHER ANTIPSYCHOTIC: a. HALOPERIDOL, Outcome 9 Adverse effects: 2 b. Specific - Movement disorder - i. Various.

Analysis 1.10. Comparison 1 RISPERIDONE vs OTHER ANTIPSYCHOTIC: a. HALOPERIDOL, Outcome 10 Adverse effects: $2 b$. Specific - Movement disorder - ii. Need for biperiden.

Analysis 1.11. Comparison 1 RISPERIDONE vs OTHER ANTIPSYCHOTIC: a. HALOPERIDOL, Outcome 11 Adverse effects: 2 b. Specific - Movement disorder - iii. Average scores (skewed data).

Analysis 1.12. Comparison 1 RISPERIDONE vs OTHER ANTIPSYCHOTIC: a. HALOPERIDOL, Outcome 12 Adverse effects: 2c. Specific - Miscellaneous.

Analysis 1.13. Comparison 1 RISPERIDONE vs OTHER ANTIPSYCHOTIC: a. HALOPERIDOL, Outcome 13 Leaving the study early. . Analysis 2.1. Comparison 2 RISPERIDONE vs OTHER ANTIPSYCHOTIC: b. OLANZAPINE, Outcome 1 Specific behaviour: 1. Agitation - Average scores - i. Up to 2 hours.

Analysis 2.2. Comparison 2 RISPERIDONE vs OTHER ANTIPSYCHOTIC: b. OLANZAPINE, Outcome 2 Specific behaviour: 1. Agitation - Average scores - ii. Up to 24 hours.

Analysis 2.3. Comparison 2 RISPERIDONE vs OTHER ANTIPSYCHOTIC: b. OLANZAPINE, Outcome 3 Specific behaviour: 1. Agitation - Average scores - iii. over 24 hours.

Analysis 2.4. Comparison 2 RISPERIDONE vs OTHER ANTIPSYCHOTIC: b. OLANZAPINE, Outcome 4 Global outcome: 1a. General - Need for additional measures.

Analysis 2.5. Comparison 2 RISPERIDONE vs OTHER ANTIPSYCHOTIC: b. OLANZAPINE, Outcome 5 Global outcome: $1 \mathrm{~b}$. General - Need for additional medication (skewed data).

Analysis 2.6. Comparison 2 RISPERIDONE vs OTHER ANTIPSYCHOTIC: b. OLANZAPINE, Outcome 6 Adverse effects: 1a. Specific - Movement disorder - i. Meed for biperiden. 
Analysis 2.7. Comparison 2 RISPERIDONE vs OTHER ANTIPSYCHOTIC: b. OLANZAPINE, Outcome 7 Adverse effects: 1 b. Specific - Movement disorder - ii. Average scores (skewed data).

Analysis 2.8. Comparison 2 RISPERIDONE vs OTHER ANTIPSYCHOTIC: b. OLANZAPINE, Outcome 8 Leaving the study early. .... Analysis 3.1. Comparison 3 RISPERIDONE vs OTHER ANTIPSYCHOTIC: c. QUETIAPINE, Outcome 1 Specific behaviour: 1. Aggression - Average scores - i. Over 24 hours.

Analysis 3.2. Comparison 3 RISPERIDONE vs OTHER ANTIPSYCHOTIC: c. QUETIAPINE, Outcome 2 Mental state: 1a. No change in general mental state.

Analysis 3.3. Comparison 3 RISPERIDONE vs OTHER ANTIPSYCHOTIC: c. QUETIAPINE, Outcome 3 Mental state: 1b. Change in general mental state.

Analysis 3.4. Comparison 3 RISPERIDONE vs OTHER ANTIPSYCHOTIC: c. QUETIAPINE, Outcome 4 Mental state: 1c. Average scores - i. Over 24 hours.

Analysis 3.5. Comparison 3 RISPERIDONE vs OTHER ANTIPSYCHOTIC: c. QUETIAPINE, Outcome 5 Adverse effects: 1a. Specific - Anticholinergic.

Analysis 3.6. Comparison 3 RISPERIDONE vs OTHER ANTIPSYCHOTIC: c. QUETIAPINE, Outcome 6 Adverse effects: 1b. Specific - Arousal.

Analysis 3.7. Comparison 3 RISPERIDONE vs OTHER ANTIPSYCHOTIC: c. QUETIAPINE, Outcome 7 Adverse effects: 1c. Specific - Cardiovascular.

Analysis 3.8. Comparison 3 RISPERIDONE vs OTHER ANTIPSYCHOTIC: c. QUETIAPINE, Outcome 8 Adverse effects: 1d. Specific - Gastrointestinal.

Analysis 3.9. Comparison 3 RISPERIDONE vs OTHER ANTIPSYCHOTIC: c. QUETIAPINE, Outcome 9 Adverse effects: 1e. Specific - Movement disorders.

Analysis 3.10. Comparison 3 RISPERIDONE vs OTHER ANTIPSYCHOTIC: c. QUETIAPINE, Outcome 10 Adverse effects: 1f. Specific - Miscellaneous.

Analysis 4.1. Comparison 4 RISPERIDONE vs COMBINATION: a. RISPERIDONE + OXCARBAZEPINE, Outcome 1 Specific behaviour: 1. Agitation - Average scores - i. over 24 hours.

Analysis 4.2. Comparison 4 RISPERIDONE vs COMBINATION: a. RISPERIDONE + OXCARBAZEPINE, Outcome 2 Global Outcome: 1. Average scores - i. Over 24 hours.

Analysis 4.3. Comparison 4 RISPERIDONE vs COMBINATION: a. RISPERIDONE + OXCARBAZEPINE, Outcome 3 Mental state: 1 a. No change in general mental state.

Analysis 4.4. Comparison 4 RISPERIDONE vs COMBINATION: a. RISPERIDONE + OXCARBAZEPINE, Outcome 4 Mental state: $1 \mathrm{~b}$. Change in general mental state.

Analysis 4.5. Comparison 4 RISPERIDONE vs COMBINATION: a. RISPERIDONE + OXCARBAZEPINE, Outcome 5 Mental state: $1 \mathrm{c}$. Average scores - i. Over 24 hours.

Analysis 4.6. Comparison 4 RISPERIDONE vs COMBINATION: a. RISPERIDONE + OXCARBAZEPINE, Outcome 6 Adverse effects: 1. General - Total number of AEs.

Analysis 4.7. Comparison 4 RISPERIDONE vs COMBINATION: a. RISPERIDONE + OXCARBAZEPINE, Outcome 7 Adverse effects: 2a. Specific - Anticholinergic.

Analysis 4.8. Comparison 4 RISPERIDONE vs COMBINATION: a. RISPERIDONE + OXCARBAZEPINE, Outcome 8 Adverse effects: 2b. Specific - Arousal.

Analysis 4.9. Comparison 4 RISPERIDONE vs COMBINATION: a. RISPERIDONE + OXCARBAZEPINE, Outcome 9 Adverse effects: 2c. Specific - Cardiovascular.

Analysis 4.10. Comparison 4 RISPERIDONE vs COMBINATION: a. RISPERIDONE + OXCARBAZEPINE, Outcome 10 Adverse effects: 2d. Specific - Gastrointestinal.

Analysis 4.11. Comparison 4 RISPERIDONE vs COMBINATION: a. RISPERIDONE + OXCARBAZEPINE, Outcome 11 Adverse effects: 2e. Specific - Movement disorders.

Analysis 4.12. Comparison 4 RISPERIDONE vs COMBINATION: a. RISPERIDONE + OXCARBAZEPINE, Outcome 12 Adverse effects: 2f. Specific - Miscellaneous.

Analysis 5.1. Comparison 5 RISPERIDONE vs COMBINATION: b. RISPERIDONE + VALPROIC ACID, Outcome 1 Specific behaviour: 1. Agitation - average scores - i. over 24 hours.

Analysis 5.2. Comparison 5 RISPERIDONE vs COMBINATION: b. RISPERIDONE + VALPROIC ACID, Outcome 2 Specific behaviour: 1. Aggression - Average scores - i. over 24 hours.

Analysis 5.3. Comparison 5 RISPERIDONE vs COMBINATION: b. RISPERIDONE + VALPROIC ACID, Outcome 3 Mental state: 1 . No change in general mental state.

Analysis 5.4. Comparison 5 RISPERIDONE vs COMBINATION: b. RISPERIDONE + VALPROIC ACID, Outcome 4 Mental state: 2. Average scores - i. over 24 hours. 
Analysis 5.5. Comparison 5 RISPERIDONE vs COMBINATION: b. RISPERIDONE + VALPROIC ACID, Outcome 5 Adverse effects: 1 a. General - Total number of AEs.

Analysis 5.6. Comparison 5 RISPERIDONE vs COMBINATION: b. RISPERIDONE + VALPROIC ACID, Outcome 6 Adverse effects: 1 b. General - Serious.

Analysis 5.7. Comparison 5 RISPERIDONE vs COMBINATION: b. RISPERIDONE + VALPROIC ACID, Outcome 7 Adverse effects: $2 a$. Specific - Anticholinergic.

Analysis 5.8. Comparison 5 RISPERIDONE vs COMBINATION: b. RISPERIDONE + VALPROIC ACID, Outcome 8 Adverse effects: 2 b. Specific - Arousal.

Analysis 5.9. Comparison 5 RISPERIDONE vs COMBINATION: b. RISPERIDONE + VALPROIC ACID, Outcome 9 Adverse effects: 2c. Specific - Cardiovascular.

Analysis 5.10. Comparison 5 RISPERIDONE vs COMBINATION: b. RISPERIDONE + VALPROIC ACID, Outcome 10 Adverse effects: 2d. Specific - Gastrointestinal.

Analysis 5.11. Comparison 5 RISPERIDONE vs COMBINATION: b. RISPERIDONE + VALPROIC ACID, Outcome 11 Adverse effects: 2e. Specific - Movement disorders.

Analysis 5.12. Comparison 5 RISPERIDONE vs COMBINATION: b. RISPERIDONE + VALPROIC ACID, Outcome 12 Adverse effects: 2f. Specific - Movement disorders - Average scores - i. Over 24 hours.

Analysis 5.13. Comparison 5 RISPERIDONE vs COMBINATION: b. RISPERIDONE + VALPROIC ACID, Outcome 13 Adverse effects: 2g. Specific - Miscellaneous.

Analysis 5.14. Comparison 5 RISPERIDONE vs COMBINATION: b. RISPERIDONE + VALPROIC ACID, Outcome 14 Leaving the study early.

ADDITIONAL TABLES

HISTORY

CONTRIBUTIONS OF AUTHORS 
[Intervention Review]

\title{
Risperidone for psychosis-induced aggression or agitation (rapid tranquillisation)
}

\author{
Edoardo G Ostinelli1, Mohsin Hussein², Uzair Ahmed³, Faiz-ur Rehman4, Krista Miramontes ${ }^{5}$, Clive E Adams 6
}

1Department of Health Sciences, Università degli Studi di Milano, Milan, Italy. 2Queens Medical Centre, The University of Nottingham, Nottingham, UK. ${ }^{3}$ Mental Health, Rathbone Hospital, Mersey Care NHS Foundation Trust, Liverpool, UK. ${ }^{4}$ Lytham Hospital, Lancashire Care NHS Foundation Trust, Lytham, UK. ${ }^{5}$ Home, Oxford, UK. ${ }^{6}$ Cochrane Schizophrenia Group, The University of Nottingham, Nottingham, UK

Contact address: Edoardo G Ostinelli, Department of Health Sciences, Università degli Studi di Milano, Via Antonio di Rudinì 8, Milan, 20142, Italy. eg.ostinelli@gmail.com.

Editorial group: Cochrane Schizophrenia Group.

Publication status and date: New, published in Issue 4, 2018.

Citation: Ostinelli EG, Hussein M, Ahmed U, Rehman FU, Miramontes K, Adams CE. Risperidone for psychosis-induced aggression or agitation (rapid tranquillisation). Cochrane Database of Systematic Reviews 2018, Issue 4. Art. No.: CD009412. DOI: 10.1002/14651858.CD009412.pub2.

Copyright () 2018 The Cochrane Collaboration. Published by John Wiley \& Sons, Ltd.

\section{A B S T R A C T}

\section{Background}

Aggressive, agitated or violent behaviour due to psychosis constitutes an emergency psychiatric treatment where fast-acting interventions are required. Risperidone is a widely accessible antipsychotic that can be used to manage psychosis-induced aggression or agitation.

\section{Objectives}

To examine whether oral risperidone alone is an effective treatment for psychosis-induced aggression or agitation.

\section{Search methods}

We searched the Cochrane Schizophrenia Group's Study-Based Register of Trials (up to April 2017); this register is compiled by systematic searches of major resources (including AMED, BIOSIS CINAHL, Embase, MEDLINE, PsycINFO, PubMed, and registries of clinical trials) and their monthly updates, handsearches, grey literature, and conference proceedings. There are no language, date, document type, or publication status limitations for inclusion of records into the register.

\section{Selection criteria}

Randomised controlled trials (RCTs) comparing rapid use of risperidone and other drugs, combinations of drugs or placebo for people exhibiting aggression or agitation (or both) thought to be due to psychosis.

\section{Data collection and analysis}

We independently inspected all citations from searches, identified relevant abstracts, and independently extracted data from all included studies. For binary data we calculated risk ratio (RR) and for continuous data we calculated mean difference (MD), all with 95\% confidence intervals $(\mathrm{CI})$ and used a fixed-effect model. We assessed risk of bias for the included studies and used the GRADE approach to produce a 'Summary of findings' tables.

\section{Main results}

The review now contains data from nine trials (total $n=582$ ) reporting on five comparisons. Due to risk of bias, small size of trials, indirectness of outcome measures and a paucity of investigated and reported 'pragmatic' outcomes, evidence was graded as very-low quality. None of the included studies provided useable data on our primary outcome 'tranquillisation or asleep' by 30 minutes, repeated 
need for tranquillisation or any economic outcomes. Data were available for our other main outcomes of agitation or aggression, needing restraint, and incidence of adverse effects.

Risperidone versus haloperidol (up to 24 hours follow-up)

For the outcome, specific behaviour - agitation, no clear difference was found between risperidone and haloperidol in terms of efficacy, measured as at least 50\% reduction in the Positive and Negative Syndrome Scale - Psychotic Agitation Sub-score (PANSS-PAS) (RR 1.04, $95 \% \mathrm{Cl} 0.86$ to 1.26 ; participants $=124$; studies $=1$; very low-quality evidence) and no effect was observed for need to use restraints (RR 2.00 , $95 \% \mathrm{Cl} 0.43$ to 9.21 ; participants $=28$; studies $=1$; very low-quality evidence). Incidence of adverse effects was similar between treatment groups (RR 0.94, 95\% Cl 0.54 to 1.66; participants = 124; studies = 1; very low-quality evidence).

\section{Risperidone versus olanzapine}

One small trial $(n=29)$ reported useable data for the comparison risperidone versus olanzapine. No effect was observed for agitation measured as PANSS-PAS endpoint score at two hours (MD 2.50, $95 \% \mathrm{Cl}-2.46$ to 7.46 ; very low-quality evidence); need to use restraints at four days (RR 1.43, 95\% Cl 0.39 to 5.28; very-low quality evidence); specific movement disorders measured as Behavioural Activity Rating Scale (BARS) endpoint score at four days (MD $0.20,95 \% \mathrm{Cl}-0.43$ to 0.83 ; very low-quality evidence).

\section{Risperidone versus quetiapine}

One trial reported $(n=40)$ useable data for the comparison risperidone versus quetiapine. Aggression was measured using the Modified Overt Aggression Scale (MOAS) endpoint score at two weeks. A clear difference, favouring quetiapine was observed (MD $1.80,95 \% \mathrm{Cl} 0.20$ to 3.40; very-low quality evidence). No evidence of a difference between treatment groups could be observed for incidence of akathisia after 24 hours (RR 1.67, 95\% Cl 0.46 to 6.06; very low-quality evidence). Two participants allocated to risperidone and one allocated to quetiapine experienced myocardial ischaemia during the trial.

\section{Risperidone versus risperidone + oxcarbazepine}

One trial $(n=68)$ measured agitation using the Positive and Negative Syndrome Scale - Excited Component.(PANSS-EC) endpoint score and found a clear difference, favouring the combination treatment at one week (MD 2.70, $95 \% \mathrm{Cl} 0.42$ to 4.98 ; very low-quality evidence), but no effect was observed for global state using Clinical Global Impression - Improvement (CGI-I) endpoint score at one week (MD -0.20, 95\% $\mathrm{Cl}-0.61$ to 0.21 ; very-low quality evidence). Incidence of extrapyramidal symptoms after 24 hours was similar between treatment groups (RR $1.59,95 \% \mathrm{Cl} 0.49$ to 5.14 ; very-low quality evidence).

Risperidone versus risperidone + valproic acid

Two trials compared risperidone with a combination of risperidone plus valproic acid. No clear differences between the treatment groups were observed for aggression (MOAS endpoint score at three days: $\mathrm{MD} 1.07,95 \% \mathrm{Cl}-0.20$ to 2.34; participants $=54$; studies $=1$; very lowquality evidence) or incidence of akathisia after 24 hours: RR $0.75,95 \% \mathrm{Cl} 0.28$ to 2.03; participants $=122$; studies $=2$; very low-quality evidence).

\section{Authors' conclusions}

Overall, results for the main outcomes show no real effect for risperidone. The only data available for use in this review are from nine undersampled trials and the evidence available is of very low quality. This casts uncertainty on the role of risperidone in rapid tranquillisation for people with psychosis-induced aggression. High-quality pragmatic RCTs are feasible and are needed before clear recommendations can be drawn on the use of risperidone for psychosis-induced aggression or agitation.

\section{PLAIN LANGUAGE SUMMARY}

\section{Risperidone as a means of calming people who are aggressive or agitated due to psychosis}

\section{Background}

People with psychosis may experience hearing voices (hallucinations) or abnormal thoughts (delusions), which can make the person frightened, distressed, and agitated. Experiencing such emotions can sometimes lead to aggressive behaviour. This poses a challenge and dilemma for staff. Mental health professionals have to diagnose and deliver the best available treatment to prevent the risk of harm to both the patient and/or others, the faster the better. Risperidone is a medication taken by mouth, widely used for treating people manage the symptoms of psychosis. As well as being an antipsychotic (preventing psychosis), it also could calm people down or help them to sleep.

\section{Aim of the review}

This review looks at whether the antipsychotic, risperidone, could be a fast, effective treatment for people who are agitated or aggressive as a result of having psychosis.

\section{Searches}

Risperidone for psychosis-induced aggression or agitation (rapid tranquillisation) (Review)

Copyright (c) 2018 The Cochrane Collaboration. Published by John Wiley \& Sons, Ltd. 
The Information Specialist of Cochrane Schizophrenia ran searches of their specialised register for randomised trials that looked at the effects of giving risperidone alone compared with giving either placebo (dummy treatment) or other treatments to people who are aggressive or agitated as a results of having psychosis. The latest date of searching was April 2017.

\section{Results}

Nine studies, with 582 participants, are included in the review but the information provided is poor in quality and tended to provide information only partially relevant to the main aim of this review, particularly a lack of information regarding immediate (i.e. under one hour after treatment) calming effects and the need for repeated tranquillisation. Economic data were also not reported. In the trials, risperidone was compared to other antipsychotics, which included haloperidol, olanzapine and quetiapine. The review found risperidone was no better or worse than haloperidol for calming aggression within 24 hours, and that two weeks after treatment, people receiving risperidone had higher (worse) scores on scales measuring levels of aggression than those receiving quetiapine. Both these results, however, were graded as very low-quality evidence. One small study found a combination of antipsychotics (risperidone plus oxcarbazepine) was better than risperidone alone at reducing levels of agitation but these data were collected after one week and again, this evidence was rated as very low quality. No clear differences in the incidence of side effects such as movement disorders were observed.

\section{Conclusions}

The review authors conclude that at the moment, there is weak, unclear evidence regarding the use of risperidone for calming people who are aggressive due to psychosis, and no firm conclusions can be made. Therefore, health professionals and people with mental health problems are left without clear evidence-based guidance. However, good quality trials are possible and more research is needed to help people dealing with psychosis-induced aggression consider and understand which medication is better at calming aggression, has fewer side effects and works quickly. 


\section{S U M MARY OF F I N D I N S}

Summary of findings for the main comparison. RISPERIDONE compared to OTHER ANTIPSYCHOTIC: a. HALOPERIDOL for psychosis-induced aggression or agitation (rapid tranquillisation)

RISPERIDONE compared to OTHER ANTIPSYCHOTIC: a. HALOPERIDOL for psychosis-induced aggression or agitation (rapid tranquillisation)

Patient or population: psychosis-induced aggression or agitation (rapid tranquillisation)

Setting: Psychiatric acute care units.

Intervention: RISPERIDONE

Comparison: OTHER ANTIPSYCHOTIC: a. HALOPERIDOL

\begin{tabular}{|c|c|c|c|c|c|c|}
\hline \multirow[t]{2}{*}{ Outcomes } & \multicolumn{2}{|c|}{ Anticipated absolute effects ${ }^{\star}(95 \% \mathrm{Cl})$} & \multirow{2}{*}{$\begin{array}{l}\text { Relative effect } \\
(95 \% \mathrm{CI})\end{array}$} & \multirow{2}{*}{$\begin{array}{l}\text { № of partici- } \\
\text { pants } \\
\text { (studies) }\end{array}$} & \multirow{2}{*}{$\begin{array}{l}\text { Quality of the } \\
\text { evidence } \\
\text { (GRADE) }\end{array}$} & \multirow[t]{2}{*}{ Comments } \\
\hline & $\begin{array}{l}\text { Risk with OTHER } \\
\text { ANTIPSYCHOTIC: } \\
\text { a. HALOPERIDOL }\end{array}$ & $\begin{array}{l}\text { Risk with RISPERI- } \\
\text { DONE }\end{array}$ & & & & \\
\hline $\begin{array}{l}\text { Tranquillisation or asleep by } 30 \text { minutes - not mea- } \\
\text { sured }\end{array}$ & - & - & - & - & - & \\
\hline $\begin{array}{l}\text { Repeated need for tranquillisation within } 24 \text { hours } \\
\text { - not measured }\end{array}$ & - & - & - & - & - & \\
\hline \multirow{2}{*}{$\begin{array}{l}\text { Specific behaviour: agitation, up to } 24 \text { hours } \\
\text { (PANSS-PAS response) } \\
\text { assessed with: } \geq 50 \% \text { reduction on PANSS-PAS } \\
\text { baseline score }\end{array}$} & \multicolumn{2}{|l|}{ Study population } & \multirow{2}{*}{$\begin{array}{l}\text { RR } 1.04 \\
\text { (0.86 to } 1.26)\end{array}$} & \multirow{2}{*}{$\begin{array}{l}124 \\
(1 \mathrm{RCT})\end{array}$} & \multirow{2}{*}{$\begin{array}{l}\oplus \ominus \ominus \ominus \\
\text { VERY LOW } 123\end{array}$} & \\
\hline & 758 per 1.000 & $\begin{array}{l}788 \text { per } 1.000 \\
\text { (652 to } 955)\end{array}$ & & & & \\
\hline \multirow{2}{*}{$\begin{array}{l}\text { Global outcome: need for additional measures } \\
\text { assessed with: use of restraints }\end{array}$} & \multicolumn{2}{|l|}{ Study population } & \multirow{2}{*}{$\begin{array}{l}\text { RR } 2.00 \\
\text { (0.43 to } 9.21)\end{array}$} & \multirow{2}{*}{$\begin{array}{l}28 \\
(1 \mathrm{RCT})\end{array}$} & \multirow{2}{*}{$\begin{array}{l}\oplus \ominus \ominus \ominus \\
\text { VERY LOW } 234 \\
5\end{array}$} & \\
\hline & 143 per 1.000 & $\begin{array}{l}286 \text { per } 1.000 \\
\text { (61 to } 1.000)\end{array}$ & & & & \\
\hline \multirow{2}{*}{$\begin{array}{l}\text { Adverse effects: up to } 24 \text { hours } \\
\text { assessed with: one or more AEs }\end{array}$} & Study population & & \multirow{2}{*}{$\begin{array}{l}\text { RR } 0.94 \\
(0.54 \text { to } 1.66)\end{array}$} & \multirow{2}{*}{$\begin{array}{l}124 \\
(1 \mathrm{RCT})\end{array}$} & \multirow{2}{*}{$\begin{array}{l}\oplus \ominus \odot \ominus \\
\text { VERY LOW } 123\end{array}$} & \\
\hline & 290 per 1.000 & $\begin{array}{l}273 \text { per } 1.000 \\
\text { (157 to } 482)\end{array}$ & & & & \\
\hline Economic outcomes - not measured & - & - & - & - & - & \\
\hline
\end{tabular}

${ }^{*}$ The risk in the intervention group (and its 95\% confidence interval) is based on the assumed risk in the comparison group and the relative effect of the intervention (and its $95 \% \mathrm{Cl})$. 


\begin{tabular}{|c|c|c|c|c|c|c|}
\hline \multicolumn{7}{|c|}{ Cl: Confidence interval; RR: Risk ratio } \\
\hline \multicolumn{7}{|c|}{$\begin{array}{l}\text { GRADE Working Group grades of evidence } \\
\text { High quality: We are very confident that the true effect lies close to that of the estimate of the effect } \\
\text { Moderate quality: We are moderately confident in the effect estimate: The true effect is likely to be close to the estimate of the effect, but there is a possibility that it is sub- } \\
\text { stantially different } \\
\text { Low quality: Our confidence in the effect estimate is limited: The true effect may be substantially different from the estimate of the effect } \\
\text { Very low quality: We have very little confidence in the effect estimate: The true effect is likely to be substantially different from the estimate of effect }\end{array}$} \\
\hline \multicolumn{7}{|c|}{$\begin{array}{l}1 \text { Risk of bias - rated 'very serious': high risk of performance and 'selective reporting' bias. Definition of the outcomes are not consistent between the multiple publications. } \\
2 \text { Imprecision - rated 'serious': Optimal Information Size (OIS) criterion not met. } \\
3 \text { Only one study available. } \\
4 \text { Risk of bias - rated 'very serious': high risk of attrition bias and 'selective reporting' bias. } \\
5 \text { Indirectness - rated 'serious': provided outcome is at a time point ( } 4 \text { days) different from those of primary importance in this setting. } \\
\text { Summary of findings 2. RISPERIDONE compared to OTHER ANTIPSYCHOTIC: b. OLANZAPINE for psychosis-induced aggression or agitation (rapid } \\
\text { tranquillisation) }\end{array}$} \\
\hline \multicolumn{7}{|c|}{ RISPERIDONE compared to OTHER ANTIPSYCHOTIC: b. OLANZAPINE for psychosis-induced aggression or agitation (rapid tranquillisation) } \\
\hline \multicolumn{7}{|c|}{$\begin{array}{l}\text { Patient or population: psychosis-induced aggression or agitation (rapid tranquillisation) } \\
\text { Setting: Psychiatric acute care units. } \\
\text { Intervention: RISPERIDONE } \\
\text { Comparison: OTHER ANTIPSYCHOTIC: b. OLANZAPINE }\end{array}$} \\
\hline \multirow[t]{2}{*}{ Outcomes } & \multicolumn{2}{|c|}{ Anticipated absolute effects ${ }^{\star}(95 \% \mathrm{Cl})$} & \multirow{2}{*}{$\begin{array}{l}\text { Relative effect } \\
(95 \% \mathrm{Cl})\end{array}$} & \multirow{2}{*}{$\begin{array}{l}\text { № of partici- } \\
\text { pants } \\
\text { (studies) }\end{array}$} & \multirow{2}{*}{$\begin{array}{l}\text { Quality of the } \\
\text { evidence } \\
\text { (GRADE) }\end{array}$} & \multirow[t]{2}{*}{ Comments } \\
\hline & $\begin{array}{l}\text { Risk with OTH- } \\
\text { ER ANTIPSY- } \\
\text { CHOTIC: b. } \\
\text { OLANZAPINE }\end{array}$ & $\begin{array}{l}\text { Risk with RISPERI- } \\
\text { DONE }\end{array}$ & & & & \\
\hline $\begin{array}{l}\text { Tranquillisation or asleep by } 30 \text { minutes - not } \\
\text { measured }\end{array}$ & - & - & - & - & - & \\
\hline $\begin{array}{l}\text { Repeated need for tranquillisation within } 24 \\
\text { hours - not measured }\end{array}$ & - & - & - & - & - & \\
\hline $\begin{array}{l}\text { Specific behaviour: agitation, up to } 2 \text { hours } \\
\text { assessed with: PANSS-PAS endpoint score }\end{array}$ & & $\begin{array}{l}\text { MD } 2.5 \text { higher } \\
\text { ( } 2.46 \text { lower to } 7.46 \\
\text { higher) }\end{array}$ & - & $\begin{array}{l}29 \\
(1 \mathrm{RCT})\end{array}$ & $\begin{array}{l}\oplus \ominus \ominus \ominus \\
\text { VERY LOW } 123\end{array}$ & \\
\hline
\end{tabular}

${ }^{1}$ Risk of bias - rated 'very serious': high risk of performance and 'selective reporting' bias. Definition of the outcomes are not consistent between the multiple publications.

2 Imprecision - rated 'serious': Optimal Information Size (OIS) criterion not met.

4 Risk of bias - rated 'very serious': high risk of attrition bias and 'selective reporting' bias.

Summary of findings 2. RISPERIDONE compared to OTHER ANTIPSYCHOTIC: b. OLANZAPINE for psychosis-induced aggression or agitation (rapid tranquillisation)

RISPERIDONE compared to OTHER ANTIPSYCHOTIC: $b$. OLANZAPINE for psychosis-induced aggression or agitation (rapid tranquillisation)

Psychiatric acute care units.

Comparison: OTHER ANTIPSYCHOTIC: b. OLANZAPINE 


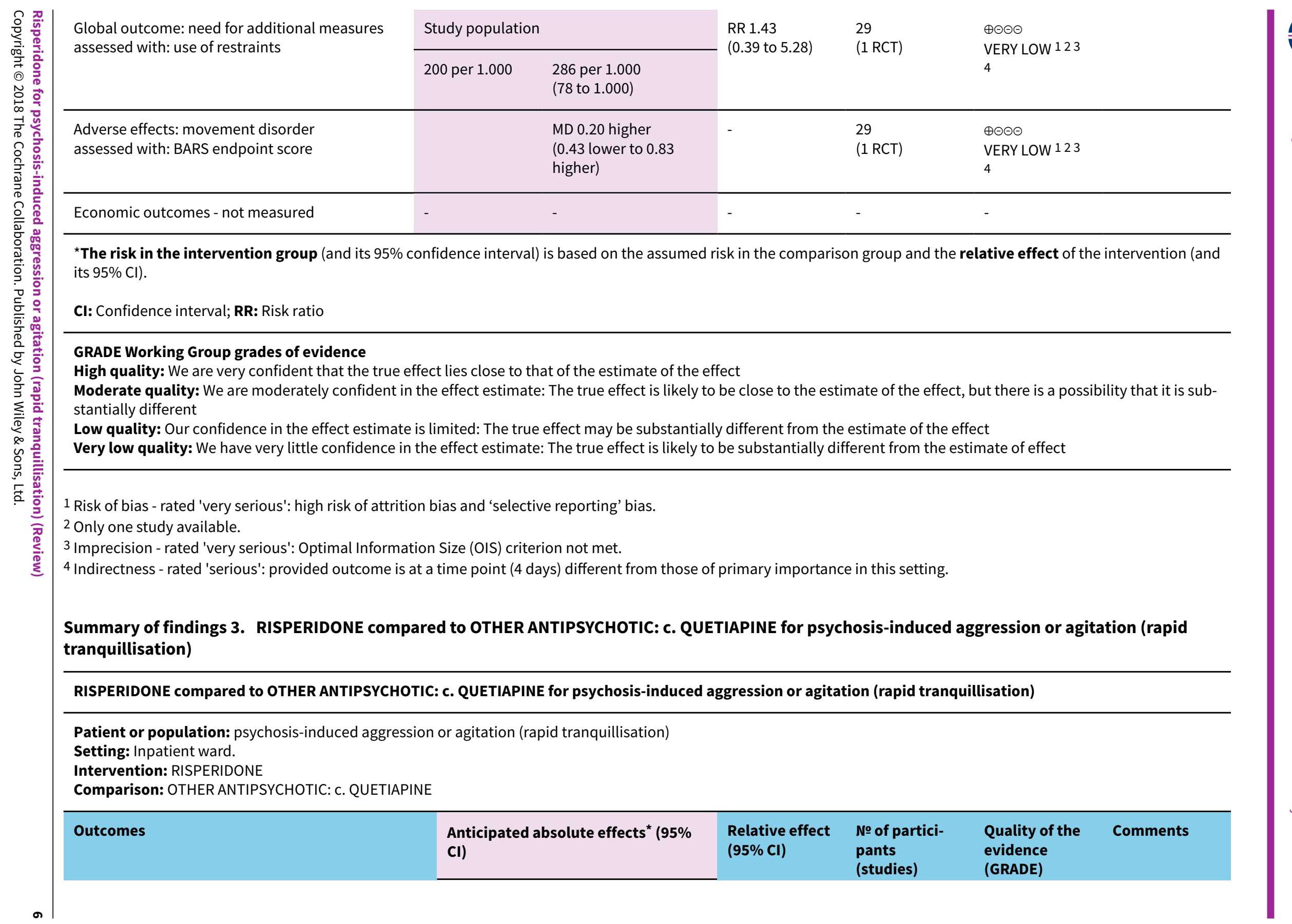




\begin{tabular}{|c|c|c|c|c|c|}
\hline & $\begin{array}{l}\text { Risk with OTH- } \\
\text { ER ANTIPSY- } \\
\text { CHOTIC: c. } \\
\text { QUETIAPINE }\end{array}$ & $\begin{array}{l}\text { Risk with RISPERI- } \\
\text { DONE }\end{array}$ & & & \\
\hline $\begin{array}{l}\text { Tranquillisation or asleep by } 30 \text { minutes - not mea- } \\
\text { sured }\end{array}$ & - & - & - & - & - \\
\hline $\begin{array}{l}\text { Repeated need for tranquillisation within } 24 \text { hours - } \\
\text { not measured }\end{array}$ & - & - & - & - & - \\
\hline $\begin{array}{l}\text { Specific behaviour - aggression, over } 24 \text { hours } \\
\text { assessed with: MOAS endpoint score at } 2 \text { weeks }\end{array}$ & & $\begin{array}{l}\text { MD } 1.80 \text { higher } \\
\text { ( } 0.20 \text { higher to } 3.40 \\
\text { higher) }\end{array}$ & - & $\begin{array}{l}40 \\
(1 \mathrm{RCT})\end{array}$ & $\begin{array}{l}\oplus \ominus \ominus \ominus \\
\text { VERY LOW } 123\end{array}$ \\
\hline Global outcome - not measured & - & - & - & - & - \\
\hline \multirow{2}{*}{$\begin{array}{l}\text { Adverse effects: movement disorders over } 24 \text { hours } \\
\text { assessed with: akathisia }\end{array}$} & \multicolumn{2}{|l|}{ Study population } & \multirow{2}{*}{$\begin{array}{l}\text { RR } 1.67 \\
\text { (0.46 to } 6.06)\end{array}$} & \multirow{2}{*}{$\begin{array}{l}40 \\
(1 \mathrm{RCT})\end{array}$} & \multirow{2}{*}{$\begin{array}{l}\oplus \ominus \ominus \ominus \\
\text { VERY LOW } 123\end{array}$} \\
\hline & 150 per 1.000 & $\begin{array}{l}251 \text { per } 1.000 \\
(69 \text { to } 909)\end{array}$ & & & \\
\hline Economic outcomes - not measured & - & - & - & - & - \\
\hline
\end{tabular}

${ }^{*}$ The risk in the intervention group (and its $95 \%$ confidence interval) is based on the assumed risk in the comparison group and the relative effect of the intervention (and its $95 \% \mathrm{Cl})$.

CI: Confidence interval; MD: mean difference; RR: Risk ratio

\section{GRADE Working Group grades of evidence}

High quality: We are very confident that the true effect lies close to that of the estimate of the effect

Moderate quality: We are moderately confident in the effect estimate: The true effect is likely to be close to the estimate of the effect, but there is a possibility that it is substantially different

Low quality: Our confidence in the effect estimate is limited: The true effect may be substantially different from the estimate of the effect

Very low quality: We have very little confidence in the effect estimate: The true effect is likely to be substantially different from the estimate of effect

1 Only one study available.

2 Indirectness - rated 'serious': provided outcome is at a time point ( 2 weeks) different from those of primary importance in this setting.

3 Imprecision - rated 'very serious': Optimal Information Size (OIS) criterion not met. 


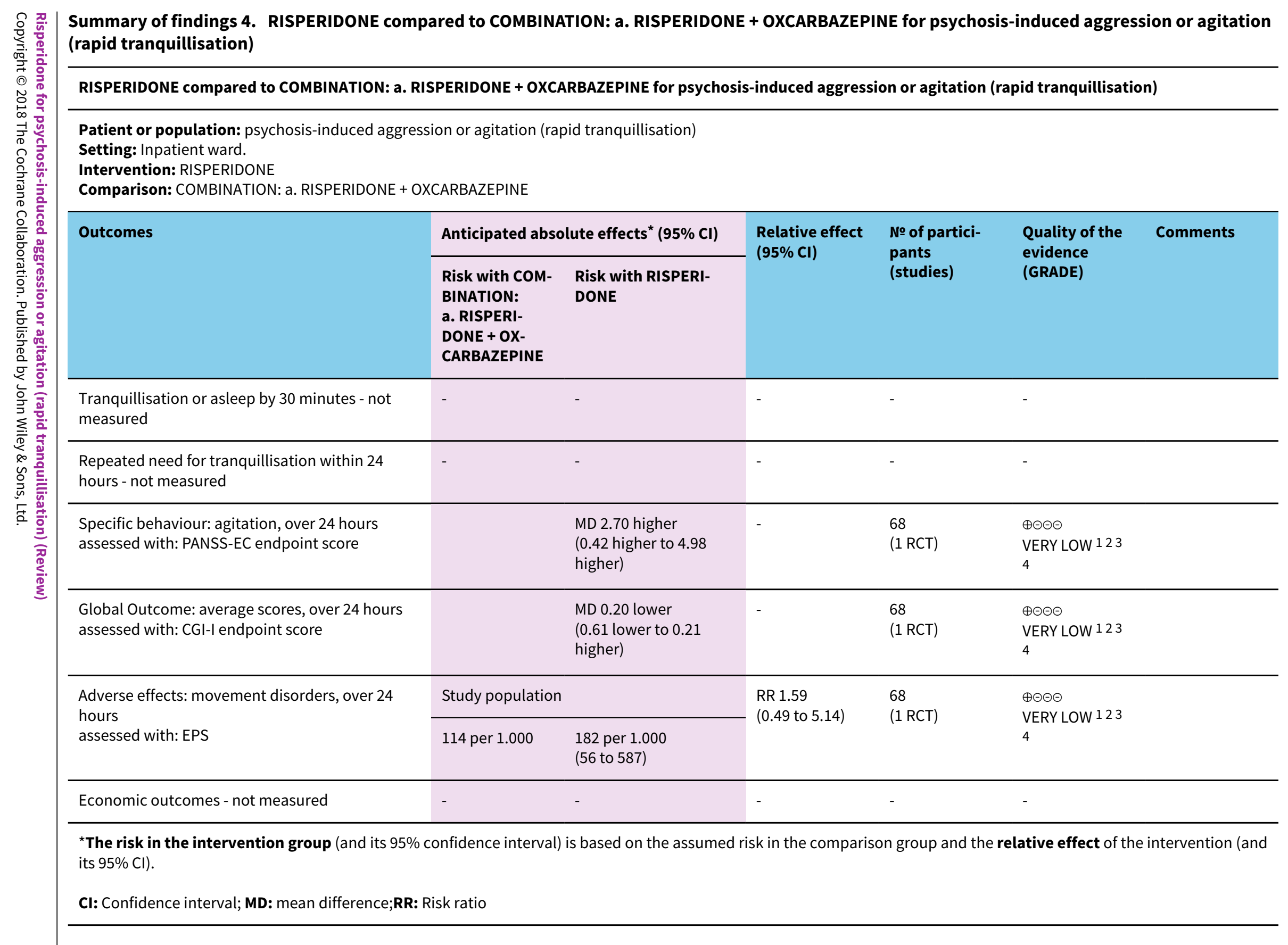

Setting: Inpatient ward.

Comparison: COMBINATION: a. RISPERIDONE + OXCARBAZEPINE

${ }^{\star}$ The risk in the intervention group (and its $95 \%$ confidence interval) is based on the assumed risk in the comparison group and the relative effect of the intervention (and 95\% Cl). 
GRADE Working Group grades of evidence

High quality: We are very confident that the true effect lies close to that of the estimate of the effect

Moderate quality: We are moderately confident in the effect estimate: The true effect is likely to be close to the estimate of the effect, but there is a possibility that it is substantially different

Low quality: Our confidence in the effect estimate is limited: The true effect may be substantially different from the estimate of the effect

Very low quality: We have very little confidence in the effect estimate: The true effect is likely to be substantially different from the estimate of effect

1 Risk of bias - rated 'very serious': high risk for performance bias and detection bias.

2 Only one study available.

3 Indirectness - rated 'serious': provided outcome is at a time point (1 week) different from those of primary importance in this setting.

4 Imprecision - rated 'very serious': Optimal Information Size (OIS) criterion not met.

Summary of findings 5. RISPERIDONE compared to COMBINATION: b. RISPERIDONE + VALPROIC ACID for psychosis-induced aggression or agitation (rapid tranquillisation)

RISPERIDONE compared to COMBINATION: b. RISPERIDONE + VALPROIC ACID for psychosis-induced aggression or agitation (rapid tranquillisation)

Patient or population: psychosis-induced aggression or agitation (rapid tranquillisation)

Setting: Inpatient ward.

Intervention: RISPERIDONE

Comparison: COMBINATION: b. RISPERIDONE + VALPROIC ACID

\begin{tabular}{|c|c|c|c|c|c|c|}
\hline \multirow[t]{2}{*}{ Outcomes } & \multicolumn{2}{|c|}{ Anticipated absolute effects ${ }^{\star}(95 \% \mathrm{Cl})$} & \multirow{2}{*}{$\begin{array}{l}\text { Relative effect } \\
(95 \% \mathrm{CI})\end{array}$} & \multirow{2}{*}{$\begin{array}{l}\text { № of partici- } \\
\text { pants } \\
\text { (studies) }\end{array}$} & \multirow{2}{*}{$\begin{array}{l}\text { Quality of the } \\
\text { evidence } \\
\text { (GRADE) }\end{array}$} & \multirow[t]{2}{*}{ Comments } \\
\hline & $\begin{array}{l}\text { Risk with COMBI- } \\
\text { NATION: b. RISPERI- } \\
\text { DONE + VALPROIC } \\
\text { ACID }\end{array}$ & $\begin{array}{l}\text { Risk with RISPERI- } \\
\text { DONE }\end{array}$ & & & & \\
\hline $\begin{array}{l}\text { Tranquillisation or asleep by } 30 \text { minutes - not } \\
\text { measured }\end{array}$ & - & - & - & - & - & \\
\hline $\begin{array}{l}\text { Repeated need for tranquillisation within } 24 \\
\text { hours - not measured }\end{array}$ & - & - & - & - & - & \\
\hline $\begin{array}{l}\text { Specific behaviour - aggression, over } 24 \text { hours } \\
\text { assessed with: MOAS endpoint score at } 3 \\
\text { days }\end{array}$ & $\begin{array}{l}\text { The mean specific be- } \\
\text { haviour - aggression, } \\
\text { over } 24 \text { hours was } 0\end{array}$ & $\begin{array}{l}\text { MD } 1.07 \text { higher } \\
\text { ( } 0.20 \text { lower to } 2.34 \\
\text { higher) }\end{array}$ & - & $\begin{array}{l}54 \\
(1 \mathrm{RCT})\end{array}$ & $\begin{array}{l}\oplus \ominus \ominus \ominus \\
\text { VERY LOW } 123\end{array}$ & \\
\hline Global outcome - not measured & - & - & - & - & - & \\
\hline
\end{tabular}




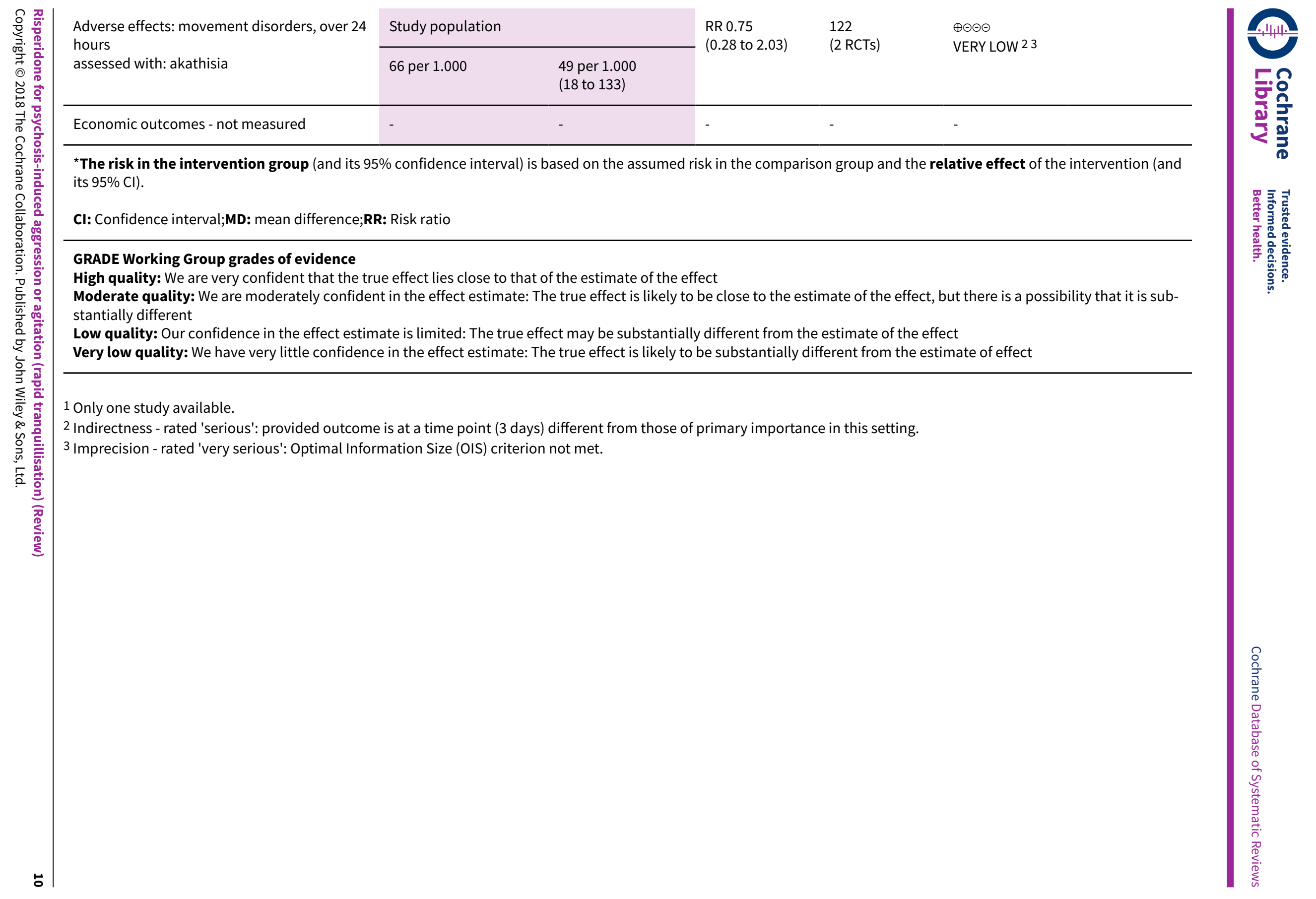




\section{B A C K G R O U N D}

\section{Description of the condition}

Aggression has been defined by NICE 2005 as a willingness to inflict harm, whether behavioural or verbally expressed, and regardless of whether physical harm is sustained. Violence has been described as the intentional use of physical force whether threatened or actual, against oneself, another person, a group, or community, that results in, or is likely to result in injury, death, psychological harm, maldevelopment or deprivation (WHO 2002; Wright 2002). Aggression is not a diagnosis in itself, but can be a feature of several mental health conditions. There is a well-established significant relationship between psychosis and violence (Arseneault 2000; Brennan 2000; Fazel 2006). Agitated or violent behaviour constitutes roughly $10 \%$ of all emergency psychiatric treatment (Tardiff 1982). Overall, the prevalence of violence in people who have schizophrenia, major depression or manic/bipolar disorder is about $11 \%$ to $13 \%$. An even higher percentage of people with alcoholism $(25 \%)$ or substance misuse $(35 \%)$ have, at some stage, presented with violence or aggression. Even when additional factors such as alcohol and drug use are taken into account, psychotic symptoms such as delusions or hallucinations are significantly and strongly associated with aggressive and violent behaviour (Swanson 1990). Low GABA (gamma-aminobutyric acid) and serotonin levels in various parts of the brain have been suggested to be associated with aggressive behaviour whilst enhanced norepinephrine and dopamine levels with increased aggression (Bazire 2009).

\section{Description of the intervention}

There are many guidelines that describe the management of people with aggression and violence. (APA 2004; Addington 2005; NICE 2015). NICE guidelines recommend preventative measures such as observation, de-escalation and use of p.r.n. (i.e.: pro re nata, as needed) medication should initially be used. If these measures fail to calm the agitated individual, restrictive measures including seclusion and manual/mechanical restraint, may be pursued. Individuals unable or unwilling to consent to treatment may require rapid tranquillisation with lorazepam on its own or intramuscular haloperidol combined with intramuscular promethazine.

Risperidone was the first novel second-generation antipsychotic and has been widely available since the $1990 \mathrm{~s}\left(\mathrm{C}_{23} \mathrm{H}_{27} \mathrm{FN}_{4} \mathrm{O}_{2}\right.$, Figure $1)$. The main pharmacological activities of risperidone include serotonin 5-HT2 receptor blockade and dopamine D2 antagonism (Megens 1994), and it has therefore been suggested that atypical antipsychotics could have an anti-aggressive effect (Buckley 1999). Risperidone is licensed in the UK for the treatment of psychotic conditions in which positive or negative symptoms are prominent, to maintain clinical improvement during continuation therapy in patients who have shown an initial treatment response, and for the treatment of mania in bipolar disorder (BNF 2017).

\section{Figure 1. Risperidone structure}

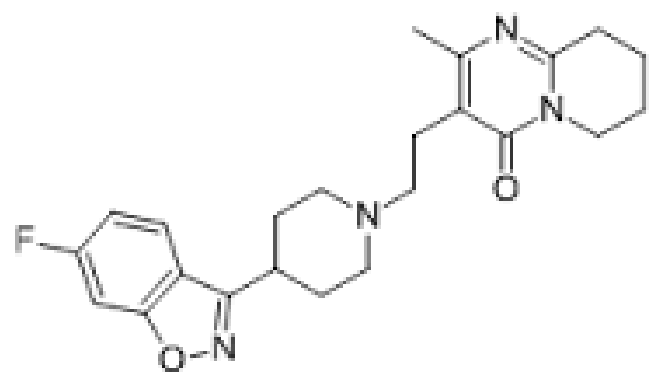

Risperidone and aripiprazole are the only two antipsychotics having FDA (Food and Drug Administration) approval for irritability associated with autistic disorder in children (Mathis 2009). Risperidone is also licensed in the UK for psychosis, persistent aggression in conduct disorder and severe aggression in autism in children (BNF 2017). A Cochrane review on atypical antipsychotics for aggression and psychosis in Alzheimer's disease found that the adverse events associated with risperidone may outweigh the benefits and suggested that risperidone should only be used for treating aggression in those with dementia when there is severe distress or risk of physical harm (Ballard 2006). Risperidone is now licensed in the UK at a low dose for the shortterm management of aggression in Alzheimer dementia which is unresponsive to non-pharmacological interventions (BNF 2017). Katz 1999 also found that $1 \mathrm{mg} /$ day of risperidone was useful in controlling aggression in severe dementia.

Risperidone has atypical properties especially at lower doses but can become more 'conventional' at high doses (Stahl 2008). Risperidone has been found to be associated with more adverse effects such as extrapyramidal side effects, hyperprolactinaemia and sexual dysfunction than other antipsychotics (Tran 1997). A double-blind study looking at risperidone use in schizophrenia found that although hyperprolactinaemia is significantly associated with long-term risperidone use, symptoms related to high prolactin levels are rare (Conley 2001). Risperidone has been found to cause weight gain, but the link is not as significant as with olanzapine (Conley 2001) and clozapine (Wirshing 1999). Respiridone may cause a disproportionate increase in weight gain in adolescents compared to adults, which is a key area in noncompliance in this group (Fleischhaker 2007). Risperidone was the first atypical antipsychotic that became available in a longterm depot injectable formulation lasting for two weeks. Such dosage formulations may improve compliance, and if compliance is enhanced, may lead to better long-term outcomes. The difficulty is patient volunteers are generally co-operative and studies therefore do not address efficacy of depot injection in the non-compliant patient population. (Sampson 2016).

\section{How the intervention might work}

Among the atypical antipsychotics, risperidone has one of the simplest pharmacological profiles and comes closest to a 
serotonin-dopamine antagonist. Risperidone is a benzisoxazole derivative which blocks dopamine 2 receptors and $5 \mathrm{HT}_{2}$ receptors (with a high ratio of serotonin to D2 receptor blockade). It also blocks alpha1 and alpha2 adrenoceptors, $\mathrm{H} 1$ receptors, and has no effect on beta adrenoceptors, muscarinic cholinoceptors or peptidergic receptors (Janssen 1988). Psychosis is considered to be associated with disturbances in the activity of neurotransmitters, dopamine in particular, in the brain. Risperidone has therefore been suggested to work by blocking the receptors in the brain that dopamine acts on, which prevents the excessive activity of dopamine and helps to control aggression or agitation. Czobor 1995 suggested that the combination of risperidone on the serotonergic and dopaminergic systems may underlie risperidone's effect on hostility.

Aleman 2001 found some evidence that risperidone is useful in reducing aggression in schizophrenia; although there is some conflicting evidence, risperidone may have less of a sedative effect than conventional antipsychotics, which in turn suggests the antiaggressive effects of risperidone is not mediated by sedation. Compared with conventional antipsychotics such as haloperidol, risperidone produces some significantly better results according to Positive and Negative Syndrome Scale (PANSS) scores (Hunter 2003).

\section{Why it is important to do this review}

Mental health problems impose a significant burden in developing countries (Shah 2000). As about $1 \%$ of any population suffers from schizophrenia (Sartorius 1972), and around $80 \%$ of the world live in developing countries (CIA 2008), most care of people with serious mental illnesses such as schizophrenia must take place in these low- and middle-income country situations. There is no evidence that the prevalence of psychiatric emergencies differ across the globe and it seems reasonable to assume that most episodes of severe aggression and agitation in people with severe mental health problems will be taking place in low- and middle-income countries. In many of these countries expensive antipsychotic drugs may be available, but they are generally not affordable (WPA 2008).

Aronson 1997 conducted a review looking at the cost-effectiveness and quality of life of patients before and after commencing risperidone treatment and found that risperidone improved symptoms of psychosis, decreased the need for hospitalisation and improved quality of life. Viale 1997 also investigated the cost-effectiveness of risperidone before and after commencing treatment in patients with schizophrenia and found days in hospital were reduced by $26 \%$, but there was a $3.4 \%$ increase in total psychiatric healthcare costs.

The fast-dissolving risperidone tablet formulation may be useful to ensure administration. These 'orodispersible' tablets are an option in acutely agitated psychosis (Normann 2006), and can be as effective as an alternative to intramuscular antipsychotics (Currier 2001). Despite being regularly used for the management of psychosis-induced agitation, we know of no systematic reviews on the use of risperidone in the emergency situation. This is one of a series of linked reviews (Table 1 ).

\section{OB JECTIVES}

To examine whether risperidone is an effective treatment for psychosis-induced aggression or agitation.

\section{METHODS}

\section{Criteria for considering studies for this review Types of studies}

We included all relevant randomised controlled trials (RCTs). If a trial had been described as 'double-blind' but had implied randomisation and the demographic details of each group had been similar, we would have included it. We excluded quasirandomised studies, such as those allocated by using alternate days of the week.

\section{Types of participants}

People exhibiting aggression or agitation (or both) thought to be due to psychosis, regardless of age and sex. Studies that also involved people with other diagnoses, such as drug or alcohol intoxication, organic problems including dementia, non-psychotic mental illnesses or learning disabilities, were included as long as the majority of participants (>50\%) were experiencing psychosis.

We are interested in making sure that information is as relevant to the current care of people with schizophrenia as possible, so, if reported, would clearly highlight the current clinical state (acute, early post-acute, partial remission, remission) as well as the stage (prodromal, first episode, early illness, persistent). In addition, where possible, we would report whether the studies primarily focused on people with particular problems (for example, negative symptoms, treatment-resistant illnesses).

\section{Types of interventions}

\section{Risperidone}

Given alone, any dose and mode of administration.

\section{Other antipsychotic medications}

Given alone, any dose and mode of administration.

\section{Placebo}

Active or non-active.

\section{Types of outcome measures}

Where possible, we grouped outcomes by time: by 30 minutes, up to two hours, up to four hours, up to 24 hours, and over 24 hours.

\section{Primary outcomes}

\section{Not tranquil or asleep}

1.1 Not tranquil or asleep - by up to 30 minutes

\section{Adverse events}

\section{Secondary outcomes}

\section{Tranquillisation or asleep}

1.1 Not tranquil

1.2 Not asleep

1.3 Time to tranquillisation/sleep 
1.4 Time to tranquillisation

1.5 Time to sleep

\section{Specific behaviours}

2.1 Self-harm, including suicide

2.2 Injury to others

2.3 Agitation

2.3.1 Another episode of agitation by 24 hours

2.3.2 No clinically important change in agitation

2.3.3 Any change in agitation

2.4 Aggression

2.4.1 Another episode of aggression by 24 hours

2.4.2 No clinically important change in aggression

2.4.3 No change in aggression

2.4.4 Average endpoint aggression score

2.4.5 Average change in aggression scores

\section{Global outcomes}

3.1 No overall improvement

3.2 Use of additional medication

3.3 Use of restraints/seclusion

3.4 Relapse - as defined by each study

3.5 Recurrence of violent incidents

3.6 Needing extra visits from the doctor

3.7 Refusing oral medication

3.8 Not accepting treatment

3.9 Average endpoint score

3.10 Average change score

3.11 Average dose of drug

\section{Service outcomes}

4.1 Duration of hospital stay

4.2 Re-admission

4.3 No clinically important engagement with services

4.4 No engagement with services

4.5 Average endpoint engagement score

4.6 Average change in engagement scores

\section{Mental state}

5.1 No clinically important change in general mental state 5.2 No change in general mental state

5.3 Average endpoint general mental state score

5.4 Average change in general mental state scores

\section{Adverse effects}

\subsection{Death}

6.2 Any general adverse effects

6.3 Any serious specific adverse effects

6.4 Average endpoint general adverse effect score

6.5 Average change in general adverse effect scores

6.6 Clinically important change in specific adverse effects

6.7 Any change in specific adverse effects

6.8 Average endpoint specific adverse effects

6.9 Average change in specific adverse effects

\section{Leaving the study early}

7.1 For specific reasons

7.2 For general reasons

\section{Satisfaction with treatment}

8.1 Recipient of treatment not satisfied with treatment

8.2 Recipient of treatment average satisfaction score

8.3 Recipient of treatment average change in satisfaction scores

8.4 Informal treatment provider not satisfied with treatment

8.5 Informal treatment providers' average satisfaction score

8.6 Informal treatment providers' average change in satisfaction scores

8.7 Professional providers not satisfied with treatment

8.8 Professional providers' average satisfaction score

8.9 Professional providers' average change in satisfaction scores

\section{Acceptance of treatment}

9.1 Not accepting treatment

9.2 Average endpoint acceptance score

9.3 Average change in acceptance score

\section{Quality of life}

10.1 No clinically important change in quality of life

10.2 Not any change in quality of life

10.3 Average endpoint quality of life score

10.4 Average change in quality of life scores

10.5 No clinically important change in specific aspects of quality of life

10.6 No change in specific aspects of quality of life

10.7 Average endpoint specific aspects of quality of life

10.8 Average change in specific aspects of quality of life

\section{Economic outcomes}

\subsection{Direct costs}

11.2 Indirect costs

\section{Outcomes used for 'Summary of findings' table}

We used the GRADE approach to interpret findings (Schünemann 2011) and used GRADEpro GDT to create 'Summary of findings' tables. These tables provide outcome-specific information concerning the overall quality of evidence from each included study in the comparison, the magnitude of effect of the interventions examined, and the sum of available data on all outcomes we rated as important to patient-care and decision making. We included the following outcomes in the 'Summary of findings' table:

1. tranquillisation or asleep - by 30 minutes;

2. repeated need for rapid tranquillisation - within 24 hours;

3. specific behaviours - agitation or aggression;

4. global state - needing restraints or seclusion;

5. adverse events - serious adverse effects (not death);

6. economic outcomes.

For assessments of the overall quality of evidence for each outcome that included pooled data from RCTs only, we downgraded the evidence from 'high quality' by one level for 'serious' (or by two for 'very serious') study limitations (risk of bias), indirectness of evidence, inconsistency, imprecision of effect estimates or potential publication bias.

\section{Search methods for identification of studies}

No language restriction was applied within the limitations of the search tools. 


\section{Electronic searches}

\section{Cochrane Schizophrenia Group Study-Based Register of Trials}

The Information Specialist searched the register (up to 12 April 2017) using the following phrase:

( ${ }^{*}$ rispe ${ }^{*}$ or ${ }^{*} 9-\mathrm{OH}$-risperid* or ${ }^{*} \mathrm{r} 64766^{*}$ in intervention of STUDY) AND ( ${ }^{*}$ aggress ${ }^{*}$ or ${ }^{*}$ violen ${ }^{\star}$ or ${ }^{\star}$ agitation ${ }^{\star}$ or ${ }^{\star}$ tranq $^{*}$ in title, abstract, index terms of REFERENCE or intervention of STUDY)

In such a study-based register, searching the major concept retrieves all the synonyms and relevant studies because all the studies have already been organised based on their interventions and linked to the relevant topics.

This register is compiled by systematic searches of major resources (including AMED, BIOSIS, CINAHL, Embase, MEDLINE, PsycINFO, PubMed, and registries of clinical trials) and their monthly updates, handsearches, grey literature, and conference proceedings (see Group's Module). There are no language, date, document type, or publication status limitations for inclusion of records into the register.

\section{Searching other resources}

\section{Reference searching}

We inspected references of all included studies for further relevant studies.

\section{Personal contact}

Where necessary, we contacted the first author of each included study for information regarding unpublished trials.

\section{Data collection and analysis}

\section{Selection of studies}

\section{2017 search}

Review authors EGO and MH independently inspected all abstracts of studies identified as above to identify potentially relevant reports. Where disagreement occurred, we resolved it by discussion, or where there was still doubt, we acquired the full article for further inspection and further discussion with CEA. We acquired the full articles of relevant reports for re-assessment and to make a final decision on inclusion (see Criteria for considering studies for this review for this review). Once we had obtained the full articles, EGO and MH independently inspected all reports and independently decided whether they met the inclusion criteria. EGO and $\mathrm{MH}$ were not blinded to the names of the authors, institutions or journal of publication. Where difficulties or disputes arose, we discussed them with CEA and if a decision could not be reached, we added these studies to those awaiting assessment and contacted the authors of the papers for clarification.

\section{2015 search}

Review author KM independently inspected all records identified in the search for potential relevance. Where difficulties or disputes arose, $\mathrm{KM}$ discussed them with CEA .

\section{2011 and 2013 searches}

Review authors UA and FR independently inspected all abstracts of studies identified as above to identify potentially relevant reports.
In addition, to ensure reliability, $\mathrm{HJ}$ (see Acknowledgements) inspected a random sample of these abstracts, comprising 10\% of the total. Where disagreement occurred, we resolved it by discussion, or where there was still doubt, we acquired the full article for further inspection and further discussion with CEA. We acquired the full articles of relevant reports for re-assessment and to make a final decision on inclusion (see Criteria for considering studies for this review for this review). Once we had obtained the full articles, UA and FR independently inspected all reports and independently decided whether they met the inclusion criteria. UA and FR were not blinded to the names of the authors, institutions or journal of publication. Where difficulties or disputes arose, we discussed them with HJ and CEA and if we had been unable to reach a decision, we would have added these studies to those awaiting assessment and contacted the authors of the papers for clarification.

\section{Data extraction and management}

\section{Extraction}

\subsection{7 search}

Review authors EGO and MH independently extracted data from all included studies. Again, any disagreement was discussed, decisions documented and, if necessary, we contacted the authors of studies for clarification. If there had been any remaining problems, we would have consulted with CEA to help clarify issues and these final decisions would have been documented. We extracted data presented only in graphs and figures whenever possible, but we only included the data if both EGO and $\mathrm{MH}$ independently had the same result; we used Plot Digitizer open source software for data extraction from figures, following instructions provided by Kadic 2016. We attempted to contact authors through an open-ended request in order to obtain missing information or for clarification whenever necessary. If studies had been multi-centre, where possible, we would have extracted data relevant to each component centre separately.

\subsection{1 and 2013 searches}

Review authors UA and FR independently extracted data from all included studies. In addition, to ensure reliability, $\mathrm{HJ}$ independently extracted data from a random sample of these studies. Again, we discussed any disagreement, documented decisions and, if necessary, we contacted the authors of studies for clarification. With any remaining problems, CA helped to clarify issues and we documented these final decisions. The need did not arise, but we had planned to extract data presented only in graphs and figures whenever possible while only including the data if two review authors independently had the same result. We had also planned to attempt to contact authors through an open-ended request in order to obtain missing information or for clarification whenever necessary, and to extract data relevant to each component of multi-centre studies separately if we had found such studies.

\section{Management}

\subsection{Forms}

We extracted data onto standard, pre-designed, simple forms.

\subsection{Scale-derived data}

We included continuous data from rating scales only if: 
a) the psychometric properties of the measuring instrument have been described in a peer-reviewed journal (Marshall 2000);

b) the measuring instrument has not been written or modified by one of the trialists for that particular trial; and

c) the instrument should be a global assessment of an area of functioning and not sub-scores which are not, in themselves, validated or shown to be reliable. However there are exceptions, we included sub-scores from mental state scales measuring positive and negative symptoms of schizophrenia.

Ideally, the measuring instrument should either be i. a self-report or ii. completed by an independent rater or relative (not the therapist). We realise that this is not often reported clearly; in Description of studies we noted if this was the case or not.

\subsection{Endpoint versus change data}

There are advantages of both endpoint and change data: change data can remove a component of between-person variability from the analysis; however, calculation of change needs two assessments (baseline and endpoint), which can be difficult to obtain in unstable and difficult-to-measure conditions such as schizophrenia. We decided primarily to use endpoint data, and only use change data if the former were not available. If necessary, we combined endpoint and change data in the analysis, as we preferred to use mean differences (MDs) rather than standardised mean differences (SMDs) throughout (Deeks 2011).

\subsection{Skewed data}

Continuous data on clinical and social outcomes are often not normally distributed. To avoid the pitfall of applying parametric tests to non-parametric data, we applied the following standards to relevant continuous data before inclusion.

For endpoint data from studies including fewer than 200 participants:

a) when a scale started from the finite number zero, we subtracted the lowest possible value from the mean, and divided this by the standard deviation (SD). If this value was lower than one, it strongly suggests that the data are skewed. We excluded these data and entered them as 'other data'. If this ratio was higher than one but less than two, there is suggestion that the data are skewed: we entered these data and tested whether their inclusion or exclusion would change the results substantially. If such data changed the results we entered them as 'other data'; if they did not change the results substantially, we used these data in the analyses. Finally, if the ratio was larger than two, we included these data, because it is less likely that they are skewed (Altman 1996; Higgins 2011).

b) if a scale starts from a positive value (such as the Positive and Negative Syndrome Scale (PANSS), which can have values from 30 to 210 (Kay 1986)), we modified the calculation described above to take the scale starting point into account. In these cases skewed data are present if $2 \mathrm{SD}>(\mathrm{S}-\mathrm{S} \mathrm{min})$, where $\mathrm{S}$ is the mean score and 'S min' is the minimum score.

Please note: we planned to enter all relevant data from studies of more than 200 participants in the analysis irrespective of the above rules, because skewed data pose less of a problem in large studies. We entered all relevant change data, as when continuous data are presented on a scale that includes a possibility of negative values (such as change data), it is difficult to tell whether or not data are skewed.

\subsection{Common measurement}

To facilitate comparison between trials we aimed, where relevant, to convert variables that can be reported in different metrics, such as days in hospital (mean days per year, per week or per month) to a common metric (e.g. mean days per month).

\subsection{Conversion of continuous to binary}

Where possible, we made efforts to convert outcome measures to dichotomous data. This can be done by identifying cut-off points on rating scales and dividing participants accordingly into 'clinically improved' or 'not clinically improved'. It is generally assumed that if there is a $50 \%$ reduction in a scale-derived score such as the Brief Psychiatric Rating Scale (BPRS) (Overall 1962), or the PANSS (Kay 1986), this could be considered as a clinically significant response (Leucht 2005; Leucht 2005a). If data based on these thresholds were not available, we used the primary cut-off presented by the original authors.

\subsection{Direction of graphs}

Where possible, we entered data in such a way that the area to the left of the line of no effect indicates a favourable outcome for risperidone. Where keeping to this made it impossible to avoid outcome titles with double-negatives (e.g. 'Not un-improved'), we reported data where the left of the line indicated an unfavourable outcome. If needed in order to improve readability, we switched labels on the $\mathrm{X}$ axis and stated it in a note accompanying the graph.

\section{Assessment of risk of bias in included studies}

For the 2017 search review authors EGO and MH independently assessed risk of bias within the included studies by using criteria described in the Cochrane Handbook for Systematic Reviews of Interventions to assess trial quality (Higgins 2011a). This set of criteria is based on evidence of associations between overestimate of effect and high risk of bias of the article such as sequence generation, allocation concealment, blinding, incomplete outcome data, and selective reporting.

If the raters had disagreed, we would have made the final rating by consensus, with the involvement of CEA. Where inadequate details of randomisation and other characteristics of trials were provided, we attempted to contact authors of the studies in order to obtain further information. If non-concurrence had occurred, we would have reported this.

We noted the level of risk of bias in the text of the review and in the text and 'Summary of findings' tables.

For the 2011 and 2013 searches, UA and FR undertook assessment of risk of bias as above.

\section{Measures of treatment effect}

\section{Binary data}

For binary outcomes we calculated a standard estimation of the risk ratio (RR) and its $95 \%$ confidence interval $(\mathrm{Cl})$, as it has been shown that RR is more intuitive than odds ratios (Boissel 1999); and that odds ratios tend to be interpreted as RR by clinicians (Deeks 2000). Although the number needed to treat for an additional beneficial outcome (NNTB) and the number needed to treat for an additional 
harmful outcome (NNTH), with their Cls are intuitively attractive to clinicians, they are problematic to calculate and interpret in metaanalyses (Hutton 2009). For binary data presented in the 'Summary of findings' tables we, where possible, we calculated illustrative comparative risks.

\section{Continuous data}

For continuous outcomes we estimated the mean difference (MD) between groups. We preferred not to calculate effect size measures (standardised mean difference (SMD)). However if scales of very considerable similarity were used, we presumed there was a small difference in measurement, and we calculated effect size and transformed the effect back to the units of one or more of the specific instruments.

\section{Unit of analysis issues}

\section{Cluster trials}

Studies increasingly employ 'cluster randomisation' (such as randomisation by clinician or practice) but analysis and pooling of clustered data poses problems. Firstly, authors often fail to account for intra-class correlation (ICC) in clustered studies, leading to a 'unit of analysis' error (Divine 1992) whereby P values are spuriously low, Cls unduly narrow and statistical significance overestimated. This causes type I errors (Bland 1997; Gulliford 1999).

If clustering had not been accounted for in primary studies, we would have presented data in a table, with a $\left({ }^{*}\right)$ symbol to indicate the presence of a probable unit of analysis error. We would have attempted to contact the first authors of studies to obtain intraclass correlation coefficients (ICCS) for their clustered data and to adjust for this by using accepted methods (Gulliford 1999). If clustering had been incorporated into the analysis of primary studies, we would have presented these data as if from a noncluster randomised study, but adjusted for the clustering effect. We have sought statistical advice and have been advised that the binary data as presented in a report should be divided by a 'designeffect'. This is calculated using the mean number of participants per cluster $(m)$ and the ICC [Design effect $\left.=1+(m-1)^{*} I C C\right]$ (Donner 2002). If the ICC was not reported it was assumed to be 0.1 (Ukoumunne 1999). If cluster studies had been appropriately analysed taking into account ICCs and relevant data documented in the report, synthesis with other studies would have been possible using the generic inverse variance technique.

\section{Cross-over trials}

A major concern of cross-over trials is the carry-over effect. It occurs if an effect (e.g. pharmacological, physiological or psychological) of the treatment in the first phase is carried over to the second phase. As a consequence, on entry to the second phase the participants can differ systematically from their initial state despite a wash-out phase. For the same reason cross-over trials are not appropriate if the condition of interest is unstable (Elbourne 2002). As both effects are very likely in severe mental illness, if we had included cross-over studies, we would only have used data from the first phase of crossover studies.

\section{Dealing with missing data}

\section{Overall loss of credibility}

At some degree of loss of follow-up, data must lose credibility (Xia 2009). We chose that, for any particular outcome, should more than
$50 \%$ of data be unaccounted for we would not reproduce these data or use them within analyses. If, however, more than $50 \%$ of those in one arm of a study were lost, but the total loss was less than $50 \%$, we would address this within the 'Summary of findings' tables by down-rating quality. Finally, we would also downgraded quality within the 'Summary of findings' tables should the loss be $25 \%$ to $50 \%$ in total.

\section{Binary}

In the case where attrition for a binary outcome was between $0 \%$ and $50 \%$ and where these data were not clearly described, we presented data on a 'once-randomised-always-analyse' basis (an intention-to-treat (ITT) analysis). Those leaving the study early were all assumed to have the same rates of negative outcome as those who completed. We used the rate of those who stayed in the study - in that particular arm of the trial - and applied this also to those who did not. We undertook a sensitivity analysis to test how prone the primary outcomes were to change when data only from people who completed the study to that point were compared to the ITT analysis using the above assumptions.

\section{Continuous}

\subsection{Attrition}

We used data where attrition for a continuous outcome was between $0 \%$ and $50 \%$, and data only from people who completed the study to that point were reported.

\subsection{Standard deviations}

If standard deviations (SDs) were not reported, we tried to obtain the missing values from the authors. If these were not available, where there were missing measures of variance for continuous data, but an exact standard error (SE) and Cls available for group means, and either $P$ value or $t$ value available for differences in mean, we could calculate SDs according to the rules described in the Cochrane Handbook for Systematic Reviews of Interventions (Higgins 2011). When only the SE is reported, SDs are calculated by the formula SD $=S E{ }^{*} \sqrt{ }(\mathrm{n})$. The Cochrane Handbook for Systematic Reviews of Interventions presents detailed formulae for estimating $\mathrm{SDs}$ from $\mathrm{P}, \mathrm{t}$ or $\mathrm{F}$ values, $\mathrm{Cls}$, ranges or other statistics (Higgins 2011). If these formulae do not apply, we could calculate the SDs according to a validated imputation method which is based on the SDs of the other included studies (Furukawa 2006). Although some of these imputation strategies can introduce error, the alternative would be to exclude a given study's outcome and thus to lose information. Nevertheless, we would have examined the validity of the imputations in a sensitivity analysis that excludes imputed values.

\subsection{Assumptions about participants who left the trials early or were lost to follow-up}

Various methods are available to account for participants who left the trials early or were lost to follow-up. Some trials just present the results of study completers; others use the method of last observation carried forward (LOCF); while more recently, methods such as multiple imputation or mixed-effects models for repeated measurements (MMRM) have become more of a standard. While the latter methods seem to be somewhat better than LOCF (Leon 2006), we feel that the high percentage of participants leaving the studies early and differences between groups in their reasons for doing so is often the core problem in randomised schizophrenia trials. We 
therefore determined not to exclude studies based on the statistical approach used. However, by preference we planned to use the more sophisticated approaches, i.e. we would have used MMRM or multiple-imputation to LOCF, and would only have presented completer analyses if some kind of ITT data were not available at all. Moreover, we planned to address this issue in the item 'Incomplete outcome data' of the 'Risk of bias' tool.

\section{Assessment of heterogeneity}

\section{Clinical heterogeneity}

We considered all included studies initially, without seeing comparison data, to judge clinical heterogeneity. We simply inspected all studies for clearly outlying situations or people which we had not predicted would arise. Where such situations or participant groups arose, we fully discussed these.

\section{Methodological heterogeneity}

We considered all included studies initially, without seeing comparison data, to judge methodological heterogeneity. We simply inspected all studies for clearly outlying methods which we had not predicted would arise. Where such methodological outliers arose, we fully discussed these.

\section{Statistical heterogeneity}

\subsection{Visual inspection}

We visually inspected graphs to investigate the possibility of statistical heterogeneity.

\subsection{Employing the $I^{2}$ statistic}

We investigated heterogeneity between studies by considering the $\mathrm{I}^{2}$ statistic alongside the $\mathrm{Chi}^{2} \mathrm{P}$ value. The $\mathrm{I}^{2}$ statistic provides an estimate of the percentage of inconsistency thought to be due to chance (Higgins 2003). The importance of the observed value of 12 depends on i. magnitude and direction of effects and ii. strength of evidence for heterogeneity (e.g. P value from $\mathrm{Chi}^{2}$ test, or a $\mathrm{Cl}$ for 12). An $\mathrm{I}^{2}$ estimate greater than or equal to $50 \%$ accompanied by a statistically significant $\mathrm{Chi}^{2}$ statistic, was interpreted as evidence of substantial levels of heterogeneity (Deeks 2011). Where substantial levels of heterogeneity were found in the primary outcome, we explored reasons for the heterogeneity (Subgroup analysis and investigation of heterogeneity).

\section{Assessment of reporting biases}

Reporting biases arise when the dissemination of research findings is influenced by the nature and direction of results ( Egger 1997). These are described in Chapter 10 of the Cochrane Handbook for Systematic Reviews of Interventions (Sterne 2011).

\section{Protocol versus full study}

We tried to locate protocols of included randomised trials. If the protocol was available, we compared outcomes in the protocol and in the published report. If the protocol was not available, we compared outcomes listed in the methods section of the trial report with actually reported results.

\section{Funnel plot}

We are aware that funnel plots may be useful in investigating reporting biases but are of limited power to detect small-study effects. We decided not to use funnel plots for outcomes where there were 10 or fewer studies, or where all studies were of similar size. In future versions of this review, if funnel plots are possible, we will seek statistical advice in their interpretation.

\section{Data synthesis}

We understand that there is no closed argument for preference for use of fixed-effect or random-effects models. The random-effects method incorporates an assumption that the different studies are estimating different, yet related, intervention effects. This often seems to be true to us and the random-effects model takes into account differences between studies even if there is no statistically significant heterogeneity. There is, however, a disadvantage to the random-effects model. It puts added weight onto small studies which often are the most biased ones. Depending on the direction of effect, these studies can either inflate or deflate the effect size. We chose the fixed-effect model for analyses.

\section{Subgroup analysis and investigation of heterogeneity}

\section{Subgroup analyses}

We did not anticipate any subgroup analyses.

\section{Investigation of heterogeneity}

If inconsistency was high, we reported it. First, we investigated whether data were entered correctly. Second, if data were correct, we visually inspected the graph and successively removed outlying studies to see if homogeneity was restored. For this review, we decided that should this occur with data contributing to the summary finding of no more than around $10 \%$ of the total weighting, we would present the data. If not, we would not pool data but would discuss the issues. We know of no supporting research for this $10 \%$ cut-off but are investigating the use of prediction intervals as an alternative to this unsatisfactory state.

When unanticipated clinical or methodological heterogeneity were obvious, we stated hypotheses regarding these for future reviews or versions of this review. We did not anticipate undertaking analyses relating to these.

\section{Sensitivity analysis}

We planned that if there were substantial differences in the direction or precision of effect estimates in any of the sensitivity analyses listed below, we would not add data from the lowerquality studies to the results of the higher-quality trials, but would present these data within a subcategory. If their inclusion did not result in a substantive difference, they would remain in the analyses.

\section{Implication of randomisation}

We aimed to include trials in a sensitivity analysis if they had been described in some way as to imply randomisation. For the primary outcomes we would have included these studies, and if there was no substantive difference when these implied randomised studies were added to those with better description of randomisation, then we would have used all data from the implied studies.

\section{Assumptions for lost binary data}

Where assumptions had to be made regarding people lost to followup (see Dealing with missing data), we compared the findings of 
the primary outcomes where we used our assumption compared with completer data only. If there was a substantial difference, we reported results and discussed them but continued to employ our assumption.

Where assumptions had to be made regarding missing SDs data (see Dealing with missing data), we compared the findings on primary outcomes where we used our assumption compared with complete data only. We undertook a sensitivity analysis to test how prone results were to change when completer data only were compared with the imputed data using the above assumption. If there was a substantial difference, we reported results and discussed them but continued to employ our assumption.

\section{Risk of bias}

We analysed the effects of excluding trials that were judged to be at high risk of bias across one or more of the domains of randomisation (see Assessment of risk of bias in included studies) for the meta-analysis of the primary outcome/s. If the exclusion of trials at high risk of bias did not substantially alter the direction of effect or the precision of the effect estimates, then we included data from these trials in the analysis.

\section{Imputed values}

We also would have undertaken a sensitivity analysis to assess the effects of including data from trials where we used imputed values for ICC in calculating the design effect in cluster-randomised trials if included. If substantial differences had been noted in the direction or precision of effect estimates in any of the sensitivity analyses listed above, we would not pool data from the excluded trials with the other trials contributing to the outcome, but would have presented them separately.

\section{Fixed and random effects}

We synthesised data using a fixed-effect model; however, we also synthesised data for the primary outcomes using a random-effects model to evaluate whether this altered the significance of the result.

\section{RE S U L T S}

\section{Description of studies}

For substantive descriptions of studies please see the Characteristics of included studies, Characteristics of studies awaiting classification, and Characteristics of excluded studies.

\section{Results of the search}

Electronic searches up to April 2017 identified 850 records of potentially eligible studies. After an initial screening of these records (checking titles and abstracts), the full-text articles of 92 records (referring to 70 studies) were obtained. From these 70 studies, 57 (76 records) were excluded with reasons, four studies (four records were placed in awaiting assessment) and nine studies (12 records) were included. Please see Figure 2 for summary of the searches up to April 2017. 
Figure 2. Search results - up to April 2017

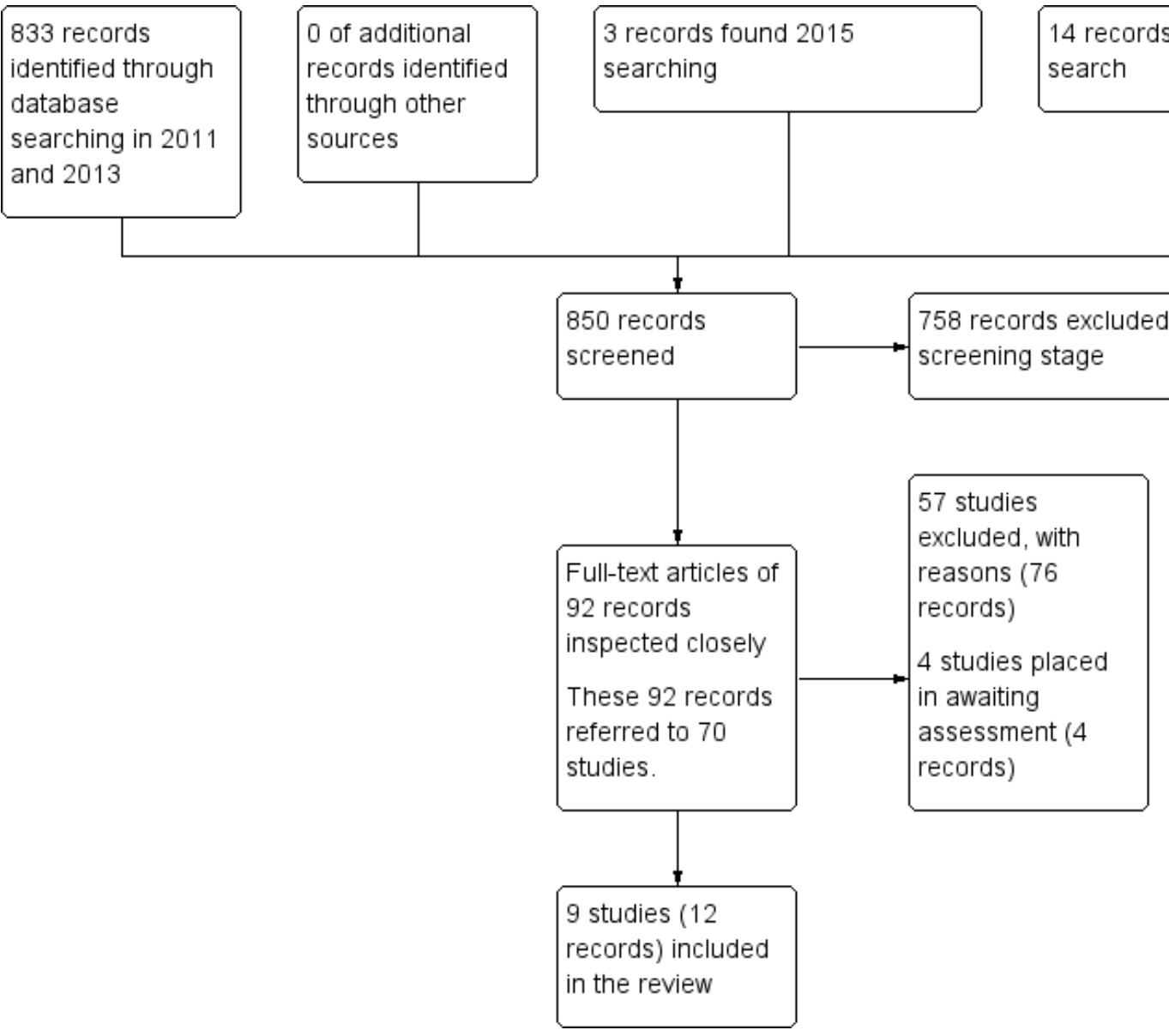

\section{Included studies}

Details of the included studies in the review are provided in the Characteristics of included studies table. Searches undertaken between 2011 and 2015 identified three studies for inclusion (Lim 2010; Walther 2014; Yao 2010). In 2017, we identified six additional studies for inclusion (Dai 2012; Jin 2013; Li 2013; Wang 2012; Wang 2013; Zhou 2013).

\section{Length of studies}

The duration of the studies ranged from 24 hours (Lim 2010) to eight weeks (Dai 2012; Li 2013; Yao 2010).

\section{Participants}

\subsection{Clinical state}

Participants presented with acute exacerbation of psychotic symptoms. All the studies focused on people whose psychosis had primarily triggered agitation (Lim 2010; Walther 2014; Wang 2012; Zhou 2013) or aggressive behaviour (Dai 2012; Jin 2013; Li 2013; Wang 2013; Yao 2010).

\subsection{Diagnosis}

Eighty-nine per cent of participants $(n=520)$ had a diagnosis of schizophrenia. Other diagnosis included schizoaffective disorder ( $\mathrm{n}$ $=6,1 \%$ ), bipolar I disorder with or without psychotic symptoms ( $\mathrm{n}$
$=43,7 \%)$, schizophreniform disorder $(n=10,2 \%)$, and psychotic disorder not otherwise specified $(n=3,1 \%)$.

\subsection{Exclusions}

Reported exclusion criteria included pregnant or lactating women, people with serious medical illnesses, people who had used certain medications (e.g. antipsychotics, long-acting antipsychotics, benzodiazepines) within a specified period prior to enrolment, people with a known allergy or hypersensitivity to the study drugs, and people with alcohol or psychoactive substance use disorder.

\subsection{Age}

Six studies reported age range and a mean age (Dai 2012; Jin 2013; Li 2013; Walther 2014; Wang 2012; Yao 2010), one study reported an age range (Lim 2010), and two studies reported a mean age (Wang 2013; Zhou 2013). Age ranges varied from the narrowest being 20-30 years (Dai 2012) to the largest one being of 18-65 (Jin 2013; Lim 2010); mean ages varied from the lowest being of 25.3 (Dai 2012) years to the highest 39.4 years ( $\operatorname{Iin} 2013$ ).

\subsection{Sex}

The studies included a total of 353 male participants and 229 female participants. 


\section{Study size}

The study sizes varied with the smallest study having 40 participants (Dai 2012) and the largest randomising 124 people (Lim 2010).

\section{Setting}

In all the included studies, participants presented at psychiatric emergency departments and were newly admitted inpatients.

\section{Interventions}

A total of five comparisons were identified in the included studies: three comparisons involved a single drug whilst the other two comparisons involved a combination. Unfortunately, only two comparisons ('risperidone versus haloperidol', and 'risperidone versus valproic acid') could benefit from more than one study as source of data; moreover, as for the first comparison this held true for a single outcome only ('leaving the study early').

Involved daily doses of risperidone started from $1 \mathrm{mg}$ (Dai 2012; Li 2013; Wang 2013; Yao 2010) or 2 mg (Lim 2010; Walther 2014) to a maximum of $4 \mathrm{mg}$ (Zhou 2013) or $6 \mathrm{mg}$ (Dai 2012; Li 2013; Lim 2010; Walther 2014; Wang 2013; Yao 2010). In one study (Wang 2012), authors declared a titration without a specification on the intended doses, reporting only a mean daily administered dose (4.2 $\mathrm{mg} \pm 0.35 \mathrm{mg}$ ). In Jin 2013 dosages were not specified.

\subsection{Versus antipsychotics}

Haloperidol intramuscular (IM) dose was in the $5 \mathrm{mg}$ to $15 \mathrm{mg}$ range (Lim 2010), whilst as for the oral formulation it was a fixed dose of 15 $\mathrm{mg}$ (Walther 2014). Olanzapine was given as a fixed dose of $20 \mathrm{mg}$, oral (Walther 2014). Quetiapine flexible dose started from $100 \mathrm{mg}$ / day and then increased to $400 \mathrm{mg}$ to $500 \mathrm{mg} /$ day with a maximum dose of $750 \mathrm{mg} /$ day (Dai 2012).

\subsection{Versus combinations}

In the risperidone + oxcarbazepine comparison (Wang 2012), daily administered dose of risperidone and oxcarbazepine were, respectively, of $4.1 \mathrm{mg} \pm 0.4 \mathrm{mg}$ (oral formulation) and $1.20 \mathrm{~g} \pm 0.42$ $\mathrm{g}$ (oral formulation).

As for the risperidone + valproic acid comparison, magnesium valproate was administered at $500 \mathrm{mg} /$ day (Yao 2010), within the $750 \mathrm{mg}$ to $1000 \mathrm{mg} /$ day range (Jin 2013; Li 2013), or with a mean dose of $800 \mathrm{mg} \pm 50 \mathrm{mg} /$ day (Li 2013); sodium valproate daily administered dose was in the $600 \mathrm{mg}$ to $1200 \mathrm{mg} /$ day range (Wang 2013) or of $400 \mathrm{mg}$ twice daily (intravenous formulation (Zhou 2013).

\section{Outcomes}

The majority of the included studies provided binary data with respect to "specific behaviour - agitation" outcome, "global state" outcome, "mental state" outcome, "adverse effects" outcome, and "leaving the study early" outcome. The majority of trials that employed continuous scales measured "specific behaviour agitation" outcome, "specific behaviour - aggression" outcome, "mental state" outcome, and "adverse effects - movement disorders" outcome.

The various rating scales, from which we were able to obtain usable data, are listed below.

\subsection{Specific behaviour - agitation}

\section{a. Positive and Negative Syndrome Scale - Excited Component (PANSS-} EC)

The PANSS-EC is a five-item scale (excitement, tension, hostility, uncooperativeness, and poor impulse control). The items are rated from one (not present) to seven (extremely severe). Scores range from five to 35 , with mean scores $\geq 20$ indicating agitation. A high score indicates high levels of agitation (Montoya 2011).

\section{b. Positive and Negative Syndrome Scale - Psychotic Agitation Subscale (PANSS-PAS)}

The PANSS-PAS is a five-item scale (excitement, hallucinatory behaviour, hostility, uncooperativeness, and poor impulse control). The items are rated from one (not present) to seven (extremely severe), with total scores ranging from five to 35 . A high score indicates high levels of psychotic agitation (Currier 2000).

\subsection{Specific behaviour - aggression}

\section{a. Modified Overt Aggression Scale (MOAS)}

The OAS (Yudofsky 1986) is a 16-item rating scale which aims to measure the intensity of verbal and physical aggression. Clinicians are required to comment on the duration of the aggressive incident as well as the intervention required to control it. High scores are indicative of higher levels of aggression.

\subsection{Global state}

\section{a. Clinical Global Impression (CGI)}

The CGI (Guy 1976) is not a diagnostic tool but rather, enables clinicians to quantify the severity of symptoms of any mental health problem at one point in time. Clinicians are then able to use this to track whether there has been any improvement or worsening of symptoms over time. A seven-point rating scale is used with high scores indicating increased severity or less recovery.

\section{b. Clinical Global Impression - Improvement (CGI-I)}

The CGI-I (Guy 1976) enables clinicians to assess whether a per- son's symptoms have improved or worsened following an intervention. Based on the clinicians judgement, a rating on a seven- point scale is given from one (very much improved) to seven (very much worse). Low scores indicate greater improvement.

\section{c. Clinical Global Impression - Severity (CGI-S)}

The CGI-S (Guy 1976) requires clinicians to consider the severity of a person's symptoms in relation to the clinicians past experience of people with the same diagnosis. Clinicians then have to give a rating from one (normal) to seven (extremely ill). High scores indicate increased severity.

\subsection{Mental state}

\section{a. Brief Psychiatric Rating Scale (BPRS)}

The Brief Psychiatric Rating Scale was originally developed by Overall and Gorham (Overall 1962) as a 14-item scale to measure the severity of a range of psychiatric symptoms, including psychosis. This rating scale items evolved over time and now consists of 24 items which can be rated on a seven-point scale from 'not present' to 'extremely severe'. A high score would suggest poor mental health. It is not clear for the majority of the studies included in this review, which version of the BPRS was used. 


\section{b. Positive and Negative Syndrome Scale (PANSS)}

The PANSS was developed and published by Kay, Flszbein and Opler (Kay 1986). The PANSS is designed as a brief interview, whereby the severity of 30 symptoms of schizophrenia can be assessed on a scale of one to seven. A high score would indicate more severe symptoms. The PANSS can be divided into separate sub scales by focusing on the statements relating to positive symptoms (e.g. hallucinations), negative symptoms (e.g. social withdrawal) or general psychopathology (e.g. anxiety and uncooperativeness).

\subsection{Adverse effects}

\section{a. Abnormal Involuntary Movement Scale (AIMS)}

The AIMS (Guy 1976) is a 12-items scale which records the occurrence of tardive dyskinesia. The first 10 items are rated from one to five, whilst the last two items are dichotomous items (yes, no).

\section{b. Barnes Akathisia Scale (BAS)}

The BAS scale was developed by Barnes 1989 and includes items which aim to rate both the observable symptoms which characterise akathisia such as restless movements and also the person's subjective experience, including any distress. The items are rated from zero $=$ normal to three $=$ severe. There is also an item for rating global severity from zero (absent) to five (severe). A high score indicates high levels of akathisia.

\section{c. Simpson-Angus Scale (SAS)}

The SAS (Simpson 1970) is a 10-item scale which measures drug induced parkinsonism (extrapyramidal side effects). Each item is scored from zero to four. A high score would indicate increased levels of parkinsonism.

\section{d. Treatment Emergent Symptom Scale (TESS)}

The TESS (Guy 1976) is a six-item scale which is used to assess the occurrence and intensity of treatment-related adverse effects. A high score indicates worse symptoms.

\section{Missing outcomes}

Not one of the studies evaluated tranquillisation within 30 minutes, satisfaction with care, acceptance of treatment, quality of life, or economic outcomes.

\section{Funders}

One of the nine included studies received sponsorship from a pharmaceutical company.

\section{Excluded studies}

In total 59 studies had to be excluded: 12 studies were excluded based on their method of allocation (Beck 1997; Buckley 1997; Currier 2000; Greenspan 2005; Hatta 2008; Hovens 2005; Lewis 2006; Li 2014; Pei 2009; Potkin 2005; Schooler 2003; Villari 2008); 35 studies were excluded based on the characteristics of their participants, who were not experiencing a psychosis-induced aggression or agitation (Belenkaya 2005; Citrome 2001; Briken 2002; Buitelaar 2001; Citrome 2004; Chan 2013; Czobor 1995; Francey 2007; Han 2005; He 2005; Huaqiang 2009; ISRCTN11736448 2003; Kane 2003; Kirwan 2002; Kolivakis 2002; Lieberman 2001; Liu 2010; NCT00174200 2005; NCT00203775 2005; NCT00205699 2005; Citrome 2007; NCT00485498 2003; Ou 2007; Peng 2009; Swanson 2008; Tang 2007; Temputrn 2007; Tosic Golubovic Suzana 2009; Veser 2006; Wan 2005; Wang 2004; Wang 2006; Wei 2010; Xi 2010; Xuan 2007). For 11 studies the intervention under investigation did not meet our inclusion criteria (Conde 2011; Currier 2004; Fang 2012; Hong 2014; Hou 2011; Jiang 2012; Liu 2012; Wang 2015; Zhang 2012; Zheng 2010; Zhou 2012); one study was excluded because the study terminated too early due to difficulties in recruiting participants (NCT00418873 2007).

\section{Risk of bias in included studies}

Please see the relevant 'Risk of bias' tables in the Characteristics of included studies, Figure 3 and Figure 4.

\section{Figure 3. 'Risk of bias' graph: review authors' judgements about each risk of bias item presented as percentages across all included studies.}

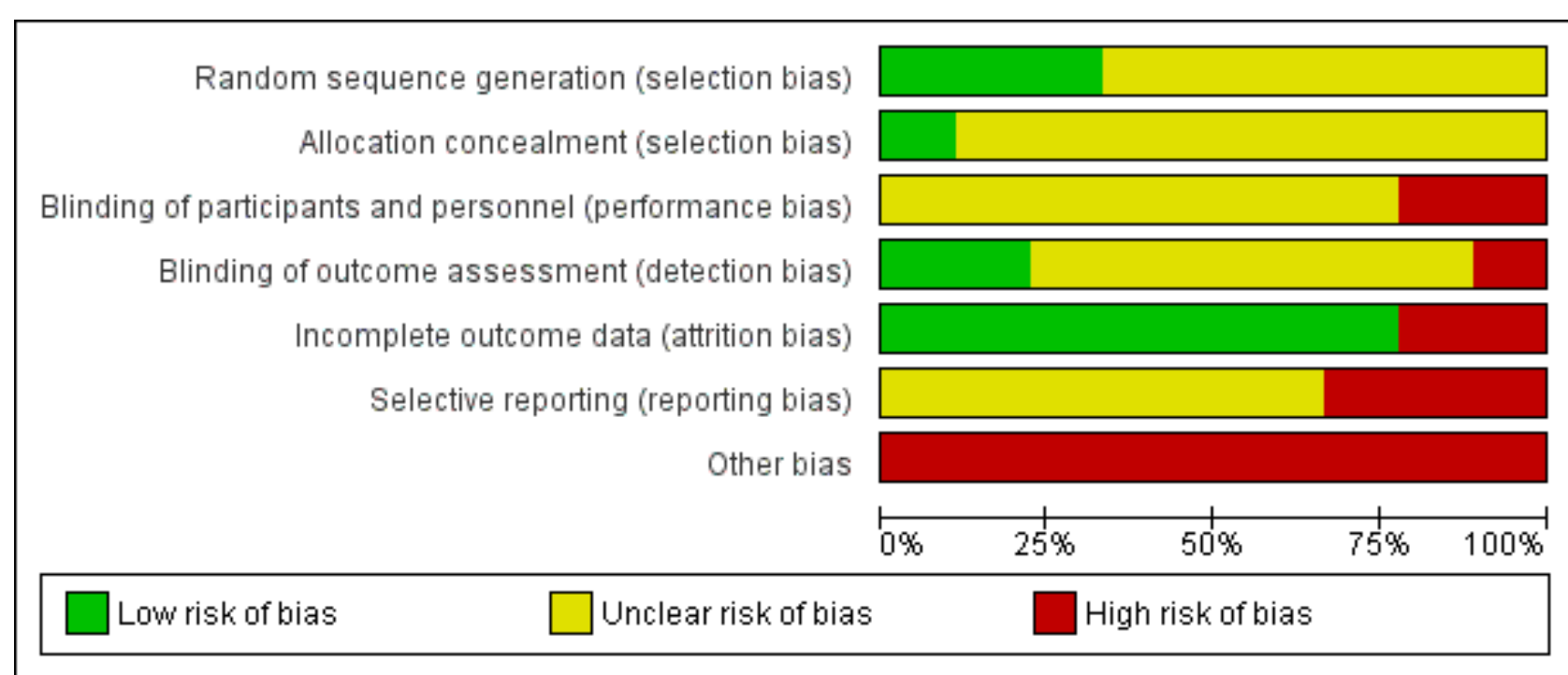


Figure 4. 'Risk of bias' summary: review authors' judgements about each risk of bias item for each included study.

\begin{tabular}{|c|c|c|c|c|c|c|c|}
\hline & 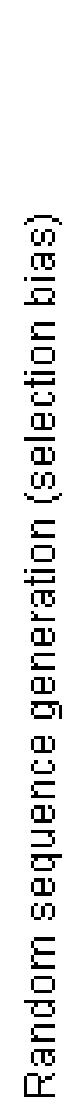 & 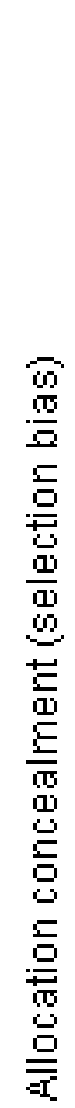 & 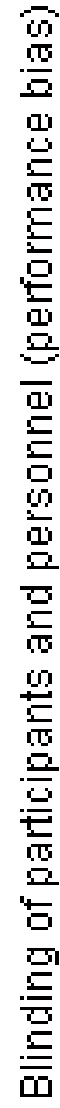 & 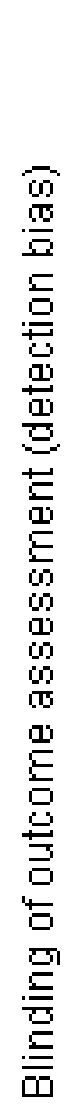 & 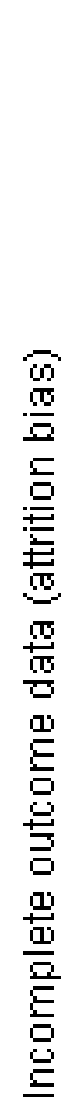 & 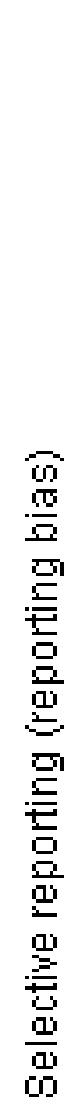 & 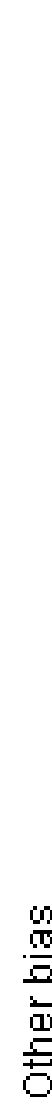 \\
\hline Dai 2012 & $?$ & $?$ & $?$ & $?$ & & $?$ & \\
\hline $\operatorname{Jin} 2013$ & $?$ & $?$ & $?$ & $?$ & & $?$ & \\
\hline Li 2013 & $?$ & $?$ & ? & $?$ & & $?$ & \\
\hline $\operatorname{Lim} 2010$ & + & $?$ & & & & & \\
\hline Walther 2014 & + & + & ? & & & & \\
\hline Wang 2012 & + & $?$ & & & & $?$ & \\
\hline Wang 2013 & $?$ & $?$ & $?$ & $?$ & & $?$ & \\
\hline Yao 2010 & $?$ & $?$ & $?$ & $?$ & & & \\
\hline Zhou 2013 & $?$ & $?$ & $?$ & $?$ & & $?$ & \\
\hline
\end{tabular}




\section{Allocation}

All nine studies were reported as randomised. In Dai 2012, Jin 2013, Li 2013, Wang 2013, Yao 2010, and Zhou 2013 randomisation is stated but no informations on randomisation procedures and allocation process were given. For the studies that did report further details, methods are described as random number sequence (Wang 2012), pre-defined randomisation code (Lim 2010), and randomisation in blocks (Walther 2014).

\section{Blinding}

None of the studies were double-blind with two studies (Lim 2010 and Wang 2012) reporting to be open-label . Only two studies reported being rater-blind (Lim 2010; Walther 2014).

\section{Incomplete outcome data}

There was no evidence of attrition bias for seven studies (Dai 2012; Li 2013; Lim 2010; Wang 2012; Wang 2013; Yao 2010; Zhou 2013). In Jin 2013, two participants left the study early due to adverse effects (without any procedure in order to take into account attrition bias), whilst in Walther 2014, nine people were excluded due to refusal to provide post-hoc consent.

\section{Selective reporting}

In Lim 2010, Walther 2014 and Yao 2010, there was evidence of selective reporting, since several outcomes - despite being stated in the methods - are not reported or reported only partially.

\section{Other potential sources of bias}

A study being sponsored by a pharmaceutical company does not automatically indicate bias, but indicates a level of risk for uncertainty. One study was sponsored by Janssen Phamaceutica Korea (Lim 2010). Although Walther 2014 stated that their study was unfunded, several authors were affiliated with Novartis, AstraZeneca, Bristol-Myers Squibb, Janssen, Servier, Eli Lilly, Zeller Medical, and Sandoz. Eight out of the nine studies had a very small sample size (Dai 2012; Jin 2013; Li 2013; Walther 2014; Wang 2012; Wang 2013; Yao 2010; Zhou 2013).

\section{Effects of interventions}

See: Summary of findings for the main comparison RISPERIDONE compared to OTHER ANTIPSYCHOTIC: a. HALOPERIDOL for psychosis-induced aggression or agitation (rapid tranquillisation); Summary of findings 2 RISPERIDONE compared to OTHER ANTIPSYCHOTIC: b. OLANZAPINE for psychosis-induced aggression or agitation (rapid tranquillisation); Summary of findings 3 RISPERIDONE compared to OTHER ANTIPSYCHOTIC: c. QUETIAPINE for psychosis-induced aggression or agitation (rapid tranquillisation); Summary of findings 4 RISPERIDONE compared to COMBINATION: a. RISPERIDONE + OXCARBAZEPINE for psychosis-induced aggression or agitation (rapid tranquillisation); Summary of findings $\mathbf{5}$ RISPERIDONE compared to COMBINATION: b. RISPERIDONE + VALPROIC ACID for psychosis-induced aggression or agitation (rapid tranquillisation)

See: Summary of findings for the main comparison; Summary of findings 2; Summary of findings 3; Summary of findings 4; Summary of findings 5 .

\section{COMPARISON 1: RISPERIDONE verSUS OTHER ANTIPSYCHOTIC: a. HALOPERIDOL}

Two studies ( $\mathrm{n}=152$ ) compared risperidone with haloperidol (Lim 2010; Walther 2014).

\subsection{Specific behaviour - agitation}

There were no clear differences in terms of Positive And Negative Syndrome Scale - Psychotic Agitation Sub-score (PANSS-PAS) response rate up to 24 hours (risk ratio (RR) 1.04, 95\% confidence interval (Cl) 0.86 to 1.26; participants $=124$; studies $=1$; Analysis 1.1 ) and PANSS-PAS rating scales up to two hours (mean difference (MD) $0.40,95 \% \mathrm{Cl}-4.42$ to 5.22 ; participants $=28$; studies $=1$; Analysis 1.2), up to 24 hours ( $\mathrm{MD} 0.20,95 \% \mathrm{Cl}-3.96$ to 4.36 ; participants $=28$; studies = 1; Analysis 1.3), and over 24 hours (at 48 hours, MD 1.50, $95 \% \mathrm{Cl}-1.36$ to 4.36 ; participants $=28$; studies $=1$; at 72 hours, MD $1.40,95 \% \mathrm{Cl}-1.62$ to 4.42 ; participants $=28$; studies $=1$; at 96 hours, MD $2.90,95 \% \mathrm{Cl}-0.34$ to 6.14 ; participants $=28$; studies $=1$; Analysis 1.4).

\subsection{Global outcome}

No clear differences were identified in terms of need for benzodiazepines (RR $0.88,95 \% \mathrm{Cl} 0.34$ to 2.27 ; participants $=124$; studies $=1$ ), need for seclusion room (RR 0.33 , $95 \% \mathrm{Cl} 0.01$ to 7.55 ; participants $=28$; studies $=1)$, and use of restraints $(\mathrm{RR} 2.00,95 \% \mathrm{Cl}$ 0.43 to 9.21; participants $=28$; studies $=1$; Analysis 1.5 ) .

\subsection{Adverse effects}

A similar proportion of participants experienced one or more adverse effects, thus resulting in no clear differences between treatment groups (RR 0.94, $95 \% \mathrm{Cl} 0.54$ to 1.66 ; participants $=124$; studies $=1$; Analysis 1.7).

More people allocated to risperidone experienced insomnia, without clear differences (RR 13.00, 95\% Cl 0.75 to 225.90 ; participants $=124$; studies $=1$ ), while a similar number of patients experienced somnolence (RR 1.29, $95 \% \mathrm{Cl} 0.51$ to 3.24; participants $=124$; studies $=1$; Analysis 1.8 ).

No clear differences resulted between risperidone and haloperidol in terms of movement disorders, both when considering the proportion of people experiencing extrapyramidal symptoms up to 24 hours (RR $0.63,95 \% \mathrm{Cl} 0.22$ to 1.80 ; participants = 124 ; studies = 1; Analysis 1.9), or continuous scale scores such as Behavioural Activity Rating Scale (BARS) (MD $-0.60,95 \% \mathrm{Cl}-1.56$ to 0.36; participants $=28$; studies $=1$ ) and SAS (MD $-0.40,95 \% \mathrm{Cl}-3.00$ to 2.20; participants $=28$; studies $=1$; Analysis 1.11 ) .

Risperidone and haloperidol were similar for adverse events such as headache (RR 0.75, $95 \% \mathrm{Cl} 0.18$ to 3.21 ; participants $=124$; studies $=1$ ) and dizziness (RR 1.00, $95 \% \mathrm{Cl} 0.26$ to 3.82; participants = 124; studies $=1$ ) up to 24 hours (Analysis 1.12).

\subsection{Leaving the study early}

A comparable proportion of participants left the study early due to any reason (RR $2.20,95 \% \mathrm{Cl} 0.51$ to 9.48; participants $=152$; studies $=2 ;\left.\right|^{2}=59 \%$ ), due to adverse effects (RR $0.50,95 \% \mathrm{Cl} 0.05$ to 5.37 ; participants $=124$; studies $=1$ ), or due to lack of efficacy (RR 9.00, $95 \% \mathrm{Cl} 0.53$ to 152.93; participants $=28$; studies $=1$; Analysis 1.13 ). 


\section{COMPARISON 2: RISPERIDONE verSUS OTHER ANTIPSYCHOTIC: b. OLANZAPINE}

One study $(n=29)$ compared risperidone with olanzapine (Walther 2014). Unsurprisingly with such a small study, no difference between the compared drugs for any of the considered outcomes could be observed.

\subsection{Specific behaviour - agitation}

There were no clear differences in PANSS-PAS endpoint scores up to two hours (MD 2.50, 95\% Cl-2.46 to 7.46; participants $=29$; studies $=1$; Analysis 2.1), up to 24 hours (MD $0.90,95 \% \mathrm{Cl}-3.40$ to 5.20 ; participants $=29$; studies $=1$; Analysis 2.2), and over 24 hours (at 48 hours, MD $-1.20,95 \% \mathrm{Cl}-5.15$ to 2.75 ; participants $=29$; studies $=1$; at 72 hours, $\mathrm{MD}-0.30,95 \% \mathrm{Cl}-4.47$ to 3.87 ; participants $=29$; studies $=1$; at 96 hours, MD $2.10,95 \% \mathrm{Cl}-1.41$ to 5.61; participants = 29; studies $=1$; Analysis 2.3).

\subsection{Global outcome}

No clear differences were found when comparing risperidone and olanzapine in terms of need for seclusion room (RR $0.36,95 \% \mathrm{Cl} 0.02$ to 8.07; participants $=29$; studies $=1$ ) and use of restraints (RR 1.43, $95 \% \mathrm{Cl} 0.39$ to 5.28; participants $=29$; studies $=1$; Analysis 2.4).

\subsection{Adverse effects}

Comparison in terms of BARS (MD $0.20,95 \% \mathrm{Cl}-0.43$ to 0.83 ; participants $=29$; studies $=1$ ) and SAS scores (MD 1.80, 95\% Cl-0.63 to 4.23; participants $=29$; studies $=1$ ) resulted in no clear difference (Analysis 2.6).

\subsection{Leaving the study early}

More people allocated to risperidone left the study early due to lack of efficacy, but there was no clear difference between treatment groups for this outcome (RR 2.14, 95\% Cl 0.46 to 9.93; participants $=29$; studies $=1$; Analysis 2.7) .

\section{COMPARISON 3: RISPERIDONE verSUS OTHER ANTIPSYCHOTIC: C. QUETIAPINE}

One study $(n=40)$ compared risperidone with quetiapine (Dai 2012).

\subsection{Specific behaviour - aggression}

A clear difference at Modified Overt Aggression Scale (MOAS) endpoint score could be seen at two weeks favouring participants allocated to quetiapine (MD 1.80, 95\% Cl 0.20 to 3.40; participants = 40; studies $=1$ ), whilst this was not the case at four weeks (MD 0.90, $95 \% \mathrm{Cl}-0.44$ to 2.24; participants $=40$; studies $=1$ ), at six weeks (MD $0.70,95 \% \mathrm{Cl}-0.29$ to 1.69 ; participants $=40$; studies $=1$ ), and at eight weeks (MD 0.55, 95\% Cl-0.40 to 1.50; participants $=40$; studies $=1$ ). (Analysis 3.1).

\subsection{Mental state}

There was no clear difference observed in the 'no response' outcome of the PANSS rating scale at eight weeks (RR 1.00, 95\% $\mathrm{Cl} 0.16$ to 6.42; participants $=40$; studies $=1$; Analysis 3.2). No clear differences were found as for the other dichotomous outcome (Analysis 3.3).

PANSS total endpoint scores and sub-scale endpoint scores (positive symptoms, negative symptoms, general psychopathology) were collected at two, four, six and eight weeks. Only PANSS positive symptoms sub-scale endpoint scores at four weeks resulted in a clear difference in favour of quetiapine (MD 1.70, $95 \% \mathrm{Cl} 0.01$ to 3.39; participants $=40$; studies $=1$; Analysis 3.4).

\subsection{Adverse effects}

No clear differences could be observed between risperidone and quetiapine for a list of different adverse effects: blurred vision (RR $0.50,95 \% \mathrm{Cl} 0.10$ to 2.43; participants $=40$; studies $=1$; Analysis 3.5), somnolence (RR $0.60,95 \% \mathrm{Cl} 0.17$ to 2.18 ; participants $=40$; studies = 1; Analysis 3.6), tachycardia (RR 4.00, 95\% Cl 0.49 to 32.72; participants $=40$; studies $=1$; Analysis 3.7), nausea and vomiting (RR 1.00, 95\% Cl 0.07 to 14.90; participants = 40; studies = 1; Analysis 3.8), akathisia (RR 1.67, $95 \% \mathrm{Cl} 0.46$ to 6.06; participants = 40; studies = 1), hypermyotonia (RR $7.00,95 \% \mathrm{Cl} 0.95$ to 51.80 ; participants $=40$; studies $=1$; Analysis 3.9), headache $(\mathrm{RR} 1.00,95 \%$ $\mathrm{Cl} 0.16$ to 6.42; participants $=40$; studies $=1$ ), liver function tests (LFTs) elevation (RR 1.00, 95\% Cl 0.07 to 14.90 ; participants $=40$; studies $=1$ ), weight gain (RR $4.00,95 \% \mathrm{Cl} 0.49$ to 32.72 ; participants $=40$; studies $=1$ ), and agitation (RR $3.50,95 \% \mathrm{Cl} 0.83$ to 14.83 ; participants $=40$; studies $=1$; Analysis 3.10).

\section{COMPARISON 4: RISPERIDONE verSUS COMBINATION: a. RISPERIDONE + OXCARBAZEPINE}

One study $(n=68)$ compared risperidone with the 'risperidone + oxcarbazepine' combination (Wang 2012).

\subsection{Specific behaviour - agitation}

There was a clear difference in the Positive And Negative Syndrome Scale - Excited Component (PANSS-EC) endpoint scores at one week (MD 2.70, 95\% Cl 0.42 to 4.98; participants $=68$; studies $=1$; Analysis 4.1) in favour of the combination.

\subsection{Global outcome}

Comparison at one week in terms of Clinical Global Impression Improvement (CGI-I) (MD $-0.20,95 \% \mathrm{Cl}-0.61$ to 0.21 ; participants = 68; studies = 1) and Clinical Global Impression - Severity (CGI-S) endpoint scores (MD 0.20, 95\% Cl -0.25 to 0.65 ; participants $=68$; studies $=1$ ) resulted in no clear difference (Analysis 4.2).

\subsection{Mental state}

There was a clear difference between Brief Psychiatric Rating Scale (BPRS) endpoint scores at one week (MD 5.20, 95\% Cl 1.04 to 9.36; participants $=68$; studies $=1$ ) in favour of the combination (Analysis 4.5).

\subsection{Adverse effects}

In the combination group a total number of 47 adverse effects were registered compared to a total of 40 adverse effects in participants allocated to risperidone. (Analysis 4.6).

There was a clear difference in the number of participants experiencing excessive sedation in favour of risperidone. (RR 0.06 , $95 \% \mathrm{Cl} 0.00$ to 0.92 ; participants $=68$; studies $=1$; Analysis 4.8 ) .

Risperidone and combination groups were comparable in terms of the number of participants that were experiencing various adverse effects at four weeks: dry mouth (RR $2.12,95 \% \mathrm{Cl} 0.81$ to 5.55 ; participants $=68$; studies $=1$ ) and constipation at four weeks (RR $1.30,95 \% \mathrm{Cl} 0.62$ to 2.72 ; participants $=68$; studies $=1$ ) (Analysis 4.7); 
tachycardia (RR 1.24, 95\% Cl 0.46 to 3.30; participants = 68; studies $=1$; Analysis 4.9); nausea (RR 2.12, $95 \% \mathrm{Cl} 0.20$ to 22.31 ; participants $=68 ;$ studies $=1 ;$ Analysis 4.10), extrapyramidal symptoms (EPS) (RR $1.59,95 \% \mathrm{Cl} 0.49$ to 5.14; participants $=68$; studies $=1$ ) and tremor (RR $0.85,95 \% \mathrm{Cl} 0.25$ to 2.89; participants $=68$; studies $=1$ ) (Analysis 4.11); headache (RR $0.07,95 \% \mathrm{Cl} 0.00$ to 1.19 ; participants $=68$; studies $=1$ ) and skin rash (RR $0.35,95 \% \mathrm{Cl} 0.01$ to 8.37 ; participants $=68 ;$ studies $=1)($ Analysis 4.12).

\section{COMPARISON 5: RISPERIDONE verSUS COMBINATION: b. RISPERIDONE + VALPROIC ACID}

Five studies $(n=307)$ compared risperidone with the 'risperidone + valproic acid' combination (Jin 2013; Li 2013; Wang 2013; Yao 2010; Zhou 2013).

\subsection{Specific behaviour - agitation}

PANSS-EC endpoint scores were comparable between risperidone and combination at three days (MD $-0.11,95 \% \mathrm{Cl}-2.98$ to 2.76; participants $=54$; studies $=1$ ); a clear difference in favour of the combination was identified at five days (MD 5.47, 95\% Cl 2.64 to 8.30; participants $=54$; studies $=1$ ) and seven days (MD 5.11, $95 \% \mathrm{Cl}$ 2.51 to 7.71 ; participants $=54$; studies $=1$; Analysis 5.1) .

Endpoint scores at PANSS-EC at two weeks (MD 0.09, 95\% Cl -0.90 to 1.08; participants $=63$; studies $=1$ ) and at four weeks (MD 0.17, $95 \% \mathrm{Cl}-0.85$ to 1.19 ; participants $=63$; studies $=1$ ) could not show a difference between the compared drugs (Analysis 5.2).

\subsection{Specific behaviour - aggression}

Risperidone and 'risperidone + valproic acid' combination were comparable both at three days (MD 1.07, 95\% Cl -0.20 to 2.34; participants $=54$; studies $=1$ ) and five days (MD 0.38, 95\% Cl -0.83 to 1.59; participants $=54$; studies $=1$ ) in terms of Modified Overt Aggression Scale (MOAS) endpoint scores. A clear difference in favour of the combination could be identified at seven days (MD $3.32,95 \% \mathrm{Cl} 2.07$ to 4.57 ; participants $=54$; studies $=1$ ), at two weeks (MD 1.13, 95\% Cl 0.23 to 2.02; participants = 128; studies = 2; $\left.\right|^{2}=$ $25 \%$ ), at four weeks (MD 1.57, 95\% Cl 0.75 to 2.39; participants = 128; studies $\left.=2 ; 1^{2}=0 \%\right)$, and at six weeks (MD 1.47, 95\% Cl 0.83 to 2.11; participants $=68$; studies $=1$ ), whilst being comparable at eight weeks (MD 1.00, 95\% Cl-0.11 to 2.11; participants $=60$; studies $=1$;Analysis 5.2).

\subsection{Mental state}

Five participants allocated to risperidone and three participants allocated to the combination showed no clinical response based on the PANSS score ( $<30 \%$ reduction from baseline score) at eight weeks (RR 1.67, 95\% Cl 0.44 to 6.38; participants $=62$; studies $=1$; Analysis 5.3).

However, when looking at PANSS endpoint scores, a clear difference favouring the combination could be seen at two weeks (MD 3.48, 95\% Cl 1.88 to 5.08; participants = 253; studies $=4 ; \mathrm{I}^{2}=$ $80 \%$ ), at four weeks (MD 5.45, 95\% Cl 3.81 to 7.08 ; participants = 253; studies $=4 ; \mathrm{I}^{2}=70 \%$ ), at six weeks (MD 9.90, 95\% Cl 7.42 to 12.37 ; participants $=130 ;$ studies $\left.=2 ; 1^{2}=92 \%\right)$ and at eight weeks (MD 5.83, $95 \% \mathrm{Cl} 4.12$ to 7.54 ; participants $=122$; studies $=2 ;\left.\right|^{2}=58 \%$ ).

High $\mathrm{I}^{2}$ values that should be translated into inconsistency of findings between the studies; data at two, four and six weeks had $\mathrm{Chi}^{2} \mathrm{P}$ values statistically significant, showing evidence of substantial levels of heterogeneity (Assessment of heterogeneity; Section 9.5.2, Higgins 2011). We investigated for input errors and found that data were entered correctly. At the visual inspection of the forest plots we identified Wang 2013 as an outlying study for the two and four weeks pooled data analyses and removed it to see if homogeneity was restored. PANSS endpoint scores at two weeks (MD 2.50, 95\% Cl 0.78 to 4.21; participants $=185$; studies = $\left.3 ; \mathrm{I}^{2}=62 \%, \mathrm{Chi}^{2}=5.23, \mathrm{P}=0.07\right)$ showed a $\mathrm{I}^{2}$ value $>50 \%$ with a $\mathrm{Chi}^{2} \mathrm{P}$ value non statistically significant, whilst at four weeks (MD $4.52,95 \% \mathrm{Cl} 2.76$ to 6.29 ; participants $=185$; studies $=3 ; 1^{2}=21 \%$, $\left.\mathrm{Chi}^{2}=2.55, \mathrm{P}=0.28\right) \mathrm{I}^{2}$ value resulted being $<50 \%$ accompanied by a non statistically significant $\mathrm{Chi}^{2} \mathrm{P}$ value. Given the concordance of direction of effects, the summary effect resulting statistically significant even by removal of the outlying study, and that the relative weights of this last were $13.3 \%$ and $14.2 \%$, (respectively, two and four weeks), we decided to present the pooled data (Subgroup analysis and investigation of heterogeneity).

Sub-scale continuous data showed a clear difference at PANSS positive symptoms sub-scale in favour of the combination at four weeks (MD 2.75, 95\% Cl 1.86 to 3.64; participants = 191; studies = $3 ; 1^{2}=76 \%$ ), six weeks (MD 4.40, 95\% Cl 1.40 to 7.40 ; participants = 68; studies $=1$ ), and eight weeks (MD 1.70, 95\% Cl 0.71 to 2.69; participants $=60$; studies $=1$ ), despite being comparable at two weeks (MD 0.64, 95\% Cl -0.24 to 1.53; participants $=191$; studies $=$ $3 ;\left.\right|^{2}=81 \%$; Analysis 5.4).

Again, we investigated for input errors and that data were entered correctly. At the visual inspection of the graphs, Li 2013 could be identified as an hypothetical outlying study. By removing it, 12 values resulted $<50 \%$ and $\mathrm{Chi}^{2} \mathrm{P}$ values resulted non statistically significant (two weeks: $12=2 \%, \mathrm{Chi}^{2}=1.02, \mathrm{P}=0.31$; four weeks: $\left.\mathrm{I}^{2}=0 \%, \mathrm{Chi}^{2}=0.36, \mathrm{P}=0.55\right)$. Given the relative weights of the outlying study being $68.8 \%$ at two weeks and $69.8 \%$ at four weeks, we decided not to consider pooled data and wait for more studies and data.

PANSS negative symptoms sub-scale could not show clear differences at two weeks (MD 0.29, $95 \% \mathrm{Cl}-0.57$ to 1.15 ; participants $=128 ;$ studies $\left.=2 ; 1^{2}=65 \%\right)$, four weeks (MD 1.23, 95\% Cl -0.16 to 2.62; participants $=128$; studies $=2 ; 1^{2}=59 \%$ ), and eight weeks $(\mathrm{MD} 1.30,95 \% \mathrm{Cl}-0.02$ to $2.62 ;$ participants $=60$; studies $=1)$; a clear difference was observed at six weeks only, favouring the combination (MD 3.80, 95\% Cl 1.07 to 6.53; participants $=68$; studies $=1)$.

PANSS general psychopathology sub-scale showed clear differences in favour of the combination at four weeks (MD 1.14, $95 \% \mathrm{Cl} 0.04$ to 2.23; participants $=128$; studies $\left.=2 ; 1^{2}=50 \%\right)$, six weeks (MD 6.50, 95\% Cl 4.06 to 8.94; participants $=68$; studies = 1), and eight weeks (MD 1.60, 95\% $\mathrm{Cl} 0.43$ to 2.77; participants = 60 ; studies $=1$ ); at two weeks data did not show a clear difference between the compared drugs (MD $0.93,95 \% \mathrm{Cl}-0.07$ to 1.93; participants $=128$; studies $=2 ; 1^{2}=66 \%$ ) (Analysis 5.4).

\subsection{Adverse effects}

In the combination group a total number of 20 adverse effects were registered, compared to the 16 total adverse effects experienced by participants allocated to risperidone (Analysis 5.5). 
Two participants allocated to risperidone and one allocated to the combination suffered from myocardial ischaemia (RR $2.00,95 \% \mathrm{Cl}$ 0.19 to 20.93; participants $=62$; studies $=1$; Analysis 5.6) .

Risperidone and combination groups resulted in comparable in terms of probability of experiencing blurred vision (RR 1.00, 95\% $\mathrm{Cl} 0.37$ to 2.68; participants $=122$; studies $\left.=2 ; 1^{2}=0 \%\right)$, dry mouth (RR 1.64, 95\% Cl 0.76 to 3.54; participants $=129$; studies $=2 ; 1^{2}=78 \%$; Analysis 5.7); insomnia (RR $2.00,95 \% \mathrm{Cl} 0.19$ to 20.77; participants $=54$; studies $=1)$, somnolence $($ RR $0.85,95 \%$ $\mathrm{Cl} 0.44$ to 1.63 ; participants $=121$; studies $=2 ; \mathrm{I}^{2}=0 \%$; Analysis 5.8); decreased blood pressure (RR $0.75,95 \% \mathrm{Cl} 0.18$ to 3.10 ; participants $=68$; studies $=1)$, tachycardia $(\mathrm{RR} 1.48,95 \% \mathrm{Cl} 0.83$ to 2.67; participants $=251$; studies $\left.=4 ; 1^{2}=35 \%\right)$, T-wave changes in ECG (RR 2.00, $95 \% \mathrm{Cl} 0.19$ to 20.77 ; participants $=54$; studies $=1$; Analysis 5.9); constipation (RR 1.11, 95\% $\mathrm{Cl} 0.70$ to 1.76; participants $=189$; studies $=3 ; \mathrm{I}^{2}=6 \%$ ), nausea $(\mathrm{RR} 0.70,95 \% \mathrm{Cl} 0.29$ to 1.71 ; participants $=122 ;$ studies $=2 ; 1^{2}=0 \%$; Analysis 5.10); EPS (RR $1.35,95 \% \mathrm{Cl} 0.76$ to 2.39 ; participants $=121$; studies $\left.=2 ; 1^{2}=91 \%\right)$, akathisia (RR $0.75,95 \% \mathrm{Cl} 0.28$ to 2.03; participants $=122$; studies = $2 ; 1^{2}=0 \%$ ), tremor (RR $1.20,95 \% \mathrm{Cl} 0.40$ to 3.56 ; participants $=68$; studies = 1 ; Analysis 5.11); headache (RR $0.94,95 \% \mathrm{Cl} 0.53$ to 1.68 ; participants $=243$; studies $\left.=4 ;\left.\right|^{2}=0 \%\right)$, weight gain $(\mathrm{RR} 1.50,95 \% \mathrm{Cl}$ 0.47 to 4.78 ; participants $=60$; studies $=1)$, oedema $(R R 0.34,95 \% \mathrm{Cl}$ 0.01 to 8.13 ; participants $=63$; studies $=1)$, leukopenia $($ RR $0.34,95 \%$ $\mathrm{Cl} 0.01$ to 8.13; participants $=63$; studies $=1$ ), and liver function tests elevation $(\mathrm{RR} 0.60,95 \% \mathrm{Cl} 0.15$ to 2.40 ; participants $=116$; studies $=$ $2 ;\left.\right|^{2}=0 \%$; Analysis 5.13)

Treatment Emergent Symptom Scale (TESS) endpoint scores did not find a clear difference in movement disorders between the compared groups at three days (MD $-0.04,95 \% \mathrm{Cl}-1.35$ to 1.27 ; participants $=54$; studies $=1)$, five days $(\mathrm{MD}-0.11,95 \% \mathrm{Cl}-1.55$ to 1.33; participants $=54$; studies $=1$ ), and at seven days (MD -0.51 , $95 \% \mathrm{Cl}-1.88$ to 0.86 ; participants $=54$; studies $=1$; Analysis 5.12).

\subsection{Leaving the study early}

Two participants allocated to the combination and none of those allocated to risperidone left the study early due to adverse effects (RR 0.21, 95\% Cl 0.01 to 4.13; participants = 63; studies = 1; Analysis 5.14).

\section{DISCUSSION}

\section{Summary of main results}

\section{COMPARISON 1: RISPERIDONE verSUS OTHER ANTIPSYCHOTIC: a. HALOPERIDOL}

Two studies were included (Lim 2010; Walther 2014), with a total number of 152 participants (risperidone, $n=76$; haloperidol, $n=$ 76); although two potential sources of data were available, only one outcome could benefit from both ('leaving the study early'). We did expect to find more relevant studies since haloperidol has an historical role in drug development research and still could be indicated as the 'common comparator' when designing randomised controlled trials (RCTs). Moreover, available outcomes were rated of very low quality (Summary of findings for the main comparison), due to high risk of attrition and 'selective reporting bias, small sample size and indirectness of outcome measures. No data concerning 'tranquillisation or asleep', repeated need for tranquillisation and economic outcomes were available.

\subsection{Agitation, global outcome}

Risperidone and haloperidol showed similar results in agitation measurement scales and global outcomes such as need for benzodiazepine, need for seclusion room or use of restraints.

Interestingly, dichotomous data on efficacy outcomes provided no strong evidence of a difference between oral risperidone and intramuscular administration of haloperidol; even if higherquality evidence is needed to draw any firm conclusion, patients preference and best interest should be taken into consideration in treatment decision making when delivering a tailored therapy.

\subsection{Adverse effects}

Analyses provides no strong evidence that the intervention yielded any differences in terms of adverse effects.

\subsection{Leaving the study early}

A comparable number of participants allocated to either risperidone or haloperidol left the study early.

\section{COMPARISON 2: RISPERIDONE verSUS OTHER ANTIPSYCHOTIC: b. OLANZAPINE}

Only one study was included (Walther 2014), with a total number of 29 participants (risperidone, $n=14$; olanzapine, $n=15$ ). Due to high risk of attrition and 'selective reporting' bias, the small sample size and the indirectness of the outcome measures, available outcomes were rated of very low quality (Summary of findings 2). No data concerning 'tranquillisation or asleep', repeated need for rapid tranquillisation and economic outcomes were available.

Analyses provides no strong evidence that risperidone has an effect any different than olanzapine for any of the considered outcomes: 'specific behaviour - agitation', 'global outcome', 'adverse effects', 'leaving the study early'.

\section{COMPARISON 3: RISPERIDONE verSUS OTHER ANTIPSYCHOTIC: C. QUETIAPINE}

Only one study was included (Dai 2012), with a total number of 40 participants (risperidone, $n=20$; quetiapine, $n=20$ ). Due to small sample size and the indirectness of the outcome measures, available outcomes were rated of very low quality (Summary of findings 3). No data concerning 'tranquillisation or asleep', repeated need for rapid tranquillisation, 'global state' and economic outcomes were available. No data were available on the 'rapid tranquillisation' topic: the first time point at which data were collected was at two weeks.

Data analyses provide no strong evidence that risperidone has an effect clinically significantly different than quetiapine for almost all the outcomes: 'specific behaviour - aggression', 'mental state', 'adverse effects'.

\section{COMPARISON 4: RISPERIDONE verSUS COMBINATION: a. RISPERIDONE + OXCARBAZEPINE}

Only one study was included (Wang 2012), with a total number of 68 participants (risperidone, $n=33$; risperidone + oxcarbazepine, $\mathrm{n}=35$ ). Due to high risk of performance and detection bias, small sample size and indirectness of outcome measures, available outcomes were rated of very low quality (Summary of findings 4); 
no data concerning 'tranquillisation or asleep', repeated need for tranquillisation and economic outcomes were available.

\subsection{Agitation, global outcome, mental state}

As for the available 'agitation' and 'mental state' outcomes (PANSS-EC and BPRS endpoint scores, respectively), we could find evidences of differences in favour of the combination, with no strong evidence of any difference for the 'global outcome'. However, it has to be noted that available data were collected at seven days, a timing far too late to be informative for the 'rapid tranquillisation' topic. Moreover, the quality of evidence was very low due to aforementioned risks.

\subsection{Adverse effects}

Very low quality of evidence was found that 'risperidone + oxcarbazepine' combination yielded to higher number of 'excessive sedation' adverse events (zero events occurred in the risperidone group, whilst nine events were reported for the combination group; Analysis 4.8). Interestingly, since we do not have further details on data and the latter have not been collected to multiple time points, we could not exclude that this evidence is just another way to read the higher efficacy one (Analysis 4.1; Analysis 4.5).

The ideal concept of 'tranquillisation' is to find a way to get people calm without causing sedation. Even if this last could be necessary within the first hours, it could not be justified in the later days (if no other aggression or agitation episodes occurred).

No strong evidence of any difference could be observed as for the other collected adverse events.

\section{COMPARISON 5: RISPERIDONE verSUS COMBINATION: b. RISPERIDONE + VALPROIC ACID}

Five studies were included (Jin 2013; Li 2013; Wang 2013; Yao 2010; Zhou 2013), with a total number of 307 participants (risperidone, $\mathrm{n}=153$; risperidone + valproic acid, $\mathrm{n}=154$ ). Available outcomes were rated of very low quality (Summary of findings 5), due to small sample size and indirectness of outcome measures. No data concerning 'tranquillisation or asleep', repeated need for tranquillisation and economic outcomes were available.

\subsection{Agitation, aggression}

As for available efficacy outcomes on agitation, continuous data analyses provides no strong evidence of different efficacy between risperidone and the 'risperidone + valproic acid' combination at three days; when focusing on later time points, a clear difference in favours of the combination at five and seven days, but not at two and four weeks, could be seen.

Concerning continuous data on aggression, evidence of a clear difference could be observed in favour of the combination at five and seven 7 days, two, four, and six weeks. However, mean difference (MD) and confidence interval $(\mathrm{Cl})$ values should be taken into account to evaluate clinically significance. At eight weeks a strong evidence of any difference between the compared drugs could not be provided.

\subsection{Mental state}

Very low quality of evidence of a clear difference in PANSS endpoint scores favouring the combination could be observed (subgroup analyses were carried out for PANSS endpoint scores data at two and four weeks); this held true for the later time points (mainly six and eight weeks) of positive symptoms, negative symptoms and general psychopathology sub-scales; PANSS positive symptoms sub-scale endpoint scores data at two and four weeks could not be pooled due to high heterogeneity.

It has to be highlighted, however, that available data were measured starting from the second week: no evidence could be found concerning time points relevant to the 'rapid tranquillisation' topic.

\subsection{Adverse effects}

Data analyses provide no strong evidence of any difference in terms of adverse effects between risperidone and the 'risperidone + valproic acid' combination. However, in one study (Yao 2010), three episodes of myocardial ischaemia were observed: an association between the drug administration and the event could not be found throughout the relevant paper, nor more information about their cardiovascular baseline risk (presumably not high since age range of participants recruited in the study was between 17 and 42 years, with a mean age of 26.9 years).

\subsection{Leaving the study early}

No strong evidence of any difference in terms of 'leaving the study early' outcome could be observed.

\section{Overall completeness and applicability of evidence}

\section{Completeness}

We identified nine relevant studies and all reported only a few outcomes: only two comparisons could benefit from more than one study as data source and - even more surprisingly - as for the haloperidol comparison this held true only for a single outcome; the most represented comparison is the one comparing risperidone with 'risperidone + valproic acid' combination (five studies). No study reported data regarding the 'tranquillisation or asleep' outcome, service outcomes, satisfaction with treatment, acceptance of treatment, quality of life, or economic outcomes. Three included studies suffered from 'selective reporting' bias, thus further limiting available data. Protocols were not available for all the included studies.

\section{Applicability}

All of the included studies were more of the explanatory type of study rather the practical/pragmatic and easily applicable to realworld practice one (Thorpe 2009).

Included studies were conducted in three different countries (China, seven; Korea, one; Switzerland, one) and in psychiatric inpatient and emergency admission settings.

Rapid tranquillisation is often used to achieve a fast resolution of this clinical state that could otherwise result in injury to self or others, hence preventing prolonged physical restraint of people, which should be seen as the very last available resource. It was therefore surprising and disappointing that few studies measured agitation and aggression outcomes at time points that one would associate with 'rapid tranquillisation'. The first available time point is at two hours (Walther 2014), with seven studies having set time points greater than 24 hours (three days, Zhou 2013; one week, Wang 2012; two weeks, Dai 2012; Jin 2013; Li 2013; Wang 2013; Yao 2010). In Lim 2010, outcomes are stated to be measured as early as 
30 minutes but, unfortunately, only 24 hours measurements were provided.

\section{Quality of the evidence}

\section{General}

All of the included studies were published after the first CONSORT guidance (1996); no studies complied with this internationally agreed standard. Disappointingly, a large proportion of data was rendered unusable, which could have been avoided had the trials been better reported.

\section{Specific}

All nine studies were randomised, but details were vaguely reported and none was double-blinded. Three studies suffered from 'selective reporting' bias. Data from more than one source were available for two comparisons only. These factors strongly limit the quality of the available evidence and this can be evinced in the 'Risk of bias' and 'Summary of findings' tables; all of the selected outcomes to be included in th 'Summary of findings' tables were rated as 'very low' quality.

\section{Potential biases in the review process}

We followed the protocol and conducted a thorough search and adhered to our pre-specified inclusion and exclusion criteria when inspecting citations. It is possible that we have failed to identify small relevant studies, but we feel that it is unlikely that we would have missed large studies that would make a substantial difference to the findings from this review. Given the small number of included studies, review authors EGO and MH independently inspected all citations obtained from the search and extracted the data to minimise bias.

In order to further limit the risk for potential biases and improve the overall quality of the work, we followed the recommendations of the Cochrane Editorial Unit (CEU) Screening Programme by $\mathrm{Dr}$ Nuala Livingstone and the Methodological Expectations of Cochrane Intervention Reviews (MECIR; Higgins 2016); the systematic review was checked and verified by using the CEU Screening Tool items. Previously excluded studies were checked for NROD exclusion bias (no relevant outcome data exclusion bias; Higgins 2016; Kirkham 2010): one study was retrieved.

\section{Agreements and disagreements with other studies or reviews}

The review authors are not aware of any other studies or systematic reviews that have focused solely on use of risperidone alone for people who are agitated or aggressive due to serious mental illnesses.

\section{AUTHORS' CONCLUSIONS}

\section{Implications for practice}

\section{For people with an interest in psychosis-induced aggression or agitation}

People during an acute episode of psychosis can be under tremendous distress; there is currently very limited high-quality research regarding effective and safe treatment for those episodes. It is essential that people receive appropriate care based on the best available evidence. The nine trials included in this review compared oral risperidone with intramuscular or oral single drugs (haloperidol, olanzapine, quetiapine) or combinations (risperidone + oxcarbazepine, risperidone + valproic acid). Data analyses could not provide strong evidence of any difference between the compared drugs when focusing on rapid tranquillisation (up to two hours, but ideally within the first 10 minutes after getting clinical attention). When checking for efficacy at medium-long terms, the combination of risperidone + oxcarbazepine yielded a greater improvement in terms of levels of agitation, even if the overall quality of evidence was rated as 'very low'. If people are at risk of needing such interventions, it would seem reasonable to expect better evidence than what research community has thus far provided.

\section{For clinicians}

Available evidence on the use of risperidone for people with psychosis-induced aggression or agitation is strongly limited. In terms of rapid tranquillisation of psychosis-induced aggression or agitation, no strong evidence could be observed between risperidone and compared drugs or combinations, including intramuscular administration of haloperidol. When widening the topic of the review to the phase after rapid tranquillisation, very low-quality evidence of a slight advantage up to one week in favour of the 'risperidone + oxcarbazepine' combination could be seen. Overall, data are very scarce: it is not possible to draw firm conclusions as to whether risperidone is more or less effective than other interventions for psychosis-induced aggression or agitation.

If researchers continue to let down the clinical community by avoiding pragmatic studies on such an important and relevant area like rapid tranquillisation in psychosis-induced aggression or agitation, clinicians should formally request such investigations: not to have good evidence in this area is always more often difficult to justify.

\section{For policy makers}

This is a greatly under researched area. Currently, the use of risperidone alone in the management of acutely agitated or aggressive patients could be efficacious but the evidence base for this is lacking. This underpins the need for high-quality trials in the rapid tranquillisation setting.

\section{Implications for research}

\section{General}

All nine studies identified for inclusion in this review were conducted after the Consolidated Standards of Reporting Trials (CONSORT, Moher 2001) statement was proposed, yet the reporting quality was rated as very-low quality due to high risk of performance, attrition and 'selective reporting' bias, small size of randomised populations, and indirectness of outcome measures. More transparency in the reporting of randomised controlled trials (RCTs) would enable readers to understand the design, conduct, analysis and interpretation, and to assess the validity of results. Although binary data are easier to interpret, where continuous data are used some measure of variance should be provided. Data presented in graphs should be accompanied by exact numbers and standard deviations (SDs) in the text. 


\section{Specific}

Large pragmatic well-designed randomised trials led by independent researchers, which measure simple, meaningful and highly applicable outcomes such as 'being tranquil', 'being asleep', 'serious adverse effect', 'needing additional medication', 'further aggressive episodes', and 'economic outcomes' are still required. These studies just need modest financial support and firm help from ethics committees who should understand the need to produce good evidence for practice in this difficult area of health. See Table 2 for a suggested design for a study.

\section{ACKNOWLEDGEMENTS}

We are grateful to Jun Xia and Fang Qi from Systematic Review Solutions Ltd. for their assistance with Chinese to English translations. We would also like to acknowledge the contribution of Hanna Jones. For the review versions based on 2011 and 2013 searches, Hanna screened and retrieved papers against eligibility criteria, extracted data from papers and helped with write up of final report.

The Cochrane Schizophrenia Group Editorial Base in Nottingham produces and maintains standard text for use in the Methods sections of their reviews. We have used this text as the basis of what appears here and adapted it as required. 


\section{R E F E R E N C E S}

\section{References to studies included in this review}

Dai 2012 \{published data only\}

Dai L, Chen QL. The comparative study of quetiapine versus risperidol for agressive behaviour in people with schizophrenia. Medical Journal of Chinese People's Health 2012;17:2061-4.

\section{Jin 2013 \{published data only\}}

Jin G. Efficacy of magnesium valproate for impulsive aggressive behavior in schizophrenia [丙戊酸镁对精神分裂症冲动攻击行 为疗效观察]. Chinese Journal of Modern Drug Application [\#\#\# \#\#\#\#] 2013;7(14):160-1.

\section{Li 2013 \{published data only\}}

Li C, Liu Y, Wang M. Magnesium valproate sustained-release tablets in combination with risperidone for impulsive aggressive behavior in people with schizophrenia [丙戊 酸镁缓释片合用利培酮对精神分裂症冲动攻击行为的辅 助治疗]. Journal of Practical Medical Techniques [\#\#\#\#\#] 2013;20(01):69-71.

\section{Lim 2010 \{published data only\}}

Kim JJ, Lim HK, Lee CU, Lee C, Pae CU, Paik IH. Comparison of risperidone orodispersible tablet and intramuscular haloperidol in treatment of acute psychotic agitation: a prospective and randomized study. Schizophrenia Research 2008;102(1-3):264-5.

Kim JJ, Lim HK, Lee CU, Lee C, Pae CU, Paik IH. Risperidone orodispersible tablet and intramuscular haloperidol in treatment of acute psychotic agitation. European Neuropsychopharmacology 2007;17(4):S467.

* Lim HK, Kim JJ, Pae CU, Lee CU, Lee C, Paik IH. Comparison of risperidone orodispersible tablet and intramuscular haloperido in the treatment of acute psychotic agitation: a randomized open, prospective study. Neuropsychobiology 2010;62(2):81-6. [MEDLINE: ISI:000280037400001]

\section{Walther 2014 \{published data only\}}

* Walther S, Moggi F, Horn H, Moskvitin K, Abderhalden C, Maier N, et al. Rapid tranquilization of severely agitated patients with schizophrenia spectrum disorders: a naturalistic, rater-blinded, randomized, controlled study with oral haloperidol, risperidone, and olanzapine. Journal of Clinical Psychopharmacology 2014;34:124-8.

Walther S, Moggi F, Horn H, Moskvitin K, Maier N, Abderhalden $\mathrm{C}$, et al. Rapid tranquilization of severely agitated patients with schizophrenia spectrum disorders: a naturalistic, rater-blinded, randomized controlled study with oral haloperidol, risperidone, and olanzapine. Pharmacopsychiatry 2013;46(6):A77.

\section{Wang 2012 \{published data only\}}

Wang J, Qiu L. A comparative study of risperidone merger oxcarbazepine in the treatment of schizophrenia agitation [利培酮合并奥卡西平治疗精神分裂症兴奋躁动的比较研 究] . Medical Journal of Chinese Civil Administration [\#\#\#\#\#] 2012;24(24):2956-7.
Wang 2013 \{published data only\}

Wang ML, Jiang TC. Clinical observation of treatment with impulsive and aggressive behavior in patients with schizophrenia risperidone combined with valproate [利培酮联 合丙戊酸钠治疗伴有冲动和攻击行为的精神分裂症患者的临 床观察]. Chinese Journal of Clinical Rational Drug Use [\#\#\#\#\#\# \#] 2013;6(01):72-3.

Yao 2010 \{published data only\}

Yao F, Jiang F. Short-term efficacy of risperidone combined with magnesium valproate retard tablets on aggressive behavior in patients with schizophrenia. Occupation and Health 2010;26(22):2713-02.

Zhou 2013 \{published data only\}

Zhou LC, Nong YX, Chen QM. Risperidone monotherapy or in combination with valproate for agitation associated with schizophrenia [利培酮单药或与丙戊酸钠联用对精神分裂症兴 奋躁动的作用及安全性比较]. Journal of Clinical Psychological Medicine [\#\#\#\#\#\#\#\#] 2013;23(04):261-2.

\section{References to studies excluded from this review}

Beck 1997 \{published data only\}

Beck NC, Greenfield SR, Gotham H, Menditto AA, Stuve P, Hemme CA. Risperidone in the management of violent, treatment resistant schizophrenics hospitalized in a maximum security forensic facility. Journal of the American Academy of Psychiatry and the Law 1997;25(4):461-8. [MEDLINE: 9460034]

Belenkaya 2005 \{published data only\}

Belenkaya DV, Kuzavkova MV, Mosolov SN. Open comparative randomized study efficacy and tolerability of risperidone, olanzapine and quetiapine in acute mania. European Neuropsychopharmacology 2005;15(Suppl 2):S130.

\section{Briken 2002 \{published data only\}}

Briken P, Nika E, Moritz S, Haasen C, Perro C, Yagdiran O, et al. Effect of zotepine, olanzapine and risperidone on hostility in schizophrenic patients. Schizophrenia Research 2002;57(2-3):311-3. [MEDLINE: 12223264]

\section{Buckley 1997 \{published data only\}}

Buckley PF, Ibrahim ZY, Singer B, Orr B, Donenwirth K, Brar PS. Aggression and schizophrenia: efficacy of risperidone. Journal of the American Academy of Psychiatry and the Law 1997;25(2):173-81.

Buitelaar 2001 \{published data only\}

Buitelaar JK, Van der Gaag RJ, Cohen-Kettenis P, Melman CT. A randomized controlled trial of risperidone in the treatment of aggression in hospitalized adolescents with subaverage cognitive abilities. Journal of Clinical Psychiatry [\#\#\#\#\#\#\#] 2001;62(4):239-48.

\section{Chan 2013 \{published data only\}}

Chan HY, Lin AS, Chen KP, Cheng JS, Chen YY, Tsai CJ. An openlabel, randomized, controlled trial of zotepine and risperidone 
for acutely ill, hospitalized, schizophrenic patients with symptoms of agitation. Journal of Clinical Psychopharmacology 2013;33:747-52.

\section{Citrome 2001 \{published data only\}}

* Citrome L, Volavka J, Czobor P, Sheitman B, Lindenmayer JP, McEvoy J, et al. Effects of clozapine, olanzapine, risperidone, and haloperidol on hostility among patients with schizophrenia. Psychiatric Services 2001;52(11):1510-4. [MEDLINE: 11684748]

Citrome LL, Volavka J, Czobor P, Nolan K, Lieberman JA, Lindenmayer JP, et al. Overt aggression and psychotic symptoms in patients with schizophrenia treated with clozapine, olanzapine, risperidone, or haloperidol. 156th Annual Meeting of the American Psychiatric Association; 2003 May 17-22; San Francisco, California, USA. 2003.

Citrome LL, Volavka J, Czobor P, Sheitman BB, Lindenmayer JP, McEvoy JP, et al. Atypical antipsychotics and hostility in schizophrenia: a DOUBLE-BLIND study. 154th Annual Meeting of the American Psychiatric Association; 2001 May 5-10; New Orleans, Louisiana, USA. Marathon Multimedia, 2001.

Citrome LL, Volavka J, Czobor P, Sheitman BB, Lindenmayer JP, McEvoy JP, et al. Atypical antipsychotics and hostility in schizophrenia: a DOUBLE-BLIND study. 155th Annual Meeting of the American Psychiatric Association; 2002 May 18-23; Philadelphia, Pennsylvania, USA. 2002.

Hoptman MJ, Volavka J, Czobor P, Gerig G, Chakos M, Blocher J, et al. Aggression and quantitative MRI measures of caudate in patients with chronic schizophrenia or schizoaffective disorder. Journal of Neuropsychiatry and Clinical Neurosciences 2006;18(4):509-15.

Nolan KA, Volavka J, Czobor P, Sheitman B, Lindenmayer JP, Citrome LL, et al. Aggression and psychopathology in treatment-resistant inpatients with schizophrenia and schizoaffective disorder. Journal of Psychiatric Research 2005;39(1):109-15. [MEDLINE: 15504429]

Volavka J, Czobor P, Nolan K, Sheitman B, Lindenmayer JP, Citrome L, et al. Overt aggression and psychotic symptoms in patients with schizophrenia treated with clozapine, olanzapine, risperidone, or haloperidol. Journal of Clinical Psychopharmacology 2004;24(2):225-8. [MEDLINE: 15206671]

Citrome 2004 \{published data only\}

Citrome L. Schizophrenia and valproate. Psychopharmacology Bulletin 2003;37(Suppl 2):74-88. [MEDLINE: 15021863]

* Citrome L, Casey DE, Daniel DG, Wozniak P, Kochan LD, Tracy KA. Adjunctive divalproex and hostility among patients with schizophrenia receiving olanzapine or risperidone. Psychiatric Services 2004;55(3):290-4. [MEDLINE: 15001730]

\section{Citrome 2007 \{published data only\}}

* Citrome L, Shope CB, Nolan KA, Czobor P, Volavka J. Risperidone alone versus risperidone plus valproate in the treatment of patients with schizophrenia and hostility. International Clinical Psychopharmacology 2007;22(6):356-62. [MEDLINE: 17917554]
NCT00308360. Risperidone alone vs risperidone plus valproate in the treatment of patients with schizophrenia and hostility. www.clinicaltrials.gov/ct2/show/NCT00308360 (first received 28 March 2006).

Nolan KA, Shope CB, Citrome L, Volavka J. Staff and patient views of the reasons for aggressive incidents: a prospective, incident-based study. Psychiatric Quarterly 2009;80(3):167-72. [MEDLINE: 19412665]

\section{Conde 2011 \{published data only\}}

Conde BL, Sobreveg EE, Sionzon MP. A randomized trial of oral risperidone versus intramuscular haloperidol in the emergency treatment of acute psychotic agitation. ASEAN Journal of Psychiatry 2011;12(1):29-36.

\section{Currier 2000 \{published data only\}}

* Currier GW, Simpson GA. Risperidone oral solution versus intramuscular haloperidol for control of psychotic agitation. European Neuropsychopharmacology 2000;10(Suppl 3):S296.

Currier GW, Simpson GM. Risperidone liquid concentrate and oral lorazepam versus intramuscular haloperidol and intramuscular lorazepam for treatment of psychotic agitation. Journal of Clinical Psychiatry 2001;62(3):153-7.

Gharabawi G, Morein J, Reyes-Harde M. A pragmatic and convenient approach for the management of acute agitation: results from a series of clinical studies. Schizophrenia Research 2002;53(3 Suppl 1):191.

Simpson GM, Morein JD, Reyes-Harde M, Gharabawi G. A pragmatic and convenient approach for the management of acute agitation: results from a series of clinical studies. 16th European College of Neuropsychopharmacology Congress; 2003 Sep 20-24; Prague, Czech Republic. 2003.

\section{Currier 2004 \{published data only\}}

* Currier GW, Chou JC, Feifel D, Bossie CA, Turkoz I, Mahmoud R, et al. Acute treatment of psychotic agitation: a randomized comparison of oral treatment with risperidone and lorazepam versus intramuscular treatment with haloperidol and lorazepam. Journal of Clinical Psychiatry 2004;65(3):386-94. [MEDLINE: 15096079]

Gharabawi G, Turkoz I, Pandina G. Emergency treatment of acute agitation in patients with schizophrenia and schizoaffective disorder: oral risperidone + lorazepam versus IM haloperidol + lorazepam. International Congress on Schizophrenia Research Biennial Meeting; March 29-April 2, 2003; Colorado Springs, Colorado, USA. 2003.

Gharabawi G, Turkoz I, Pandina G. Oral risperidone + lorazepam versus IM haloperidol + lorazepam in the emergency treatment of acute psychosis in schizophrenia and schizoaffective disorder. Schizophrenia Research 2003;60:284.

\section{Czobor 1995 \{published data only\}}

Czobor P, Volavka J, Meibach RC. Effect of risperidone on hostility in schizophrenia. Journal of Clinical Psychopharmacology 1995;15(4):243-9. [MEDLINE: 7593706] 
Fang 2012 \{published data only\}

Fang M, Chen H, Li LH, Wu R, Li Y, Liu L, et al. Comparison of risperidone oral solution and intramuscular haloperidol with the latter shifting to oral therapy for the treatment of acute agitation in patients with schizophrenia. International Clinical Psychopharmacology 2012;27(2):107-13.

\section{Francey 2007 \{published data only\}}

ACTRN12607000608460. A randomised placebo controlled trial of intensive psychosocial treatment plus or minus antipsychotic medication for first episode psychosis with lowrisk of self-harm or aggression. The STAGES Study: Staged Treatment and Acceptability Guidelines in Early Psychosis. https://www.anzctr.org.au/Trial/Registration/TrialReview.aspx? id=82439 2007.

\section{Greenspan 2005 \{published data only\}}

Greenspan A, Kosik-Gonzalez C, Moreau-Mallet V, Bossie CA, Rupnow MFT, Zhu Y, et al. Risperidone vs quetiapine in inpatients with schizophrenia: a double-blind placebocontrolled study. European Neuropsychopharmacology 2005;15(Suppl 3):S503.

\section{Han 2005 \{published data only\}}

Han ZY, Wang LJ, Wang J. Efficacy of risperidone, clonazepam in the treatment of schizophrenia. Ningxia Medical Journal 2005;27(9):631-2.

\section{Hatta 2008 \{published data only\}}

Hatta K, Kawabata T, Yoshida K, Hamakawa H, Wakejima T, Furuta K, et al. Olanzapine orally disintegrating tablet vs risperidone oral solution in the treatment of acutely agitated psychotic patients. General Hospital Psychiatry 2008;30(4):367-71.

\section{He 2005 \{published data only\}}

He YQ, Ma SH, Du J. A controlled study on hostility and side effects in clozapine and risperidone for treatment of patients with schizophrenia. Journal of Xinxiang Medical College 2005;22(2):118-20.

\section{Hong 2014 \{published data only\}}

Hong ML, Luo J, Yang J. Clinical analysis of modern electro convulsive treatment of schizophrenia [现代电抽搐治疗精神分 裂症临床分析] . For All Health [\#\#\#\#] 2014;8(6):480.

\section{Hou 2011 \{published data only\}}

Hou CL, Hou LF, Zhang DS, Dong JX. Risperidone oral solution with lorazepam treatment of schizophrenia excited state. Chinese Journal of Health Psychology 2011;19(7):787-9.

\section{Hovens 2005 \{published data only\}}

Hovens JE, Beijeman S, Tollenaar J, Dries PJT, Loonen AJM. Risperidone versus zuclopentixol in acute psychosis in emergency psychiatry: a prospective naturalistic study. European Neuropsychopharmacology 2003;13(4):S293.

\footnotetext{
* Hovens JE, Dries PJT, Melman CTM, Wapenaar RJC, Loonen AJM. Oral risperidone with lorazepam versus oral zuclopenthixol with lorazepam in the treatment of acute psychosis in emergency psychiatry: a prospective,
}

comparative, open-label study. Journal of Psychopharmacology 2005;19(1):51-7. [MEDLINE: 15671129]

\section{Huaqiang 2009 \{published data only\}}

Huaqiang C, Yongchun M, Weidong J, Weiming L. Efficacy and safety of oxcarbazepine as adjuvant therapy in excited patients with schizophrenia and schizophreniform psychosis. Shanghai Archives of Psychiatry 2009;21(5):282-4.

ISRCTN11736448 2003 \{published data only\}

ISRCTN11736448. Neuroleptics in adults with aggressive challenging behaviour and intellectual disability. www.isrctn.com/ISRCTN11736448 (first received 25 April 2003).

\section{Jiang 2012 \{published data only\}}

Jiang XY, Xu Q, Zhou DX, Fang XY, Lu YN, Xia MH. The controlled clinical study of combined oral risperidone and clonazepam with intramuscular haloperidol replaced by oral risperidone [利 培酮口服液合并氯硝西泮与氟哌啶醇肌注后换用利培酮口服 液临床对照研究]. Chinese Journal of Health Psychology [\#\#\#\# \#\#\#\#] 2012;20(11):1604-6.

\section{Kane 2003 \{published data only\}}

Kane JM, Eerdekens M, Lindenmayer JP, Keith SJ, Lesem M, Karcher K. Long-acting injectable risperidone: efficacy and safety of the first long-acting atypical antipsychotic. American Journal of Psychiatry 2003;160(6):1125-32.

\section{Kirwan 2002 \{published data only\}}

Kirwan J, Brodaty H, Ames D, Snowdon J, Woodward M, Clarnette R, et al. Risperidone in the treatment of agitation and psychosis of dementia. 155th Annual Meeting of the American Psychiatric Association; 2002 May 18-23; Philadelphia, Pennsylvania, USA. 2002.

\section{Kolivakis 2002 \{published data only\}}

Kolivakis TT, Margolese HC, Beauclair L, Chouinard G. Adjunctive anticonvulsant use in first-episode schizophrenia. 155th Annual Meeting of the American Psychiatric Association; 2002 May 18-23; Philadelphia, Pennsylvania, USA. 2002.

\section{Lewis 2006 \{published data only\}}

Lewis CF. Haloperidol versus risperidone in the treatment of aggressive psychotic male inmates. 159th Annual Meeting of the American Psychiatric Association; 2006 May 20-25; Toronto, Canada. 2006.

\section{Li 2014 \{published data only\}}

Li Y. A comparative study of antipsychotic drugs combined with small doses of magnesium valproate in the treatment of schizophrenia [抗精神病药物联合小剂量丙戊酸镁治疗精神 分裂症攻击行为的对照研究]. World Health Digest [\#\#\#\#\#] 2014;3(11):53.

\section{Lieberman 2001 \{published data only\}}

Lieberman JA. Risperidone and clozapine in chronic schizophrenia. CRISP database (https://wwwcommons.cit.nih.gov/crisp/index.html accessed 19th February 2001) 2001. 
Liu 2010 \{published data only\}

Liu SH, Liu CX, Tu ZM, Zhang XF. Clinical study of olanzapine and risperidone in the treatment of Schizophrenia. Chinese Journal of Mental Health [\#\#\#\#\#] 2010;22(17):2245-7.

\section{Liu 2012 \{published data only\}}

Liu K, Liu Y, Ning NY, Sun JZ, Sun YJ, Sun TX, et al. Randomized controlled study of the efficacy of short-term risperidone combined with intramuscular haloperidol in the treatment of acute agitation in schizophrenia behavior [利培酮合并短期肌 注氟哌啶醇治疗精神分裂症急性期激越行为疗效的随机对照 研究] . China Medical Herald [\#\#\#\#\#] 2012;12(35):104-6.

\section{NCT00174200 2005 \{published data only\}}

NCT00174200. A randomized, double-blind, crossover add-on study to assess the differential sensitivity of 2 spatial working memory tests (the Groton Maze Learning Test [GMLT] and the Motor Delayed Response Test [MDR]) in non-agitated, antipsychotic drug-naive first-episode schizophrenic or schizophreniform patients treated with risperidone $2 \mathrm{mg}$ daily or placebo. www.clinicaltrials.gov/ct2/show/NCT00174200 (first received 9 September 2005).

\section{NCT00203775 2005 \{published data only\}}

NCT00203775. Efficacy of risperidone versus haloperidol in the treatment of aggression and hostility in psychotic inmates. www.clinicaltrials.gov/ct2/show/NCT00203775 (first received 12 September 2005).

\section{NCT00205699 2005 \{published data only\}}

NCT00205699. Metabolic effects of antipsychotics in children. www.clinicaltrials.gov/ct2/show/NCT00205699 (first received 13 September 2005).

\section{NCT00418873 2007 \{published data only\}}

NCT00418873. A multi-centre comparative study to evaluate the anti-aggression effect and safety of zotepine versus risperidone in aggressive schizophrenic patients in an acute ward. www.clinicaltrials.gov/ct2/show/NCT00418873 (first received 3 January 2007).

\section{NCT00485498 2003 \{published data only\}}

Eli Lilly. Managing acute schizophrenia, a comparison between two atypical antipsychotics. Eli Lilly and Company Clinical Trial Registry 2003.

* NCT00485498. Managing acute schizophrenia, a double blind comparison between two atypical antipsychotics - olanzapine and risperidone. www.clinicaltrials.gov/ct2/show/NCT00485498 (first received 11 June 2007).

\section{Ou 2007 \{published data only\}}

Ou G. A control study on risperidone combined with clozapine in the treatment of schizophrenia with aggressive behavior. Journal of Clinical Psychosomatic Diseases 2007;13(2):117-9.

\section{Pei 2009 \{published data only\}}

Pei SJ, Yang HW. Oral risperidone treatment of schizophrenia clinical observation of excited agitation. Journal of Clinical Psychiatry 2009;19(6):405-6.
Peng 2009 \{published data only\}

Peng RC, Liu AH. Comparative study of ziprasidone and risperidone in the treatment of female patients with schizophrenia. Sichuan Mental Health 2009;22(3):168-70.

\section{Potkin 2005 \{published data only\}}

Potkin SG, Greenspan A, Kosik-Gonzalez C, Bossie C, Rupnow M, Zhu Y, et al. A placebo - controlled study of risperidone vs quetiapine for symptom response and readiness for discharge among agitated inpatients with schizophrenia. Schizophrenia Bulletin 2005;31:501.

\section{Schooler 2003 \{published data only\}}

Schooler N, Davidson M, Kopala L. Reduced relapse rates in recent onset schizophrenia patients treated with risperidone vs. haloperidol. European Neuropsychopharmacology 2003;13(4):S337.

\section{Swanson 2008 \{published data only\}}

Covell NH. Antipsychotic medications do not differ substantially in ability to reduce violent behaviour in people with schizophrenia. Evidence-Based Mental Health 2009;12(1):13.

* Swanson JW, Swartz MS, Van Dorn RA, Volavka J, Monahan J, Stroup TS, et al. Comparison of antipsychotic medication effects on reducing violence in people with schizophrenia. British Journal of Psychiatry 2008;193(1):37-43.

\section{Tang 2007 \{published data only\}}

Tang Q, Yang L, Lai G, Zhand J. A clinical study of risperidone oral solution combined with clonazepam injection in the treatment of acute excitement phase schizophrenia patient. Shanghai Archives of Psychiatry 2007;19(3):153-5.

\section{Temputrn 2007 \{published data only\}}

NCT01193153. A study to evaluate the efficacy of paliperidone palmitate in the prevention of relapse of the symptoms of schizoaffective disorder. https://clinicaltrials.gov/ct2/show/ NCT01193153 2007.

\section{Tosic Golubovic Suzana 2009 \{published data only\}} Tosic Golubovic Suzana ST, Zikic Olivera ZO, Nikolic Gordana NG, Slavkovic Violeta SV, Gugleta Dragoslava GD, Sibinovic Vladica SV. Adjunctive mood stabilising treatment: the effects on hostility and impulsivity among patients with schizophrenia. European Neuropsychopharmacology 2009;19(Sppl 3):S532.

\section{Veser 2006 \{published data only\}}

Veser F, Zealburg J, Veser B, Zhu Y, Gharabawi G. Oral risperidone in the management of agitated behavior in emergency settings. European Neuropsychopharmacology 2002;12(Suppl 3):S313.

* Veser FH, Veser BD, McMullan JT, Zealberg J, Currier GW. Risperidone versus haloperidol, in combination with lorazepam, in the treatment of acute agitation and psychosis: a pilot, randomized, double blind, placebo-controlled trial. Journal of Psychiatric Practice 2006;12(2):103-8. [MEDLINE: 16728906] 
Villari 2008 \{published data only\}

Villari V, Rocca P, Fonzo V, Montemagni C, Pandullo P, Bogetto F. Oral risperidone, olanzapine and quetiapine versus haloperidol in psychotic agitation. Progress in Neuro-psychopharmacology and Biological Psychiatry 2008;32(2):405-13.

Wan 2005 \{published data only\}

Wan Z, Zhong Z. Curative effect of risperidone with BDZs in the treatment of excitement and agitate with schizophrenia in acute phase. Health Psychology Journal 2005;13(1):23-4.

\section{Wang 2004 \{published data only\}}

Wang G, Cai ZJ, Wang LF. A multicenter study of risperidone treatment for acute agitation in patients with schizophrenia. Chinese Journal of Psychiatry 2004;37(2):88-91.

Wang 2006 \{published data only\}

Wang $\mathrm{H}$. Therapeutic effect of risperidone combined with magnesium valproate in aggressive behaviors of schizophrenics. Chinese Journal of Health Psychology 2006;14(4):441-2.

Wang 2015 \{published data only\}

Wang CD. Observation of curative effect of electroconvulsive therapy in treatment of aggressive behaviour in Schizophrenia [无抽搐电休克治疗精神分裂症暴力攻击行为疗效观 察] . Journal of Clinical Psychosomatic Diseases [\#\#\#\#\#\#\#] 2015;21(6):117-8.

\section{Wei 2010 \{published data only\}}

Wei SZ. Olanzapine and risperidone in adolescent schizophrenia starting control study of 60 cases. Medical Journal of Chinese Peoples Health 2010;22(11):1414-5.

\section{Xi 2010 \{published data only\}}

Xi MA. A study of additive effect of magnesium valproate in the treatment of schizophrenia. Chinese Journal of Practical Medicine 2010;5(12):43-4.

\section{Xuan 2007 \{published data only\}}

Xuan GH, Chu Y. Clinical observation on the effect of risperidone combined with BZD on schizophrenia. China Tropical Medicine 2007;7(2):244.

\section{Zhang 2012 \{published data only\}}

Zhang QE, Wang G, Zhang L, Wang X, Luo J, Lu YZ, et al. Controlled study of risperidone oral solution in combination with clonazepam tablets for acute agitation in schizophrenia [利培酮口服液合并氯硝西泮片治疗精神分裂症急性激越的对 照研究]. The 10th National Conference of Psychiatry [\#\#\#\#\#\#\# \#\#\#\#\#\#\#\#] 2012;22(02):89-91.

\section{Zheng 2010 \{published data only\}}

Zheng C, Suoyu Z, Hui W, Ying Q, Yan W, Yun X, et al. Randomized controlled study of psychotic agitation in schizophrenic patients comparing combination treatment with oral risperidone and clonazepam versus initial treatment with intramuscular haloperidol followed by oral risperidone. Shandong Archives of Psychiatry 2010;22(6):354-7.

\section{Zhou 2012 \{published data only\}}

Zhou DX, Jiang XY, Xu Q, Fang XY, Xia MH, Lu YN. A randomized controlled study of risperidone oral solution combined with clonazepam in the treatment of schizophrenic symptoms [利培 酮口服液合并氯硝西泮治疗精神分裂症兴奋激越症状的随机 对照研究] . Chinese Journal of Health Psychology [\#\#\#\#\#\#\#] 2012;8:1123-4.

\section{References to studies awaiting assessment}

Herrera 2005 \{published data only\}

Herrera M. Double blind study with risperidone vs haloperidol in schizophrenic patients with agitation and/or aggression. 8th World Congress of Psychiatry; 2005 Sep 10-15; Cairo, Egypt. 2005.

\section{Hsu 2010 \{published data only\}}

Hsu WY, Huang SS, Lee BS, Chiu NY. Comparison of intramuscular olanzapine, orally disintegrating olanzapine tablets, oral risperidone solution, and intramuscular haloperidol in the management of acute agitation in an acute care psychiatric ward in Taiwan. Journal of Clinical Psychopharmacology 2010;30(3):230-4.

Lasic 2006 \{published data only\}

Lasic D, Rubesa G, Dodig G, Katavic Z, Glavina T, ZuljanCvitanovic M. Risperidone oral solution, therapeutic possibility in treatment of acute and agitated psychotic patients. European Neuropsychopharmacology 2006;16(Suppl 4):S445.

NCT00859872 \{published data only\}

NCT00859872. Efficacy and safety of risperidone oral solution combination clonazepam versus haloperidol IM injection for treatment of acute psychotic agitation in schizophrenia. www.clinicaltrials.gov/ct2/show/NCT00859872? term=NCT00859872\&rank=1 (first received 10 March 2009).

\section{Additional references}

\section{Addington 2005}

Addington D, Bouchard RH, Goldberg J, Honer B, Malla A, Norman R, et al. Clinical practice guidelines: treatment of schizophrenia. Canadian Journal of Psychiatry 2005;50(1):1-56.

\section{Ahmed 2010}

Ahmed U, Jones H, Adams CE. Chlorpromazine for psychosis-induced aggression or agitation. Cochrane Database of Systematic Reviews 2010, Issue 4. [DOI: 10.1002/14651858.CD007445.pub2]

\section{Aleman 2001}

Aleman A, Kahn RS. Effects of the atypical antipsychotic risperidone on hostility and aggression in schizophrenia: a meta-analysis of controlled trials. European Neuropsychopharmacology 2001;11:289-93.

\section{Altman 1996}

Altman DG, Bland JM. Detecting skewness from summary information. BMJ 1996;313:1200. 


\section{APA 2004}

Lehman AF, Lieberman JA, Dixon LB, McGlashan TH, Miller AL, Perkins DO, et al. Practice guideline for the treatment of patients with schizophrenia. American Journal of Psychiatry 2004;161(2):1-56.

\section{Aronson 1997}

Aronson SM. Cost-effectiveness and quality of live in psychosis: the pharmacoeconomics of risperidone. Clinical Therapeutics 1997;19(1):139-47.

\section{Arseneault 2000}

Arseneault L, Moffitt TE, Caspi A, Taylor PJ, Silva PA. Mental disorders and violence in a total birth cohort. Results from the Dunedin study. Archives of General Psychiatry 2000;57:979-86.

\section{Ballard 2006}

Ballard CG, Waite J, Birks J. Atypical antipsychotics for aggression and psychosis in Alzheimer's disease. Cochrane Database of Systematic Reviews 2006, Issue 1. [DOI: 10.1002/14651858.CD003476.pub2]

\section{Barnes 1989}

Barnes TR. A rating scale for drug-induced akathisia. British Journal of Psychiatry 1989;154:672-6.

\section{Bazire 2009}

Bazire S. Psychotropic Drug Directory. Aberdeen: HealthComm UK Limited, 2009.

\section{Belgamwar 2005}

Belgamwar RB, Fenton M. Olanzapine IM or velotab for acutely disturbed/agitated people with suspected serious mental illnesses. Cochrane Database of Systematic Reviews 2005, Issue 2. [DOI: 10.1002/14651858.CD003729.pub2]

\section{Bland 1997}

Bland JM. Statistics notes. Trials randomised in clusters. BMJ 1997;315:600.

\section{BNF 2017}

Joint Formulary Committee. British National Formulary. Vol. 73, London: British Medical Journal and Royal Pharmaceutical Society, 2017.

\section{Boissel 1999}

Boissel JP, Cucherat M, Li W, Chatellier G, Gueyffier F, Buyse $M$, et al. The problem of therapeutic efficacy indices. 3. Comparison of the indices and their use [Apercu sur la problematique des indices d'efficacite therapeutique, 3: comparaison des indices et utilisation. Groupe d'etude des indices d'efficacite]. Therapie 1999;54(4):405-11.

\section{Brennan 2000}

Brennan PA, Mednick SA, Hodgins S. Major mental disorders and criminal violence in a Danish birth cohort. Archives of General Psychiatry 2000;57(5):494-500.

\section{Buckley 1999}

Buckley PF. The role of the typical and atypical antipsychotic medications in the management of agitation and aggression. Journal of Clinical Psychiatry 1999;60(10):52-60.

\section{CIA 2008}

Central Intelligence Agency. The World Factbook. www.cia.gov/ library/publications/resources/the-world-factbook/index.html (accessed 21 July 2008).

\section{Conley 2001}

Conley R, Mahmoud R. A randomized double-blind study of risperidone and olanzapine in the treatment of schizophrenia or schizoaffective disorder. American Journal of Psychiatry 2001;158(5):765-74.

\section{Currier 2001}

Currier GW, Simpson GM. Risperidone liquid concentrate and oral lorazepam versus intramuscular haloperidol and intramuscular lorazepam for treatment of psychotic agitation. Journal of Clinical Psychiatry 2001;62:153-7.

\section{Deeks 2000}

Deeks J. Issues in the selection for meta-analyses of binary data. 8th International Cochrane Colloquium; 2000 Oct 25-28; Cape Town. The Cochrane Collaboration, 2000.

\section{Deeks 2011}

Deeks JJ, Higgins JPT, Altman DG (editors). Chapter 9: Analysing data and undertaking meta-analyses. In: Higgins JPT, Green S (editors). Cochrane Handbook for Systematic Reviews of Interventions Version 5.1.0 (updated March 2011). The Cochrane Collaboration, 2011. Available from www.handbook.cochrane.org.

\section{Divine 1992}

Divine GW, Brown JT, Frazier LM. The unit of analysis error in studies about physicians' patient care behavior. Journal of General Internal Medicine 1992;7(6):623-9.

\section{Donner 2002}

Donner A, Klar N. Issues in the meta-analysis of cluster randomized trials. Statistics in Medicine 2002;21:2971-80.

\section{Du 2017}

Du M, Wang X, Yin S, Shu W, Hao R, Zhao S. De-escalation techniques for psychosis-induced aggression or agitation. Cochrane Database of Systematic Reviews 2017, Issue 4. [DOI: 10.1002/14651858.CD009922.pub2]

\section{Egger 1997}

Egger M, Davey-Smith G, Schneider M, Minder CSO. Bias in meta-analysis detected by a simple, graphical test. $B M J$ 1997;13:629-34.

\section{Elbourne 2002}

Elbourne D, Altman DG, Higgins JPT, Curtina F, Worthingtond HV, Vaile A. Meta-analyses involving crossover trials: methodological issues. International Journal of Epidemiology 2002;31(1):140-9. 


\section{Fazel 2006}

Fazel S, Grann M. The population impact of severe mental illness on violent crime. American Journal of Psychiatry 2006;163(8):1397-403.

\section{Fleischhaker 2007}

Fleischhaker C, Heiser P, Hennighausen K, HerpertzDahlmann B, Holtkamp K, Mehler-Wex C, et al. Weight gain associated with clozapine, olanzapine and risperidone in children and adolescents. Journal of Neural Transmission 2007;114(2):273-80.

\section{Furukawa 2006}

Furukawa TA, Barbui C, Cipriani A, Brambilla P, Watanabe N. Imputing missing standard deviations in meta-analyses can provide accurate results. Journal of Clinical Epidemiology 2006;59(7):7-10.

\section{Gulliford 1999}

Gulliford MC. Components of variance and intraclass correlations for the design of community-based surveys and intervention studies: data from the Health Survey for England 1994. American Journal of Epidemiology 1999;149:876-83.

\section{Guy 1976}

Guy W. Clinical Global Impression. In: Guy W editor(s). ECDEU Assessment Manual for Psychopharmacology (revised). Rockville, Md: National Institute of Mental Health, 1976:217-21.

\section{Higgins 2003}

Higgins JPT, Thompson SG. Quantifying heterogeneity in a meta-analysis. Statistics in Medicine 2003;21:1539-58.

\section{Higgins 2011}

Higgins JPT, Green S (editors). Chapter 7: Selecting studies and collecting data. In: Higgins JPT, Green S (editors), Cochrane Handbook for Systematic Reviews of Interventions Version 5.1.0 (updated March 2011). The Cochrane Collaboration, 2011. Available from www.handbook.cochrane.org.

\section{Higgins 2011a}

Higgins JPT, Altman DG, Sterne JAC (editors). Chapter 8: Assessing risk of bias in included studies. In: Higgins JPT, Green S (editors). Cochrane Handbook for Systematic Reviews of Interventions Version 5.1.0 (updated March 2011). The Cochrane Collaboration, 2011. Available from www.handbook.cochrane.org.

\section{Higgins 2016}

Higgins JPT, Lasserson T, Chandler J, Tovey D, Churchill R. Methodological Expectations of Cochrane Intervention Reviews. 2016. London: Cochrane, 2016.

\section{Huf 2016}

Huf G, Alexander J, Ghandi P, Allen MH. Haloperidol plus promethazine for psychosis-induced aggression. Cochrane Database of Systematic Reviews 2016, Issue 11. [DOI: 10.1002/14651858.CD005146.pub3]

\section{Hunter 2003}

Hunter R, Kennedy E, Song F, Gadon L, Irving CB. Risperidone versus typical antipsychotic medication for schizophrenia. Cochrane Database of Systematic Reviews 2003, Issue 2. [DOI: 10.1002/14651858.CD000440; PUBMED: 12804396]

\section{Hutton 2009}

Hutton JL. Number needed to treat and number needed to harm are not the best way to report and assess the results of randomised clinical trials. British Journal of Haematology 2009;146(1):27-30. [PUBMED: 19438480]

\section{Janssen 1988}

Janssen PAJ, Niemegeers CJE, Awouters F, Schellekens KHL, Megens AAHP, Meert TF. Pharmacology of risperidone (R 64 766), a new antipsychotic with serotonin-S2 and dopamineD2 antagonistic properties. Journal of Pharmacology and Experimental Therapeutics 1988;244:685-93.

\section{Jayakody 2012}

Jayakody K, Gibson RC, Kumar A, Gunadasa S. Zuclopenthixol acetate for acute schizophrenia and similar serious mental illnesses. Cochrane Database of Systematic Reviews 2012, Issue 4. [DOI: 10.1002/14651858.CD000525.pub3]

\section{Kadic 2016}

Kadic AJ, Vucic K, Dosenovic S, Sapunar D, Puljak L. Extracting data from figures with software was faster, with higher interrater reliability than manual extraction. Journal of Clinical Epidemiology 2016;74:119-23.

\section{Katz 1999}

Katz IR, Jeste DV, Mintzer JE, Clyde C, Napolitano J, Brecher M. Comparison of risperidone and placebo for psychosis and behavioral disturbances associated with dementia: a randomized, double-blind trial. Risperidone study group. Journal of Clinical Psychiatry 1999;60(2):107-15.

\section{Kay 1986}

Kay SR, Opler LA, Fiszbein A. Positive and Negative Syndrome Scale (PANSS) Manual. North Tonawanda, NY: Multi-Health Systems, 1986.

\section{Khokhar 2016}

Khokhar M, Rathbone J. Droperidol for psychosisinduced aggression or agitation. Cochrane Database of Systematic Reviews 2016, Issue 12. [DOI: 10.1002/14651858.CD002830.pub3]

\section{Kirkham 2010}

Kirkham JJ, Dwan KW, Altman DG, Gamble C, Dodd S, Smyth R, et al. The impact of outcome reporting bias in randomised controlled trials on a cohort of systematic reviews. BMJ 2010;340(c365):1-10.

\section{Leon 2006}

Leon AC, Mallinckrodt CH, Chuang-Stein C, Archibald DG, Archer GE, Chartier K. Attrition in randomized controlled clinical trials: methodological issues in psychopharmacology. Biological Psychiatry 2006;59(11):1001-5. [PUBMED: 16905632] 


\section{Leucht 2005}

Leucht S, Kane JM, Kissling W, Hamann J, Etschel E, Engel R. Clinical implications of brief psychiatric rating scale scores. British Journal of Psychiatry 2005;187:366-71. [PUBMED: 16199797]

\section{Leucht 2005a}

Leucht S, Kane JM, Kissling W, Hamann J, Etschel E, Engel RR. What does the PANSS mean?. Schizophrenia Research 2005;79(2-3):231-8.

\section{Marshall 2000}

Marshall M, Lockwood A, Bradley C, Adams C, Joy C, Fenton M. Unpublished rating scales: a major source of bias in randomised controlled trials of treatments for schizophrenia. British Journal of Psychiatry 2000;176:249-52.

\section{Mathis 2009}

Mathis MV. Atypical Antipsychotics and Pediatrics: Background and Update. Psychopharmacological Drugs Advisory Committee Meeting 2009.

\section{Megens 1994}

Megens AA. Survey on the pharmacodynamics of the new antipsychotic risperidone. Psychopharmacology 1994;114(1):9-23.

\section{Moher 2001}

Moher D, Schulz KF, Altman D. The CONSORT statement: revised recommendations for improving the quality of reports of parallel-group randomized trials. JAMA 2001;285(12):1987-91.

\section{Montoya 2011}

Montoya A, Valladares A, Lizán L, San L, Escobar R, Paz S. Validation of the Excited Component of the Positive and Negative Syndrome Scale (PANSS-EC) in a naturalistic sample of 278 patients with acute psychosis and agitation in a psychiatric emergency room. Health Quality Life Outcomes 2011;9:18.

\section{Muralidharan 2006}

Muralidharan S, Fenton M. Containment strategies for people with serious mental illness. Cochrane Database of Systematic Reviews 2006, Issue 3. [DOI: 10.1002/14651858.CD002084.pub2]

\section{NICE 2005}

National Collaborating Centre for Nursing and Supportive Care. The short-term management of disturbed/violent behaviour in in-patient psychiatric settings and emergency departments. www.ncbi.nlm.nih.gov/books/NBK55521/ (accessed 10 August 2008).

\section{NICE 2015}

National Institute for Health and Care Excellence. Violence and aggression: short-term management in mental health, health and community settings. www.nice.org.uk/guidance/ng10 (accessed prior to 21 July 2017).

\section{Normann 2006}

Normann C, Schmauss M, Bakri N, Gerwe M, Schreiner A. Initial treatment of severe acute psychosis with risperidone fast orally disintegrating tablets. Pharmacopsychiatry 2006;39:209-12.

\section{Ostinelli 2017}

Ostinelli EG, Brooke-Powney M, Li X, Adams CE. Haloperidol for psychosis-induced aggression or agitation (rapid tranquillisation). Cochrane Database of Systematic Reviews 2017, Issue 7. [DOI: 10.1002/14651858.CD009377.pub3]

\section{Ostinelli 2018}

Ostinelli EG, Jajawi S, Spyridi S, Sayal K, Jayaram MB. Aripiprazole (intramuscular) for psychosis-induced aggression or agitation (rapid tranquillisation). Cochrane Database of Systematic Reviews 2018, Issue 1. [DOI: 10.1002/14651858.CD008074]

\section{Overall 1962}

Overall JE, Gorham DR. The brief psychiatric rating scale. Psychological Reports 1962;10:799-812.

\section{Sampson 2016}

Sampson S, Hosalli P, Furtado VA, Davis JM. Risperidone (depot) for schizophrenia. Cochrane Database of Systematic Reviews 2016, Issue 4. [DOI: 10.1002/14651858.CD004161.pub2]

\section{Sartorius 1972}

Sartorius N, Shapiro R, Kimura M, Barrett K. WHO international pilot study of schizophrenia. Psychological Medicine 1972;2(4):422-5. [PUBMED: 4656537]

\section{Schünemann 2011}

Schünemann HJ, Oxman AD, Vist GE, Higgins JPT, Deeks JJ, Glasziou P, et al. Chapter 12: Interpreting results and drawing conclusions. In Higgins JPT, Green S editor(s), Cochrane Handbook for Systematic Reviews of Interventions Version 5.1.0 (updated March 2011).. Available from www.cochranehandbook.org.

\section{Shah 2000}

Shah A, Jenkins R. Mental health economic studies from developing countries reviewed in the context of those from developed countries. Acta Psychiatrica Scandinavica 2000;101(2):87-103.

\section{Simpson 1970}

Simpson GM, Angus JSW. A rating scale for extrapyramidal side effects. Acta Psychiatrica Scandinavica 1970;212:11-9.

\section{Stahl 2008}

Stahl SM. Stahl's Essential Psychopharmacology, Neuroscientific Basis and Practical Applications. 3rd Edition. New York: Cambridge University Press, 2008.

\section{Sterne 2011}

Sterne JAC, Egger M, Moher D (editors). Chapter 10: Addressing reporting biases. In: Higgins JPT, Green S (editors). Cochrane Handbook for Systematic Reviews of Intervention.. Available from www.handbook.cochrane.org.

\section{Swanson 1990}

Swanson J, Hozler C, Ganju VR. Violence and psychiatric disorder in the community: evidence from the epidemiologic catchment area surveys. Hospital and Community Psychiatry 1990;41:761-70. 


\section{Tardiff 1982}

Tardiff K, Sweillam A. Assaultive behavior among chronic inpatients. American Journal of Psychiatry 1982;139:212-5.

\section{Thorpe 2009}

Thorpe KE, Zwarenstein M, Oxman AD, Treweek S, Furberg CD, Altman DG, et al. A pragmatic-explanatory continuum indicator summary (PRECIS): a tool to help trial designers. Journal of Clinical Epidemiology 2009;62(5):464-75.

\section{Tran 1997}

Tran PV, Hamilton SH, Kuntz AJ, Potvin JH, Andersen SW, Beasley C Jr, et al. Double-blind comparison of olanzapine versus risperidone in the treatment of schizophrenia and other psychotic disorders. Journal of Clinical Psychopharmacology 1997;17(5):407-18.

\section{Ukoumunne 1999}

Ukoumunne OC, Gulliford MC, Chinn S, Sterne JAC, Burney PGJ. Methods for evaluating area-wide and organisation-based intervention in health and health care: a systematic review. Health Technology Assessment 1999;3(5):1-75.

\section{Vangala 2012}

Vangala R, Ahmed U, Ahmed R. Loxapine inhaler for psychosis-induced aggression or agitation. Cochrane Database of Systematic Reviews 2012, Issue 11. [DOI: 10.1002/14651858.CD010190]

\section{Viale 1997}

Viale G, Mechling L, Maislin G, Durkin M, Engelhart L, Lawrence BJ. Impact of risperidone on the use of mental health care resources. Psychiatric Services 1997;48(9):1153-9.

\section{WHO 2002}

World Health Organization. World Report on Violence and Health. Geneva: World Health Organization, 2002.

\section{Wilkie 2012}

Wilkie F, Fenton M. Quetiapine for psychosis-induced aggression or agitation. Cochrane Database of Systematic Reviews 2012, Issue 4. [DOI: 10.1002/14651858.CD009801]

\section{Wirshing 1999}

Wirshing DA, Wirshing WC, Kysar L, Berisford MA, Goldstein D, Pashdag J, et al. Novel antipsychotics: comparison of weight gain liabilities. Journal of Clinical Psychiatry 1999;60(6):358-63.

\section{CHARACTERISTICS OF STUDIES}

Characteristics of included studies [ordered by study ID]

\section{WPA 2008}

World Psychiatric Association. The usefulness and use of second-generation antipsychotic medications (An update of the review of evidence and recommendations by a task force of the World Psychiatric Association). www.peoplewho.org/ documents/WPA2ndgenanti-pDOC.doc. Yokohama, Japan, (accessed 21 July 2008).

\section{Wright 2002}

Wright S, Gray R, Parkes J, Gournay K. The Recognition, Prevention and Therapeutic Management of Violence in Acute In-patient Psychiatry: a Literature Review and Evidence-based Recommendations for Good Practice. London: United Kingdom Central Council for Nursing, Midwifery and Health Visiting, 2002.

\section{Xia 2009}

Xia J, Adams CE, Bhagat N, Bhagat V, Bhoopathi P, El-Sayeh H, et al. Loss to outcomes stakeholder survey: the LOSS study. Psychiatric Bulletin 2009;33(7):254-7.

\section{Yudofsky 1986}

Yudofsky SC, Silver JM, Jackson W, Endicott J, Williams D. The Overt Aggression Scale for the for the objective rating of verbal and physical aggression. American Journal of Psychiatry 1986;143(1):35-9.

\section{Zaman 2017}

Zaman H, Sampson SJ, Beck ALS, Sharma T, Clay FJ, Spyridi S, Zhao S, Gillies D. Benzodiazepines for psychosis-induced aggression or agitation. Cochrane Database of Systematic Reviews 2017, Issue 12. [DOI: 10.1002/14651858.CD003079.pub4]

\section{References to other published versions of this review}

\section{Ahmed 2011}

Ahmed U, Rehman F, Jones H, Adams CE. Risperidone for psychosis induced aggression or agitation. Cochrane Database of Systematic Reviews 2011, Issue 11. [DOI: 10.1002/14651858.CD009412]

* Indicates the major publication for the study

Dai 2012

Methods
Blindness: not reported
Duration: 8 weeks

Participants

Diagnosis: schizophrenia with aggressive behaviour (ICD-10) 
Dai 2012 (Continued)

$$
N=40
$$

Age: mean 25.3 years; range $20-30$ years.

Sex: 32 males, 8 females.

History: mean length of illness of 1.45 years, range from 1 month to 3 years; history of aggressive behaviour (total score of Modified overt aggression scale more than 5 after admission for 1 week); type of schizophrenia: 29 participants with paranoid schizophrenia; 5 participants with hebephrenic schizophrenia; 6 participants with unclear type.

Excluded: organic psychosis, affective disorder or other psychogeny; body diseases, epilepsy, encephalosis, alcohol or drug dependence; women in gestational or suckling period.

Setting: Dalian, China (inpatient).

Interventions

1. Risperidone: initial dose of $1 \mathrm{mg} /$ day, increased to $3 \mathrm{mg}$ to $4 \mathrm{mg} /$ day in 7 days, then dose adjusted according to illness condition within 1 month, maximum dose $<6 \mathrm{mg} /$ day. $\mathrm{N}=20$.

2. Quetiapine: initial dose of $100 \mathrm{mg} /$ day, increased to $400 \mathrm{mg}$ to $500 \mathrm{mg} /$ day in 7 days, then dose adjusted according to illness condition within 1 month, maximum dose $<750 \mathrm{mg} / \mathrm{day} . \mathrm{N}=20$.

Trihexyphenidyl or benzodiazepines could be used as p.r.n. drugs.

Outcomes Specific behaviour: aggression - MOAS endpoint score (2, 4, 6, 8 weeks; Table 3 in p.2063).

Mental state: Clinical response (8 weeks; section 2.1 in p.2062), PANSS endpoint score (2, 4, 6, 8 weeks; Table 2 in p.2062), PANSS positive symptoms sub-scale endpoint score $(2,4,6,8$ weeks; Table 2 in p.2062), PANSS negative symptoms sub-scale endpoint score (2, 4, 6, 8 weeks; Table 2 in p.2062), PANSS general psychopathology sub-scale endpoint score (2, 4, 6, 8 weeks; Table 2 in p.2062).

Adverse events: specific adverse events (8 weeks; Table 4 in p.2063).

\section{Notes}

\section{Risk of bias}

\begin{tabular}{lll}
\hline Bias & Authors' judgement & Support for judgement \\
\hline $\begin{array}{l}\text { Random sequence genera- } \\
\text { tion (selection bias) }\end{array}$ & Unclear risk & $\begin{array}{l}\text { Quote: “All the cases were randomly assigned to two group...” (p.2061) } \\
\text { Comments: the author described a random component, but no more detail } \\
\text { about random methods were given. }\end{array}$ \\
\hline $\begin{array}{l}\text { Allocation concealment } \\
\text { (selection bias) }\end{array}$ & Unclear risk & Not stated \\
\hline $\begin{array}{l}\text { Blinding of participants } \\
\text { and personnel (perfor- } \\
\text { mance bias) } \\
\text { All outcomes }\end{array}$ & Unclear risk & Not stated \\
\hline
\end{tabular}

Blinding of outcome as- Unclear risk Not stated
sessment (detection bias)

All outcomes

Incomplete outcome data Low risk No evidence of attrition bias
(attrition bias)

All outcomes 
Dai 2012 (Continued)

Selective reporting (re- Unclear risk Data on p.r.n. drugs usage not reported. Protocol not available; compared to porting bias)

the 'methods' section, no evidence of 'selective reporting' bias.

Other bias High risk Small sample size

Jin 2013

$\begin{array}{ll}\text { Methods } & \text { Allocation: randomised } \\ \text { Blindness: not reported } \\ \text { Duration: } 4 \text { weeks }\end{array}$

Participants $\quad$ Diagnosis: schizophrenia with impulsive and aggressive behaviour (CCMD-3)
$\mathrm{N}=63$

$N=63$

Age: mean 39.4 years; range 18-65 years.

Sex: 32 males, 31 females.

History: length of illness: mean 3.3 years; PANSS total score before treatment: mean 89.69; all patients received risperidone before enrolment.

Excluded: severe heart disease, hepatic disease, renal disease or physical ailments; drug allergies or leukopenia; epilepsy, alcohol and substance dependence.

Setting: Liaoning, China (inpatient).

2. Risperidone + magnesium valproate sustained release tablet: risperidone dosage not stated; magnesium valproate sustained release initial dose $500 \mathrm{mg} /$ day, increased to $750 \mathrm{mg}$ to $1000 \mathrm{mg} /$ day over one week. $\mathrm{N}=32$.

Trihexyphenidyl and propanolol could be used as p.r.n. drugs.

Outcomes Specific behaviour: agitation - PANSS-EC endpoint score (2, 4 weeks; Table 1 in p.161).

Mental state: PANSS endpoint score (2, 4 weeks; Table 1 in p.161), PANSS positive symptoms sub-scale endpoint score (2, 4 weeks; Table 1 in p.161).

Adverse effects: specific adverse effects (4 weeks; Table 3 in p.161).

Unable to use:

Adverse effects: TESS endpoint score (4 weeks; Table 2 in p.161)*.

Notes * typo input error is likely

\section{Risk of bias}

\section{Bias}

Random sequence genera- Unclear risk tion (selection bias)

\section{Authors' judgement Support for judgement}

Quote: "All the cases were randomly assigned to two group...” (p.161).

Comments: the author described a random component, but no more detail about random methods were given. 
Jin 2013 (Continued)

\begin{tabular}{lll}
$\begin{array}{l}\text { Allocation concealment } \\
\text { (selection bias) }\end{array}$ & Unclear risk & Not stated \\
\hline $\begin{array}{l}\text { Blinding of participants } \\
\text { and personnel (perfor- }\end{array}$ & Unclear risk & Not stated \\
mance bias) & \\
All outcomes &
\end{tabular}

Blinding of outcome as-
sessment (detection bias) $\quad$ Unclear risk $\quad$ Not stated

All outcomes

$\begin{array}{ll}\begin{array}{l}\text { Incomplete outcome data } \\ \text { (attrition bias) }\end{array} & \text { High risk } \\ \text { lost. }\end{array}$

All outcomes

\begin{tabular}{|c|c|c|}
\hline $\begin{array}{l}\text { Selective reporting (re- } \\
\text { porting bias) }\end{array}$ & Unclear risk & $\begin{array}{l}\text { Data on p.r.n. drugs usage not reported. Protocol not available; compared to } \\
\text { the 'methods' section, no evidence of 'selective reporting' bias. }\end{array}$ \\
\hline
\end{tabular}

\begin{tabular}{lll}
\hline Other bias $\quad$ High risk & Small sample size \\
\hline
\end{tabular}

Li 2013

\begin{tabular}{ll}
\hline Methods & Allocation: randomised \\
Blindness: not reported \\
Duration: 8 weeks
\end{tabular}

\begin{tabular}{|c|c|}
\hline \multirow[t]{6}{*}{ Participants } & Diagnosis: schizophrenia with aggressive behaviour (ICD-10).N = 60 \\
\hline & Age: mean 30 years; range $18-60$ years. \\
\hline & Sex: 31 males, 29 females \\
\hline & $\begin{array}{l}\text { History: length of illness: mean } 5.3 \text { years; education years: mean } 8 \text { years; PANSS total score before en- } \\
\text { rolment: mean } 78.5 \text {; range more than } 70 \text {; MOAS total score before enrolment: mean } 8.8 \text {; range more } \\
\text { than } 4 .\end{array}$ \\
\hline & Excluded: severe body diseases; drug dependence; women in gestational or suckling period. \\
\hline & Setting: Shanxi, China (outpatient). \\
\hline \multirow[t]{3}{*}{ Interventions } & $\begin{array}{l}\text { 1. Risperidone: initial dose of } 1 \mathrm{mg} / \text { day, maximum dose of } 6 \mathrm{mg} / \text { day; mean dose of } 3.3 \pm 1.6 \mathrm{mg} / \text { day. } \mathrm{N} \\
=30\end{array}$ \\
\hline & $\begin{array}{l}\text { 2. Risperidone + magnesium valproate sustained release: risperidone initial dose of } 1 \mathrm{mg} / \text { day, maxi- } \\
\text { mum dose of } 4 \mathrm{mg} / \text { day; mean dose of } 2.5 \mathrm{mg} \pm 1.5 \mathrm{mg} / \text { day; magnesium valproate sustained release ini- } \\
\text { tial dose of } 500 \mathrm{mg} / \text { day, maximum dose of } 1000 \mathrm{mg} / \text { day; mean dose of } 800 \mathrm{mg} \pm 50 \mathrm{mg} / \text { day. } \mathrm{N}=30 \text {. }\end{array}$ \\
\hline & Benzodiazepines could be used as p.r.n. drugs. \\
\hline
\end{tabular}

Outcomes

Specific behaviour: agitation - MOAS endpoint score (2, 4, 8 weeks; Table 2 in p.70).

Mental state: PANSS endpoint score (2, 4, 8 weeks; Table 1 in p.70), PANSS positive symptoms sub-scale endpoint score (2, 4, 8 weeks; Table 1 in p.70), PANSS negative symptoms endpoint score (2, 4, 8 weeks; Table 1 in p.70), PANSS general psychopathology endpoint score (2, 4, 8 weeks; Table 1 in p.70).

Adverse effects: specific adverse events (4 weeks; section 2.3 in p.70). 
Li 2013 (Continued)

Unable to use:

Adverse effects: gastrointestinal reaction (definition too vague).

\title{
Notes
}

\section{Risk of bias}

\begin{tabular}{lll}
\hline Bias & Authors' judgement & Support for judgement \\
\hline $\begin{array}{l}\text { Random sequence genera- } \\
\text { tion (selection bias) }\end{array}$ & Unclear risk & Quote: "All the cases were randomly assigned to two group...” (p.69) \\
& & $\begin{array}{l}\text { Comments: the author described a random component, but no more detail } \\
\text { about random methods. }\end{array}$ \\
\hline $\begin{array}{l}\text { Allocation concealment } \\
\text { (selection bias) }\end{array}$ & Unclear risk & Not stated \\
\hline $\begin{array}{l}\text { Blinding of participants } \\
\begin{array}{l}\text { and personnel (perfor- } \\
\text { mance bias) }\end{array}\end{array}$ & Unclear risk & Not stated \\
$\begin{array}{l}\text { All outcomes } \\
\end{array}$ & &
\end{tabular}

\begin{tabular}{|c|c|c|}
\hline $\begin{array}{l}\text { Blinding of outcome as- } \\
\text { sessment (detection bias) } \\
\text { All outcomes }\end{array}$ & Unclear risk & Not stated \\
\hline $\begin{array}{l}\text { Incomplete outcome data } \\
\text { (attrition bias) } \\
\text { All outcomes }\end{array}$ & Low risk & No evidence of attrition bias \\
\hline $\begin{array}{l}\text { Selective reporting (re- } \\
\text { porting bias) }\end{array}$ & Unclear risk & $\begin{array}{l}\text { Data on p.r.n. drugs usage not reported. Protocol not available; compared to } \\
\text { the 'methods' section, no evidence of 'selective reporting' bias. }\end{array}$ \\
\hline Other bias & High risk & Small sample size \\
\hline
\end{tabular}

\section{Lim 2010}

\begin{tabular}{ll}
\hline Methods & Allocation: randomised \\
Blindness: open-label, rater blind. \\
Duration: 24 hours
\end{tabular}

\begin{abstract}
Participants
Diagnosis: DSM-IV diagnosis of schizophrenia $(N=78)$, bipolar disorder $(N=43)$, others $(N=3)$.

$N=124$

Age: range $18-65$ years

Sex: 66 males, 58 females

History: "acute psychotic agitation in the emergency room or inpatient ward" (p.82).

Excluded: neurological disorder, severe medical disease, alcohol or other psychoactive substance misusers, history of neuromalignant syndrome or hypersensitivity to trial medications, pregnant or lactating women, people treated with antipsychotics or benzodiazepines within 6 hours to the start of the trial or with depot antipsychotic within one treatment cycle of enrolment.
\end{abstract}


Lim 2010 (Continued)

Setting: Korea (psychiatric emergency room inpatient ward).

Interventions $\quad$ 1. Risperidone: oral dose $2 \mathrm{mg}$, maximum $6 \mathrm{mg}$ during 24 hours. $\mathrm{N}=62$.

2. Haloperidol: IM dose $5 \mathrm{mg}$, maximum $15 \mathrm{mg}$ during 24 hours. $\mathrm{N}=62$.

Outcomes

Specific behaviour: no clinically important change in agitation (defined as PANSS-PAS $50 \%$ reduction from the baseline score).

Use of additional medication - lorazepam.

Adverse events

Leaving the study early

Unable to use:

Mental state: PANSS Total (mean, SE/SD not reported, P values of significant findings reported, overall F value).

Mental state: YMRS Total (mean, SE/SD/CI not reported).

Global state: CGI-S (mean, SE/SD not reported, P values of significant findings reported, overall F value).

Specific behaviour: Behaviorally Anchored Rating Scale (mean, SE/SD/CI not reported). previously stated maximum dose.

Intramuscular injection of $4 \mathrm{mg}$ lorazepam or $2 \mathrm{mg}$ of oral lorazepam was used as a rescue medicine if severe extrapyramidal symptoms (EPS) had occurred. Although paper gives information about use of additional lorazepam in 7 participants from risperidone and 8 from haloperidol group, it does not provide further details.

* Authors of the manuscript use the "PANSS-EC" term but provide the items list of PANSS-PAS; in other published studies they refers to this as an " 5 item acute agitation cluster [...] from PANSS score".

\section{Risk of bias}

Bias Authors' judgement Support for judgement

Random sequence genera- Low risk tion (selection bias)

Participants were assigned "according to a predefined randomization code that was balanced to ensure even distribution of patients in each treatment group" (p.82).

\begin{tabular}{lll}
\hline $\begin{array}{l}\text { Allocation concealment } \\
\text { (selection bias) }\end{array}$ & Unclear risk & Not reported \\
\hline $\begin{array}{l}\text { Blinding of participants } \\
\text { and personnel (perfor- } \\
\text { mance bias) }\end{array}$ & High risk & $\begin{array}{l}\text { This was an open-label study where one group received IM. and the other } \\
\text { group received an orodispersible tablet. }\end{array}$ \\
All outcomes & \\
\hline
\end{tabular}

\begin{tabular}{lll}
\hline $\begin{array}{l}\text { Blinding of outcome as- } \\
\text { sessment (detection bias) } \\
\text { All outcomes }\end{array}$ & Low risk & The study was rater-blinded \\
\hline $\begin{array}{l}\text { Incomplete outcome data } \\
\text { (attrition bias) }\end{array}$ & Low risk & $\begin{array}{l}\text { There is no evidence of incomplete outcome data. The authors give reasons } \\
\text { All outcomes }\end{array}$
\end{tabular}


Lim 2010 (Continued)

Selective reporting (re- High risk Authors report that anti-parkinsonian drugs could be given at the lowest effecporting bias) tive dose, however the amount administered is not described in the results. Several outcomes are not reported. Protocol not available.

Other bias

High risk

Sponsored by Janssen Phamaceutica Korea. Authors state they used PANSSEC but provide description for PANSS-PAS, while calling this scale a " 5 item acute agitation cluster" in the other linked publications.

Walther 2014

Methods
Bllocation: randomised.
Duration: 96 hours.

Participants

Diagnosis: DSM-IV criteria for schizophrenia $(n=27)$, schizoaffective $(n=6)$, or schizophreniform disor$\operatorname{der}(n=10)$.

$N=43^{*}$

Age: mean 34 years (SD 10), range 18-55 years.

Sex: 31 males, 12 females.

History: severely agitated, admitted to acute care inpatient unit.

Excluded: people who did not give post hoc informed consent, duration ill 7 years, $84 \%$ free of antipsychotics or mood stabilisers at the time of study inclusion.

Setting: Switzerland (acute care psychiatry units).

2. Haloperidol: $15 \mathrm{mg} /$ day for 5 days, fixed dose, oral. $\mathrm{N}=14$.

3. Olanzapine: $20 \mathrm{mg} /$ day for 5 days, fixed dose, oral. $\mathrm{N}=15$.

Additional use of up to $30 \mathrm{mg}$ diazepam/day was permitted (day 1), up to $60 \mathrm{mg} /$ day, days 2-5.

Specific behaviour: PANSS-PAS score ${ }^{\star \star}$, need for seclusion room.
Leaving the study early
Lack of efficacy
Adverse effects: movement disorders (AIMS for risperidone vs haloperidol, Barnes scale, SAS).
Unable to use:
Use of additional medication - diazepam/biperiden (data not reported by group).
Adverse effects: movement disorders (AIMS for risperidone vs olanzapine: no SD).
* eligible patients were 52 patients but 9 refused to provide post-hoc consent
** scores and SE values were extracted from figures, see methods for further details; SD values were
then calculated
Authors were contacted (2nd July 2016, 9th July 2016).


Walther 2014 (Continued)

Risk of bias

\begin{tabular}{|c|c|c|}
\hline Bias & Authors' judgement & Support for judgement \\
\hline $\begin{array}{l}\text { Random sequence genera- } \\
\text { tion (selection bias) }\end{array}$ & Low risk & $\begin{array}{l}\text { "Randomization was performed by creating } 3 \text { sets of random numbers be- } \\
\text { tween } 1 \text { and } 60 \text { using a computer-based research randomizer (www.randomiz- } \\
\text { er.org)" (pg.125). }\end{array}$ \\
\hline $\begin{array}{l}\text { Allocation concealment } \\
\text { (selection bias) }\end{array}$ & Low risk & $\begin{array}{l}\text { "The order of inclusion determined allocation to treatment group. The ran- } \\
\text { domisation list was locked in the office of the principal investigator [...], who } \\
\text { was engaged neither in treatment nor in study assessments" (pg.125). }\end{array}$ \\
\hline $\begin{array}{l}\text { Blinding of participants } \\
\text { and personnel (perfor- } \\
\text { mance bias) } \\
\text { All outcomes }\end{array}$ & Unclear risk & Not stated \\
\hline $\begin{array}{l}\text { Blinding of outcome as- } \\
\text { sessment (detection bias) } \\
\text { All outcomes }\end{array}$ & Low risk & $\begin{array}{l}\text { "All ratings were performed by } 1 \text { of } 2 \text { raters who were blind to treatment allo- } \\
\text { cation." (pg. 215). }\end{array}$ \\
\hline $\begin{array}{l}\text { Incomplete outcome data } \\
\text { (attrition bias) } \\
\text { All outcomes }\end{array}$ & High risk & $\begin{array}{l}9 \text { participants were excluded post-randomisation due to refusal to provide } \\
\text { post-hoc consent; their treatment assignment was not provided. } 6 \text { participants } \\
\text { dropped out but LOCF method was used to deal with attrition bias. }\end{array}$ \\
\hline \multirow[t]{4}{*}{$\begin{array}{l}\text { Selective reporting (re- } \\
\text { porting bias) }\end{array}$} & High risk & $\begin{array}{l}\text { PANSS-PAS scores at } 24,48,72 \text {, and } 96 \text { hours not provided. } \\
\text { PANSS scores at } 96 \text { hours not provided. }\end{array}$ \\
\hline & & Number of patients that needed additional BDZ not provided. \\
\hline & & Number of patients that needed additional biperiden not provided. \\
\hline & & Protocol not available. \\
\hline \multirow[t]{2}{*}{ Other bias } & High risk & $\begin{array}{l}\text { Authors declare no conflicts of interest but all do have some affiliation with } \\
\text { relevant companies. }\end{array}$ \\
\hline & & Small sample size. \\
\hline
\end{tabular}

Wang 2012

$\begin{array}{ll}\text { Methods } & \text { Allocation: randomised } \\ \text { Blindness: open-label } & \text { Duration: } 4 \text { weeks }\end{array}$

Participants Diagnosis: schizophrenia with agitation (CCMD-3).

$N=68$

Age: mean 30.5 years; range $17^{\sim} 60$ years.

Sex: 57 males, 11 females.

History: all patients did not receive clozapine; BPRS total score > $=35$ before enrolment.

Excluded: severe body diseases, alcohol or drug dependence. 
Wang 2012 (Continued)

Setting: Liaoning, China (inpatient)

Interventions $\quad$ 1. Risperidone: initial dose not stated, increased to treatment dosage in 7 to 10 days, then adjust dose according to illness condition; mean dose $(4.2 \pm 0.35) \mathrm{mg} /$ day. $\mathrm{N}=33$.

2. Risperidone + oxcarbazepine: initial dose not stated for both drugs. Risperidone increased to treatment dosage in 7 to 10 days, then adjust dose according to illness condition; mean dose (4.1 \pm 0.4$) \mathrm{mg} /$ day. Oxcarbazepine: initial dose not stated, increased to $0.9^{\sim} 1.8 \mathrm{~g} /$ day in one week, then adjust dose according to illness condition; mean dose $(1.20 \pm 0.42) \mathrm{g} /$ day. $\mathrm{N}=35$.

Outcomes

Mental state: BPRS endpoint score (1, 2, 4 weeks; Table 1 in p.2957).

Global outcome: CGI endpoint score (1, 2, 4 weeks; Table 1 in p.2957).

Adverse effects: specific adverse effects (4 weeks; 2.3 in p.2957).

Unable to use:

No clinical response (4 weeks; 2.2 in p.2957), data is available at 4 weeks only which is not consistent with the "rapid tranquillisation" topic.

Notes

\section{Risk of bias}

\begin{tabular}{|c|c|c|}
\hline Bias & Authors' judgement & Support for judgement \\
\hline $\begin{array}{l}\text { Random sequence genera- } \\
\text { tion (selection bias) }\end{array}$ & Low risk & $\begin{array}{l}\text { Quote: "All the cases were randomly assigned to two group according to ran- } \\
\text { dom number table" (p.2061). }\end{array}$ \\
\hline $\begin{array}{l}\text { Allocation concealment } \\
\text { (selection bias) }\end{array}$ & Unclear risk & The author did not describe the allocation concealment. \\
\hline $\begin{array}{l}\text { Blinding of participants } \\
\text { and personnel (perfor- } \\
\text { mance bias) } \\
\text { All outcomes }\end{array}$ & High risk & Open trial. The blinding of participants and personnel not ensured. \\
\hline $\begin{array}{l}\text { Blinding of outcome as- } \\
\text { sessment (detection bias) } \\
\text { All outcomes }\end{array}$ & High risk & Open trial. The blinding of outcome assessment not ensured. \\
\hline $\begin{array}{l}\text { Incomplete outcome data } \\
\text { (attrition bias) } \\
\text { All outcomes }\end{array}$ & Low risk & $\begin{array}{l}3 \text { participants }(3 / 68,4.4 \%) \text { left study early due to poor clinical response ( } 2 \text { par- } \\
\text { ticipants in } \\
\text { risperidone alone group), however, the author used LOCF methodology to deal } \\
\text { with missing data. }\end{array}$ \\
\hline $\begin{array}{l}\text { Selective reporting (re- } \\
\text { porting bias) }\end{array}$ & Unclear risk & $\begin{array}{l}\text { Protocol not available; compared to the 'methods' section, no evidence of 'se- } \\
\text { lective reporting' bias. }\end{array}$ \\
\hline Other bias & High risk & Small sample size \\
\hline
\end{tabular}

Wang 2013

Methods Allocation: randomised


Wang 2013 (Continued)

Blindness: not reported

Duration: 6 weeks

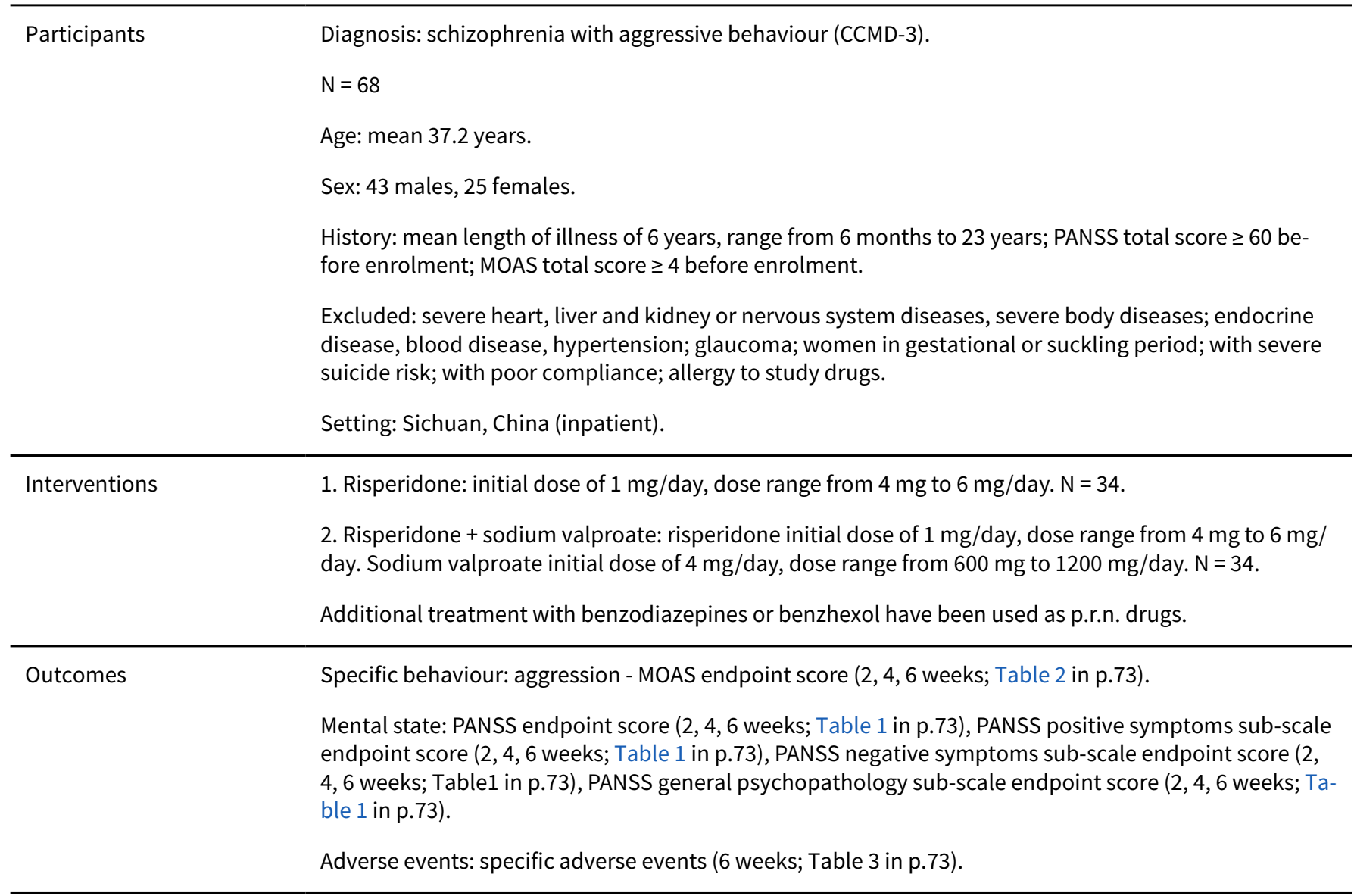

Notes

\section{Risk of bias}

\begin{tabular}{lll}
\hline Bias & Authors' judgement & Support for judgement \\
\hline $\begin{array}{l}\text { Random sequence genera- } \\
\text { tion (selection bias) }\end{array}$ & Unclear risk & $\begin{array}{l}\text { Quote: "All the cases were randomly assigned to two group..." (p.73). Com- } \\
\text { ments: the author described a randomised component, but no more detail } \\
\text { about random methods were given. }\end{array}$ \\
\hline $\begin{array}{l}\text { Allocation concealment } \\
\text { (selection bias) }\end{array}$ & Unclear risk & Not stated \\
\hline $\begin{array}{l}\text { Blinding of participants } \\
\text { and personnel (perfor- } \\
\text { mance bias) } \\
\text { All outcomes }\end{array}$ & Unclear risk & Not stated \\
\hline
\end{tabular}

$\begin{array}{ll}\text { Blinding of outcome as- } & \text { Unclear risk } \\ \text { sessment (detection bias) } & \\ \text { All outcomes } & \end{array}$

$\begin{aligned} & \text { Incomplete outcome data } \\ & \text { (attrition bias) }\end{aligned}$
Low risk No missing outcome date


Wang 2013 (Continued)

All outcomes

\begin{tabular}{|c|c|c|}
\hline $\begin{array}{l}\text { Selective reporting (re- } \\
\text { porting bias) }\end{array}$ & Unclear risk & $\begin{array}{l}\text { Data on p.r.n. drugs usage not reported. Protocol not available; compared to } \\
\text { the 'methods' section, no evidence of 'selective reporting' bias. }\end{array}$ \\
\hline
\end{tabular}

\begin{tabular}{ll}
\hline Other bias $\quad$ High risk small sample size \\
\hline
\end{tabular}

Yao 2010

Methods
Bllocation: randomised
Buration: 8 weeks, follow-up 6 months on participants which had clinical response after treatment.

\begin{tabular}{|c|c|}
\hline \multirow[t]{6}{*}{ Participants } & $\begin{array}{l}\text { Diagnosis: schizophrenia with aggressive behaviour (CCMD-3). } \\
N=62\end{array}$ \\
\hline & Age: mean 26.9 years; range $17^{\sim} 42$ years. \\
\hline & Sex: 33 males, 29 females. \\
\hline & $\begin{array}{l}\text { History: length of illness: not stated; marital status: } 23 \text { unmarried, } 38 \text { married; education: } 3 \text { illiterate, } 53 \\
\text { less than Bachelor degree, } 6 \text { Bachelor degree or more. }\end{array}$ \\
\hline & $\begin{array}{l}\text { Excluded: severe physical ailments; patients received antipsychotics within } 2 \text { weeks before enrolment; } \\
\text { patients with positive family history. }\end{array}$ \\
\hline & Setting: Henan, China (inpatient). \\
\hline \multirow[t]{3}{*}{ Interventions } & $\begin{array}{l}\text { 1. Risperidone: initial dose of } 1 \mathrm{mg} / \text { day, increased to } 4 \mathrm{mg} \text { to } 6 \mathrm{mg} / \text { day in } 7-15 \text { days; mean (SD): } 4.98 \\
\text { (1.07) } \mathrm{mg} / \text { ay. } \mathrm{N}=31 .\end{array}$ \\
\hline & $\begin{array}{l}\text { 2. Risperidone + magnesium valproate sustained release tablet: risperidone initial dose of } 1 \mathrm{mg} / \text { day, } \\
\text { increased to } 4 \mathrm{mg} \text { to } 6 \mathrm{mg} / \text { day in } 7-15 \text { days; magnesium valproate sustained release tablet dose of } 500 \\
\mathrm{mg} / \text { day. } \mathrm{N}=31 .\end{array}$ \\
\hline & $\begin{array}{l}\text { Benzodiazepines (alprazolam, } 0.8 \mathrm{mg} \text { bed-time) could be used for participants with poor quality of } \\
\text { sleep as p.r.n. drugs. }\end{array}$ \\
\hline \multirow[t]{4}{*}{ Outcomes } & $\begin{array}{l}\text { Mental state: no clinical response at PANSS ( } 8 \text { weeks; section } 2.1 \text { in p.2714), PANSS endpoint score }(2,4 \text {, } \\
6,8 \text { weeks; Table } 1 \text { in p.2714). }\end{array}$ \\
\hline & Adverse effects: specific adverse effects. \\
\hline & Unable to use: \\
\hline & Global state: CGI endpoint score (not reported). \\
\hline
\end{tabular}

\section{Risk of bias}

\begin{tabular}{lll}
\hline Bias & Authors' judgement & Support for judgement \\
\hline $\begin{array}{l}\text { Random sequence genera- } \\
\text { tion (selection bias) }\end{array}$ & Unclear risk & Quote: “... were randomly into...” (p.2713)
\end{tabular}


Yao 2010 (Continued)

Comments: the author described a random component, but no more detail about random methods.

\begin{tabular}{lll}
\hline $\begin{array}{l}\text { Allocation concealment } \\
\text { (selection bias) }\end{array}$ & Unclear risk & Not stated \\
\hline $\begin{array}{l}\text { Blinding of participants } \\
\text { and personnel (perfor- } \\
\text { mance bias) }\end{array}$ & Unclear risk & \\
All outcomes & &
\end{tabular}

\begin{tabular}{ll}
\hline Blinding of outcome as- & Not state \\
sessment (detection bias) & \\
All outcomes & \\
\hline
\end{tabular}

Incomplete outcome data Low risk No evidence of attrition bias
(attrition bias)

All outcomes

\begin{tabular}{lll}
\hline $\begin{array}{l}\text { Selective reporting (re- } \\
\text { porting bias) }\end{array}$ & High risk & $\begin{array}{l}\text { CGI endpoint score measured at 2, 4, 6, 8 weeks but not reported. Data on } \\
\text { p.r.n. drugs usage not reported. Protocol not available. }\end{array}$ \\
\hline Other bias & High risk & Small sample size. \\
\hline
\end{tabular}

\section{Zhou 2013}

\begin{tabular}{ll}
\hline Methods & Allocation: randomised \\
Blindness: not reported \\
Duration: 7 days \\
\hline
\end{tabular}

Participants $\quad \begin{aligned} & \text { Diagnosis: schizophrenia with agitation (CCMD-3) } \\ & \mathrm{N}=54\end{aligned}$

Age: mean 26.0 years

Sex: 28 males, 26 females.

History: mean length of illness of 2.47 years; mean PANSS-EC baseline score of 21.98 , range starting from 15; mean MOAS total baseline score of 8.37 .

Excluded: organic diseases, alcohol or drug dependence.

Setting: Guangxi, China (inpatient).

Interventions
1. Risperidone: initial dose $1 \mathrm{mg} /$ day, twice daily from day 1 to day 3 , increased to $2 \mathrm{mg} /$ day twice daily from the day 4 to day $7 . \mathrm{N}=27$.

2. Risperidone + sodium valproate: Risperidone initial dose $1 \mathrm{mg} /$ day twice daily from the day 1 to day 3 , increased to $2 \mathrm{mg} /$ day twice daily from the day 4 to the day 7 . Sodium valproate: intravenous drip $400 \mathrm{mg}$ twice daily from day 2 to day $4 . \mathrm{N}=27$.

Benzhexol ( $2 \mathrm{mg} /$ day) or alprazolam ( $0.4 \mathrm{mg}$ to $0.8 \mathrm{mg} /$ day) could be used when necessary.
Specific behaviour - agitation: PANSS-EC endpoint score (3, 5, 7 days; Table 1 in p.262), Specific behaviour - aggression: MOAS endpoint score (3, 5, 7 days; Table 1 in p.262). 
Zhou 2013 (Continued)

Adverse events: TESS endpoint score (3, 5, 7 days; Table 2 in p.262), specific adverse events ( 7 days; 2.2

in p.262).

Notes

Risk of bias

\begin{tabular}{|c|c|c|}
\hline Bias & Authors' judgement & Support for judgement \\
\hline $\begin{array}{l}\text { Random sequence genera- } \\
\text { tion (selection bias) }\end{array}$ & Unclear risk & $\begin{array}{l}\text { Quote: "[...] were randomly divided into }[\ldots . .] \text { " (p.261). Authors describe a ran- } \\
\text { dom component, but no more detail about random methods were given. }\end{array}$ \\
\hline $\begin{array}{l}\text { Allocation concealment } \\
\text { (selection bias) }\end{array}$ & Unclear risk & Not stated \\
\hline $\begin{array}{l}\text { Blinding of participants } \\
\text { and personnel (perfor- } \\
\text { mance bias) } \\
\text { All outcomes }\end{array}$ & Unclear risk & Not stated \\
\hline $\begin{array}{l}\text { Blinding of outcome as- } \\
\text { sessment (detection bias) } \\
\text { All outcomes }\end{array}$ & Unclear risk & Not stated \\
\hline $\begin{array}{l}\text { Incomplete outcome data } \\
\text { (attrition bias) } \\
\text { All outcomes }\end{array}$ & Low risk & No missing outcome data \\
\hline $\begin{array}{l}\text { Selective reporting (re- } \\
\text { porting bias) }\end{array}$ & Unclear risk & $\begin{array}{l}\text { Data on p.r.n. drugs usage not reported. Protocol not available; compared to } \\
\text { the 'methods' section, no evidence of 'selective reporting' bias. }\end{array}$ \\
\hline Other bias & High risk & Small sample size \\
\hline
\end{tabular}

AIMS: Abnormal Involuntary Movement Scale.

BDZ: Benzodiazepine

BPRS: Brief Psychiatric Rating Scale.

CCMD: Chinese Classification of Mental Disorders.

CGI: Clinical Global Impression.

CGI-I: Clinical Global Impression - Improvement.

CGI-S: Clinical Global Impression - Severity.

$\mathrm{Cl}$ : Confidence Interval.

DSM: Diagnostic and Statistical Manual of mental disorders.

ICD-10: International Classification of Diseases 10th edition.

IM: Intramuscular.

LOCF: Last Observation Carried Forward.

MOAS: Modified Overt Aggression Scale.

PANSS-EC: Positive and Negative Syndrome Scale - Excited Component.

PANSS-PAS: Positive and Negative Syndrome Scale - Psychotic Agitation Sub-score.

P.r.n.: Pro re nata (if needed).

SAS: Simpson-Angus Scale.

SD: Standard Deviation.

SE: Standard Error.

TESS: Treatment Emergent Symptom Scale.

YMRS: Young Mania Rating Scale.

Characteristics of excluded studies [ordered by study ID] 


\begin{tabular}{ll}
\hline Study & Reason for exclusion \\
\hline Beck 1997 & Allocation: quasi-randomised \\
\hline Belenkaya 2005 & $\begin{array}{l}\text { Allocation: randomised } \\
\text { Participants: patients with acute mania; not psychosis-induced aggression or agitation that re- } \\
\text { quired rapid tranquillisation. }\end{array}$ \\
\hline
\end{tabular}

\section{Briken 2002}

Allocation: randomised

Participants: schizophrenia or schizoaffective-disorder

PANSS mean score of 2.00 (SD: 1.28) and a 3-day washout period suggests improbability on psychosis-induced aggression or agitation requiring rapid tranquillisation.

\begin{tabular}{ll}
\hline Buckley 1997 & Allocation: not randomised \\
\hline Buitelaar 2001 & $\begin{array}{l}\text { Allocation: randomised } \\
\text { Participants: adolescents with severe aggressive behaviour and borderline intelligence or mild } \\
\text { mental retardation; not psychosis-induced aggression or agitation that required rapid tranquillisa- } \\
\text { tion. }\end{array}$
\end{tabular}

\begin{tabular}{ll}
\hline Chan 2013 & Allocation: randomised \\
& Participants: schizophrenia; not psychosis-induced aggression or agitation that required rapid \\
tranquillisation.
\end{tabular}

\begin{tabular}{ll}
\hline Citrome 2001 & $\begin{array}{l}\text { Allocation: randomised } \\
\text { Participants: schizophrenia and persistent aggressive behaviour; not psychosis-induced aggres- } \\
\text { sion or agitation that required rapid tranquillisation. }\end{array}$ \\
\hline Citrome 2004 & Allocation: randomised \\
& $\begin{array}{l}\text { Participants: acute exacerbation of schizophrenia; not psychosis-induced aggression or agitation } \\
\text { that required rapid tranquillisation. }\end{array}$ \\
\hline
\end{tabular}

\begin{tabular}{ll}
\hline Citrome 2007 & Allocation: randomised \\
& $\begin{array}{l}\text { Participants: schizophrenia patients who also exhibit problems with hostility; not psychosis-in- } \\
\text { duced aggression or agitation that required rapid tranquillisation. }\end{array}$
\end{tabular}

Conde $2011 \quad$ Allocation: randomised

Participants: individuals with acute psychotic agitation.

Intervention: risperidone + clonazepam vs haloperidol + clonazepam.

\begin{tabular}{ll}
\hline Currier 2000 & Allocation: not randomised \\
\hline Currier 2004 & Allocation: randomised \\
& Participants: individuals with schizophrenia, exhibiting agitation. \\
Intervention: risperidone + lorazepam vs haloperidol vs lorazepam \\
\hline
\end{tabular}

Participants: schizophrenia; not psychosis-induced aggression or agitation that required rapid tranquillisation.

Fang $2012 \quad$ Allocation: randomised




\begin{tabular}{|c|c|}
\hline Study & Reason for exclusion \\
\hline & $\begin{array}{l}\text { Participants: schizophrenia exhibiting agitation } \\
\text { Intervention: risperidone + clonazepam vs haloperidol }\end{array}$ \\
\hline Francey 2007 & $\begin{array}{l}\text { Allocation: randomised } \\
\text { Participants: first episode psychosis with low risk of self-harm or aggression; not psychosis-induced } \\
\text { aggression or agitation that required rapid tranquillisation. }\end{array}$ \\
\hline Greenspan 2005 & Allocation: not randomised \\
\hline Han 2005 & $\begin{array}{l}\text { Allocation: randomised } \\
\text { Participants: schizophrenia with agitation/aggression; not psychosis-induced aggression requiring } \\
\text { rapid tranquillisation. }\end{array}$ \\
\hline Hatta 2008 & Allocation: not randomised \\
\hline He 2005 & $\begin{array}{l}\text { Allocation: randomised } \\
\text { Participants: patients with schizophrenia; not psychosis-induced aggression or agitation that re- } \\
\text { quired rapid tranquillisation. }\end{array}$ \\
\hline Hong 2014 & $\begin{array}{l}\text { Allocation: randomised } \\
\text { Participants: individuals with schizophrenia exhibiting agitation. } \\
\text { Intervention: risperidone + clonazepam vs MECT }\end{array}$ \\
\hline
\end{tabular}

Hou $2011 \quad \begin{aligned} & \text { Allocation: randomised } \\ & \text { Participants: acute schizophrenia with excitement and agitation. } \\ & \text { Intervention: risperidone + lorazepam vs haloperidol + promethazine }\end{aligned}$

\begin{tabular}{ll}
\hline Hovens 2005 & Allocation: not randomised \\
\hline Huaqiang 2009 & $\begin{array}{l}\text { Allocation: randomised } \\
\text { Participants: schizophrenia and schizophreniform psychosis and dominated with excitement and } \\
\text { agitation; not psychosis-induced aggression or agitation that required rapid tranquillisation. }\end{array}$
\end{tabular}

Participants: aggressive challenging behaviour and intellectual disability; not psychosis-induced aggression or agitation that required rapid tranquillisation.

\section{Jiang 2012}

\section{Allocation: randomised}

Participants: patients with schizophrenia exhibiting agitation or aggression.

Intervention: risperidone + clonazepam vs haloperidol

\section{Allocation: randomised}

Participants: patients with schizophrenia; not psychosis-induced aggression or agitation that required rapid tranquillisation. 


\begin{tabular}{ll}
\hline Study & Reason for exclusion \\
\hline Kolivakis 2002 & Allocation: randomised \\
& $\begin{array}{l}\text { Participants: schizophreniform disorder and early paranoid schizophrenia; not psychosis-induced } \\
\text { aggression or agitation that required rapid tranquillisation. }\end{array}$ \\
\hline Lewis 2006 & Allocation: not randomised \\
\hline Li 2014 & Allocation: not randomised (full text not consistent with abstract text). \\
\hline Lieberman 2001 & $\begin{array}{l}\text { Allocation: randomised } \\
\text { Participants: treatment resistant patients with schizophrenia; not psychosis-induced aggression or } \\
\text { agitation that required rapid tranquillisation. }\end{array}$
\end{tabular}

\begin{tabular}{ll}
\hline Liu 2010 & Allocation: randomised \\
& Participants: schizophrenia with excitement and agitation in the acute stage; not psychosis-in- \\
duced aggression or agitation that required rapid tranquillisation.
\end{tabular}

\begin{tabular}{ll}
\hline Liu 2012 & Allocation: randomised \\
& Participants: patients with schizophrenia exhibiting agitation or aggression. \\
& Intervention: risperidone + haloperidol vs risperidone + clonazepam vs haloperidol \\
\hline NCT00174200 2005 & $\begin{array}{l}\text { Allocation: randomised } \\
\text { Participants: antipsychotic-naive, non-agitated patients diagnosed with first-episode schizophre- } \\
\text { nia or schizophreniform disorder; not psychosis-induced aggression or agitation that required } \\
\text { rapid tranquillisation. }\end{array}$
\end{tabular}

\begin{tabular}{ll}
\hline NCT00203775 2005 & Allocation: randomised \\
& Participants: psychotic disorder; not psychosis-induced aggression or agitation that required rapid \\
& tranquillisation.
\end{tabular}

NCT00205699 $2005 \quad$ Allocation: randomised

Participants: not psychosis-induced aggression or agitation that required rapid tranquillisation.

\begin{tabular}{ll}
\hline NCT00418873 2007 & Allocation: randomised \\
& Participants: aggressive schizophrenic patients in an acute ward. \\
& Intervention: risperidone vs zotepine \\
& Outcomes: study terminated due to difficulty in recruiting participants - no usable data.
\end{tabular}

\begin{tabular}{ll}
\hline NCT004854982003 & Allocation: randomised \\
& $\begin{array}{l}\text { Participants: schizophrenia; not psychosis-induced aggression or agitation that required rapid } \\
\text { tranquillisation. }\end{array}$ \\
\hline Ou 2007 & Allocation: randomised \\
Participants: schizophrenia with aggressive behavior; not psychosis-induced aggression or agita- \\
tion that required rapid tranquillisation. \\
\hline Pei 2009 & Allocation: quasi-randomised \\
\hline
\end{tabular}




\begin{tabular}{ll}
\hline Study & Reason for exclusion \\
\hline Participants: people with schizophrenia who are hospitalised for the first time; not psychosis-in- \\
duced aggression or agitation that required rapid tranquillisation.
\end{tabular}

\begin{tabular}{ll}
\hline Potkin 2005 & Allocation: not randomised \\
\hline Schooler 2003 & Allocation: not randomised \\
\hline Swanson 2008 & Allocation: randomised \\
& $\begin{array}{l}\text { Participants: schizophrenia; not psychosis-induced aggression or agitation that required rapid } \\
\text { tranquillisation. }\end{array}$ \\
\hline Tang 2007 & Allocation: randomised \\
& $\begin{array}{l}\text { Participants: acute excitement phase of schizophrenia; not psychosis-induced aggression or agita- } \\
\text { tion. }\end{array}$ \\
\hline Temputrn 2007 & $\begin{array}{l}\text { Allocation: randomised } \\
\text { Participants: schizoaffective disorder experiencing an acute exacerbation of psychotic symptoms; } \\
\text { not psychosis-induced aggression or agitation that required rapid tranquillisation. }\end{array}$
\end{tabular}

\section{Tosic Golubovic Suzana 2009 Allocation: randomised.}

Participants: people with schizophrenia or schizoaffective experiencing an acute psychotic episode; not psychosis-induced aggression or agitation that required rapid tranquillisation.

\begin{tabular}{|c|c|}
\hline \multirow[t]{2}{*}{ Veser 2006} & Allocation: randomised \\
\hline & $\begin{array}{l}\text { Participants: people with psychosis-induced agitation, however the study exclusion criteria includ- } \\
\text { ed an inability to give informed consent; not psychosis-induced aggression or agitation that re- } \\
\text { quired rapid tranquillisation. }\end{array}$ \\
\hline
\end{tabular}

\begin{tabular}{ll}
\hline Villari 2008 & Allocation: quasi-randomised \\
\hline Wan 2005 & Allocation: randomised \\
& $\begin{array}{l}\text { Participants: people with schizophrenia and agitation/aggression; not psychosis-induced aggres- } \\
\text { sion or agitation that required rapid tranquillisation. }\end{array}$
\end{tabular}

\begin{tabular}{ll}
\hline Wang 2004 & Allocation: randomised \\
& $\begin{array}{l}\text { Participants: acute agitation in schizophrenia; not psychosis-induced aggression or agitation that } \\
\text { required rapid tranquillisation. }\end{array}$
\end{tabular}

\begin{tabular}{ll}
\hline Wang 2006 & Allocation: randomised \\
& Participants: people with schizophrenia who are displaying aggressive behaviours, not acute agita- \\
tion or aggressive episodes and thus not requiring rapid tranquillisation.
\end{tabular}

Participants: people with schizophrenia exhibiting agitation or aggression.

Intervention: risperidone + haloperidol vs risperidone + ECT

\begin{tabular}{ll}
\hline Wei 2010 & Allocation: randomised \\
& Participants: adolescents with schizophrenia; not psychosis-induced aggression or agitation that \\
& required rapid tranquillisation.
\end{tabular}

Xi $2010 \quad$ Allocation: randomised




\begin{tabular}{ll}
\hline Study & Reason for exclusion \\
\hline Xuan 2007 & $\begin{array}{l}\text { Participants: schizophrenia with impulsive and aggressive symptoms; not psychosis-induced ag- } \\
\text { gression or agitation that required rapid tranquillisation. }\end{array}$ \\
\hline Allocation: randomised \\
$\begin{array}{l}\text { Participants: people with acute schizophrenia with excitement/agitation and other behavioural } \\
\text { disorders; not psychosis-induced aggression or agitation that required rapid tranquillisation. }\end{array}$ \\
Allocation: randomised \\
Participants: people with schizophrenia exhibiting agitation or aggression. \\
Intervention: risperidone + clonazepam vs haloperidol. \\
\hline Zheng 2010 & $\begin{array}{l}\text { Allocation: randomised } \\
\text { Participants: people with schizophrenia who have acute psychotic agitation. }\end{array}$ \\
Intervention: risperidone + clonazepam vs haloperidol
\end{tabular}

ECT: electroconvulsive therapy.

MECT: modern electroconvulsive therapy.

PANSS: Positive And Negative Syndrome Scale.

SD: standard deviation.

Characteristics of studies awaiting assessment [ordered by study ID]

Herrera 2005

Methods Allocation: randomised.

Blindness: double.

Duration: not stated.

Participants Diagnosis: psychosis with agitation and/or violence.

$N=20$.

Age: not stated.

Sex: not stated.

History: not stated.

Exclusion: not stated.

Setting: psychiatric emergency department.

$\begin{array}{ll}\text { Interventions } & \text { 1. Haloperidol: dose } 10 \mathrm{mg} / \mathrm{IM} . \\ \text { 2. Risperidone: dose } 2 \mathrm{mg} / \text { liquid. }\end{array}$

Outcomes

Specific behaviour - agitation: PANSS-EC. 
Herrera 2005 (Continued)

Notes

Conference abstract, full characteristics and outcome data not reported. Attempted to contact author.

Hsu 2010

Methods Allocation: randomised.

Blindness: single.

Duration: 24 hours.

Participants Diagnosis: DSM-IV diagnosis of schizophrenia $(N=20)$, bipolar disorder $(N=18)$, schizoaffective dis$\operatorname{order}(\mathrm{N}=1)$, delusional disorder or others $(\mathrm{N}=3)$.

$N=42$.

Age: range 18-65 years.

Sex: 20 males and 22 females.

History: within 24 hours of admission - previous psychiatric history not stated.

Exclusion: "pregnant or lactating women; patients with serious medical illnesses; patients with closed-angle glaucoma; patients with an allergic reaction to olanzapine, risperidone, or haloperidol; or patients who had received a long-acting antipsychotic agent injection within 30 days were excluded".

Setting: Taiwan (acute medical centre).

1. Haloperidol: dose $7.5 \mathrm{mg} / \mathrm{IM} . \mathrm{N}=11$.

2. Risperidone: dose $3 \mathrm{mg} /$ liquid. $\mathrm{N}=10$.

3. Olanzapine: dose $10 \mathrm{mg} / \mathrm{IM} . \mathrm{N}=11$.

4. Olanzapine: dose $10 \mathrm{mg} /$ velotab. $\mathrm{N}=10$.

Outcomes Specific behaviour - agitation: PANSS-EC*.

Notes * attempted to contact authors to ask for any usable data.

Lasic 2006

\begin{tabular}{ll}
\hline Methods & Allocation: randomised. \\
& Blindness: not stated. \\
& Duration: up to 3 months. \\
\hline Participants & $\begin{array}{l}\text { Diagnosis: ICD X diagnosis of acute exacerbation of schizophrenia or schizoaffective disorder, ma- } \\
\text { nia with psychotic features, acute paranoid reaction, or delusional disorders. }\end{array}$ \\
Age: $\geq 18$ years. & $\begin{array}{l}\text { Exclusion: "delirium, epilepsy, or mental retardation; intoxication or symptoms of withdrawal from } \\
\text { alcohol or other psychoactive substances; clinical laboratory values indicating serious medical ill- }\end{array}$
\end{tabular}


Lasic 2006 (Continued)

ness; treatment with any antipsychotic or benzodiazepine within 6 hours of screening; a history of neuroleptic malignant syndrome or known hypersensitivity to any of the trial medications; treatment with a depot antipsychotic within 1 treatment cycle of screening and use of disallowed medications".

Setting: Croatia (acute psychiatric inpatient ward).

Interventions $\quad \begin{aligned} & \text { 1. Haloperidol IM (dose not reported). } \\ & \text { 2. Risperidol liquid (dose not reported). }\end{aligned}$

\begin{tabular}{ll} 
Outcomes & Specific behaviour - agitation: BARS, PANSS agitation cluster. \\
& Mental state: PANSS. \\
& Global state: CGI-I. \\
& Adverse effects. \\
\hline Notes & $\begin{array}{l}\text { Conference abstract, full characteristics and outcome data not reported. Attempted to contact au- } \\
\text { thor. }\end{array}$
\end{tabular}

\section{NCT00859872}

\begin{tabular}{ll} 
Methods & Allocation: randomised. \\
& Blindness: single. \\
& Duration: 47 days. \\
\hline Participants & $\begin{array}{l}\text { Diagnosis: DSM-IV diagnosis of acute exacerbation of schizophrenia or schizoaffective disorder with } \\
\text { agitation. }\end{array}$
\end{tabular}

Age: range $18-45$ years.

Sex: males and females.

History: not stated.

Exclusion: pregnant or lactating women, serious medical illness, known sensitivity to study medication, treatment with a depot antipsychotic with 1 cycle of screening, use of disallowed medication, psychosis caused by "delirium, epilepsy, mental retardation and affective disorder; intoxication or symptoms of withdrawal from alcohol of other psychoactive substances."

Setting: China (psychiatric inpatient ward).

Interventions

1. Haloperidol: dose $5 \mathrm{mg}$ to $20 \mathrm{mg} / \mathrm{IM} /$ day.

2. Risperidone: dose $2 \mathrm{mg}$ to $6 \mathrm{mg} /$ oral/day + clonazepam: dose $4 \mathrm{mg}$ to $8 \mathrm{mg} /$ oral/day.
Specific behaviour - agitation: PANSS-EC.

Mental state: PANSS.

Notes

Protocol, full characteristics and outcome data not reported. Unable to establish contact details at this time.

BARS: Behavioural Activity Rating Scale.

CGI-I: Clinical Global Impression - Improvement.

DSM: Diagnostic and Statistical Manual of mental disorders. 
ICD: International Classification of Diseases.

IM: Intramuscular.

PANSS: Positive and Negative Syndrome Scale.

PANSS-EC: Positive and Negative Syndrome Scale - Excited Component.

\section{DATA AND ANALYSES}

\section{Comparison 1. RISPERIDONE vs OTHER ANTIPSYCHOTIC: a. HALOPERIDOL}

\begin{tabular}{|c|c|c|c|c|}
\hline Outcome or subgroup title & No. of studies & $\begin{array}{l}\text { No. of partici- } \\
\text { pants }\end{array}$ & Statistical method & Effect size \\
\hline $\begin{array}{l}1 \text { Specific behaviour: 1a. Agitation - Vari- } \\
\text { ous measures }\end{array}$ & 1 & & $\begin{array}{l}\text { Risk Ratio (M-H, Fixed, 95\% } \\
\mathrm{Cl} \text { ) }\end{array}$ & Subtotals only \\
\hline $\begin{array}{l}\text { 1.1 PANSS-PAS response up to } 24 \text { hours } \\
\text { ( } \geq 50 \% \text { reduction at PANSS-PAS score) }\end{array}$ & 1 & 124 & $\begin{array}{l}\text { Risk Ratio (M-H, Fixed, 95\% } \\
\mathrm{Cl})\end{array}$ & $1.04[0.86,1.26]$ \\
\hline $\begin{array}{l}2 \text { Specific behaviour: } 1 \text { b. Agitation - Av- } \\
\text { erage scores - i. up to } 2 \text { hours }\end{array}$ & 1 & & $\begin{array}{l}\text { Mean Difference (IV, Fixed, } \\
95 \% \mathrm{CI})\end{array}$ & Subtotals only \\
\hline $\begin{array}{l}\text { 2.1 Endpoint score (PANSS-PAS, high = } \\
\text { worse) }\end{array}$ & 1 & 28 & $\begin{array}{l}\text { Mean Difference (IV, Fixed, } \\
95 \% \mathrm{CI})\end{array}$ & $0.40[-4.42,5.22]$ \\
\hline $\begin{array}{l}3 \text { Specific behaviour: } 1 \mathrm{c} \text {. Agitation - Av- } \\
\text { erage scores - ii. up to } 24 \text { hours }\end{array}$ & 1 & & $\begin{array}{l}\text { Mean Difference (IV, Fixed, } \\
95 \% \mathrm{CI})\end{array}$ & Subtotals only \\
\hline $\begin{array}{l}\text { 3.1 Endpoint score (PANSS-PAS, high = } \\
\text { worse) }\end{array}$ & 1 & 28 & $\begin{array}{l}\text { Mean Difference (IV, Fixed, } \\
95 \% \mathrm{CI})\end{array}$ & $0.20[-3.96,4.36]$ \\
\hline $\begin{array}{l}4 \text { Specific behaviour: } 1 \mathrm{~d} \text {. Agitation - Av- } \\
\text { erage scores - iii. over } 24 \text { hours }\end{array}$ & 1 & & $\begin{array}{l}\text { Mean Difference (IV, Fixed, } \\
95 \% \mathrm{CI})\end{array}$ & Subtotals only \\
\hline $\begin{array}{l}\text { 4.1 Endpoint score at } 48 \text { hours (PANSS- } \\
\text { PAS, high = worse) }\end{array}$ & 1 & 28 & $\begin{array}{l}\text { Mean Difference (IV, Fixed, } \\
95 \% \mathrm{CI})\end{array}$ & $1.5[-1.36,4.36]$ \\
\hline $\begin{array}{l}\text { 4.2 Endpoint score at } 72 \text { hours (PANSS- } \\
\text { PAS, high = worse) }\end{array}$ & 1 & 28 & $\begin{array}{l}\text { Mean Difference (IV, Fixed, } \\
95 \% \mathrm{CI})\end{array}$ & $1.40[-1.62,4.42]$ \\
\hline $\begin{array}{l}\text { 4.3 Endpoint score at } 96 \text { hours (PANSS- } \\
\text { PAS, high = worse) }\end{array}$ & 1 & 28 & $\begin{array}{l}\text { Mean Difference (IV, Fixed, } \\
95 \% \mathrm{CI})\end{array}$ & $2.90[-0.34,6.14]$ \\
\hline $\begin{array}{l}5 \text { Global outcome: } 1 \text { a. General - Need for } \\
\text { additional measures }\end{array}$ & 2 & & $\begin{array}{l}\text { Risk Ratio (M-H, Fixed, 95\% } \\
\mathrm{Cl})\end{array}$ & Subtotals only \\
\hline $\begin{array}{l}5.1 \text { Need for benzodiazepine up to } 24 \\
\text { hours }\end{array}$ & 1 & 124 & $\begin{array}{l}\text { Risk Ratio (M-H, Fixed, 95\% } \\
\mathrm{Cl} \text { ) }\end{array}$ & $0.88[0.34,2.27]$ \\
\hline 5.2 Need for seclusion room & 1 & 28 & $\begin{array}{l}\text { Risk Ratio (M-H, Fixed, 95\% } \\
\mathrm{Cl} \text { ) }\end{array}$ & $0.33[0.01,7.55]$ \\
\hline 5.3 Use of restraints & 1 & 28 & $\begin{array}{l}\text { Risk Ratio (M-H, Fixed, 95\% } \\
\mathrm{Cl} \text { ) }\end{array}$ & $2.0[0.43,9.21]$ \\
\hline $\begin{array}{l}6 \text { Global outcome: } 1 \text { b. General - Need for } \\
\text { additional medication (skewed data) }\end{array}$ & & & Other data & No numeric data \\
\hline
\end{tabular}




\begin{tabular}{|c|c|c|c|c|}
\hline Outcome or subgroup title & No. of studies & $\begin{array}{l}\text { No. of partici- } \\
\text { pants }\end{array}$ & Statistical method & Effect size \\
\hline 7 Adverse effects: 1 . General & 1 & & $\begin{array}{l}\text { Risk Ratio (M-H, Fixed, 95\% } \\
\mathrm{Cl})\end{array}$ & Subtotals only \\
\hline 7.1 One or more AEs up to 24 hours & 1 & 124 & $\begin{array}{l}\text { Risk Ratio (M-H, Fixed, 95\% } \\
\text { Cl) }\end{array}$ & $0.94[0.54,1.66]$ \\
\hline $\begin{array}{l}8 \text { Adverse effects: } 2 a \text {. Specific - Arousal } \\
\text { level }\end{array}$ & 1 & & $\begin{array}{l}\text { Risk Ratio (M-H, Fixed, 95\% } \\
\mathrm{Cl})\end{array}$ & Subtotals only \\
\hline 8.1 Insomnia up to 24 hours & 1 & 124 & $\begin{array}{l}\text { Risk Ratio (M-H, Fixed, 95\% } \\
\mathrm{Cl})\end{array}$ & $\begin{array}{l}13.0[0.75 \\
225.90]\end{array}$ \\
\hline 8.2 Somnolence up to 24 hours & 1 & 124 & $\begin{array}{l}\text { Risk Ratio (M-H, Fixed, 95\% } \\
\mathrm{Cl})\end{array}$ & $1.29[0.51,3.24]$ \\
\hline $\begin{array}{l}9 \text { Adverse effects: } 2 \text { b. Specific - Move- } \\
\text { ment disorder - i. Various }\end{array}$ & 1 & & $\begin{array}{l}\text { Risk Ratio (M-H, Fixed, 95\% } \\
\mathrm{Cl})\end{array}$ & Subtotals only \\
\hline 9.1 EPS up to 24 hours & 1 & 124 & $\begin{array}{l}\text { Risk Ratio (M-H, Fixed, 95\% } \\
\mathrm{Cl})\end{array}$ & $0.63[0.22,1.80]$ \\
\hline $\begin{array}{l}10 \text { Adverse effects: } 2 b \text {. Specific - Move- } \\
\text { ment disorder - ii. Need for biperiden }\end{array}$ & & & Other data & No numeric data \\
\hline $\begin{array}{l}11 \text { Adverse effects: } 2 b \text {. Specific - Move- } \\
\text { ment disorder - iii. Average scores } \\
\text { (skewed data) }\end{array}$ & 1 & & $\begin{array}{l}\text { Mean Difference (IV, Fixed, } \\
95 \% \mathrm{CI})\end{array}$ & Subtotals only \\
\hline $\begin{array}{l}11.1 \text { Endpoint scores at } 96 \text { hours (AIMS, } \\
\text { high = worse) }\end{array}$ & 1 & 28 & $\begin{array}{l}\text { Mean Difference (IV, Fixed, } \\
95 \% \mathrm{CI})\end{array}$ & $0.0[0.0,0.0]$ \\
\hline $\begin{array}{l}\text { 11.2 Endpoint scores at } 96 \text { hours (BARS, } \\
\text { high = worse) }\end{array}$ & 1 & 28 & $\begin{array}{l}\text { Mean Difference (IV, Fixed, } \\
95 \% \mathrm{CI})\end{array}$ & $-0.60[-1.56,0.36]$ \\
\hline $\begin{array}{l}11.3 \text { Endpoint scores at } 96 \text { hours (SAS, } \\
\text { high = worse) }\end{array}$ & 1 & 28 & $\begin{array}{l}\text { Mean Difference (IV, Fixed, } \\
95 \% \mathrm{CI})\end{array}$ & $-0.40[-1.00,2.20]$ \\
\hline $\begin{array}{l}12 \text { Adverse effects: } 2 c \text {. Specific - Miscel- } \\
\text { laneous }\end{array}$ & 1 & & $\begin{array}{l}\text { Risk Ratio (M-H, Fixed, 95\% } \\
\text { Cl) }\end{array}$ & Subtotals only \\
\hline 12.1 Headache up to 24 hours & 1 & 124 & $\begin{array}{l}\text { Risk Ratio (M-H, Fixed, 95\% } \\
\mathrm{Cl})\end{array}$ & $0.75[0.18,3.21]$ \\
\hline 12.2 Dizziness up to 24 hours & 1 & 124 & $\begin{array}{l}\text { Risk Ratio (M-H, Fixed, 95\% } \\
\mathrm{Cl})\end{array}$ & $1.0[0.26,3.82]$ \\
\hline 13 Leaving the study early & 2 & & $\begin{array}{l}\text { Risk Ratio (M-H, Fixed, 95\% } \\
\text { Cl) }\end{array}$ & Subtotals only \\
\hline 13.1 For any reason & 2 & 152 & $\begin{array}{l}\text { Risk Ratio (M-H, Fixed, 95\% } \\
\text { Cl) }\end{array}$ & $2.2[0.51,9.48]$ \\
\hline 13.2 Due to adverse effects & 1 & 124 & $\begin{array}{l}\text { Risk Ratio (M-H, Fixed, 95\% } \\
\text { Cl) }\end{array}$ & $0.5[0.05,5.37]$ \\
\hline
\end{tabular}




\begin{tabular}{lllll}
\hline Outcome or subgroup title & No. of studies & $\begin{array}{l}\text { No. of partici- } \\
\text { pants }\end{array}$ & Statistical method & Effect size \\
\hline 13.3 Lack of efficacy & 1 & 28 & $\begin{array}{l}\text { Risk Ratio (M-H, Fixed, 95\% } \\
\text { Cl) }\end{array}$ & $9.0[0.53,152.93]$ \\
\hline
\end{tabular}

Analysis 1.1. Comparison 1 RISPERIDONE vs OTHER ANTIPSYCHOTIC: a. HALOPERIDOL, Outcome 1 Specific behaviour: 1a. Agitation - Various measures.

\begin{tabular}{|c|c|c|c|c|c|}
\hline Study or subgroup & $\begin{array}{l}\text { Risperidone } \\
\mathrm{n} / \mathrm{N}\end{array}$ & $\begin{array}{l}\text { Haloperidol } \\
\mathrm{n} / \mathrm{N}\end{array}$ & $\begin{array}{c}\text { Risk Ratio } \\
\text { M-H, Fixed, } 95 \% \mathrm{Cl}\end{array}$ & Weight & $\begin{array}{c}\text { Risk Ratio } \\
\text { M-H, Fixed, } 95 \% \mathrm{Cl}\end{array}$ \\
\hline \multicolumn{6}{|c|}{$\begin{array}{l}\text { 1.1.1 PANSS-PAS response up to } 24 \text { hours ( } \geq 50 \% \text { reduction at PANSS- } \\
\text { PAS score) }\end{array}$} \\
\hline $\operatorname{Lim} 2010$ & $49 / 62$ & $47 / 62$ & 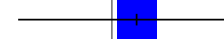 & $100 \%$ & $1.04[0.86,1.26]$ \\
\hline Subtotal $(95 \% \mathrm{Cl})$ & 62 & 62 & & $100 \%$ & $1.04[0.86,1.26]$ \\
\hline \multicolumn{6}{|c|}{ Total events: 49 (Risperidone), 47 (Haloperidol) } \\
\hline \multicolumn{6}{|c|}{ Heterogeneity: Not applicable } \\
\hline Test for overall effect & & & & & \\
\hline
\end{tabular}

Analysis 1.2. Comparison 1 RISPERIDONE vs OTHER ANTIPSYCHOTIC: a. HALOPERIDOL, Outcome 2 Specific behaviour: 1b. Agitation - Average scores - $i$. up to 2 hours.

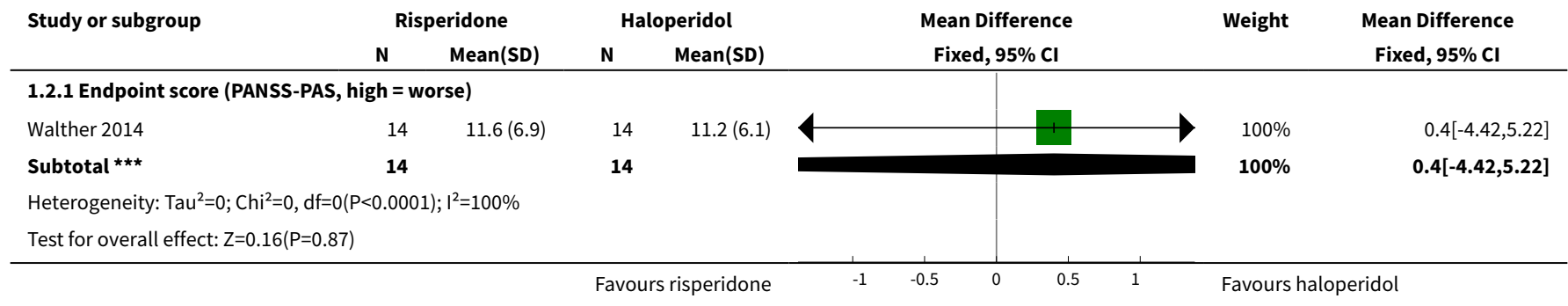

Analysis 1.3. Comparison 1 RISPERIDONE vs OTHER ANTIPSYCHOTIC: a. HALOPERIDOL, Outcome 3 Specific behaviour: 1c. Agitation - Average scores - ii. up to 24 hours.

\begin{tabular}{|c|c|c|c|c|c|c|c|}
\hline \multirow[t]{2}{*}{ Study or subgroup } & \multicolumn{2}{|c|}{ Risperidone } & \multicolumn{2}{|c|}{ Haloperidol } & \multirow{2}{*}{$\begin{array}{c}\text { Mean Difference } \\
\text { Fixed, } 95 \% \mathrm{Cl} \\
\end{array}$} & \multirow[t]{2}{*}{ Weight } & \multirow{2}{*}{$\begin{array}{c}\text { Mean Difference } \\
\text { Fixed, } 95 \% \mathrm{Cl}\end{array}$} \\
\hline & $\mathbf{N}$ & Mean(SD) & $\mathbf{N}$ & Mean(SD) & & & \\
\hline \multicolumn{8}{|c|}{ 1.3.1 Endpoint score (PANSS-PAS, high = worse) } \\
\hline Walther 2014 & 14 & $14.4(5.5)$ & 14 & $14.2(5.8)$ & & $100 \%$ & $0.2[-3.96,4.36]$ \\
\hline Subtotal $* \star \star$ & 14 & & 14 & & & $100 \%$ & $0.2[-3.96,4.36]$ \\
\hline \multicolumn{8}{|c|}{ Heterogeneity: $\mathrm{Tau}^{2}=0 ; \mathrm{Chi}^{2}=0, \mathrm{df}=0(\mathrm{P}<0.0001) ; \mathrm{I}^{2}=100 \%$} \\
\hline \multicolumn{8}{|c|}{ Test for overall effect: $Z=0.09(P=0.92)$} \\
\hline
\end{tabular}


Analysis 1.4. Comparison 1 RISPERIDONE vs OTHER ANTIPSYCHOTIC: a. HALOPERIDOL, Outcome 4 Specific behaviour: 1d. Agitation - Average scores - iii. over 24 hours.

\begin{tabular}{|c|c|c|c|c|c|c|c|}
\hline \multirow[t]{2}{*}{ Study or subgroup } & \multicolumn{2}{|c|}{ Risperidone } & \multicolumn{2}{|c|}{ Haloperidol } & \multirow{2}{*}{$\begin{array}{c}\text { Mean Difference } \\
\text { Fixed, 95\% Cl }\end{array}$} & \multirow[t]{2}{*}{ Weight } & \multirow{2}{*}{$\begin{array}{c}\text { Mean Difference } \\
\text { Fixed, } 95 \% \mathrm{Cl}\end{array}$} \\
\hline & $\mathbf{N}$ & Mean(SD) & $\mathbf{N}$ & $\operatorname{Mean}(\mathrm{SD})$ & & & \\
\hline \multicolumn{8}{|c|}{ 1.4.1 Endpoint score at 48 hours (PANSS-PAS, high = worse) } \\
\hline Walther 2014 & 14 & $11.9(4.6)$ & 14 & $10.4(2.9)$ & & $100 \%$ & $1.5[-1.36,4.36]$ \\
\hline Subtotal ${ }^{\star \star \star}$ & 14 & & 14 & & & $100 \%$ & $1.5[-1.36,4.36]$ \\
\hline \multicolumn{8}{|c|}{ Heterogeneity: Not applicable } \\
\hline \multicolumn{8}{|c|}{ Test for overall effect: $Z=1.03(P=0.3)$} \\
\hline \multicolumn{8}{|c|}{ 1.4.2 Endpoint score at 72 hours (PANSS-PAS, high = worse) } \\
\hline Walther 2014 & 14 & $11.2(5.2)$ & 14 & $9.8(2.6)$ & & $100 \%$ & $1.4[-1.62,4.42]$ \\
\hline 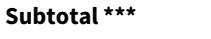 & 14 & & 14 & & & $100 \%$ & $1.4[-1.62,4.42]$ \\
\hline \multicolumn{8}{|c|}{ Heterogeneity: Not applicable } \\
\hline \multicolumn{8}{|c|}{ Test for overall effect: $Z=0.91(P=0.36)$} \\
\hline Walther 2014 & 14 & $12.4(4.8)$ & 14 & $9.5(4)$ & & $100 \%$ & $2.9[-0.34,6.14]$ \\
\hline Subtotal $* \star \star$ & 14 & & 14 & & & $100 \%$ & $2.9[-0.34,6.14]$ \\
\hline \multicolumn{8}{|c|}{ Heterogeneity: $\mathrm{Tau}^{2}=0 ; \mathrm{Chi}^{2}=0, \mathrm{df}=0(\mathrm{P}<0.0001) ; \mathrm{I}^{2}=100 \%$} \\
\hline \multicolumn{8}{|c|}{ Test for overall effect: $Z=1.75(P=0.08)$} \\
\hline Test for subgroup dif & $54, \mathrm{df}=$ & $P=0.76), I^{2}=0$ & & & & & \\
\hline
\end{tabular}

Analysis 1.5. Comparison 1 RISPERIDONE vs OTHER ANTIPSYCHOTIC: a. HALOPERIDOL, Outcome 5 Global outcome: 1a. General - Need for additional measures.

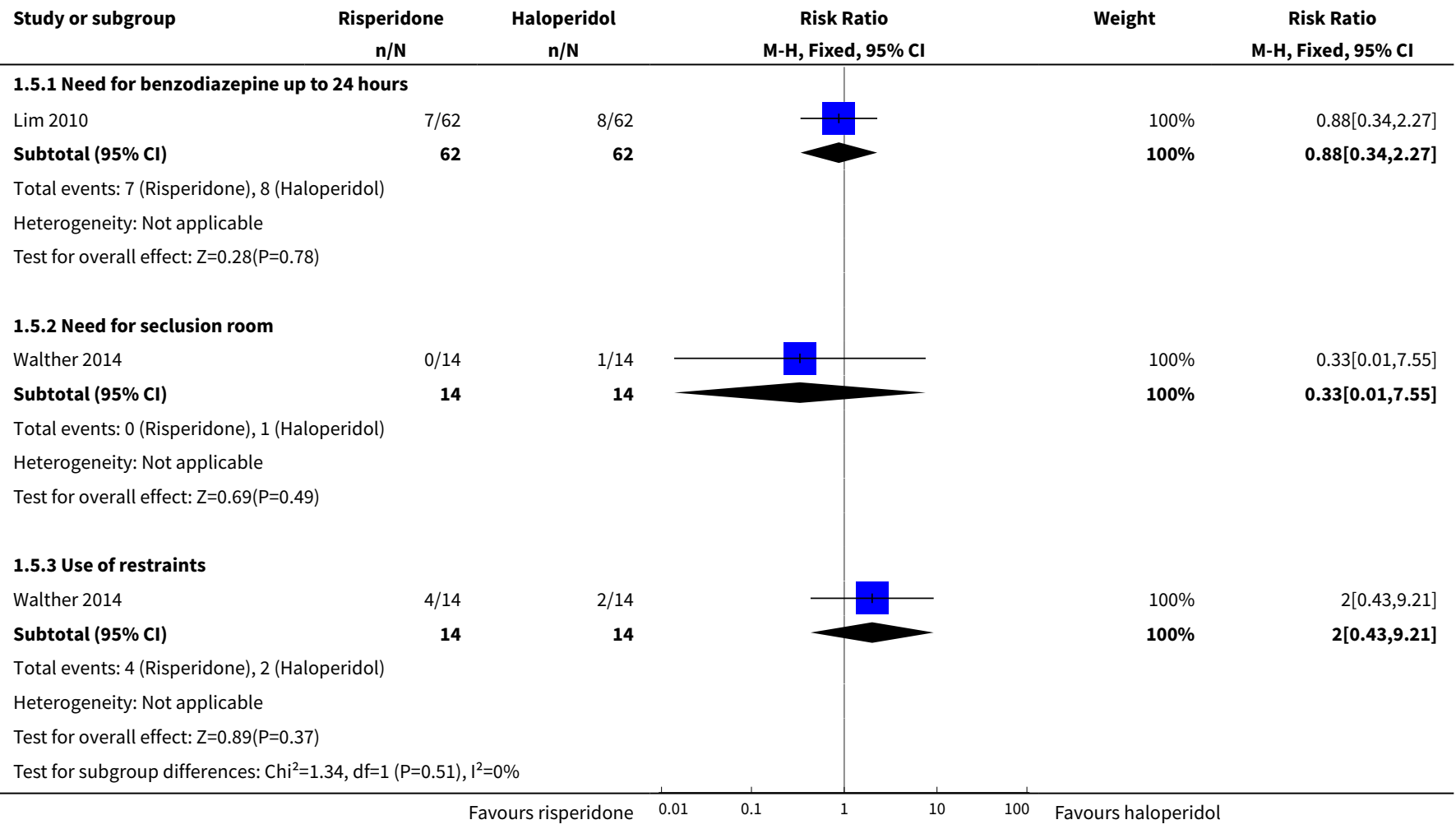


Analysis 1.6. Comparison 1 RISPERIDONE vs OTHER ANTIPSYCHOTIC: a. HALOPERIDOL, Outcome 6 Global outcome: 1 b. General - Need for additional medication (skewed data).

Global outcome: 1b. General - Need for additional medication (skewed data)

Study Intervention

Mean

SD

(total $\mathrm{mg}$ of diazepam

needed during the en-

tire study per patient)

\begin{tabular}{lllll}
\hline Walther 2014 & Risperidone & 92.9 & 86.8 & \\
\hline Walther 2014 & Haloperidol & 71.1 & 70.4 & 14 \\
\hline
\end{tabular}

Analysis 1.7. Comparison 1 RISPERIDONE vs OTHER ANTIPSYCHOTIC:

a. HALOPERIDOL, Outcome 7 Adverse effects: 1 . General.

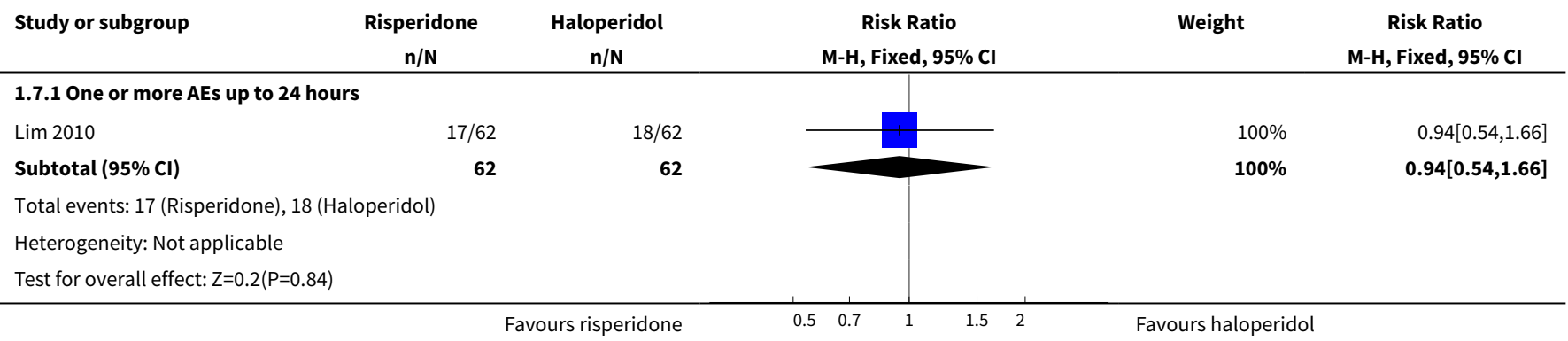

Analysis 1.8. Comparison 1 RISPERIDONE vs OTHER ANTIPSYCHOTIC: a.

HALOPERIDOL, Outcome 8 Adverse effects: 2a. Specific - Arousal level.

\begin{tabular}{|c|c|c|c|c|c|}
\hline Study or subgroup & $\begin{array}{c}\text { Risperidone } \\
n / N\end{array}$ & $\begin{array}{c}\text { Haloperidol } \\
n / N\end{array}$ & $\begin{array}{c}\text { Risk Ratio } \\
\text { M-H, Fixed, 95\% Cl }\end{array}$ & Weight & $\begin{array}{c}\text { Risk Ratio } \\
\text { M-H, Fixed, } 95 \% \mathrm{Cl}\end{array}$ \\
\hline \multicolumn{6}{|c|}{ 1.8.1 Insomnia up to 24 hours } \\
\hline Lim 2010 & $6 / 62$ & $0 / 62$ & & $100 \%$ & $13[0.75,225.9]$ \\
\hline Subtotal $(95 \% \mathrm{Cl})$ & 62 & 62 & & $100 \%$ & $13[0.75,225.9]$ \\
\hline \multicolumn{6}{|c|}{ Total events: 6 (Risperidone), 0 (Haloperidol) } \\
\hline \multicolumn{6}{|c|}{ Heterogeneity: Not applicable } \\
\hline \multicolumn{6}{|c|}{ 1.8.2 Somnolence up to 24 hours } \\
\hline Lim 2010 & $9 / 62$ & $7 / 62$ & - & $100 \%$ & $1.29[0.51,3.24]$ \\
\hline Subtotal $(95 \% \mathrm{Cl})$ & 62 & 62 & & $100 \%$ & $1.29[0.51,3.24]$ \\
\hline \multicolumn{6}{|c|}{ Total events: 9 (Risperidone), 7 (Haloperidol) } \\
\hline \multicolumn{6}{|c|}{ Heterogeneity: Not applicable } \\
\hline \multicolumn{6}{|c|}{ Test for subgroup differences: $\mathrm{Chi}^{2}=2.28, \mathrm{df}=1(\mathrm{P}=0.13), \mathrm{I}^{2}=56.21 \%$} \\
\hline
\end{tabular}


Analysis 1.9. Comparison 1 RISPERIDONE vs OTHER ANTIPSYCHOTIC: a. HALOPERIDOL, Outcome 9 Adverse effects: 2 b. Specific - Movement disorder - i. Various.

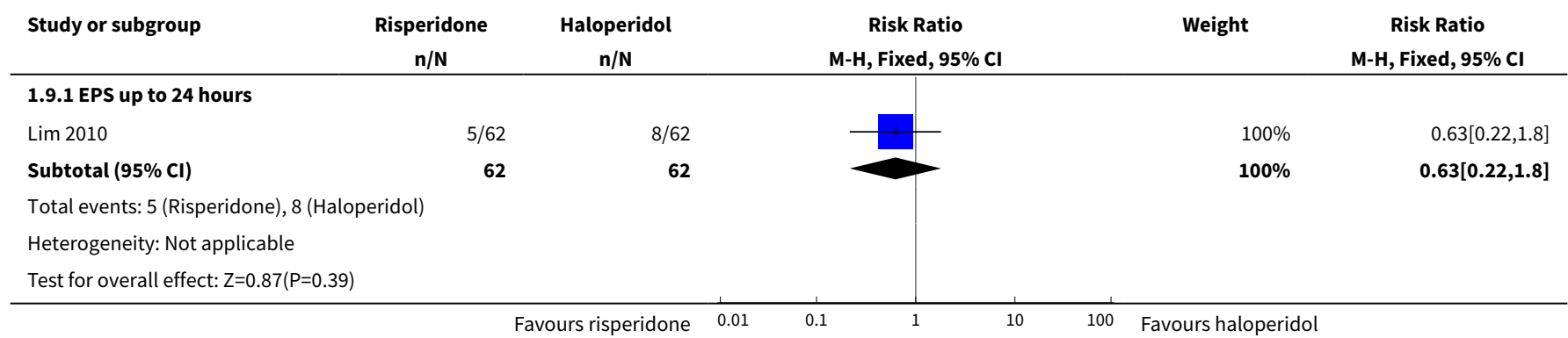

Analysis 1.10. Comparison 1 RISPERIDONE vs OTHER ANTIPSYCHOTIC: a. HALOPERIDOL, Outcome 10 Adverse effects: 2 b. Specific - Movement disorder - ii. Need for biperiden.

Adverse effects: 2 b. Specific - Movement disorder - ii. Need for biperiden

Study Intervention

$$
\text { Mean }
$$

(total $\mathrm{mg}$ of biperiden

needed during the en-

tire study per patient)

\begin{tabular}{lllll}
\hline Walther 2014 & Risperidone & 4.1 & 7.3 & 14 \\
\hline Walther 2014 & Haloperidol & 5.2 & 8.3 & 14 \\
\hline
\end{tabular}

Analysis 1.11. Comparison 1 RISPERIDONE vs OTHER ANTIPSYCHOTIC: a. HALOPERIDOL, Outcome 11 Adverse effects: 2 b. Specific - Movement disorder - iii. Average scores (skewed data).

\begin{tabular}{|c|c|c|c|c|c|c|c|}
\hline \multirow[t]{2}{*}{ Study or subgroup } & \multicolumn{2}{|c|}{ Risperidone } & \multicolumn{2}{|c|}{ Haloperidol } & \multirow{2}{*}{$\begin{array}{c}\text { Mean Difference } \\
\text { Fixed, } 95 \% \mathrm{Cl}\end{array}$} & \multirow[t]{2}{*}{ Weight } & \multirow{2}{*}{$\begin{array}{c}\text { Mean Difference } \\
\text { Fixed, } 95 \% \mathrm{Cl}\end{array}$} \\
\hline & $\mathbf{N}$ & Mean(SD) & $\mathbf{N}$ & $\operatorname{Mean}(S D)$ & & & \\
\hline \multicolumn{8}{|c|}{ 1.11.1 Endpoint scores at 96 hours (AIMS, high = worse) } \\
\hline Walther 2014 & 14 & $7(0)$ & 14 & $7.6(1.6)$ & & & Not estimable \\
\hline 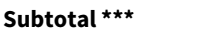 & 14 & & 14 & & & & Not estimable \\
\hline \multicolumn{8}{|c|}{ Heterogeneity: Not applicable } \\
\hline \multicolumn{8}{|c|}{ Test for overall effect: Not applicable } \\
\hline \multicolumn{8}{|c|}{ 1.11.2 Endpoint scores at 96 hours (BARS, high = worse) } \\
\hline Walther 2014 & 14 & $0.3(1.1)$ & 14 & $0.9(1.5)$ & - & $100 \%$ & $-0.6[-1.56,0.36]$ \\
\hline 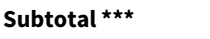 & 14 & & 14 & & & $100 \%$ & $-0.6[-1.56,0.36]$ \\
\hline \multicolumn{8}{|c|}{ Heterogeneity: Not applicable } \\
\hline \multicolumn{8}{|c|}{ Test for overall effect: $Z=1.23(P=0.22)$} \\
\hline \multicolumn{8}{|c|}{ 1.11.3 Endpoint scores at 96 hours (SAS, high = worse) } \\
\hline Walther 2014 & 14 & $3(3.7)$ & 14 & $3.4(3.3)$ & & $100 \%$ & $-0.4[-3,2.2]$ \\
\hline Subtotal $\star \star \star$ & 14 & & 14 & & & $100 \%$ & $-0.4[-3,2.2]$ \\
\hline \multicolumn{8}{|c|}{ Heterogeneity: Not applicable } \\
\hline \multicolumn{8}{|c|}{ Test for overall effect: $Z=0.3(P=0.76)$} \\
\hline Test for subgroup dif & $2, \mathrm{df}=$ & $P=0.89), I^{2}=0 \%$ & & & & & \\
\hline
\end{tabular}


Analysis 1.12. Comparison 1 RISPERIDONE vs OTHER ANTIPSYCHOTIC: a.

HALOPERIDOL, Outcome 12 Adverse effects: 2c. Specific - Miscellaneous.

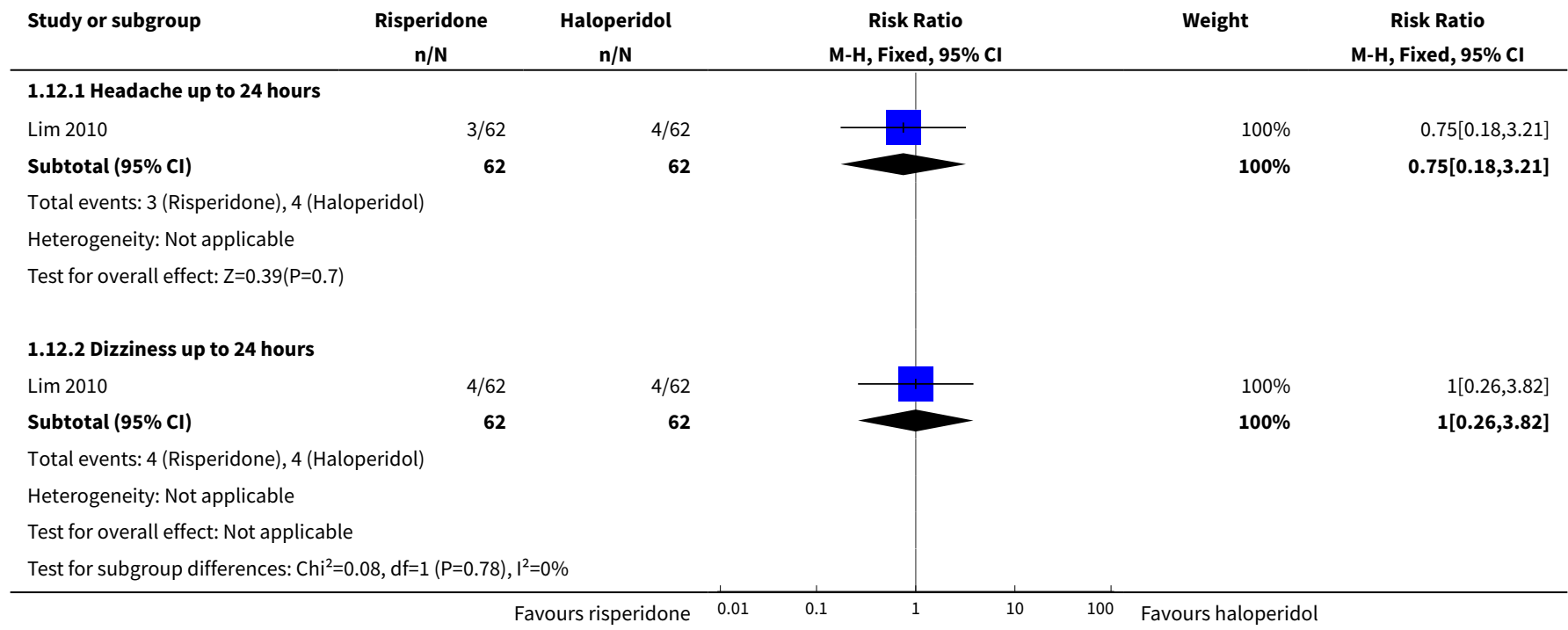

Analysis 1.13. Comparison 1 RISPERIDONE vS OTHER ANTIPSYCHOTIC:

a. HALOPERIDOL, Outcome 13 Leaving the study early.

\begin{tabular}{|c|c|c|c|c|c|}
\hline \multirow{2}{*}{$\begin{array}{l}\text { Study or subgroup } \\
\text { 1.13.1 For any reaso }\end{array}$} & \multirow[t]{2}{*}{$\begin{array}{c}\text { Risperidone } \\
n / N\end{array}$} & \multirow[t]{2}{*}{$\begin{array}{c}\text { Haloperidol } \\
\mathrm{n} / \mathrm{N} \\
\end{array}$} & \multirow[t]{2}{*}{$\begin{array}{c}\text { Risk Ratio } \\
\text { M-H, Fixed, 95\% Cl }\end{array}$} & \multirow[t]{2}{*}{ Weight } & \multirow[t]{2}{*}{$\begin{array}{c}\text { Risk Ratio } \\
\text { M-H, Fixed, } 95 \% \mathrm{Cl} \\
\end{array}$} \\
\hline & & & & & \\
\hline $\operatorname{Lim} 2010$ & $1 / 62$ & $2 / 62$ & & $80 \%$ & $0.5[0.05,5.37]$ \\
\hline Walther 2014 & $4 / 14$ & $0 / 14$ & & $20 \%$ & $9[0.53,152.93]$ \\
\hline Subtotal $(95 \% \mathrm{Cl})$ & 76 & 76 & & $100 \%$ & $2.2[0.51,9.48]$ \\
\hline \multicolumn{6}{|c|}{ Total events: 5 (Risperidone), 2 (Haloperidol) } \\
\hline \multicolumn{6}{|c|}{ Test for overall effect: $Z=1.06(P=0.29)$} \\
\hline \multicolumn{6}{|c|}{ 1.13.2 Due to adverse effects } \\
\hline Lim 2010 & $1 / 62$ & $2 / 62$ & & $100 \%$ & $0.5[0.05,5.37]$ \\
\hline Subtotal $(95 \% \mathrm{Cl})$ & 62 & 62 & & $100 \%$ & $0.5[0.05,5.37]$ \\
\hline \multicolumn{6}{|c|}{ Total events: 1 (Risperidone), 2 (Haloperidol) } \\
\hline \multicolumn{6}{|c|}{ Test for overall effect: $Z=0.57(P=0.57)$} \\
\hline \multicolumn{6}{|c|}{ 1.13.3 Lack of efficacy } \\
\hline Walther 2014 & $4 / 14$ & $0 / 14$ & & $100 \%$ & $9[0.53,152.93]$ \\
\hline Subtotal $(95 \% \mathrm{Cl})$ & 14 & 14 & & $100 \%$ & $9[0.53,152.93]$ \\
\hline \multicolumn{6}{|c|}{ Total events: 4 (Risperidone), 0 (Haloperidol) } \\
\hline \multicolumn{6}{|c|}{ Heterogeneity: Not applicable } \\
\hline \multicolumn{6}{|c|}{ Test for overall effect: $Z=1.52(P=0.13)$} \\
\hline Test for subgroup di & $41, \mathrm{df}=1(\mathrm{P}=0.3), \mathrm{I}$ & $.94 \%$ & & & \\
\hline
\end{tabular}


Comparison 2. RISPERIDONE vS OTHER ANTIPSYCHOTIC: b. OLANZAPINE

\begin{tabular}{|c|c|c|c|c|}
\hline Outcome or subgroup title & No. of studies & $\begin{array}{l}\text { No. of partici- } \\
\text { pants }\end{array}$ & Statistical method & Effect size \\
\hline $\begin{array}{l}1 \text { Specific behaviour: } 1 \text {. Agitation - Aver- } \\
\text { age scores - i. Up to } 2 \text { hours }\end{array}$ & 1 & & $\begin{array}{l}\text { Mean Difference (IV, Fixed, } \\
95 \% \mathrm{Cl})\end{array}$ & Subtotals only \\
\hline $\begin{array}{l}\text { 1.1 Endpoint score (PANSS-PAS, high = } \\
\text { worse) }\end{array}$ & 1 & 29 & $\begin{array}{l}\text { Mean Difference (IV, Fixed, } \\
95 \% \mathrm{CI})\end{array}$ & $2.5[-2.46,7.46]$ \\
\hline $\begin{array}{l}2 \text { Specific behaviour: } 1 \text {. Agitation - Aver- } \\
\text { age scores - ii. Up to } 24 \text { hours }\end{array}$ & 1 & & $\begin{array}{l}\text { Mean Difference (IV, Fixed, } \\
95 \% \mathrm{CI})\end{array}$ & Subtotals only \\
\hline $\begin{array}{l}2.1 \text { Endpoint score (PANSS-PAS, high = } \\
\text { worse) }\end{array}$ & 1 & 29 & $\begin{array}{l}\text { Mean Difference (IV, Fixed, } \\
95 \% \mathrm{CI})\end{array}$ & $0.90[-3.40,5.20]$ \\
\hline $\begin{array}{l}3 \text { Specific behaviour: } 1 \text {. Agitation - Aver- } \\
\text { age scores - iii. over } 24 \text { hours }\end{array}$ & 1 & & $\begin{array}{l}\text { Mean Difference (IV, Fixed, } \\
95 \% \mathrm{CI})\end{array}$ & Subtotals only \\
\hline $\begin{array}{l}\text { 3.1 Endpoint score at } 48 \text { hours (PANSS- } \\
\text { PAS, high = worse) }\end{array}$ & 1 & 29 & $\begin{array}{l}\text { Mean Difference (IV, Fixed, } \\
95 \% \mathrm{Cl})\end{array}$ & $-1.20[-5.15,2.75]$ \\
\hline $\begin{array}{l}\text { 3.2 Endpoint score at } 72 \text { hours (PANSS- } \\
\text { PAS, high=worse) }\end{array}$ & 1 & 29 & $\begin{array}{l}\text { Mean Difference (IV, Fixed, } \\
95 \% \mathrm{CI})\end{array}$ & $-0.30[-4.47,3.87]$ \\
\hline $\begin{array}{l}\text { 3.3 Endpoint score at } 96 \text { hours (PANSS- } \\
\text { PAS, high = worse) }\end{array}$ & 1 & 29 & $\begin{array}{l}\text { Mean Difference (IV, Fixed, } \\
95 \% \mathrm{CI})\end{array}$ & $2.10[-1.41,5.61]$ \\
\hline $\begin{array}{l}4 \text { Global outcome: 1a. General - Need for } \\
\text { additional measures }\end{array}$ & 1 & & $\begin{array}{l}\text { Risk Ratio (M-H, Fixed, } \\
95 \% \mathrm{Cl})\end{array}$ & Subtotals only \\
\hline 4.1 Need for seclusion room & 1 & 29 & $\begin{array}{l}\text { Risk Ratio (M-H, Fixed, } \\
95 \% \mathrm{Cl})\end{array}$ & $0.36[0.02,8.07]$ \\
\hline 4.2 Use of restraints & 1 & 29 & $\begin{array}{l}\text { Risk Ratio (M-H, Fixed, } \\
95 \% \mathrm{Cl})\end{array}$ & $1.43[0.39,5.28]$ \\
\hline $\begin{array}{l}5 \text { Global outcome: } 1 \text { b. General - Need for } \\
\text { additional medication (skewed data) }\end{array}$ & & & Other data & No numeric data \\
\hline $\begin{array}{l}6 \text { Adverse effects: 1a. Specific - Movement } \\
\text { disorder - i. Meed for biperiden }\end{array}$ & & & Other data & No numeric data \\
\hline $\begin{array}{l}7 \text { Adverse effects: 1b. Specific - Movement } \\
\text { disorder - ii. Average scores (skewed data) }\end{array}$ & 1 & & $\begin{array}{l}\text { Mean Difference (IV, Fixed, } \\
95 \% \mathrm{CI} \text { ) }\end{array}$ & Subtotals only \\
\hline 7.1 Endpoint score (BARS, high = worse) & 1 & 29 & $\begin{array}{l}\text { Mean Difference (IV, Fixed, } \\
95 \% \mathrm{CI})\end{array}$ & $0.20[-0.43,0.83]$ \\
\hline 7.2 Endpoint score (SAS, high = worse) & 1 & 29 & $\begin{array}{l}\text { Mean Difference (IV, Fixed, } \\
95 \% \mathrm{Cl})\end{array}$ & $1.80[-0.63,4.23]$ \\
\hline 8 Leaving the study early & 1 & & $\begin{array}{l}\text { Risk Ratio (M-H, Fixed, } \\
95 \% \mathrm{Cl})\end{array}$ & Subtotals only \\
\hline 8.1 Lack of efficacy & 1 & 29 & $\begin{array}{l}\text { Risk Ratio (M-H, Fixed, } \\
95 \% \mathrm{Cl})\end{array}$ & $2.14[0.46,9.93]$ \\
\hline
\end{tabular}


Analysis 2.1. Comparison 2 RISPERIDONE vs OTHER ANTIPSYCHOTIC: b. OLANZAPINE, Outcome 1 Specific behaviour: 1. Agitation - Average scores - i. Up to 2 hours.

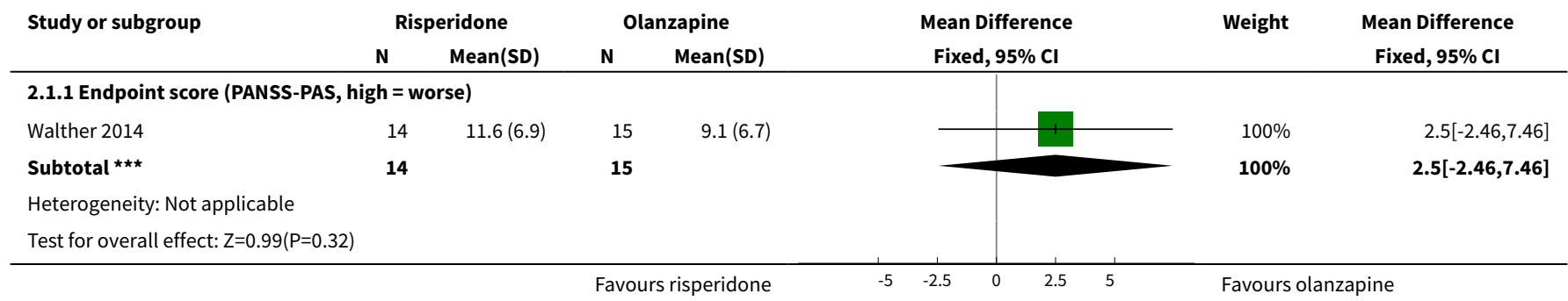

Analysis 2.2. Comparison 2 RISPERIDONE vs OTHER ANTIPSYCHOTIC: b. OLANZAPINE, Outcome 2 Specific behaviour: 1. Agitation - Average scores - ii. Up to 24 hours.

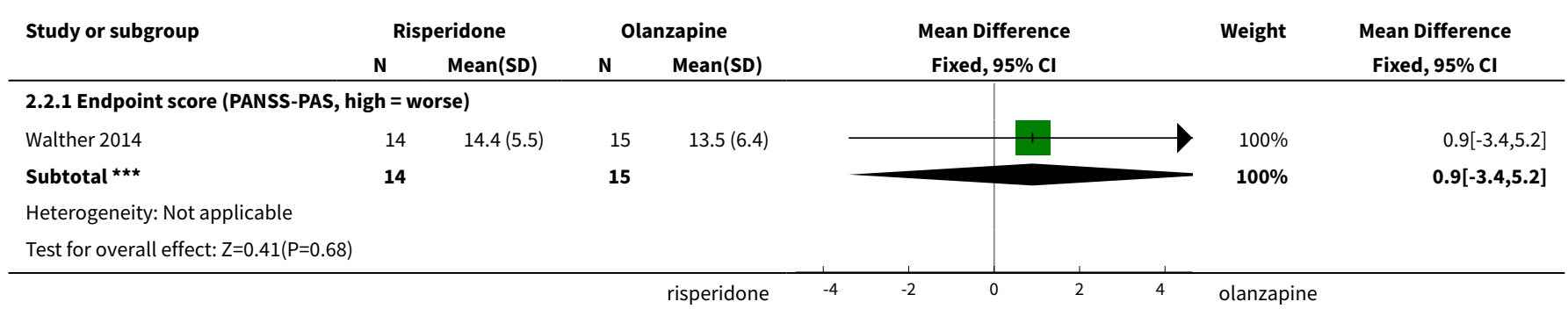

Analysis 2.3. Comparison 2 RISPERIDONE vs OTHER ANTIPSYCHOTIC: b. OLANZAPINE, Outcome 3 Specific behaviour: 1. Agitation - Average scores - iii. over 24 hours.

\begin{tabular}{|c|c|c|c|c|c|c|c|}
\hline \multirow[t]{2}{*}{ Study or subgroup } & \multicolumn{2}{|c|}{ Risperidone } & \multicolumn{2}{|c|}{ Olanzapine } & \multirow{2}{*}{$\begin{array}{c}\text { Mean Difference } \\
\text { Fixed, } 95 \% \mathrm{Cl}\end{array}$} & \multirow[t]{2}{*}{ Weight } & \multirow{2}{*}{$\begin{array}{c}\text { Mean Difference } \\
\text { Fixed, } 95 \% \mathrm{Cl}\end{array}$} \\
\hline & $\mathbf{N}$ & Mean(SD) & $\mathbf{N}$ & $\operatorname{Mean}(S D)$ & & & \\
\hline \multicolumn{8}{|c|}{ 2.3.1 Endpoint score at 48 hours (PANSS-PAS, high = worse) } \\
\hline Walther 2014 & 14 & $11.9(4.6)$ & 15 & $13.1(6.2)$ & & $100 \%$ & $-1.2[-5.15,2.75]$ \\
\hline 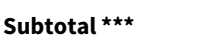 & 14 & & 15 & & & $100 \%$ & $-1.2[-5.15,2.75]$ \\
\hline \multicolumn{8}{|c|}{ Heterogeneity: Not applicable } \\
\hline \multicolumn{8}{|c|}{ Test for overall effect: $\mathrm{Z}=0.6(\mathrm{P}=0.55)$} \\
\hline \multicolumn{8}{|c|}{ 2.3.2 Endpoint score at 72 hours (PANSS-PAS, high=worse) } \\
\hline Walther 2014 & 14 & $11.2(5.2)$ & 15 & $11.5(6.3)$ & & $100 \%$ & $-0.3[-4.47,3.87]$ \\
\hline 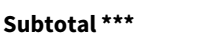 & 14 & & 15 & & & $100 \%$ & $-0.3[-4.47,3.87]$ \\
\hline \multicolumn{8}{|c|}{ Heterogeneity: Not applicable } \\
\hline \multicolumn{8}{|c|}{ Test for overall effect: $Z=0.14(P=0.89)$} \\
\hline \multicolumn{8}{|c|}{ 2.3.3 Endpoint score at 96 hours (PANSS-PAS, high = worse) } \\
\hline Walther 2014 & 14 & $12.4(4.8)$ & 15 & $10.3(4.9)$ & & $100 \%$ & $2.1[-1.41,5.61]$ \\
\hline Subtotal $\star \star \star ~$ & 14 & & 15 & & & $100 \%$ & $2.1[-1.41,5.61]$ \\
\hline \multicolumn{8}{|c|}{ Heterogeneity: Not applicable } \\
\hline \multicolumn{8}{|c|}{ Test for overall effect: $Z=1.17(P=0.24)$} \\
\hline Test for subgroup dif & $64, \mathrm{df}=$ & $P=0.44), I^{2}=0$ & & & & & \\
\hline
\end{tabular}


Analysis 2.4. Comparison 2 RISPERIDONE vs OTHER ANTIPSYCHOTIC: $b$. OLANZAPINE, Outcome 4 Global outcome: 1a. General - Need for additional measures.

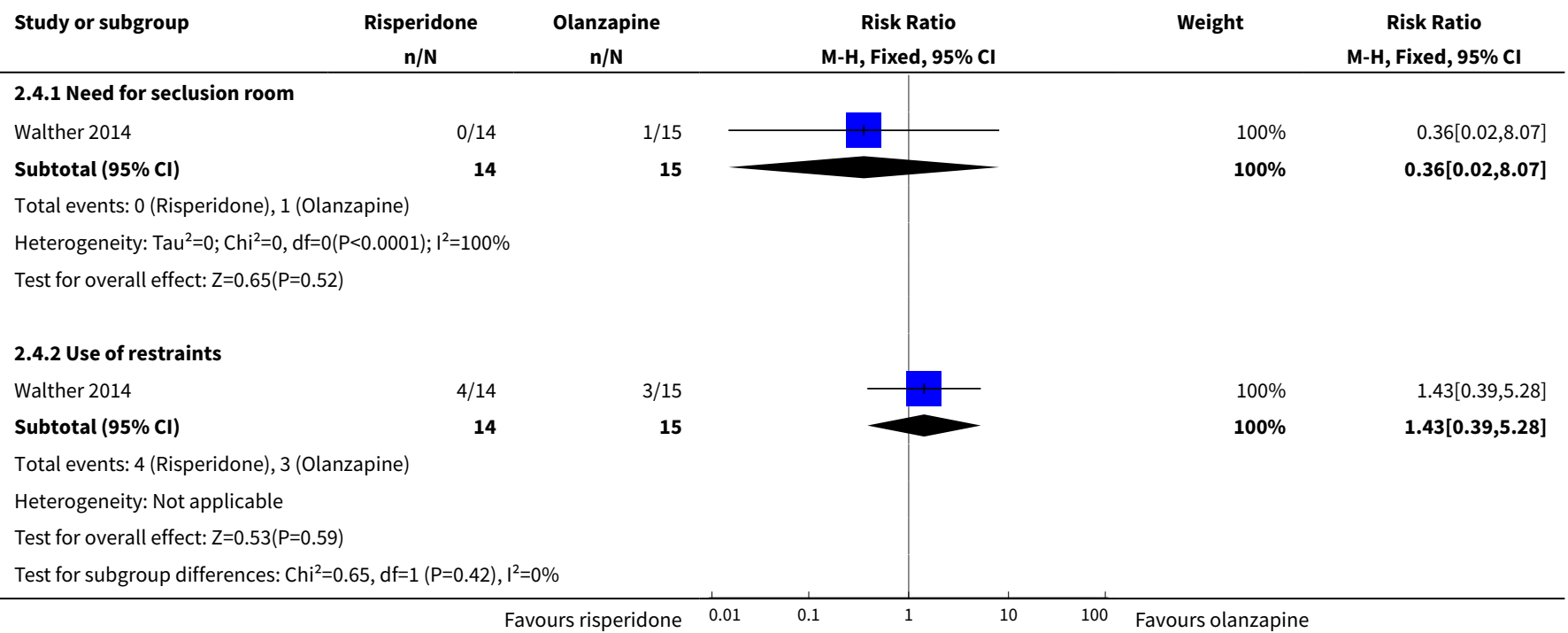

Analysis 2.5. Comparison 2 RISPERIDONE vs OTHER ANTIPSYCHOTIC: b. OLANZAPINE, Outcome 5 Global outcome: 1b. General - Need for additional medication (skewed data).

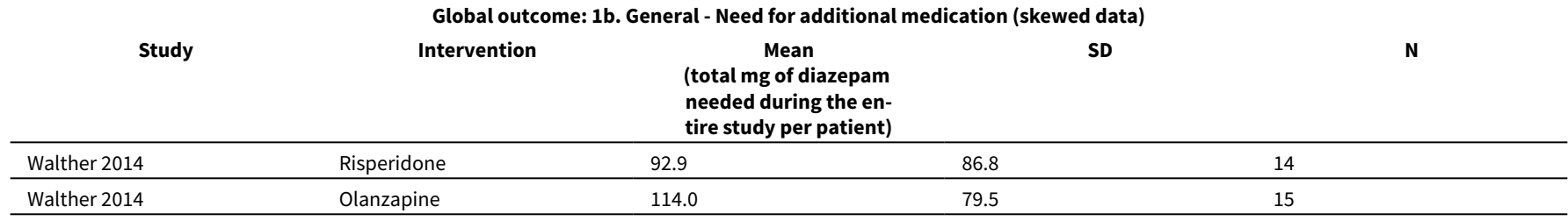

Analysis 2.6. Comparison 2 RISPERIDONE vs OTHER ANTIPSYCHOTIC: b. OLANZAPINE, Outcome 6 Adverse effects: 1a. Specific - Movement disorder - i. Meed for biperiden.

\begin{tabular}{lllll} 
& \multicolumn{2}{c}{$\begin{array}{c}\text { Adverse effects: 1a. Specific - Movement disorder - } \mathbf{i} \text {. Meed for biperiden } \\
\text { Study }\end{array}$} & $\begin{array}{c}\text { Mean } \\
\text { (total mg of biperiden } \\
\text { needed during the en- } \\
\text { tire study per patient) }\end{array}$ & SD \\
\hline Walther 2014 & Risperidone & 4.1 & 7.3 & \\
\hline Walther 2014 & Olanzapine & 0.7 & 2.6 & 14 \\
\hline
\end{tabular}

Analysis 2.7. Comparison 2 RISPERIDONE vs OTHER ANTIPSYCHOTIC: b. OLANZAPINE, Outcome 7 Adverse effects: 1b. Specific - Movement disorder - ii. Average scores (skewed data).

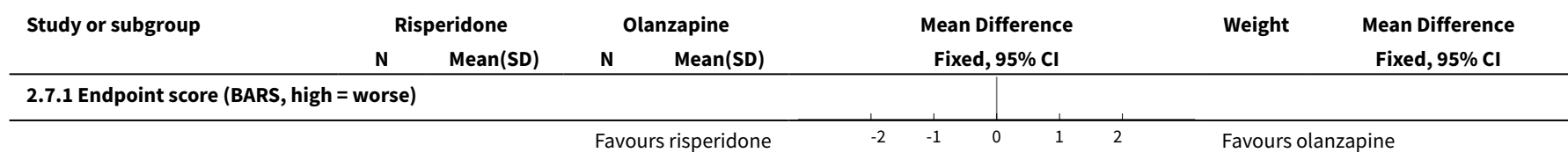




\begin{tabular}{|c|c|c|c|c|c|c|c|}
\hline \multirow[t]{2}{*}{ Study or subgroup } & \multicolumn{2}{|c|}{ Risperidone } & \multicolumn{2}{|c|}{ Olanzapine } & \multirow{2}{*}{$\begin{array}{c}\text { Mean Difference } \\
\text { Fixed, } 95 \% \mathrm{Cl}\end{array}$} & \multirow[t]{2}{*}{ Weight } & \multirow{2}{*}{$\begin{array}{c}\text { Mean Difference } \\
\text { Fixed, } 95 \% \mathrm{Cl}\end{array}$} \\
\hline & $\mathbf{N}$ & Mean(SD) & $\mathbf{N}$ & Mean(SD) & & & \\
\hline Walther 2014 & 14 & $0.3(1.1)$ & 15 & $0.1(0.5)$ & - & $100 \%$ & $0.2[-0.43,0.83]$ \\
\hline Subtotal $\star \star \star$ & 14 & & 15 & & & $100 \%$ & $0.2[-0.43,0.83]$ \\
\hline \multicolumn{8}{|c|}{ Heterogeneity: Not applicable } \\
\hline \multicolumn{8}{|c|}{ Test for overall effect: $Z=0.62(P=0.53)$} \\
\hline \multicolumn{8}{|c|}{ 2.7.2 Endpoint score (SAS, high = worse) } \\
\hline Walther 2014 & 14 & $3(3.7)$ & 15 & $1.2(2.9)$ & & $100 \%$ & $1.8[-0.63,4.23]$ \\
\hline Subtotal $\star \star \star$ & 14 & & 15 & & & $100 \%$ & $1.8[-0.63,4.23]$ \\
\hline \multicolumn{8}{|c|}{ Heterogeneity: $\mathrm{Tau}^{2}=0 ; \mathrm{Chi}^{2}=0, \mathrm{df}=0(\mathrm{P}<0.0001) ; \mathrm{I}^{2}=100 \%$} \\
\hline \multicolumn{8}{|c|}{ Test for overall effect: $Z=1.45(P=0.15)$} \\
\hline \multicolumn{8}{|c|}{ Test for subgroup differences: $\mathrm{Chi}^{2}=1.56, \mathrm{df}=1(\mathrm{P}=0.21), \mathrm{I}^{2}=35.87 \%$} \\
\hline
\end{tabular}

Analysis 2.8. Comparison 2 RISPERIDONE vs OTHER ANTIPSYCHOTIC: b. OLANZAPINE, Outcome 8 Leaving the study early.

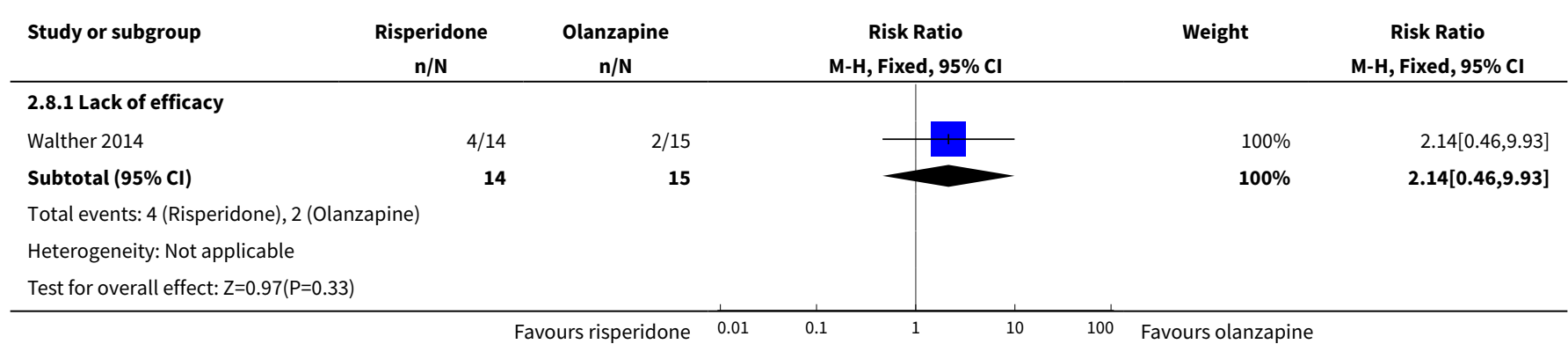

\section{Comparison 3. RISPERIDONE vS OTHER ANTIPSYCHOTIC: c. QUETIAPINE}

\begin{tabular}{lllll}
\hline Outcome or subgroup title & No. of studies & $\begin{array}{l}\text { No. of partici- } \\
\text { pants }\end{array}$ & Statistical method & Effect size \\
\hline $\begin{array}{l}1 \text { Specific behaviour: 1. Aggression - Aver- } \\
\text { age scores - i. Over 24 hours }\end{array}$ & 1 & & $\begin{array}{l}\text { Mean Difference (IV, Fixed, } \\
95 \% \text { CI) }\end{array}$ & Subtotals only \\
\hline $\begin{array}{l}1.1 \text { Endpoint score at 2 weeks (MOAS, } \\
\text { high = worse) }\end{array}$ & 1 & 40 & $\begin{array}{l}\text { Mean Difference (IV, Fixed, } \\
95 \% \text { Cl) }\end{array}$ & 1.80 [0.20, 3.40] \\
\hline $\begin{array}{l}1.2 \text { Endpoint score at 4 weeks (MOAS, } \\
\text { high = worse) }\end{array}$ & 1 & 40 & $\begin{array}{l}\text { Mean Difference (IV, Fixed, } \\
95 \% \text { Cl) }\end{array}$ & 0.90 [-0.44, 2.24] \\
\hline $\begin{array}{l}1.3 \text { Endpoint score at } 6 \text { weeks (MOAS, } \\
\text { high = worse) }\end{array}$ & 1 & 40 & $\begin{array}{l}\text { Mean Difference (IV, Fixed, } \\
95 \% \text { CI) }\end{array}$ & 0.70 [-0.29, 1.69] \\
\hline $\begin{array}{l}1.4 \text { Endpoint score at } 8 \text { weeks (MOAS, } \\
\text { high = worse) }\end{array}$ & 1 & 40 & $\begin{array}{l}\text { Mean Difference (IV, Fixed, } \\
95 \% \text { Cl) }\end{array}$ & 0.55 [-0.40, 1.50] \\
\hline $\begin{array}{l}2 \text { Mental state: 1a. No change in general } \\
\text { mental state }\end{array}$ & 1 & Risk Ratio (M-H, Fixed, & Subtotals only \\
\hline
\end{tabular}




\begin{tabular}{|c|c|c|c|c|}
\hline Outcome or subgroup title & No. of studies & $\begin{array}{l}\text { No. of partici- } \\
\text { pants }\end{array}$ & Statistical method & Effect size \\
\hline $\begin{array}{l}2.1 \text { No response at } 8 \text { weeks ( } \leq 25 \% \text { reduc- } \\
\text { tion at PANSS score) }\end{array}$ & 1 & 40 & $\begin{array}{l}\text { Risk Ratio (M-H, Fixed, } \\
95 \% \mathrm{Cl})\end{array}$ & $1.0[0.16,6.42]$ \\
\hline $\begin{array}{l}3 \text { Mental state: } 1 \mathrm{~b} \text {. Change in general } \\
\text { mental state }\end{array}$ & 1 & & $\begin{array}{l}\text { Risk Ratio (M-H, Fixed, } \\
95 \% \mathrm{Cl})\end{array}$ & Subtotals only \\
\hline $\begin{array}{l}3.1 \text { Clinical response at } 8 \text { weeks ( } 25-50 \% \\
\text { reduction at PANSS score) }\end{array}$ & 1 & 40 & $\begin{array}{l}\text { Risk Ratio (M-H, Fixed, } \\
95 \% \mathrm{Cl})\end{array}$ & $1.33[0.34,5.21]$ \\
\hline $\begin{array}{l}3.2 \text { Clinical response at } 8 \text { weeks ( } 50 \text { - } 75 \% \\
\text { reduction at PANSS score) }\end{array}$ & 1 & 40 & $\begin{array}{l}\text { Risk Ratio (M-H, Fixed, } \\
95 \% \mathrm{Cl})\end{array}$ & $0.88[0.39,1.95]$ \\
\hline $\begin{array}{l}3.3 \text { Clinical response at } 8 \text { weeks ( } \geq 75 \% \\
\text { reduction at PANSS score) }\end{array}$ & 1 & 40 & $\begin{array}{l}\text { Risk Ratio (M-H, Fixed, } \\
95 \% \mathrm{Cl})\end{array}$ & $1.0[0.43,2.33]$ \\
\hline $\begin{array}{l}4 \text { Mental state: 1c. Average scores - i. Over } \\
24 \text { hours }\end{array}$ & 1 & & $\begin{array}{l}\text { Mean Difference (IV, Fixed, } \\
95 \% \mathrm{CI})\end{array}$ & Subtotals only \\
\hline $\begin{array}{l}\text { 4.1 Endpoint score at } 2 \text { weeks (PANSS, } \\
\text { high = worse) }\end{array}$ & 1 & 40 & $\begin{array}{l}\text { Mean Difference (IV, Fixed, } \\
95 \% \mathrm{CI})\end{array}$ & $2.40[-2.15,6.95]$ \\
\hline $\begin{array}{l}\text { 4.2 Endpoint score at } 4 \text { weeks (PANSS, } \\
\text { high = worse) }\end{array}$ & 1 & 40 & $\begin{array}{l}\text { Mean Difference (IV, Fixed, } \\
95 \% \mathrm{CI})\end{array}$ & $1.95[-3.07,6.97]$ \\
\hline $\begin{array}{l}4.3 \text { Endpoint score at } 6 \text { weeks (PANSS, } \\
\text { high = worse) }\end{array}$ & 1 & 40 & $\begin{array}{l}\text { Mean Difference (IV, Fixed, } \\
95 \% \mathrm{CI})\end{array}$ & $\begin{array}{l}5.75[-0.09 \\
11.59]\end{array}$ \\
\hline $\begin{array}{l}\text { 4.4 Endpoint score at } 8 \text { weeks (PANSS, } \\
\text { high = worse) }\end{array}$ & 1 & 40 & $\begin{array}{l}\text { Mean Difference (IV, Fixed, } \\
95 \% \mathrm{CI})\end{array}$ & $3.55[-0.69,7.79]$ \\
\hline $\begin{array}{l}4.5 \text { Endpoint score at } 2 \text { weeks (PANSS } \\
\text { positive symptoms sub-scale, high = } \\
\text { worse) }\end{array}$ & 1 & 40 & $\begin{array}{l}\text { Mean Difference (IV, Fixed, } \\
95 \% \mathrm{CI} \text { ) }\end{array}$ & $1.15[-0.37,2.67]$ \\
\hline $\begin{array}{l}4.6 \text { Endpoint score at } 4 \text { weeks (PANSS } \\
\text { positive symptoms sub-scale, high = } \\
\text { worse) }\end{array}$ & 1 & 40 & $\begin{array}{l}\text { Mean Difference (IV, Fixed, } \\
95 \% \mathrm{CI})\end{array}$ & $1.70[0.01,3.39]$ \\
\hline $\begin{array}{l}4.7 \text { Endpoint score at } 6 \text { weeks (PANSS } \\
\text { positive symptoms sub-scale, high = } \\
\text { worse) }\end{array}$ & 1 & 40 & $\begin{array}{l}\text { Mean Difference (IV, Fixed, } \\
95 \% \mathrm{CI})\end{array}$ & $2.05[-0.15,4.25]$ \\
\hline $\begin{array}{l}4.8 \text { Endpoint score at } 8 \text { weeks (PANSS } \\
\text { positive symptoms sub-scale, high = } \\
\text { worse) }\end{array}$ & 1 & 40 & $\begin{array}{l}\text { Mean Difference (IV, Fixed, } \\
95 \% \mathrm{CI})\end{array}$ & $2.25[-0.36,4.86]$ \\
\hline $\begin{array}{l}4.9 \text { Endpoint score at } 2 \text { weeks (PANSS } \\
\text { negative symptoms sub-scale, high = } \\
\text { worse) }\end{array}$ & 1 & 40 & $\begin{array}{l}\text { Mean Difference (IV, Fixed, } \\
95 \% \mathrm{CI})\end{array}$ & $1.30[-0.07,2.67]$ \\
\hline $\begin{array}{l}\text { 4.10 Endpoint score at } 4 \text { weeks (PANSS } \\
\text { negative symptoms sub-scale, high = } \\
\text { worse) }\end{array}$ & 1 & 40 & $\begin{array}{l}\text { Mean Difference (IV, Fixed, } \\
95 \% \mathrm{CI})\end{array}$ & $1.31[-0.04,2.66]$ \\
\hline
\end{tabular}




\begin{tabular}{|c|c|c|c|c|}
\hline Outcome or subgroup title & No. of studies & $\begin{array}{l}\text { No. of partici- } \\
\text { pants }\end{array}$ & Statistical method & Effect size \\
\hline $\begin{array}{l}\text { 4.11 Endpoint score at } 6 \text { weeks (PANSS } \\
\text { negative symptoms sub-scale, high = } \\
\text { worse) }\end{array}$ & 1 & 40 & $\begin{array}{l}\text { Mean Difference (IV, Fixed, } \\
95 \% \mathrm{CI} \text { ) }\end{array}$ & $1.70[-0.12,3.52]$ \\
\hline $\begin{array}{l}\text { 4.12 Endpoint score at } 8 \text { weeks (PANSS } \\
\text { negative symptoms sub-scale, high = } \\
\text { worse) }\end{array}$ & 1 & 40 & $\begin{array}{l}\text { Mean Difference (IV, Fixed, } \\
95 \% \mathrm{CI} \text { ) }\end{array}$ & $2.05[-0.06,4.16]$ \\
\hline $\begin{array}{l}4.13 \text { Endpoint score at } 2 \text { weeks (PANSS } \\
\text { general psychopathology sub-scale, high } \\
=\text { worse) }\end{array}$ & 1 & 40 & $\begin{array}{l}\text { Mean Difference (IV, Fixed, } \\
95 \% \mathrm{CI} \text { ) }\end{array}$ & $-1.75[-4.73,1.23]$ \\
\hline $\begin{array}{l}\text { 4.14 Endpoint score at } 4 \text { weeks (PANSS } \\
\text { general psychopathology sub-scale, high } \\
\text { = worse) }\end{array}$ & 1 & 40 & $\begin{array}{l}\text { Mean Difference (IV, Fixed, } \\
95 \% \mathrm{CI} \text { ) }\end{array}$ & $-0.60[-3.73,2.53]$ \\
\hline $\begin{array}{l}\text { 4.15 Endpoint score at } 6 \text { weeks (PANSS } \\
\text { general psychopathology sub-scale, high } \\
\text { = worse) }\end{array}$ & 1 & 40 & $\begin{array}{l}\text { Mean Difference (IV, Fixed, } \\
95 \% \mathrm{CI} \text { ) }\end{array}$ & $1.01[-1.88,3.90]$ \\
\hline $\begin{array}{l}\text { 4.16 Endpoint score at } 8 \text { weeks (PANSS } \\
\text { general psychopathology sub-scale, high } \\
\text { = worse) }\end{array}$ & 1 & 40 & $\begin{array}{l}\text { Mean Difference (IV, Fixed, } \\
95 \% \mathrm{CI} \text { ) }\end{array}$ & $1.37[-1.30,4.04]$ \\
\hline $\begin{array}{l}5 \text { Adverse effects: } 1 \text { a. Specific - Anti- } \\
\text { cholinergic }\end{array}$ & 1 & & $\begin{array}{l}\text { Risk Ratio (M-H, Fixed, } \\
95 \% \mathrm{Cl})\end{array}$ & Subtotals only \\
\hline 5.1 Blurred vision over 24 hours & 1 & 40 & $\begin{array}{l}\text { Risk Ratio (M-H, Fixed, } \\
95 \% \mathrm{Cl})\end{array}$ & $0.5[0.10,2.43]$ \\
\hline 6 Adverse effects: 1 b. Specific - Arousal & 1 & & $\begin{array}{l}\text { Risk Ratio (M-H, Fixed, } \\
95 \% \mathrm{Cl})\end{array}$ & Subtotals only \\
\hline 6.1 Somnolence over 24 hours & 1 & 40 & $\begin{array}{l}\text { Risk Ratio (M-H, Fixed, } \\
95 \% \mathrm{Cl})\end{array}$ & $0.6[0.17,2.18]$ \\
\hline $\begin{array}{l}7 \text { Adverse effects: 1c. Specific - Cardiovas- } \\
\text { cular }\end{array}$ & 1 & & $\begin{array}{l}\text { Risk Ratio (M-H, Fixed, } \\
95 \% \mathrm{Cl})\end{array}$ & Subtotals only \\
\hline 7.1 Tachycardia over 24 hours & 1 & 40 & $\begin{array}{l}\text { Risk Ratio (M-H, Fixed, } \\
95 \% \mathrm{Cl})\end{array}$ & $4.0[0.49,32.72]$ \\
\hline $\begin{array}{l}8 \text { Adverse effects: } 1 d \text {. Specific - Gastroin- } \\
\text { testinal }\end{array}$ & 1 & & $\begin{array}{l}\text { Risk Ratio (M-H, Fixed, } \\
95 \% \mathrm{Cl})\end{array}$ & Subtotals only \\
\hline 8.1 Nausea and vomiting over 24 hours & 1 & 40 & $\begin{array}{l}\text { Risk Ratio (M-H, Fixed, } \\
95 \% \mathrm{Cl})\end{array}$ & $1.0[0.07,14.90]$ \\
\hline $\begin{array}{l}9 \text { Adverse effects: 1e. Specific - Movement } \\
\text { disorders }\end{array}$ & 1 & & $\begin{array}{l}\text { Risk Ratio (M-H, Fixed, } \\
95 \% \mathrm{Cl})\end{array}$ & Subtotals only \\
\hline 9.1 Akathisia over 24 hours & 1 & 40 & $\begin{array}{l}\text { Risk Ratio (M-H, Fixed, } \\
95 \% \mathrm{Cl})\end{array}$ & $1.67[0.46,6.06]$ \\
\hline
\end{tabular}




\begin{tabular}{|c|c|c|c|c|}
\hline Outcome or subgroup title & No. of studies & $\begin{array}{l}\text { No. of partici- } \\
\text { pants }\end{array}$ & Statistical method & Effect size \\
\hline 9.2 Hypermyotonia over 24 hours & 1 & 40 & $\begin{array}{l}\text { Risk Ratio (M-H, Fixed, } \\
95 \% \mathrm{Cl})\end{array}$ & $7.0[0.95,51.80]$ \\
\hline $\begin{array}{l}10 \text { Adverse effects: } 1 f \text {. Specific - Miscella- } \\
\text { neous }\end{array}$ & 1 & & $\begin{array}{l}\text { Risk Ratio (M-H, Fixed, } \\
95 \% \mathrm{Cl})\end{array}$ & Subtotals only \\
\hline 10.1 Headache over 24 hours & 1 & 40 & $\begin{array}{l}\text { Risk Ratio (M-H, Fixed, } \\
95 \% \mathrm{Cl})\end{array}$ & $1.0[0.16,6.42]$ \\
\hline $\begin{array}{l}\text { 10.2 Liver Function Tests (LFTs) elevation } \\
\text { over } 24 \text { hours }\end{array}$ & 1 & 40 & $\begin{array}{l}\text { Risk Ratio (M-H, Fixed, } \\
95 \% \mathrm{Cl})\end{array}$ & $1.0[0.07,14.90]$ \\
\hline 10.3 Weight gain over 24 hours & 1 & 40 & $\begin{array}{l}\text { Risk Ratio (M-H, Fixed, } \\
95 \% \mathrm{Cl})\end{array}$ & $4.0[0.49,32.72]$ \\
\hline 10.4 Agitation over 24 hours & 1 & 40 & $\begin{array}{l}\text { Risk Ratio (M-H, Fixed, } \\
95 \% \mathrm{Cl})\end{array}$ & $3.5[0.83,14.83]$ \\
\hline
\end{tabular}

\section{Analysis 3.1. Comparison 3 RISPERIDONE vs OTHER ANTIPSYCHOTIC: C. QUETIAPINE, Outcome 1 Specific behaviour: 1. Aggression - Average scores - i. Over 24 hours.}

\begin{tabular}{|c|c|c|c|c|c|c|c|}
\hline \multirow[t]{2}{*}{ Study or subgroup } & \multicolumn{2}{|c|}{ Risperidone } & \multicolumn{2}{|c|}{ Quetiapine } & \multirow{2}{*}{$\begin{array}{c}\text { Mean Difference } \\
\text { Fixed, } 95 \% \mathrm{Cl}\end{array}$} & \multirow[t]{2}{*}{ Weight } & \multirow{2}{*}{$\begin{array}{c}\text { Mean Difference } \\
\text { Fixed, } 95 \% \mathrm{Cl}\end{array}$} \\
\hline & $\mathbf{N}$ & Mean(SD) & $\mathbf{N}$ & $\operatorname{Mean}(S D)$ & & & \\
\hline \multicolumn{8}{|c|}{ 3.1.1 Endpoint score at 2 weeks (MOAS, high = worse) } \\
\hline Dai 2012 & 20 & $10.9(2.8)$ & 20 & $9.1(2.3)$ & & $100 \%$ & $1.8[0.2,3.4]$ \\
\hline Subtotal $\star \star \star$ & 20 & & 20 & & & $100 \%$ & $1.8[0.2,3.4]$ \\
\hline \multicolumn{8}{|c|}{ Heterogeneity: $\mathrm{Tau}^{2}=0 ; \mathrm{Chi}^{2}=0, \mathrm{df}=0(\mathrm{P}<0.0001) ; \mathrm{I}^{2}=100 \%$} \\
\hline \multicolumn{8}{|c|}{ Test for overall effect: $Z=2.21(P=0.03)$} \\
\hline \multicolumn{8}{|c|}{ 3.1.2 Endpoint score at 4 weeks (MOAS, high = worse) } \\
\hline Dai 2012 & 20 & $8.5(2.3)$ & 20 & $7.6(2)$ & & $100 \%$ & $0.9[-0.44,2.24]$ \\
\hline Subtotal $\star \star \star$ & 20 & & 20 & & & $100 \%$ & $0.9[-0.44,2.24]$ \\
\hline \multicolumn{8}{|c|}{ Heterogeneity: Not applicable } \\
\hline \multicolumn{8}{|c|}{ Test for overall effect: $Z=1.32(P=0.19)$} \\
\hline \multicolumn{8}{|c|}{ 3.1.3 Endpoint score at 6 weeks (MOAS, high = worse) } \\
\hline Dai 2012 & 20 & $6.6(1.6)$ & 20 & $5.9(1.6)$ & & $100 \%$ & $0.7[-0.29,1.69]$ \\
\hline Subtotal $* \star \star$ & 20 & & 20 & & & $100 \%$ & $0.7[-0.29,1.69]$ \\
\hline \multicolumn{8}{|c|}{ Heterogeneity: Not applicable } \\
\hline \multicolumn{8}{|c|}{ Test for overall effect: $\mathrm{Z}=1.38(\mathrm{P}=0.17)$} \\
\hline \multicolumn{8}{|c|}{ 3.1.4 Endpoint score at 8 weeks (MOAS, high = worse) } \\
\hline Dai 2012 & 20 & $4.1(1.2)$ & 20 & $3.6(1.8)$ & & $100 \%$ & $0.55[-0.4,1.5]$ \\
\hline Subtotal $* \star \star$ & 20 & & 20 & & & $100 \%$ & $0.55[-0.4,1.5]$ \\
\hline \multicolumn{8}{|c|}{ Heterogeneity: Not applicable } \\
\hline \multicolumn{8}{|c|}{ Test for overall effect: $\mathrm{Z}=1.14(\mathrm{P}=0.25)$} \\
\hline \multicolumn{8}{|c|}{ Test for subgroup differences: $\mathrm{Chi}^{2}=1.82, \mathrm{df}=1(\mathrm{P}=0.61), \mathrm{I}^{2}=0 \%$} \\
\hline & & & Favol & speridone & -2 & Favours & ine \\
\hline
\end{tabular}


Analysis 3.2. Comparison 3 RISPERIDONE vs OTHER ANTIPSYCHOTIC: c.

QUETIAPINE, Outcome 2 Mental state: 1a. No change in general mental state.

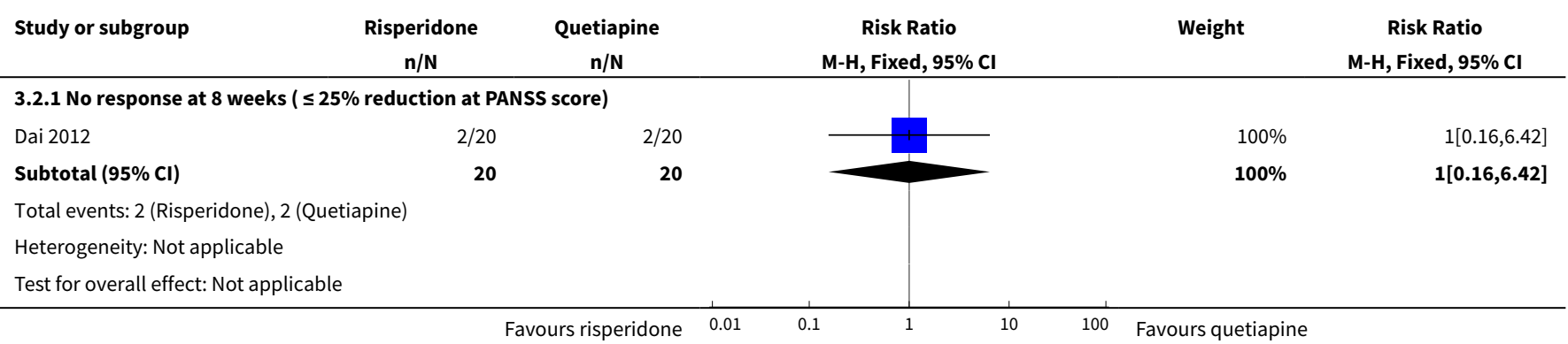

Analysis 3.3. Comparison 3 RISPERIDONE vs OTHER ANTIPSYCHOTIC: c. QUETIAPINE, Outcome 3 Mental state: $1 \mathrm{~b}$. Change in general mental state.

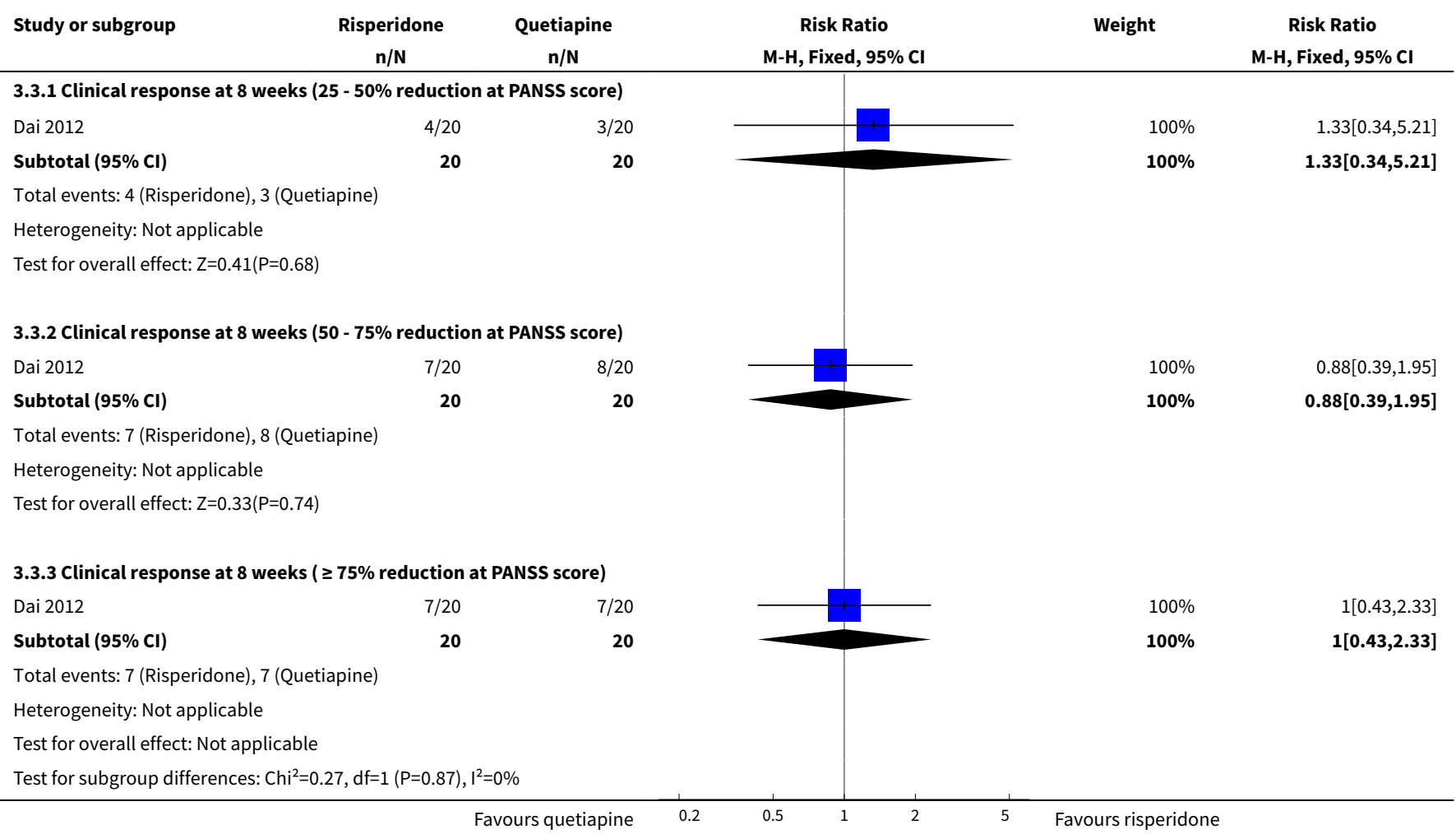

Analysis 3.4. Comparison 3 RISPERIDONE vs OTHER ANTIPSYCHOTIC: c. QUETIAPINE, Outcome 4 Mental state: 1c. Average scores - i. Over 24 hours.

\begin{tabular}{|c|c|c|c|c|c|c|c|c|}
\hline \multirow[t]{2}{*}{ Study or subgroup } & \multicolumn{2}{|c|}{ Risperidone } & \multicolumn{2}{|c|}{ Quetiapine } & \multirow{2}{*}{\multicolumn{2}{|c|}{$\begin{array}{c}\text { Mean Difference } \\
\text { Fixed, } 95 \% \mathrm{Cl}\end{array}$}} & \multirow[t]{2}{*}{ Weight } & \multirow{2}{*}{$\begin{array}{c}\text { Mean Difference } \\
\text { Fixed, } 95 \% \mathrm{Cl}\end{array}$} \\
\hline & $\mathbf{N}$ & Mean(SD) & $\mathbf{N}$ & Mean(SD) & & & & \\
\hline \multicolumn{9}{|c|}{ 3.4.1 Endpoint score at 2 weeks (PANSS, high = worse) } \\
\hline Dai 2012 & 20 & $87.3(6.7)$ & 20 & $84.9(7.9)$ & & & $100 \%$ & $2.4[-2.15,6.95]$ \\
\hline
\end{tabular}




\begin{tabular}{|c|c|c|c|c|c|c|c|}
\hline \multirow[t]{2}{*}{ Study or subgroup } & \multicolumn{2}{|c|}{ Risperidone } & \multicolumn{2}{|c|}{ Quetiapine } & \multirow{2}{*}{$\begin{array}{c}\text { Mean Difference } \\
\text { Fixed, } 95 \% \mathrm{Cl}\end{array}$} & \multirow[t]{2}{*}{ Weight } & \multirow{2}{*}{$\begin{array}{l}\text { Mean Difference } \\
\text { Fixed, } 95 \% \mathrm{Cl}\end{array}$} \\
\hline & $\mathbf{N}$ & Mean(SD) & $\mathbf{N}$ & Mean(SD) & & & \\
\hline 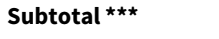 & 20 & & 20 & & & $100 \%$ & $2.4[-2.15,6.95]$ \\
\hline \multicolumn{8}{|c|}{ Heterogeneity: Not applicable } \\
\hline \multicolumn{8}{|c|}{ Test for overall effect: $Z=1.03(P=0.3)$} \\
\hline \multicolumn{8}{|c|}{ 3.4.2 Endpoint score at 4 weeks (PANSS, high = worse) } \\
\hline Dai 2012 & 20 & $76.9(7.1)$ & 20 & $75(9)$ & & $100 \%$ & $1.95[-3.07,6.97]$ \\
\hline Subtotal $* \star \star$ & 20 & & 20 & & & $100 \%$ & $1.95[-3.07,6.97]$ \\
\hline \multicolumn{8}{|c|}{ Heterogeneity: Not applicable } \\
\hline \multicolumn{8}{|c|}{ Test for overall effect: $Z=0.76(P=0.45)$} \\
\hline \multicolumn{8}{|c|}{ 3.4.3 Endpoint score at 6 weeks (PANSS, high = worse) } \\
\hline Dai 2012 & 20 & $67.5(7.4)$ & 20 & $61.8(11.1)$ & & $100 \%$ & $5.75[-0.09,11.59]$ \\
\hline Subtotal $* \star \star$ & 20 & & 20 & & & $100 \%$ & $5.75[-0.09,11.59]$ \\
\hline \multicolumn{8}{|c|}{ Heterogeneity: Not applicable } \\
\hline \multicolumn{8}{|c|}{ Test for overall effect: $Z=1.93(P=0.05)$} \\
\hline \multicolumn{8}{|c|}{ 3.4.4 Endpoint score at 8 weeks (PANSS, high = worse) } \\
\hline Dai 2012 & 20 & $52.3(7.3)$ & 20 & $48.7(6.4)$ & & $100 \%$ & $3.55[-0.69,7.79]$ \\
\hline 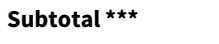 & 20 & & 20 & & & $100 \%$ & $3.55[-0.69,7.79]$ \\
\hline \multicolumn{8}{|c|}{ Heterogeneity: Not applicable } \\
\hline \multicolumn{8}{|c|}{ Test for overall effect: $Z=1.64(P=0.1)$} \\
\hline \multicolumn{8}{|c|}{$\begin{array}{l}\text { 3.4.5 Endpoint score at } 2 \text { weeks (PANSS positive symptoms sub-scale, high = } \\
\text { worse) }\end{array}$} \\
\hline Dai 2012 & 20 & $27.2(2.1)$ & 20 & $26.1(2.7)$ & & $100 \%$ & $1.15[-0.37,2.67]$ \\
\hline 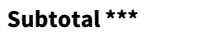 & 20 & & 20 & & & $100 \%$ & $1.15[-0.37,2.67]$ \\
\hline \multicolumn{8}{|c|}{ Heterogeneity: Not applicable } \\
\hline \multicolumn{8}{|c|}{ Test for overall effect: $Z=1.49(P=0.14)$} \\
\hline \multicolumn{8}{|c|}{$\begin{array}{l}\text { 3.4.6 Endpoint score at } 4 \text { weeks (PANSS positive symptoms sub-scale, high = } \\
\text { worse) }\end{array}$} \\
\hline Dai 2012 & 20 & $23.8(2.5)$ & 20 & $22.1(2.9)$ & & $100 \%$ & $1.7[0.01,3.39]$ \\
\hline Subtotal $* \star \star$ & 20 & & 20 & & & $100 \%$ & $1.7[0.01,3.39]$ \\
\hline \multicolumn{8}{|c|}{ Heterogeneity: $\operatorname{Tau}^{2}=0 ; \mathrm{Chi}^{2}=0, \mathrm{df}=0(\mathrm{P}<0.0001) ; \mathrm{I}^{2}=100 \%$} \\
\hline \multicolumn{8}{|c|}{ Test for overall effect: $Z=1.98(P=0.05)$} \\
\hline \multicolumn{8}{|c|}{$\begin{array}{l}\text { 3.4.7 Endpoint score at } 6 \text { weeks (PANSS positive symptoms sub-scale, high = } \\
\text { worse) }\end{array}$} \\
\hline Dai 2012 & 20 & $19.8(3.2)$ & 20 & $17.7(3.9)$ & & $100 \%$ & $2.05[-0.15,4.25]$ \\
\hline Subtotal $* \star \star$ & 20 & & 20 & & & $100 \%$ & $2.05[-0.15,4.25]$ \\
\hline Heterogeneity: Not a & & & & & & & \\
\hline Test for overall effect & & & & & & & \\
\hline $\begin{array}{l}\text { 3.4.8 Endpoint score } \\
\text { worse) }\end{array}$ & SS po & tive symptor & b-sc & e, high = & & & \\
\hline Dai 2012 & 20 & $17.6(3.9)$ & 20 & $15.3(4.5)$ & & $100 \%$ & $2.25[-0.36,4.86]$ \\
\hline 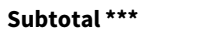 & 20 & & 20 & & & $100 \%$ & $2.25[-0.36,4.86]$ \\
\hline Heterogeneity: Not a & & & & & & & \\
\hline Test for overall effect & & & & & & & \\
\hline $\begin{array}{l}\text { 3.4.9 Endpoint score } \\
\text { worse) }\end{array}$ & ISS ne & tive sympto & ub-sc & le, high = & & & \\
\hline Dai 2012 & 20 & $21.4(1.9)$ & 20 & $20.1(2.5)$ & & $100 \%$ & $1.3[-0.07,2.67]$ \\
\hline
\end{tabular}


Analysis 3.5. Comparison 3 RISPERIDONE vs OTHER ANTIPSYCHOTIC: c. QUETIAPINE, Outcome 5 Adverse effects: 1a. Specific - Anticholinergic.

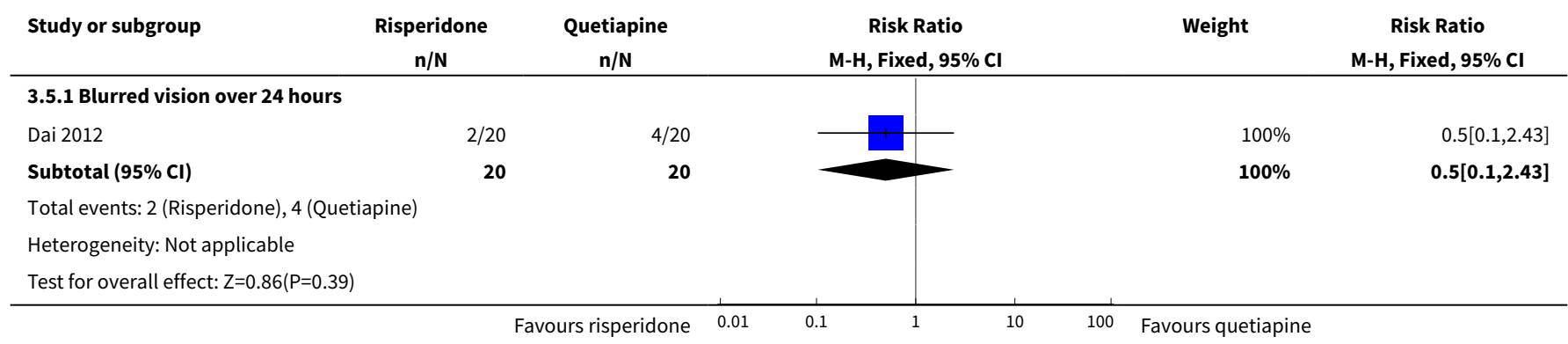

Analysis 3.6. Comparison 3 RISPERIDONE vs OTHER ANTIPSYCHOTIC: c. QUETIAPINE, Outcome 6 Adverse effects: 1b. Specific - Arousal.

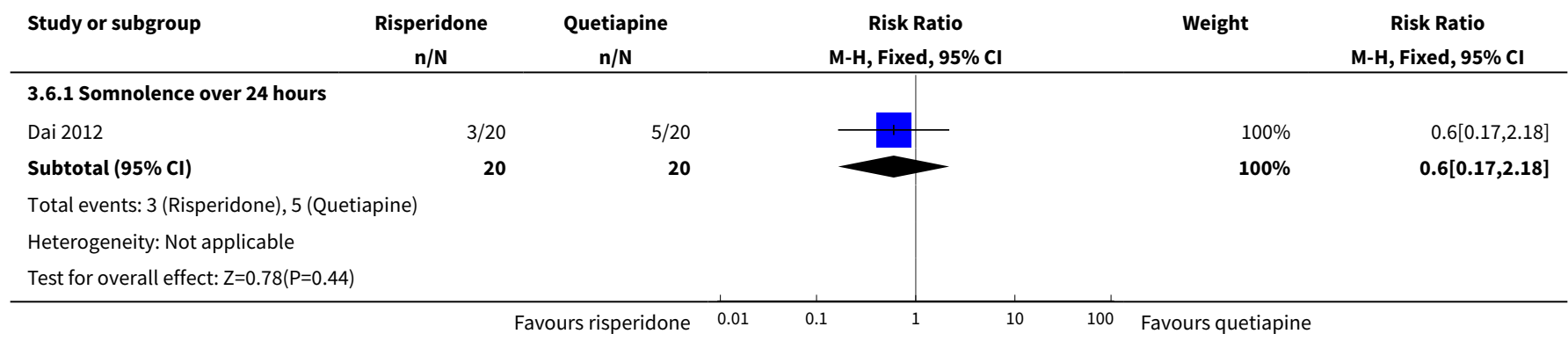

Analysis 3.7. Comparison 3 RISPERIDONE vs OTHER ANTIPSYCHOTIC: c. QUETIAPINE, Outcome 7 Adverse effects: 1c. Specific - Cardiovascular.

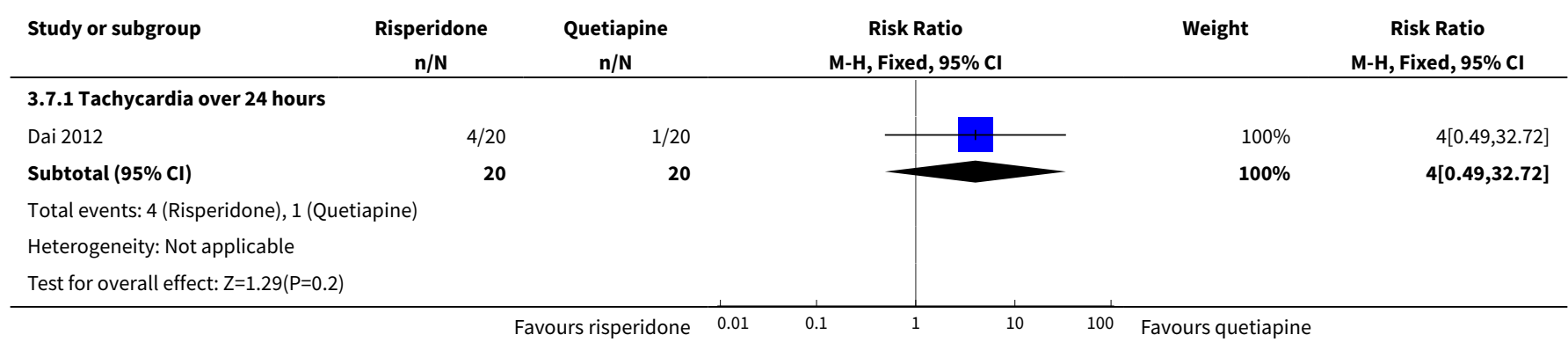

Analysis 3.8. Comparison 3 RISPERIDONE vs OTHER ANTIPSYCHOTIC: c. QUETIAPINE, Outcome 8 Adverse effects: 1d. Specific - Gastrointestinal.

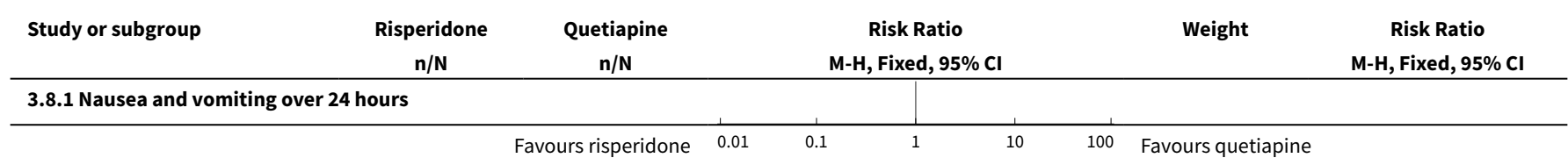




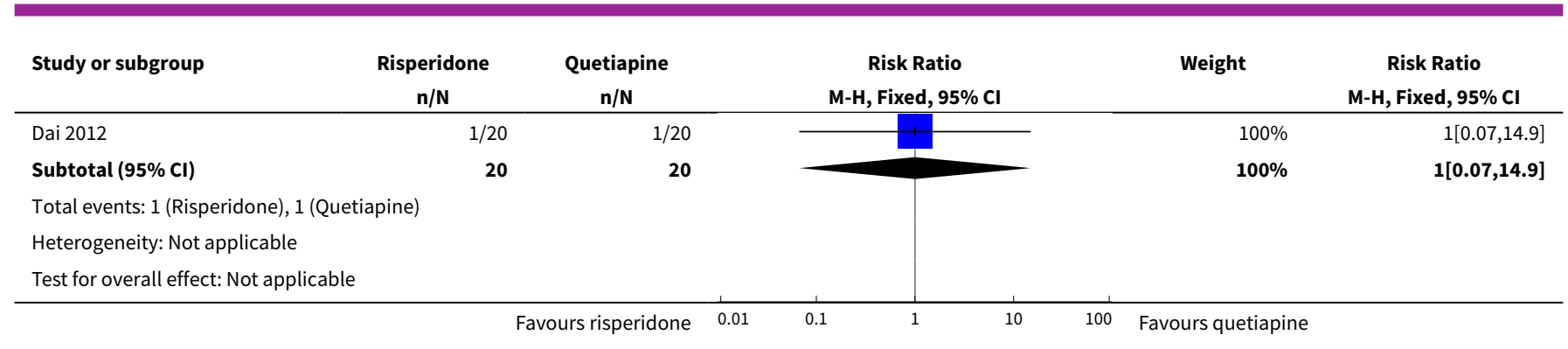

Analysis 3.9. Comparison 3 RISPERIDONE vs OTHER ANTIPSYCHOTIC: c. QUETIAPINE, Outcome 9 Adverse effects: 1e. Specific - Movement disorders.

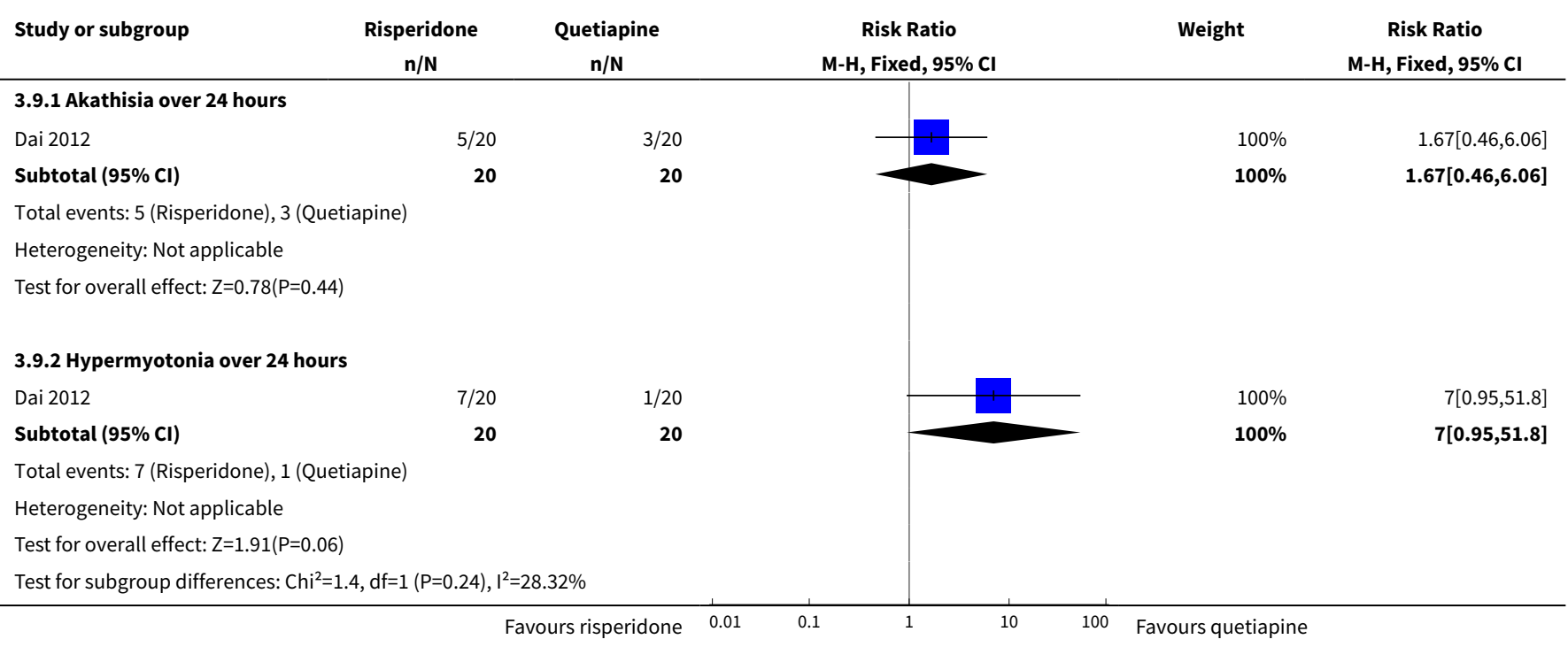

Analysis 3.10. Comparison 3 RISPERIDONE vS OTHER ANTIPSYCHOTIC: c. QUETIAPINE, Outcome 10 Adverse effects: 1f. Specific - Miscellaneous.

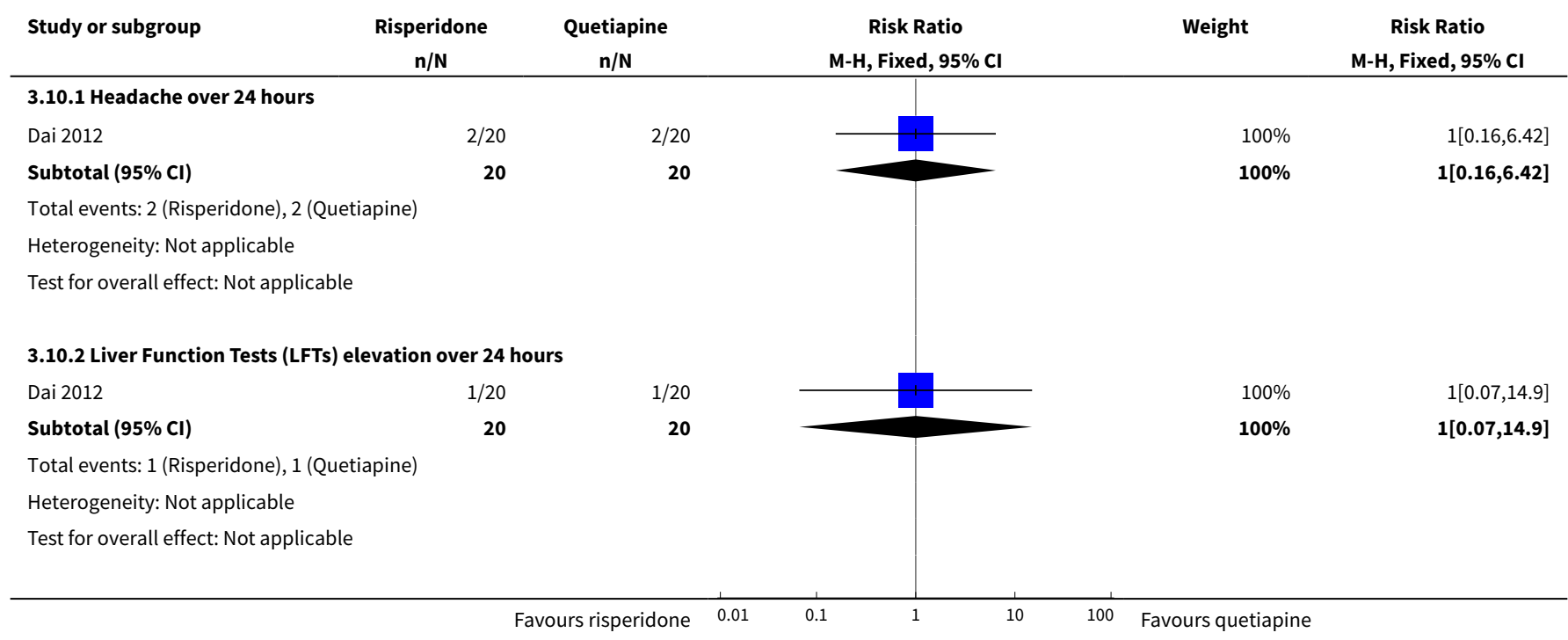




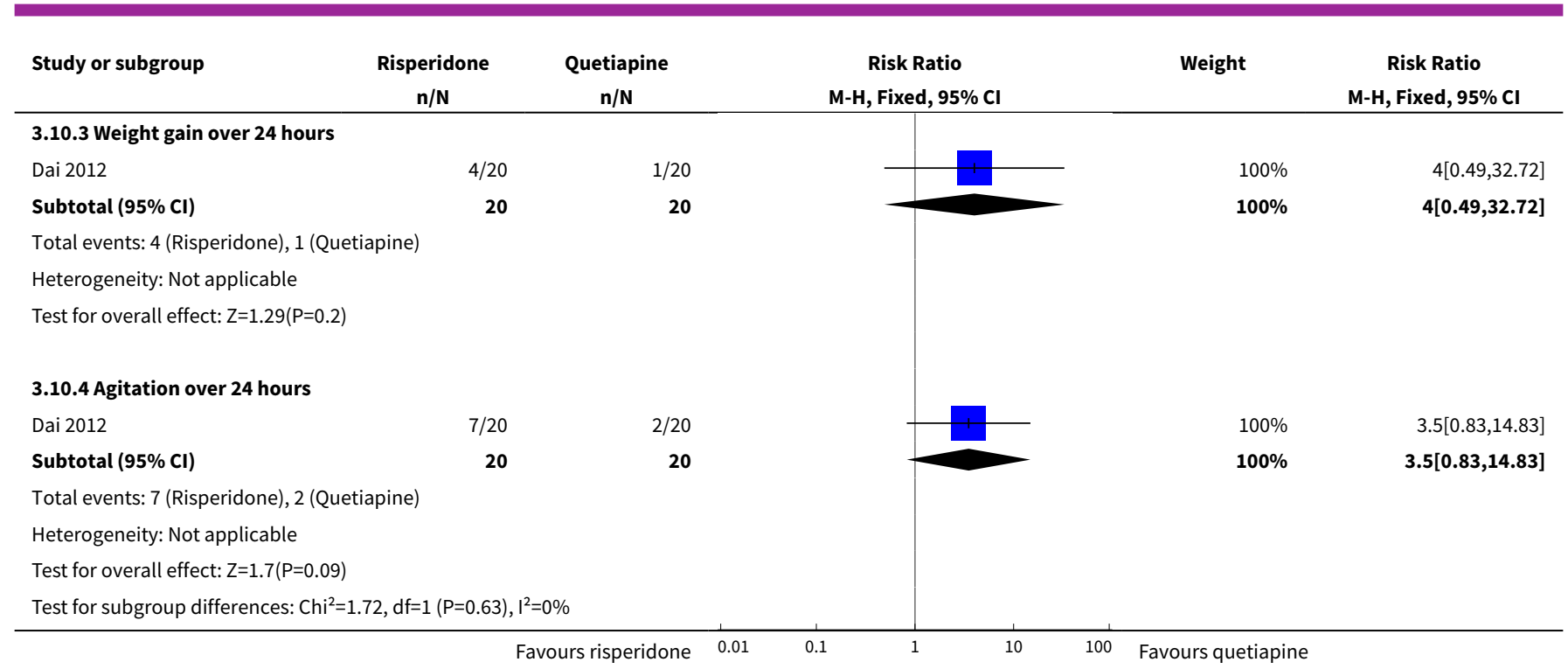

\section{Comparison 4. RISPERIDONE vs COMBINATION: a. RISPERIDONE + OXCARBAZEPINE}

\begin{tabular}{|c|c|c|c|c|}
\hline Outcome or subgroup title & No. of studies & $\begin{array}{l}\text { No. of partici- } \\
\text { pants }\end{array}$ & Statistical method & Effect size \\
\hline $\begin{array}{l}1 \text { Specific behaviour: } 1 \text {. Agitation - Aver- } \\
\text { age scores - i. over } 24 \text { hours }\end{array}$ & 1 & & $\begin{array}{l}\text { Mean Difference (IV, Fixed, } \\
95 \% \mathrm{Cl})\end{array}$ & Subtotals only \\
\hline $\begin{array}{l}\text { 1.1 Endpoint score at } 1 \text { week (PANSS-EC, } \\
\text { high = worse) }\end{array}$ & 1 & 68 & $\begin{array}{l}\text { Mean Difference (IV, Fixed, } \\
95 \% \mathrm{Cl})\end{array}$ & $2.70[0.42,4.98]$ \\
\hline $\begin{array}{l}\text { 1.2 Endpoint score at } 2 \text { weeks (PANSS- } \\
\text { EC, high = worse) }\end{array}$ & 1 & 68 & $\begin{array}{l}\text { Mean Difference (IV, Fixed, } \\
95 \% \mathrm{CI})\end{array}$ & $2.40[0.32,4.48]$ \\
\hline $\begin{array}{l}\text { 1.3 Endpoint score at } 4 \text { weeks (PANSS- } \\
\text { EC, high = worse) }\end{array}$ & 1 & 68 & $\begin{array}{l}\text { Mean Difference (IV, Fixed, } \\
95 \% \mathrm{CI})\end{array}$ & $2.40[0.53,4.27]$ \\
\hline $\begin{array}{l}2 \text { Global Outcome: } 1 \text {. Average scores - i. } \\
\text { Over } 24 \text { hours }\end{array}$ & 1 & & $\begin{array}{l}\text { Mean Difference (IV, Fixed, } \\
95 \% \mathrm{Cl} \text { ) }\end{array}$ & Subtotals only \\
\hline $\begin{array}{l}2.1 \text { Endpoint score at } 1 \text { week (CGI-I, high } \\
=\text { worse) }\end{array}$ & 1 & 68 & $\begin{array}{l}\text { Mean Difference (IV, Fixed, } \\
95 \% \mathrm{CI})\end{array}$ & $-0.20[-0.61,0.21]$ \\
\hline $\begin{array}{l}\text { 2.2 Endpoint score at } 2 \text { weeks (CGI-I, } \\
\text { high = worse) }\end{array}$ & 1 & 68 & $\begin{array}{l}\text { Mean Difference (IV, Fixed, } \\
95 \% \mathrm{CI})\end{array}$ & $0.5[0.07,0.93]$ \\
\hline $\begin{array}{l}\text { 2.3 Endpoint score at } 4 \text { weeks (CGI-I, } \\
\text { high = worse) }\end{array}$ & 1 & 68 & $\begin{array}{l}\text { Mean Difference (IV, Fixed, } \\
95 \% \mathrm{Cl} \text { ) }\end{array}$ & $0.50[0.14,0.86]$ \\
\hline $\begin{array}{l}\text { 2.4 Endpoint score at } 1 \text { week (CGI-S, } \\
\text { high = worse) }\end{array}$ & 1 & 68 & $\begin{array}{l}\text { Mean Difference (IV, Fixed, } \\
95 \% \mathrm{CI})\end{array}$ & $0.20[-0.25,0.65]$ \\
\hline $\begin{array}{l}2.5 \text { Endpoint score at } 2 \text { weeks (CGI-S, } \\
\text { high = worse) }\end{array}$ & 1 & 68 & $\begin{array}{l}\text { Mean Difference (IV, Fixed, } \\
95 \% \mathrm{Cl})\end{array}$ & $0.5[0.07,0.93]$ \\
\hline
\end{tabular}




\begin{tabular}{|c|c|c|c|c|}
\hline Outcome or subgroup title & No. of studies & $\begin{array}{l}\text { No. of partici- } \\
\text { pants }\end{array}$ & Statistical method & Effect size \\
\hline $\begin{array}{l}\text { 2.6 Endpoint score at } 4 \text { weeks (CGI-S, } \\
\text { high = worse) }\end{array}$ & 1 & 68 & $\begin{array}{l}\text { Mean Difference (IV, Fixed, } \\
95 \% \mathrm{Cl})\end{array}$ & $0.5[0.14,0.86]$ \\
\hline $\begin{array}{l}3 \text { Mental state: } 1 \text { a. No change in general } \\
\text { mental state }\end{array}$ & 1 & & $\begin{array}{l}\text { Risk Ratio (M-H, Fixed, 95\% } \\
\text { Cl) }\end{array}$ & Subtotals only \\
\hline $\begin{array}{l}3.1 \text { No response at } 4 \text { weeks ( }<50 \% \text { re- } \\
\text { duction BPRS score) }\end{array}$ & 1 & 68 & $\begin{array}{l}\text { Risk Ratio (M-H, Fixed, 95\% } \\
\mathrm{Cl})\end{array}$ & $\begin{array}{l}10.61[1.44 \\
78.36]\end{array}$ \\
\hline $\begin{array}{l}4 \text { Mental state: } 1 \mathrm{~b} \text {. Change in general } \\
\text { mental state }\end{array}$ & 1 & & $\begin{array}{l}\text { Risk Ratio (M-H, Fixed, 95\% } \\
\mathrm{Cl})\end{array}$ & Subtotals only \\
\hline $\begin{array}{l}4.1 \text { Clinical response at } 4 \text { weeks ( } 50 \text { - } \\
75 \% \text { reduction at BPRS score) }\end{array}$ & 1 & 68 & $\begin{array}{l}\text { Risk Ratio (M-H, Fixed, 95\% } \\
\mathrm{Cl})\end{array}$ & $0.69[0.50,0.97]$ \\
\hline $\begin{array}{l}4.2 \text { Clinical response at } 4 \text { weeks ( } \geq 75 \% \\
\text { reduction at BPRS score) }\end{array}$ & 1 & 68 & $\begin{array}{l}\text { Risk Ratio (M-H, Fixed, 95\% } \\
\mathrm{Cl})\end{array}$ & $0.85[0.25,2.89]$ \\
\hline $\begin{array}{l}5 \text { Mental state: } 1 \text { c. Average scores - i. } \\
\text { Over } 24 \text { hours }\end{array}$ & 1 & & $\begin{array}{l}\text { Mean Difference (IV, Fixed, } \\
95 \% \mathrm{CI})\end{array}$ & Subtotals only \\
\hline $\begin{array}{l}5.1 \text { Endpoint score at } 1 \text { week (BPRS, } \\
\text { high = worse) }\end{array}$ & 1 & 68 & $\begin{array}{l}\text { Mean Difference (IV, Fixed, } \\
95 \% \mathrm{CI})\end{array}$ & $5.20[1.04,9.36]$ \\
\hline $\begin{array}{l}5.2 \text { Endpoint score at } 2 \text { weeks (BPRS, } \\
\text { high = worse) }\end{array}$ & 1 & 68 & $\begin{array}{l}\text { Mean Difference (IV, Fixed, } \\
95 \% \mathrm{CI} \text { ) }\end{array}$ & $6.20[2.48,9.92]$ \\
\hline $\begin{array}{l}5.3 \text { Endpoint score at } 4 \text { weeks (BPRS, } \\
\text { high = worse) }\end{array}$ & 1 & 68 & $\begin{array}{l}\text { Mean Difference (IV, Fixed, } \\
95 \% \mathrm{Cl} \text { ) }\end{array}$ & $5.40[1.84,8.96]$ \\
\hline $\begin{array}{l}6 \text { Adverse effects: } 1 \text {. General - Total } \\
\text { number of AEs }\end{array}$ & & & Other data & No numeric data \\
\hline $\begin{array}{l}7 \text { Adverse effects: } 2 \text { a. Specific - Anti- } \\
\text { cholinergic }\end{array}$ & 1 & & $\begin{array}{l}\text { Risk Ratio (M-H, Fixed, 95\% } \\
\mathrm{Cl})\end{array}$ & Subtotals only \\
\hline 7.1 Dry mouth over 24 hours & 1 & 68 & $\begin{array}{l}\text { Risk Ratio (M-H, Fixed, 95\% } \\
\mathrm{Cl})\end{array}$ & $2.12[0.81,5.55]$ \\
\hline 7.2 Constipation over 24 hours & 1 & 68 & $\begin{array}{l}\text { Risk Ratio (M-H, Fixed, 95\% } \\
\mathrm{Cl} \text { ) }\end{array}$ & $1.30[0.62,2.72]$ \\
\hline 8 Adverse effects: $2 b$. Specific - Arousal & 1 & & $\begin{array}{l}\text { Risk Ratio (M-H, Fixed, 95\% } \\
\mathrm{Cl})\end{array}$ & Subtotals only \\
\hline 8.1 Excessive sedation over 24 hours & 1 & 68 & $\begin{array}{l}\text { Risk Ratio (M-H, Fixed, 95\% } \\
\mathrm{Cl})\end{array}$ & $0.06[0.00,0.92]$ \\
\hline $\begin{array}{l}9 \text { Adverse effects: } 2 \text { c. Specific - Cardio- } \\
\text { vascular }\end{array}$ & 1 & & $\begin{array}{l}\text { Risk Ratio (M-H, Fixed, 95\% } \\
\text { Cl) }\end{array}$ & Subtotals only \\
\hline 9.1 Tachycardia over 24 hours & 1 & 68 & $\begin{array}{l}\text { Risk Ratio (M-H, Fixed, 95\% } \\
\mathrm{Cl})\end{array}$ & $1.24[0.46,3.30]$ \\
\hline
\end{tabular}




\begin{tabular}{|c|c|c|c|c|}
\hline Outcome or subgroup title & No. of studies & $\begin{array}{l}\text { No. of partici- } \\
\text { pants }\end{array}$ & Statistical method & Effect size \\
\hline $\begin{array}{l}10 \text { Adverse effects: } 2 \text { d. Specific - Gas- } \\
\text { trointestinal }\end{array}$ & 1 & & $\begin{array}{l}\text { Risk Ratio (M-H, Fixed, 95\% } \\
\mathrm{CI})\end{array}$ & Subtotals only \\
\hline 10.1 Nausea over 24 hours & 1 & 68 & $\begin{array}{l}\text { Risk Ratio (M-H, Fixed, 95\% } \\
\mathrm{Cl})\end{array}$ & $2.12[0.20,22.31]$ \\
\hline $\begin{array}{l}11 \text { Adverse effects: 2e. Specific - Move- } \\
\text { ment disorders }\end{array}$ & 1 & & $\begin{array}{l}\text { Risk Ratio (M-H, Fixed, 95\% } \\
\mathrm{Cl})\end{array}$ & Subtotals only \\
\hline 11.1 EPS over 24 hours & 1 & 68 & $\begin{array}{l}\text { Risk Ratio (M-H, Fixed, 95\% } \\
\mathrm{CI})\end{array}$ & $1.59[0.49,5.14]$ \\
\hline 11.2 Tremor over 24 hours & 1 & 68 & $\begin{array}{l}\text { Risk Ratio (M-H, Fixed, 95\% } \\
\mathrm{Cl})\end{array}$ & $0.85[0.25,2.89]$ \\
\hline $\begin{array}{l}12 \text { Adverse effects: } 2 \text { f. Specific - Miscella- } \\
\text { neous }\end{array}$ & 1 & & $\begin{array}{l}\text { Risk Ratio (M-H, Fixed, 95\% } \\
\mathrm{Cl})\end{array}$ & Subtotals only \\
\hline 12.1 Headache over 24 hours & 1 & 68 & $\begin{array}{l}\text { Risk Ratio (M-H, Fixed, 95\% } \\
\mathrm{Cl})\end{array}$ & $0.07[0.00,1.19]$ \\
\hline 12.2 Skin rash over 24 hours & 1 & 68 & $\begin{array}{l}\text { Risk Ratio (M-H, Fixed, 95\% } \\
\mathrm{Cl})\end{array}$ & $0.35[0.01,8.37]$ \\
\hline
\end{tabular}

Analysis 4.1. Comparison 4 RISPERIDONE vs COMBINATION: a. RISPERIDONE + OXCARBAZEPINE, Outcome 1 Specific behaviour: 1. Agitation - Average scores - i. over 24 hours.

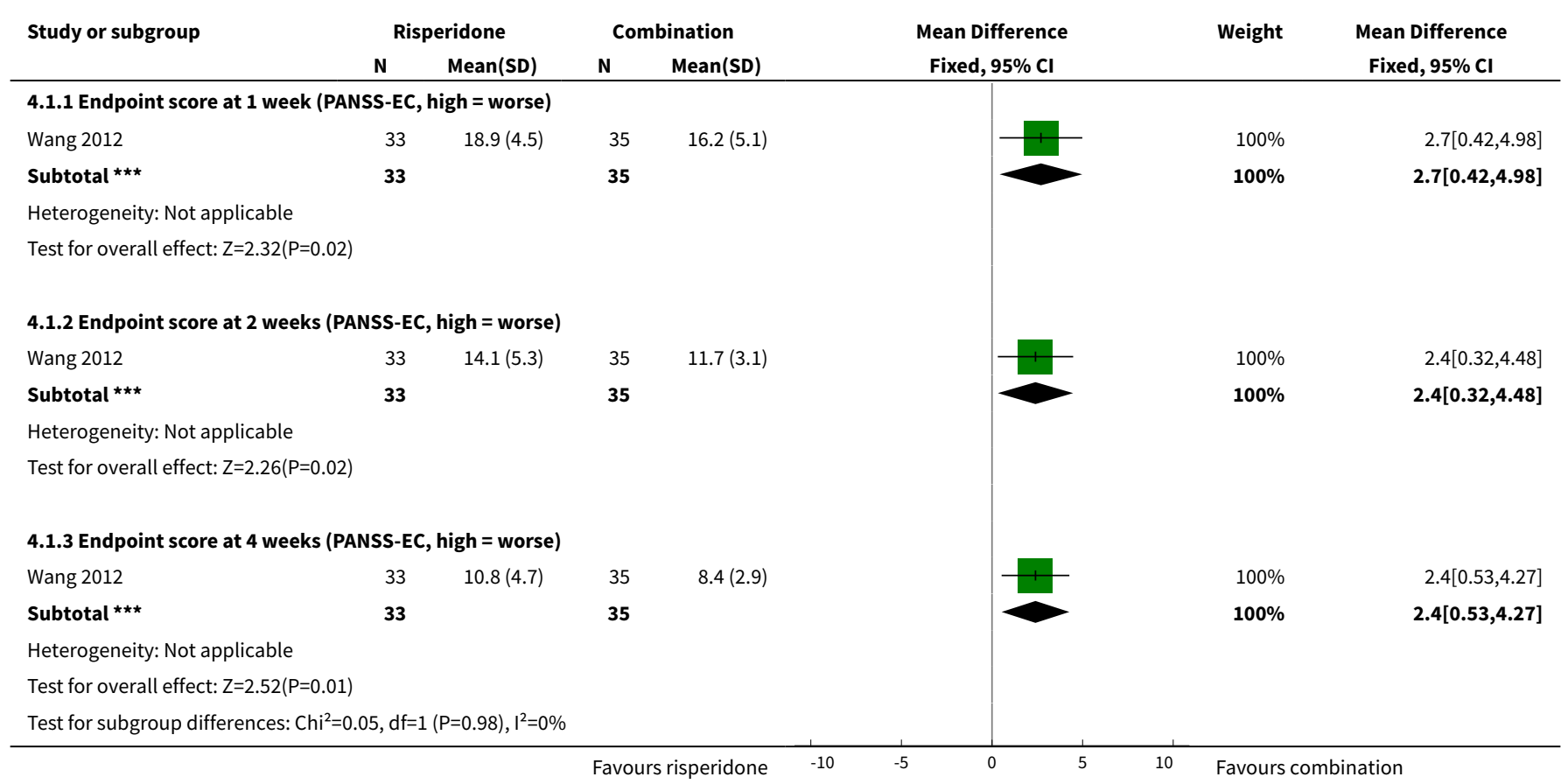


Analysis 4.2. Comparison 4 RISPERIDONE vs COMBINATION: a. RISPERIDONE + OXCARBAZEPINE, Outcome 2 Global Outcome: 1. Average scores - i. Over 24 hours.

\begin{tabular}{|c|c|c|c|c|c|c|c|}
\hline \multirow[t]{2}{*}{ Study or subgroup } & \multicolumn{2}{|c|}{ Risperidone } & \multicolumn{2}{|c|}{ Combination } & \multirow{2}{*}{$\begin{array}{c}\text { Mean Difference } \\
\text { Fixed, } 95 \% \mathrm{Cl}\end{array}$} & \multirow[t]{2}{*}{ Weight } & \multirow{2}{*}{$\begin{array}{c}\text { Mean Difference } \\
\text { Fixed, } 95 \% \mathrm{Cl}\end{array}$} \\
\hline & $\mathbf{N}$ & Mean(SD) & $\mathbf{N}$ & Mean(SD) & & & \\
\hline \multicolumn{8}{|c|}{ 4.2.1 Endpoint score at 1 week (CGI-I, high = worse) } \\
\hline Wang 2012 & 33 & $2.6(0.7)$ & 35 & $2.8(1)$ & 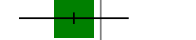 & $100 \%$ & $-0.2[-0.61,0.21]$ \\
\hline 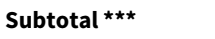 & 33 & & 35 & & & $100 \%$ & $-0.2[-0.61,0.21]$ \\
\hline \multicolumn{8}{|c|}{ Heterogeneity: Not applicable } \\
\hline \multicolumn{8}{|c|}{ Test for overall effect: $Z=0.96(P=0.34)$} \\
\hline \multicolumn{8}{|c|}{ 4.2.2 Endpoint score at 2 weeks (CGI-I, high = worse) } \\
\hline Wang 2012 & 33 & $2.4(1)$ & 35 & $1.9(0.8)$ & & $100 \%$ & $0.5[0.07,0.93]$ \\
\hline 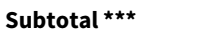 & 33 & & 35 & & & $100 \%$ & $0.5[0.07,0.93]$ \\
\hline \multicolumn{8}{|c|}{ Heterogeneity: Not applicable } \\
\hline \multicolumn{8}{|c|}{ Test for overall effect: $Z=2.27(P=0.02)$} \\
\hline Wang 2012 & 33 & $2.2(0.8)$ & 35 & $1.7(0.7)$ & & $100 \%$ & $0.5[0.14,0.86]$ \\
\hline Subtotal $* \star \star$ & 33 & & 35 & & & $100 \%$ & $0.5[0.14,0.86]$ \\
\hline \multicolumn{8}{|c|}{ Heterogeneity: Not applicable } \\
\hline \multicolumn{8}{|c|}{ Test for overall effect: $Z=2.74(P=0.01)$} \\
\hline \multicolumn{8}{|c|}{ 4.2.4 Endpoint score at 1 week ( $\mathrm{CGI}-\mathrm{S}$, high = worse) } \\
\hline Wang 2012 & 33 & $4.2(0.9)$ & 35 & $4(1)$ & & $100 \%$ & $0.2[-0.25,0.65]$ \\
\hline Subtotal $\star \star \star ~$ & 33 & & 35 & & & $100 \%$ & $0.2[-0.25,0.65]$ \\
\hline \multicolumn{8}{|c|}{ Heterogeneity: Not applicable } \\
\hline \multicolumn{8}{|c|}{ Test for overall effect: $\mathrm{Z}=0.87(\mathrm{P}=0.39)$} \\
\hline \multicolumn{8}{|c|}{ 4.2.5 Endpoint score at 2 weeks (CGI-S, high = worse) } \\
\hline Wang 2012 & 33 & $3.4(1)$ & 35 & $2.9(0.8)$ & & $100 \%$ & $0.5[0.07,0.93]$ \\
\hline \multicolumn{8}{|c|}{ Heterogeneity: Not applicable } \\
\hline \multicolumn{8}{|c|}{ Test for overall effect: $\mathrm{Z}=2.27(\mathrm{P}=0.02)$} \\
\hline \multicolumn{8}{|c|}{ 4.2.6 Endpoint score at 4 weeks (CGI-S, high = worse) } \\
\hline Wang 2012 & 33 & $3.2(0.8)$ & 35 & $2.7(0.7)$ & & $100 \%$ & $0.5[0.14,0.86]$ \\
\hline 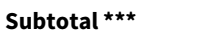 & 33 & & 35 & & & $100 \%$ & $0.5[0.14,0.86]$ \\
\hline \multicolumn{8}{|c|}{ Heterogeneity: Not applicable } \\
\hline \multicolumn{8}{|c|}{ Test for overall effect: $Z=2.74(P=0.01)$} \\
\hline Test for subgroup dif & $56, \mathrm{df}=$ & $P=0.09), 1^{2}=4 \varepsilon$ & & & & & \\
\hline
\end{tabular}

Analysis 4.3. Comparison 4 RISPERIDONE vs COMBINATION: a. RISPERIDONE + OXCARBAZEPINE, Outcome 3 Mental state: 1a. No change in general mental state.

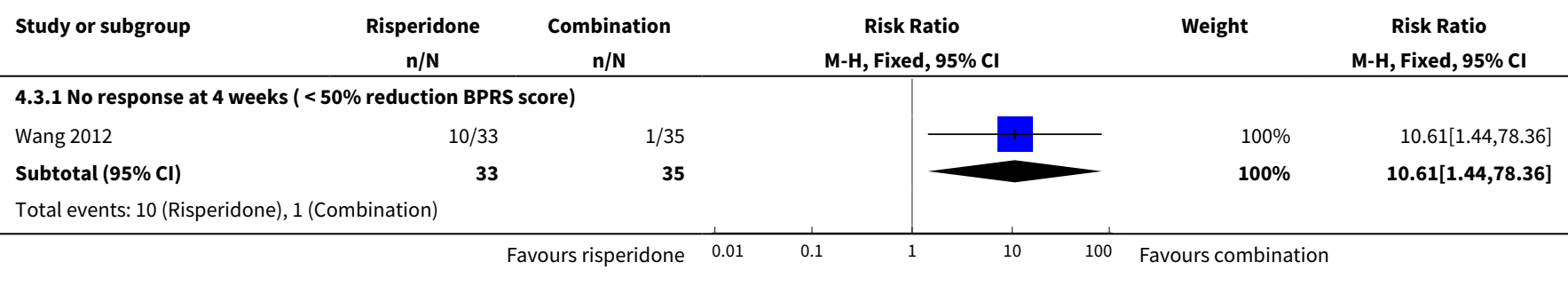




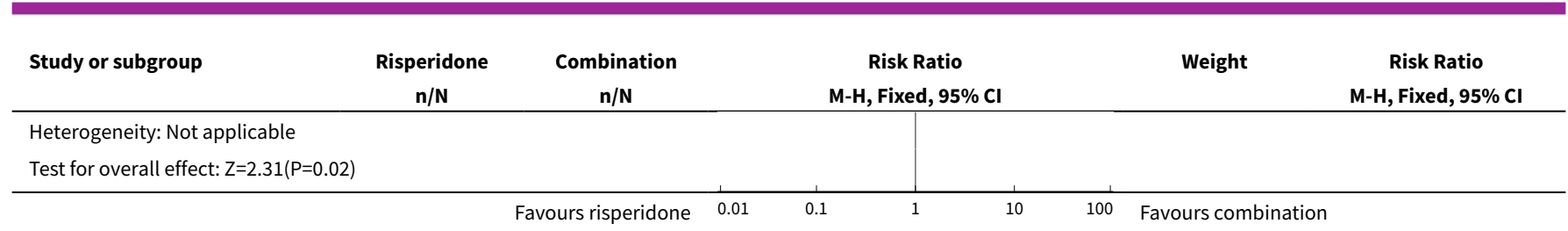

Analysis 4.4. Comparison 4 RISPERIDONE vs COMBINATION: a. RISPERIDONE + OXCARBAZEPINE, Outcome 4 Mental state: $1 \mathrm{~b}$. Change in general mental state.

\begin{tabular}{|c|c|c|c|c|c|}
\hline Study or subgroup & $\begin{array}{c}\text { Risperidone } \\
n / N\end{array}$ & $\begin{array}{c}\text { Combination } \\
n / N\end{array}$ & $\begin{array}{c}\text { Risk Ratio } \\
\text { M-H, Fixed, 95\% Cl }\end{array}$ & Weight & $\begin{array}{c}\text { Risk Ratio } \\
\text { M-H, Fixed, 95\% Cl }\end{array}$ \\
\hline \multicolumn{6}{|c|}{ 4.4.1 Clinical response at 4 weeks ( $50-75 \%$ reduction at BPRS score) } \\
\hline Wang 2012 & $19 / 33$ & $29 / 35$ & & $100 \%$ & $0.69[0.5,0.97]$ \\
\hline Subtotal $(95 \% \mathrm{Cl})$ & 33 & 35 & & $100 \%$ & $0.69[0.5,0.97]$ \\
\hline \multicolumn{6}{|c|}{ Total events: 19 (Risperidone), 29 (Combination) } \\
\hline \multicolumn{6}{|c|}{ Heterogeneity: Not applicable } \\
\hline \multicolumn{6}{|c|}{ 4.4.2 Clinical response at 4 weeks ( $\geq 75 \%$ reduction at BPRS score) } \\
\hline Wang 2012 & $4 / 33$ & $5 / 35$ & & $100 \%$ & $0.85[0.25,2.89]$ \\
\hline Subtotal $(95 \% \mathrm{CI})$ & 33 & 35 & & $100 \%$ & $0.85[0.25,2.89]$ \\
\hline \multicolumn{6}{|c|}{ Total events: 4 (Risperidone), 5 (Combination) } \\
\hline \multicolumn{6}{|c|}{ Heterogeneity: Not applicable } \\
\hline Test for subgroup dif & $1, \mathrm{df}=1(\mathrm{P}=0.76), \mathrm{I}^{2}$ & & & & \\
\hline
\end{tabular}

Analysis 4.5. Comparison 4 RISPERIDONE vs COMBINATION: a. RISPERIDONE + OXCARBAZEPINE, Outcome 5 Mental state: 1c. Average scores - i. Over 24 hours.

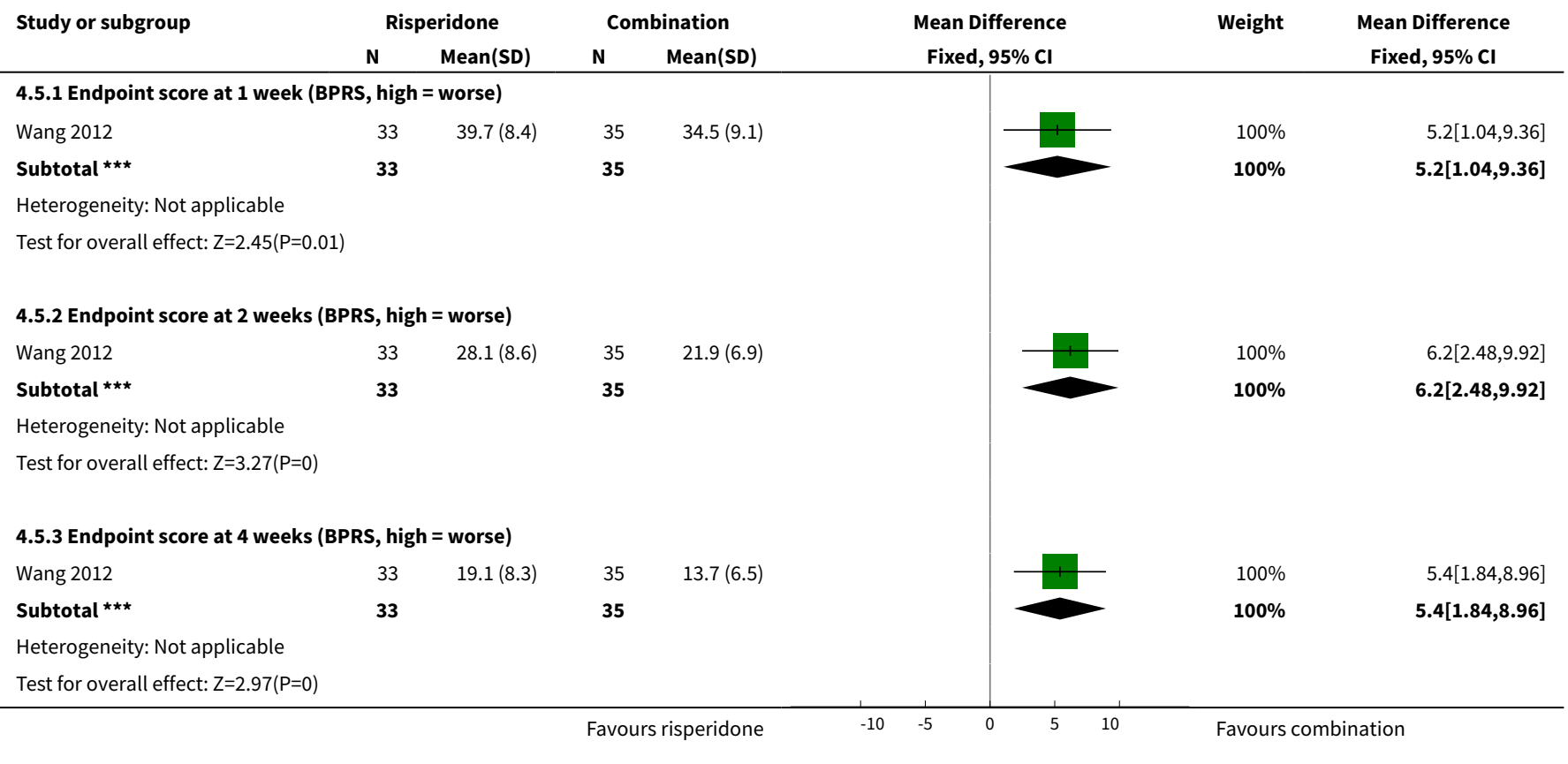




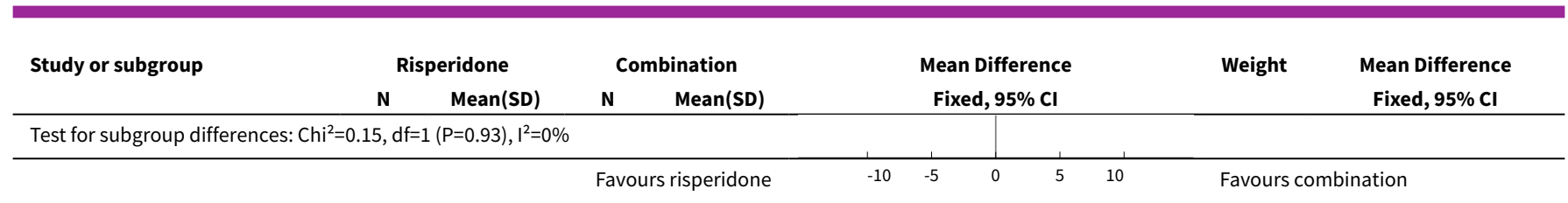

Analysis 4.6. Comparison 4 RISPERIDONE vs COMBINATION: a. RISPERIDONE + OXCARBAZEPINE, Outcome 6 Adverse effects: 1. General - Total number of AEs.

\begin{tabular}{|c|c|c|c|c|}
\hline \multicolumn{5}{|c|}{ Adverse effects: 1 . General - Total number of AEs } \\
\hline Study & AEs $(n)$, risperidone & patients $(n)$, risperidone & AEs $(n)$, combination & patients ( $n$ ), combination \\
\hline Wang 2012 & 40 & 33 & 47 & 35 \\
\hline
\end{tabular}

Analysis 4.7. Comparison 4 RISPERIDONE vs COMBINATION: a. RISPERIDONE + OXCARBAZEPINE, Outcome 7 Adverse effects: 2a. Specific - Anticholinergic.

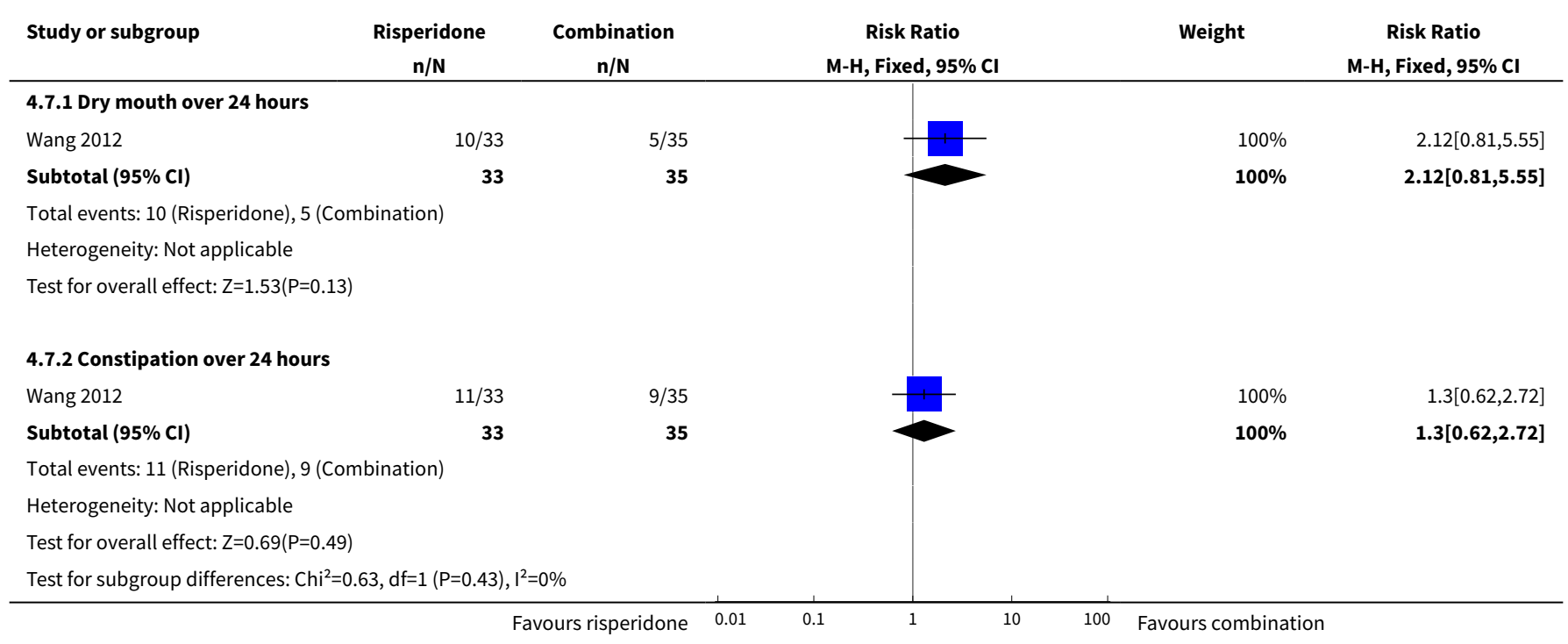

Analysis 4.8. Comparison 4 RISPERIDONE vs COMBINATION: a. RISPERIDONE + OXCARBAZEPINE, Outcome 8 Adverse effects: 2 b. Specific - Arousal.

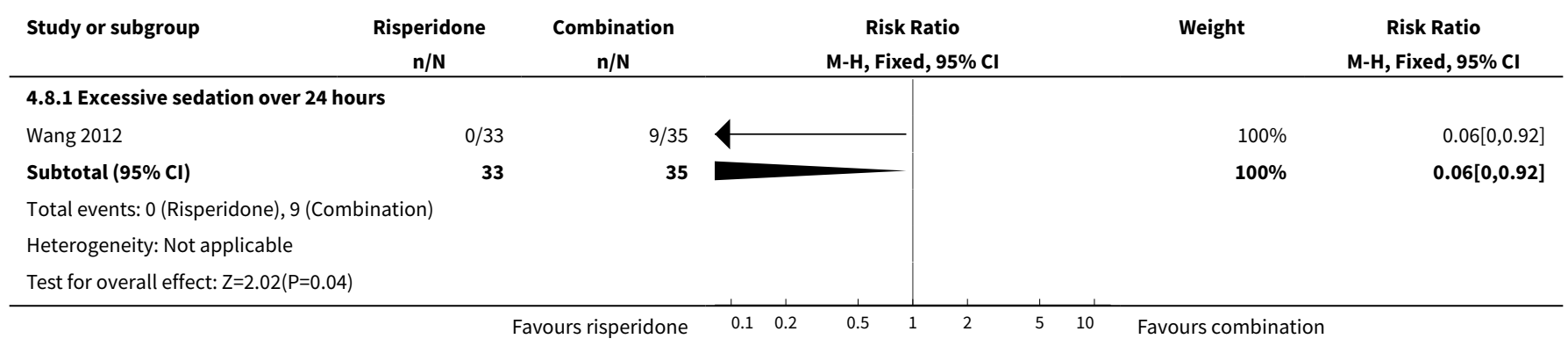


Analysis 4.9. Comparison 4 RISPERIDONE vs COMBINATION: a. RISPERIDONE

+ OXCARBAZEPINE, Outcome 9 Adverse effects: 2c. Specific - Cardiovascular.

\begin{tabular}{|c|c|c|c|c|c|}
\hline Study or subgroup & $\begin{array}{c}\text { Risperidone } \\
\mathrm{n} / \mathrm{N} \\
\end{array}$ & $\begin{array}{c}\text { Combination } \\
\mathrm{n} / \mathrm{N} \\
\end{array}$ & $\begin{array}{c}\text { Risk Ratio } \\
\text { M-H, Fixed, 95\% Cl }\end{array}$ & Weight & $\begin{array}{c}\text { Risk Ratio } \\
\text { M-H, Fixed, 95\% CI }\end{array}$ \\
\hline \multicolumn{6}{|c|}{ 4.9.1 Tachycardia over 24 hours } \\
\hline Wang 2012 & $7 / 33$ & $6 / 35$ & - & $100 \%$ & $1.24[0.46,3.3]$ \\
\hline Subtotal $(95 \% \mathrm{Cl})$ & 33 & 35 & & $100 \%$ & $1.24[0.46,3.3]$ \\
\hline \multicolumn{6}{|c|}{ Total events: 7 (Risperidone), 6 (Combination) } \\
\hline \multicolumn{6}{|c|}{ Heterogeneity: Not applicable } \\
\hline
\end{tabular}

Analysis 4.10. Comparison 4 RISPERIDONE vs COMBINATION: a. RISPERIDONE + OXCARBAZEPINE, Outcome 10 Adverse effects: $2 \mathrm{~d}$. Specific - Gastrointestinal.

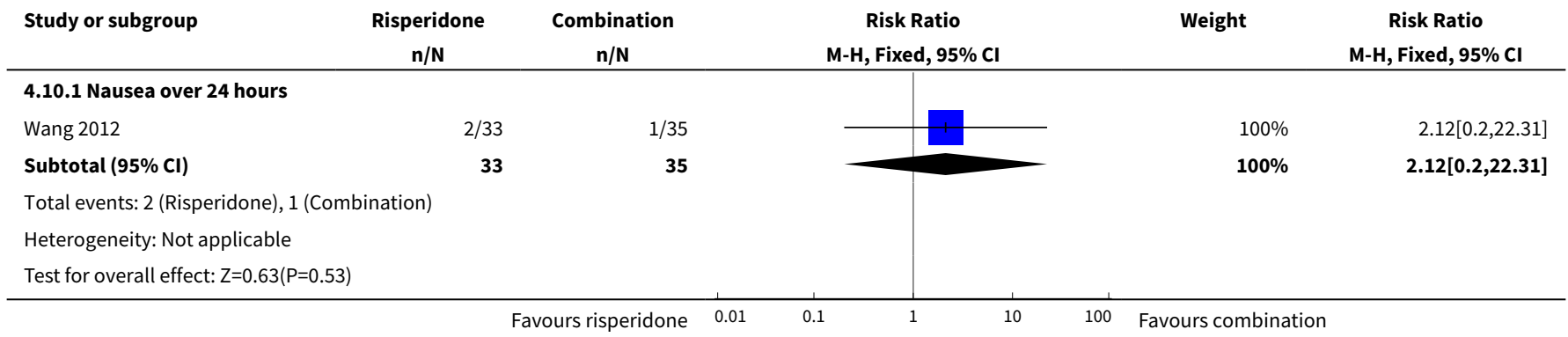

Analysis 4.11. Comparison 4 RISPERIDONE vs COMBINATION: a. RISPERIDONE + OXCARBAZEPINE, Outcome 11 Adverse effects: 2e. Specific - Movement disorders.

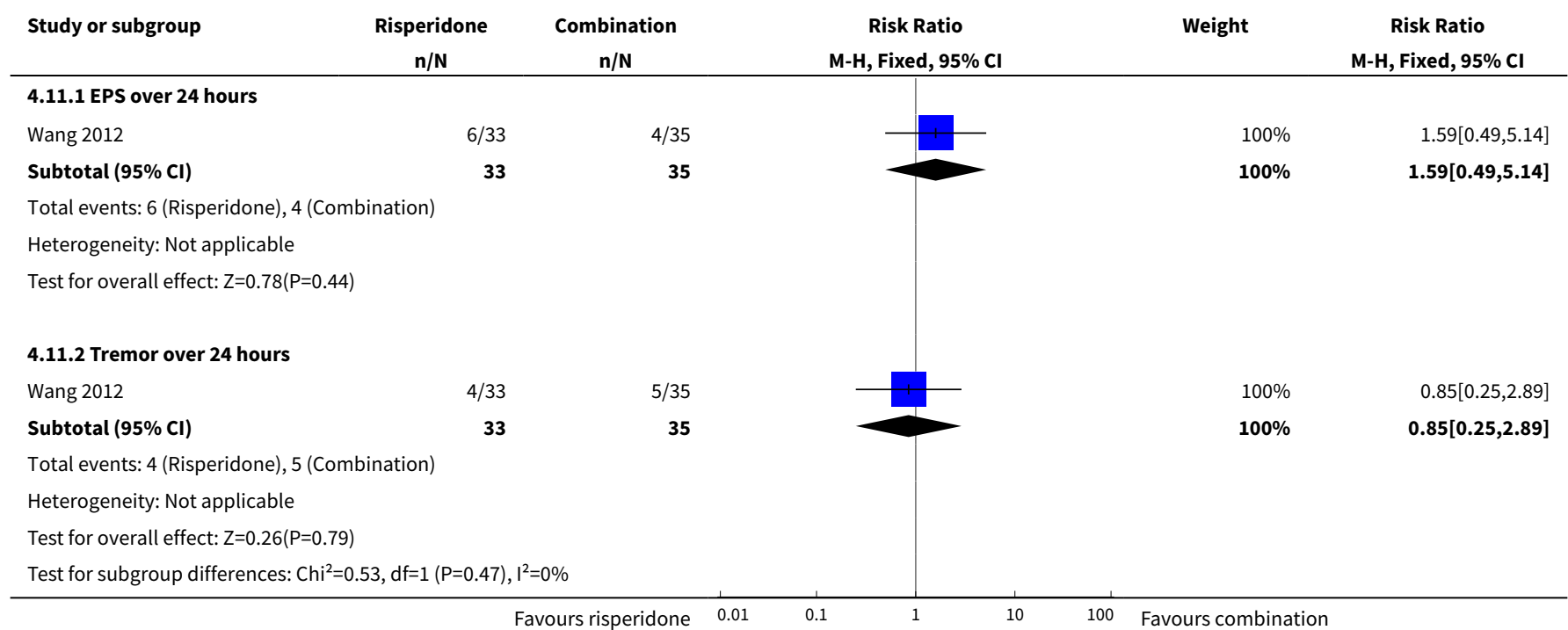


Analysis 4.12. Comparison 4 RISPERIDONE vs COMBINATION: a. RISPERIDONE

+ OXCARBAZEPINE, Outcome 12 Adverse effects: 2f. Specific - Miscellaneous.

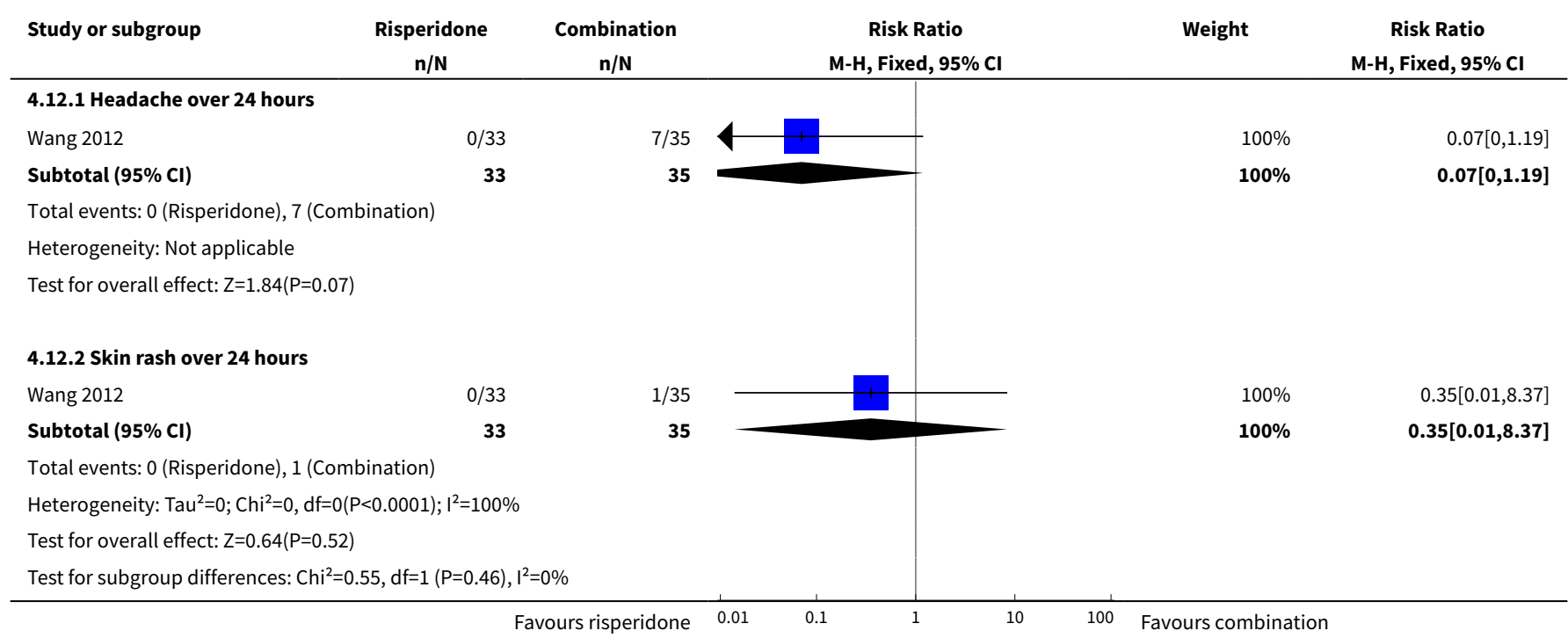

\section{Comparison 5. RISPERIDONE vs COMBINATION: b. RISPERIDONE + VALPROIC ACID}

\begin{tabular}{|c|c|c|c|c|}
\hline Outcome or subgroup title & No. of studies & $\begin{array}{l}\text { No. of partici- } \\
\text { pants }\end{array}$ & Statistical method & Effect size \\
\hline $\begin{array}{l}1 \text { Specific behaviour: } 1 \text {. Agitation - aver- } \\
\text { age scores - i. over } 24 \text { hours }\end{array}$ & 2 & & $\begin{array}{l}\text { Mean Difference (IV, Fixed, } \\
95 \% \mathrm{CI})\end{array}$ & Subtotals only \\
\hline $\begin{array}{l}1.1 \text { Endpoint score at } 3 \text { days (PANSS-EC, } \\
\text { high = worse) }\end{array}$ & 1 & 54 & $\begin{array}{l}\text { Mean Difference (IV, Fixed, } \\
95 \% \mathrm{CI})\end{array}$ & $-0.11[-2.98,2.76]$ \\
\hline $\begin{array}{l}1.2 \text { Endpoint score at } 5 \text { days (PANSS-EC, } \\
\text { high = worse) }\end{array}$ & 1 & 54 & $\begin{array}{l}\text { Mean Difference (IV, Fixed, } \\
95 \% \mathrm{CI})\end{array}$ & $5.47[2.64,8.30]$ \\
\hline $\begin{array}{l}1.3 \text { Endpoint score at } 7 \text { days (PANSS-EC, } \\
\text { high = worse) }\end{array}$ & 1 & 54 & $\begin{array}{l}\text { Mean Difference (IV, Fixed, } \\
95 \% \mathrm{CI})\end{array}$ & $5.11[2.51,7.71]$ \\
\hline $\begin{array}{l}\text { 1.4 Endpoint score at } 2 \text { weeks (PANSS- } \\
\text { EC, high = worse) }\end{array}$ & 1 & 63 & $\begin{array}{l}\text { Mean Difference (IV, Fixed, } \\
95 \% \mathrm{CI})\end{array}$ & $0.09[-0.90,1.08]$ \\
\hline $\begin{array}{l}\text { 1.5 Endpoint score at } 4 \text { weeks (PANSS- } \\
\text { EC, high = worse) }\end{array}$ & 1 & 63 & $\begin{array}{l}\text { Mean Difference (IV, Fixed, } \\
95 \% \mathrm{CI})\end{array}$ & $0.17[-0.85,1.19]$ \\
\hline $\begin{array}{l}2 \text { Specific behaviour: } 1 \text {. Aggression - Av- } \\
\text { erage scores - i. over } 24 \text { hours }\end{array}$ & 3 & & $\begin{array}{l}\text { Mean Difference (IV, Fixed, } \\
95 \% \mathrm{CI})\end{array}$ & Subtotals only \\
\hline $\begin{array}{l}2.1 \text { Endpoint score at } 3 \text { days (MOAS, high } \\
=\text { worse) }\end{array}$ & 1 & 54 & $\begin{array}{l}\text { Mean Difference (IV, Fixed, } \\
95 \% \mathrm{CI} \text { ) }\end{array}$ & $1.07[-0.20,2.34]$ \\
\hline $\begin{array}{l}2.2 \text { Endpoint score at } 5 \text { days (MOAS, high } \\
=\text { worse) }\end{array}$ & 1 & 54 & $\begin{array}{l}\text { Mean Difference (IV, Fixed, } \\
95 \% \mathrm{CI})\end{array}$ & $0.38[-0.83,1.59]$ \\
\hline $\begin{array}{l}2.3 \text { Endpoint score at } 7 \text { days (MOAS, high } \\
=\text { worse) }\end{array}$ & 1 & 54 & $\begin{array}{l}\text { Mean Difference (IV, Fixed, } \\
95 \% \mathrm{CI})\end{array}$ & $3.32[2.07,4.57]$ \\
\hline
\end{tabular}




\begin{tabular}{|c|c|c|c|c|}
\hline Outcome or subgroup title & No. of studies & $\begin{array}{l}\text { No. of partici- } \\
\text { pants }\end{array}$ & Statistical method & Effect size \\
\hline $\begin{array}{l}\text { 2.4 Endpoint score at } 2 \text { weeks (MOAS, } \\
\text { high = worse) }\end{array}$ & 2 & 128 & $\begin{array}{l}\text { Mean Difference (IV, Fixed, } \\
95 \% \mathrm{CI})\end{array}$ & $1.13[0.23,2.02]$ \\
\hline $\begin{array}{l}2.5 \text { Endpoint score at } 4 \text { weeks (MOAS, } \\
\text { high = worse) }\end{array}$ & 2 & 128 & $\begin{array}{l}\text { Mean Difference (IV, Fixed, } \\
95 \% \mathrm{Cl})\end{array}$ & $1.57[0.75,2.39]$ \\
\hline $\begin{array}{l}2.6 \text { Endpoint score at } 6 \text { weeks (MOAS, } \\
\text { high = worse) }\end{array}$ & 1 & 68 & $\begin{array}{l}\text { Mean Difference (IV, Fixed, } \\
95 \% \mathrm{CI})\end{array}$ & $1.47[0.83,2.11]$ \\
\hline $\begin{array}{l}2.7 \text { Endpoint score at } 8 \text { weeks (MOAS, } \\
\text { high = worse) }\end{array}$ & 1 & 60 & $\begin{array}{l}\text { Mean Difference (IV, Fixed, } \\
95 \% \mathrm{CI})\end{array}$ & $1.00[-0.11,2.11]$ \\
\hline $\begin{array}{l}3 \text { Mental state: } 1 \text {. No change in general } \\
\text { mental state }\end{array}$ & 1 & & $\begin{array}{l}\text { Risk Ratio (M-H, Fixed, 95\% } \\
\text { Cl) }\end{array}$ & Subtotals only \\
\hline $\begin{array}{l}3.1 \text { No clinical response at } 8 \text { weeks (< } \\
30 \% \text { reduction at PANSS score) }\end{array}$ & 1 & 62 & $\begin{array}{l}\text { Risk Ratio (M-H, Fixed, 95\% } \\
\text { Cl) }\end{array}$ & $1.67[0.44,6.38]$ \\
\hline $\begin{array}{l}4 \text { Mental state: } 2 \text {. Average scores - i. over } \\
24 \text { hours }\end{array}$ & 4 & & $\begin{array}{l}\text { Mean Difference (IV, Fixed, } \\
95 \% \mathrm{CI})\end{array}$ & Subtotals only \\
\hline $\begin{array}{l}\text { 4.1 Endpoint score at } 2 \text { weeks (PANSS, } \\
\text { high = worse) }\end{array}$ & 4 & 253 & $\begin{array}{l}\text { Mean Difference (IV, Fixed, } \\
95 \% \mathrm{CI})\end{array}$ & $3.48[1.88,5.08]$ \\
\hline $\begin{array}{l}\text { 4.2 Sub-group analysis: Endpoint score } \\
\text { at } 2 \text { weeks (PANSS, high }=\text { worse) }\end{array}$ & 3 & 185 & $\begin{array}{l}\text { Mean Difference (IV, Fixed, } \\
95 \% \mathrm{CI})\end{array}$ & $2.50[0.78,4.21]$ \\
\hline $\begin{array}{l}4.3 \text { Endpoint score at } 4 \text { weeks (PANSS, } \\
\text { high = worse) }\end{array}$ & 4 & 253 & $\begin{array}{l}\text { Mean Difference (IV, Fixed, } \\
95 \% \mathrm{CI})\end{array}$ & $5.45[3.81,7.08]$ \\
\hline $\begin{array}{l}\text { 4.4 Sub-group analysis: Endpoint score } \\
\text { at } 4 \text { weeks (PANSS, high }=\text { worse) }\end{array}$ & 3 & 185 & $\begin{array}{l}\text { Mean Difference (IV, Fixed, } \\
95 \% \mathrm{CI})\end{array}$ & $4.52[2.76,6.29]$ \\
\hline $\begin{array}{l}\text { 4.5 Endpoint score at } 6 \text { weeks (PANSS, } \\
\text { high }=\text { worse) }\end{array}$ & 2 & 130 & $\begin{array}{l}\text { Mean Difference (IV, Fixed, } \\
95 \% \mathrm{CI})\end{array}$ & $9.90[7.42,12.37]$ \\
\hline $\begin{array}{l}\text { 4.6 Endpoint score at } 8 \text { weeks (PANSS, } \\
\text { high = worse) }\end{array}$ & 2 & 122 & $\begin{array}{l}\text { Mean Difference (IV, Fixed, } \\
95 \% \mathrm{CI})\end{array}$ & $5.83[4.12,7.54]$ \\
\hline $\begin{array}{l}4.7 \text { Endpoint score at } 2 \text { weeks (PANSS } \\
\text { positive symptoms sub-scale, high = } \\
\text { worse) }\end{array}$ & 3 & 191 & $\begin{array}{l}\text { Mean Difference (IV, Fixed, } \\
95 \% \mathrm{CI})\end{array}$ & $0.64[-0.24,1.53]$ \\
\hline $\begin{array}{l}4.8 \text { Endpoint score at } 4 \text { weeks (PANSS } \\
\text { positive symptoms sub-scale, high = } \\
\text { worse) }\end{array}$ & 3 & 191 & $\begin{array}{l}\text { Mean Difference (IV, Fixed, } \\
95 \% \mathrm{CI})\end{array}$ & $2.75[1.86,3.64]$ \\
\hline $\begin{array}{l}4.9 \text { Endpoint score at } 6 \text { weeks (PANSS } \\
\text { positive symptoms sub-scale, high = } \\
\text { worse) }\end{array}$ & 1 & 68 & $\begin{array}{l}\text { Mean Difference (IV, Fixed, } \\
95 \% \mathrm{CI})\end{array}$ & $4.4[1.40,7.40]$ \\
\hline $\begin{array}{l}\text { 4.10 Endpoint score at } 8 \text { weeks (PANSS } \\
\text { positive symptoms sub-scale, high = } \\
\text { worse) }\end{array}$ & 1 & 60 & $\begin{array}{l}\text { Mean Difference (IV, Fixed, } \\
95 \% \mathrm{CI})\end{array}$ & $1.70[0.71,2.69]$ \\
\hline
\end{tabular}




\begin{tabular}{|c|c|c|c|c|}
\hline Outcome or subgroup title & No. of studies & $\begin{array}{l}\text { No. of partici- } \\
\text { pants }\end{array}$ & Statistical method & Effect size \\
\hline $\begin{array}{l}4.11 \text { Endpoint score at } 2 \text { weeks (PANSS } \\
\text { negative symptoms sub-scale, high = } \\
\text { worse) }\end{array}$ & 2 & 128 & $\begin{array}{l}\text { Mean Difference (IV, Fixed, } \\
95 \% \mathrm{Cl} \text { ) }\end{array}$ & $0.29[-0.57,1.15]$ \\
\hline $\begin{array}{l}\text { 4.12 Endpoint score at } 4 \text { weeks (PANSS } \\
\text { negative symptoms sub-scale, high = } \\
\text { worse) }\end{array}$ & 2 & 128 & $\begin{array}{l}\text { Mean Difference (IV, Fixed, } \\
95 \% \mathrm{CI})\end{array}$ & $1.23[-0.16,2.62]$ \\
\hline $\begin{array}{l}4.13 \text { Endpoint score at } 6 \text { weeks (PANSS } \\
\text { negative symptoms sub-scale, high = } \\
\text { worse) }\end{array}$ & 1 & 68 & $\begin{array}{l}\text { Mean Difference (IV, Fixed, } \\
95 \% \mathrm{Cl} \text { ) }\end{array}$ & $3.80[1.07,6.53]$ \\
\hline $\begin{array}{l}\text { 4.14 Endpoint score at } 8 \text { weeks (PANSS } \\
\text { negative symptoms sub-scale, high = } \\
\text { worse) }\end{array}$ & 1 & 60 & $\begin{array}{l}\text { Mean Difference (IV, Fixed, } \\
95 \% \mathrm{CI})\end{array}$ & $1.30[-0.02,2.62]$ \\
\hline $\begin{array}{l}4.15 \text { Endpoint score at } 2 \text { weeks (PANSS } \\
\text { general psychopathology sub-scale, } \\
\text { high = worse) }\end{array}$ & 2 & 128 & $\begin{array}{l}\text { Mean Difference (IV, Fixed, } \\
95 \% \mathrm{CI})\end{array}$ & $0.93[-0.07,1.93]$ \\
\hline $\begin{array}{l}\text { 4.16 Endpoint score at } 4 \text { weeks (PANSS } \\
\text { general psychopathology sub-scale, } \\
\text { high = worse) }\end{array}$ & 2 & 128 & $\begin{array}{l}\text { Mean Difference (IV, Fixed, } \\
95 \% \mathrm{Cl})\end{array}$ & $1.14[0.04,2.23]$ \\
\hline $\begin{array}{l}\text { 4.17 Endpoint score at } 6 \text { weeks (PANSS } \\
\text { general psychopathology sub-scale, } \\
\text { high = worse) }\end{array}$ & 1 & 68 & $\begin{array}{l}\text { Mean Difference (IV, Fixed, } \\
95 \% \mathrm{CI})\end{array}$ & $6.5[4.06,8.94]$ \\
\hline $\begin{array}{l}\text { 4.18 Endpoint score at } 8 \text { weeks (PANSS } \\
\text { general psychopathology sub-scale, } \\
\text { high = worse) }\end{array}$ & 1 & 60 & $\begin{array}{l}\text { Mean Difference (IV, Fixed, } \\
95 \% \mathrm{Cl})\end{array}$ & $1.60[0.43,2.77]$ \\
\hline $\begin{array}{l}5 \text { Adverse effects: } 1 \text { a. General - Total } \\
\text { number of AEs }\end{array}$ & & & Other data & No numeric data \\
\hline 6 Adverse effects: 1 b. General - Serious & 1 & & $\begin{array}{l}\text { Risk Ratio (M-H, Fixed, 95\% } \\
\mathrm{Cl})\end{array}$ & Subtotals only \\
\hline 6.1 myocardial ischaemia (at 8 weeks) & 1 & 62 & $\begin{array}{l}\text { Risk Ratio (M-H, Fixed, 95\% } \\
\mathrm{Cl})\end{array}$ & $2.0[0.19,20.93]$ \\
\hline $\begin{array}{l}7 \text { Adverse effects: } 2 a \text {. Specific - Anti- } \\
\text { cholinergic }\end{array}$ & 3 & & $\begin{array}{l}\text { Risk Ratio (M-H, Fixed, 95\% } \\
\mathrm{Cl})\end{array}$ & Subtotals only \\
\hline 7.1 Blurred vision over 24 hours & 2 & 122 & $\begin{array}{l}\text { Risk Ratio (M-H, Fixed, 95\% } \\
\mathrm{Cl})\end{array}$ & $1.0[0.37,2.68]$ \\
\hline 7.2 Dry mouth over 24 hours & 2 & 129 & $\begin{array}{l}\text { Risk Ratio (M-H, Fixed, 95\% } \\
\mathrm{Cl})\end{array}$ & $1.64[0.76,3.54]$ \\
\hline 8 Adverse effects: $2 b$. Specific - Arousal & 3 & & $\begin{array}{l}\text { Risk Ratio (M-H, Fixed, 95\% } \\
\mathrm{Cl} \text { ) }\end{array}$ & Subtotals only \\
\hline 8.1 Insomnia over 24 hours & 1 & 54 & $\begin{array}{l}\text { Risk Ratio (M-H, Fixed, 95\% } \\
\mathrm{Cl} \text { ) }\end{array}$ & $2.0[0.19,20.77]$ \\
\hline
\end{tabular}




\begin{tabular}{|c|c|c|c|c|}
\hline Outcome or subgroup title & No. of studies & $\begin{array}{l}\text { No. of partici- } \\
\text { pants }\end{array}$ & Statistical method & Effect size \\
\hline 8.2 Somnolence over 24 hours & 2 & 121 & $\begin{array}{l}\text { Risk Ratio (M-H, Fixed, 95\% } \\
\mathrm{CI})\end{array}$ & $0.85[0.44,1.63]$ \\
\hline $\begin{array}{l}9 \text { Adverse effects: } 2 c \text {. Specific - Cardio- } \\
\text { vascular }\end{array}$ & 5 & & $\begin{array}{l}\text { Risk Ratio (M-H, Fixed, 95\% } \\
\text { Cl) }\end{array}$ & Subtotals only \\
\hline $\begin{array}{l}9.1 \text { Decreased blood pressure over } 24 \\
\text { hours }\end{array}$ & 1 & 68 & $\begin{array}{l}\text { Risk Ratio (M-H, Fixed, 95\% } \\
\mathrm{Cl})\end{array}$ & $0.75[0.18,3.10]$ \\
\hline 9.2 Tachycardia over 24 hours & 4 & 251 & $\begin{array}{l}\text { Risk Ratio (M-H, Fixed, 95\% } \\
\mathrm{Cl})\end{array}$ & $1.48[0.83,2.67]$ \\
\hline 9.3 T-wave changes in ECG over 24 hours & 1 & 54 & $\begin{array}{l}\text { Risk Ratio (M-H, Fixed, 95\% } \\
\mathrm{Cl})\end{array}$ & $2.0[0.19,20.77]$ \\
\hline $\begin{array}{l}10 \text { Adverse effects: } 2 d \text {. Specific - Gas- } \\
\text { trointestinal }\end{array}$ & 4 & & $\begin{array}{l}\text { Risk Ratio (M-H, Fixed, 95\% } \\
\mathrm{Cl})\end{array}$ & Subtotals only \\
\hline 10.1 Constipation over 24 hours & 3 & 189 & $\begin{array}{l}\text { Risk Ratio (M-H, Fixed, 95\% } \\
\mathrm{CI})\end{array}$ & $1.11[0.70,1.76]$ \\
\hline 10.2 Nausea over 24 hours & 2 & 122 & $\begin{array}{l}\text { Risk Ratio (M-H, Fixed, 95\% } \\
\text { Cl) }\end{array}$ & $0.7[0.29,1.71]$ \\
\hline $\begin{array}{l}11 \text { Adverse effects: 2e. Specific - Move- } \\
\text { ment disorders }\end{array}$ & 4 & & $\begin{array}{l}\text { Risk Ratio (M-H, Fixed, 95\% } \\
\mathrm{Cl})\end{array}$ & Subtotals only \\
\hline 11.1 EPS over 24 hours & 2 & 121 & $\begin{array}{l}\text { Risk Ratio (M-H, Fixed, 95\% } \\
\mathrm{Cl})\end{array}$ & $1.35[0.76,2.39]$ \\
\hline 11.2 Akathisia over 24 hours & 2 & 122 & $\begin{array}{l}\text { Risk Ratio (M-H, Fixed, 95\% } \\
\mathrm{Cl})\end{array}$ & $0.75[0.28,2.03]$ \\
\hline 11.3 Tremor over 24 hours & 1 & 68 & $\begin{array}{l}\text { Risk Ratio (M-H, Fixed, 95\% } \\
\mathrm{Cl})\end{array}$ & $1.2[0.40,3.56]$ \\
\hline $\begin{array}{l}12 \text { Adverse effects: } 2 \text { f. Specific - Move- } \\
\text { ment disorders - Average scores - i. Over } \\
24 \text { hours }\end{array}$ & 1 & & $\begin{array}{l}\text { Mean Difference (IV, Fixed, } \\
95 \% \mathrm{CI})\end{array}$ & Subtotals only \\
\hline $\begin{array}{l}\text { 12.1 Endpoint score at } 3 \text { days (TESS, } \\
\text { high = worse) }\end{array}$ & 1 & 54 & $\begin{array}{l}\text { Mean Difference (IV, Fixed, } \\
95 \% \mathrm{Cl} \text { ) }\end{array}$ & $-0.04[-1.35,1.27]$ \\
\hline $\begin{array}{l}\text { 12.2 Endpoint score at } 5 \text { days (TESS, } \\
\text { high = worse) }\end{array}$ & 1 & 54 & $\begin{array}{l}\text { Mean Difference (IV, Fixed, } \\
95 \% \mathrm{CI})\end{array}$ & $-0.11[-1.55,1.33]$ \\
\hline $\begin{array}{l}\text { 12.3 Endpoint score at } 7 \text { days (TESS, } \\
\text { high = worse) }\end{array}$ & 1 & 54 & $\begin{array}{l}\text { Mean Difference (IV, Fixed, } \\
95 \% \mathrm{Cl} \text { ) }\end{array}$ & $-0.51[-1.88,0.86]$ \\
\hline $\begin{array}{l}13 \text { Adverse effects: } 2 g \text {. Specific - Miscel- } \\
\text { laneous }\end{array}$ & 5 & & $\begin{array}{l}\text { Risk Ratio (M-H, Fixed, 95\% } \\
\mathrm{Cl})\end{array}$ & Subtotals only \\
\hline 13.1 Headache over 24 hours & 4 & 243 & $\begin{array}{l}\text { Risk Ratio (M-H, Fixed, 95\% } \\
\mathrm{Cl})\end{array}$ & $0.94[0.53,1.68]$ \\
\hline
\end{tabular}




\begin{tabular}{|c|c|c|c|c|}
\hline Outcome or subgroup title & No. of studies & $\begin{array}{l}\text { No. of partici- } \\
\text { pants }\end{array}$ & Statistical method & Effect size \\
\hline 13.2 Weight gain over 24 hours & 1 & 60 & $\begin{array}{l}\text { Risk Ratio (M-H, Fixed, 95\% } \\
\mathrm{CI})\end{array}$ & $1.5[0.47,4.78]$ \\
\hline 13.3 Oedema over 24 hours & 1 & 63 & $\begin{array}{l}\text { Risk Ratio (M-H, Fixed, 95\% } \\
\mathrm{Cl})\end{array}$ & $0.34[0.01,8.13]$ \\
\hline 13.4 Leukopenia over 24 hours & 1 & 63 & $\begin{array}{l}\text { Risk Ratio (M-H, Fixed, 95\% } \\
\mathrm{Cl})\end{array}$ & $0.34[0.01,8.13]$ \\
\hline $\begin{array}{l}\text { 13.5 Liver Function Tests (LFTs) eleva- } \\
\text { tion over } 24 \text { hours }\end{array}$ & 2 & 116 & $\begin{array}{l}\text { Risk Ratio (M-H, Fixed, 95\% } \\
\mathrm{CI})\end{array}$ & $0.6[0.15,2.40]$ \\
\hline 14 Leaving the study early & 1 & & $\begin{array}{l}\text { Risk Ratio (M-H, Fixed, 95\% } \\
\mathrm{Cl} \text { ) }\end{array}$ & Subtotals only \\
\hline 14.1 For any reason & 1 & 63 & $\begin{array}{l}\text { Risk Ratio (M-H, Fixed, 95\% } \\
\mathrm{Cl} \text { ) }\end{array}$ & $0.21[0.01,4.13]$ \\
\hline 14.2 Due to adverse effects & 1 & 63 & $\begin{array}{l}\text { Risk Ratio (M-H, Fixed, 95\% } \\
\mathrm{Cl})\end{array}$ & $0.21[0.01,4.13]$ \\
\hline
\end{tabular}
Analysis 5.1. Comparison 5 RISPERIDONE vs COMBINATION: b. RISPERIDONE + VALPROIC
ACID, Outcome 1 Specific behaviour: 1 . Agitation - average scores - i. over 24 hours.

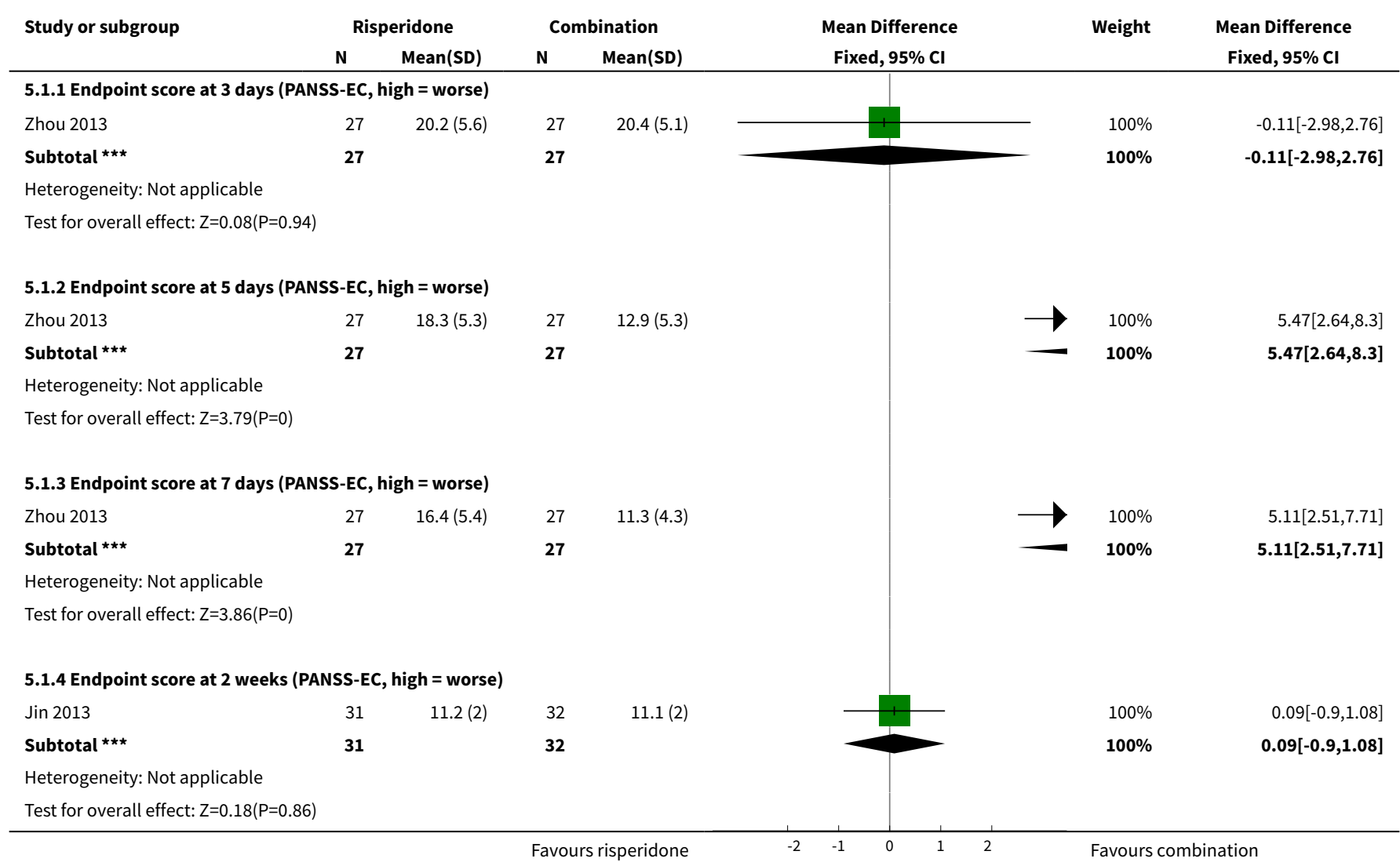




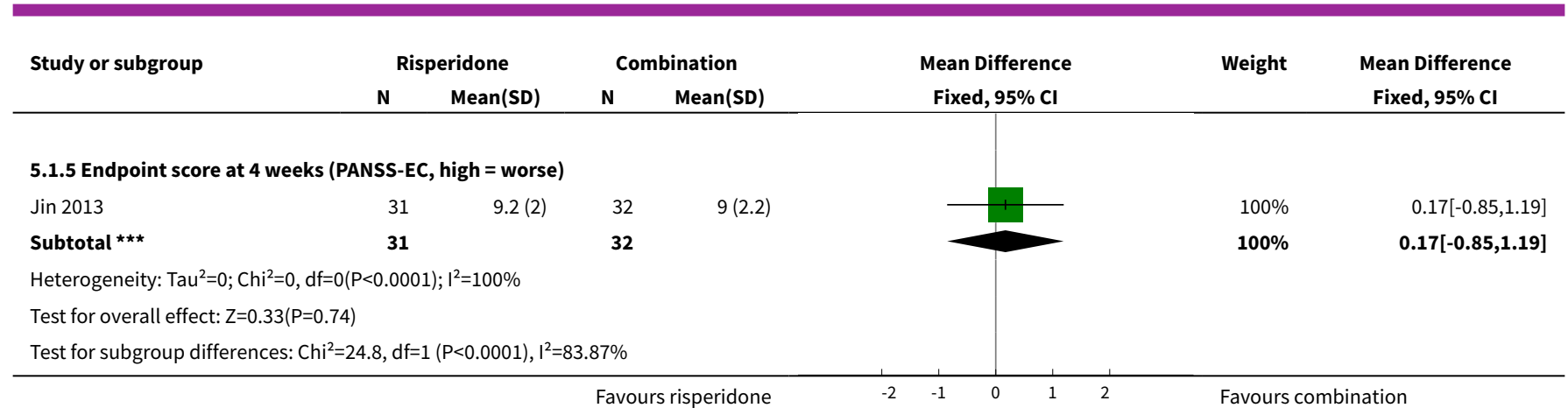

Analysis 5.2. Comparison 5 RISPERIDONE vs COMBINATION: b. RISPERIDONE + VALPROIC ACID, Outcome 2 Specific behaviour: 1. Aggression - Average scores - i. over 24 hours.

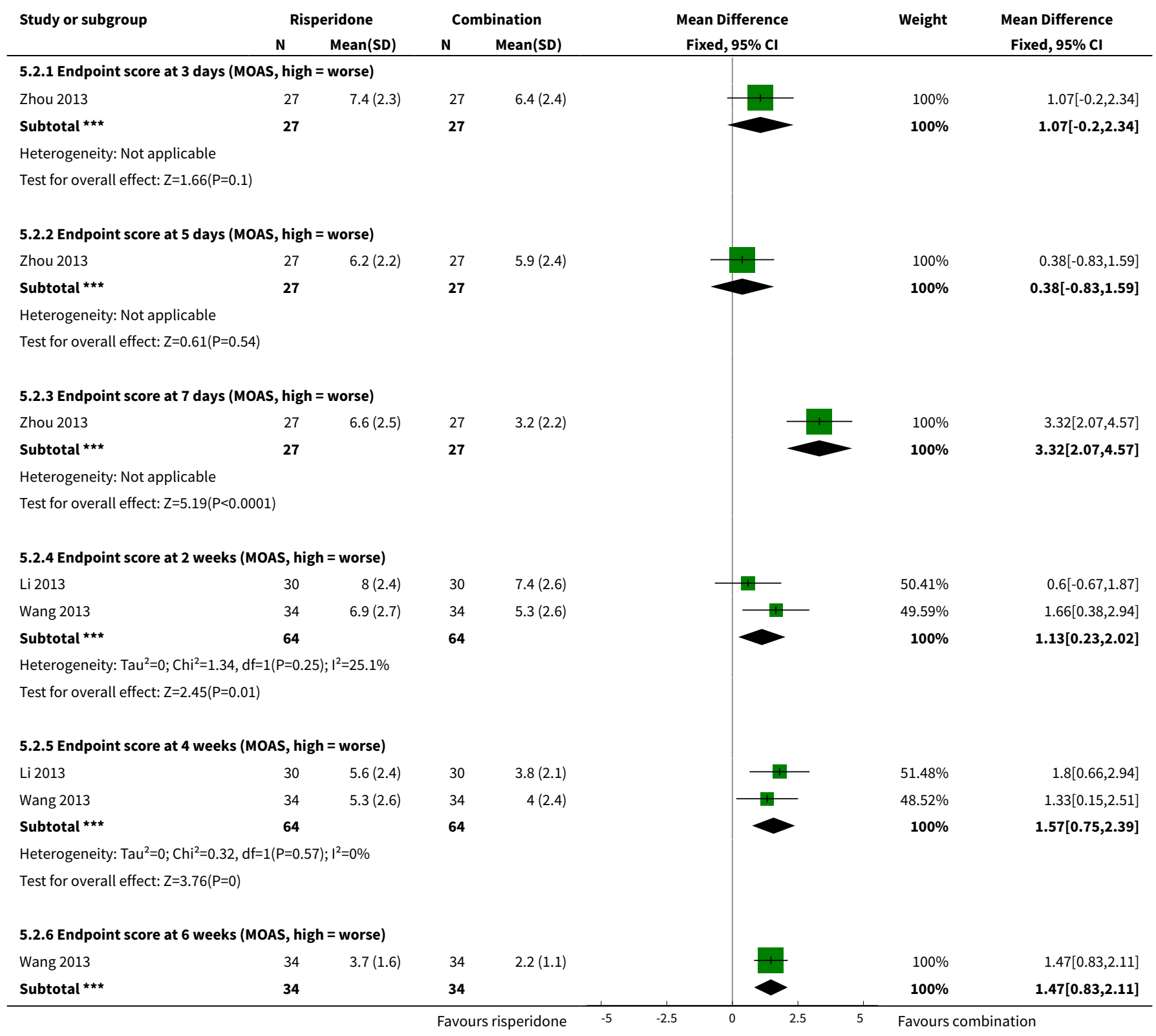




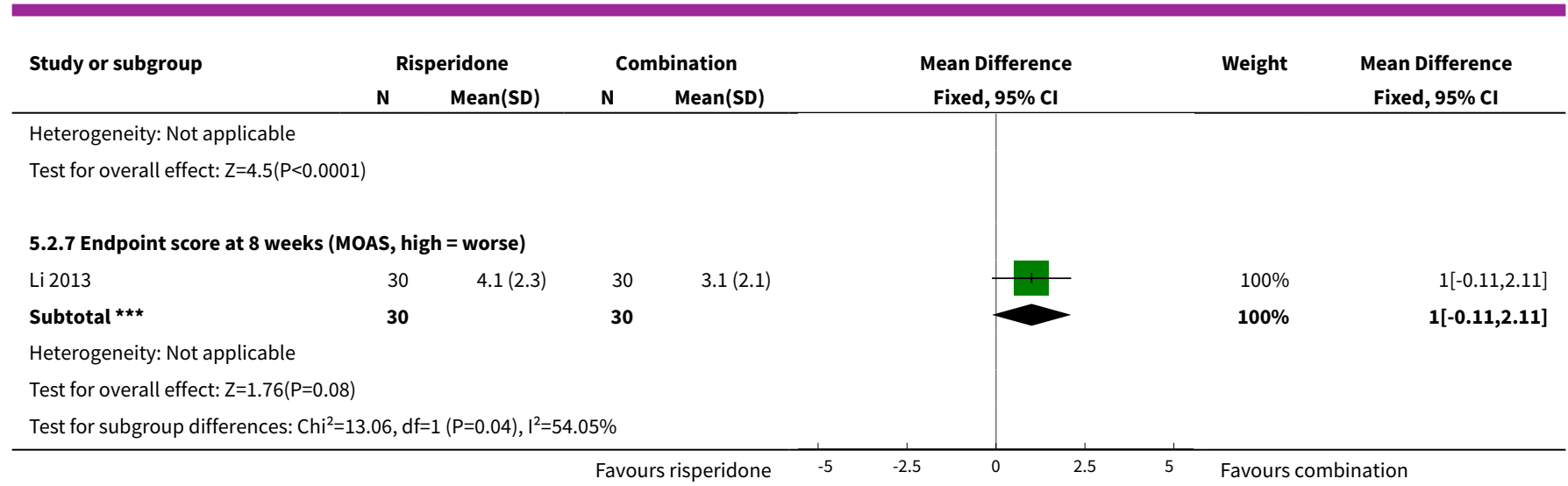

Analysis 5.3. Comparison 5 RISPERIDONE vs COMBINATION: b. RISPERIDONE + VALPROIC ACID, Outcome 3 Mental state: 1 . No change in general mental state.

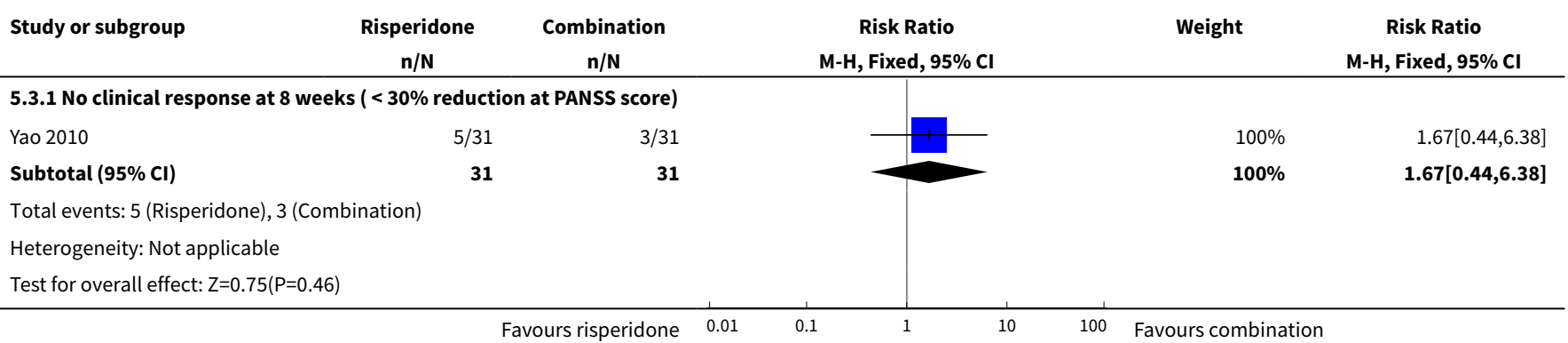

Analysis 5.4. Comparison 5 RISPERIDONE vs COMBINATION: b. RISPERIDONE + VALPROIC ACID, Outcome 4 Mental state: 2. Average scores - i. over 24 hours.

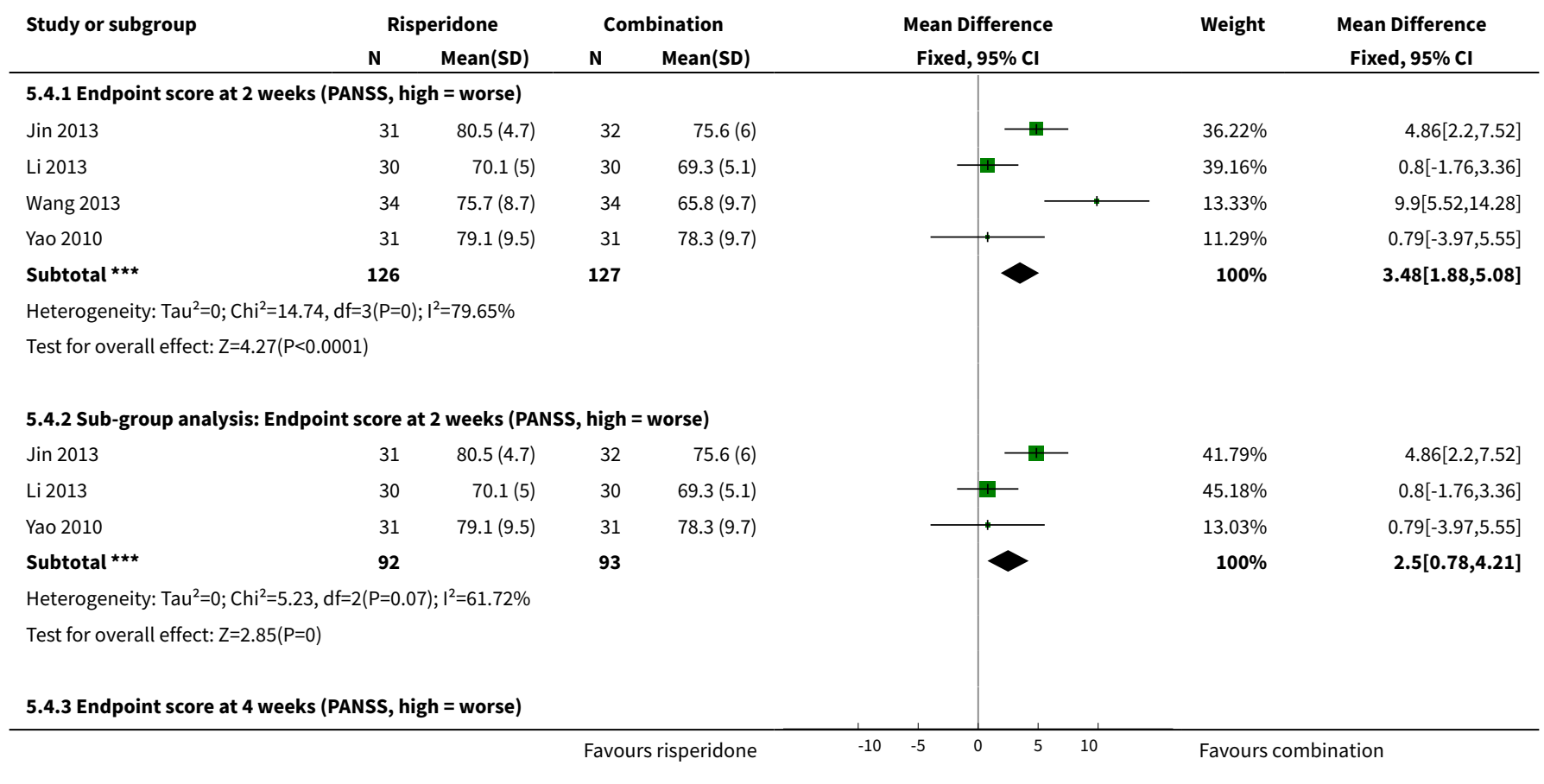




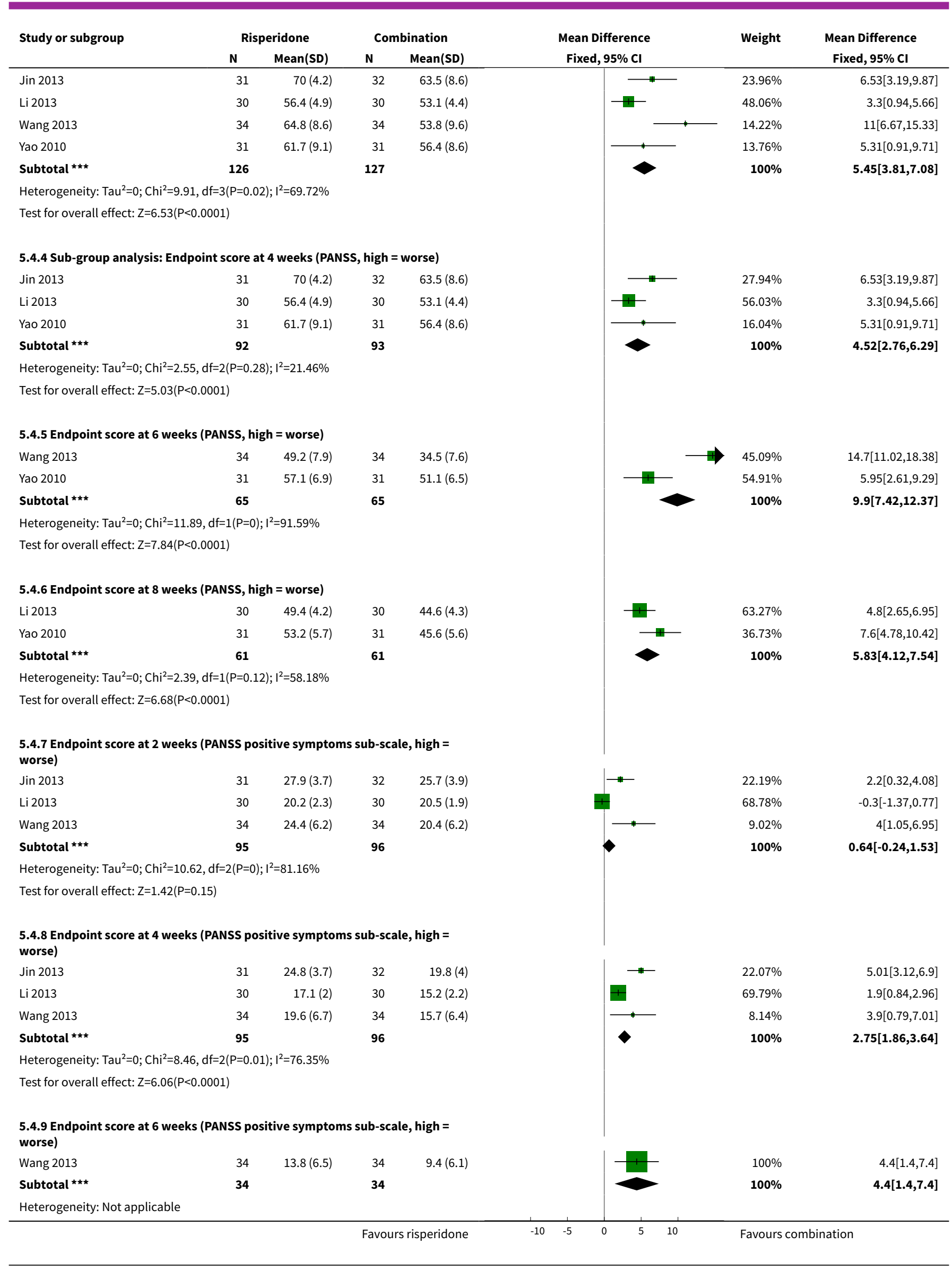




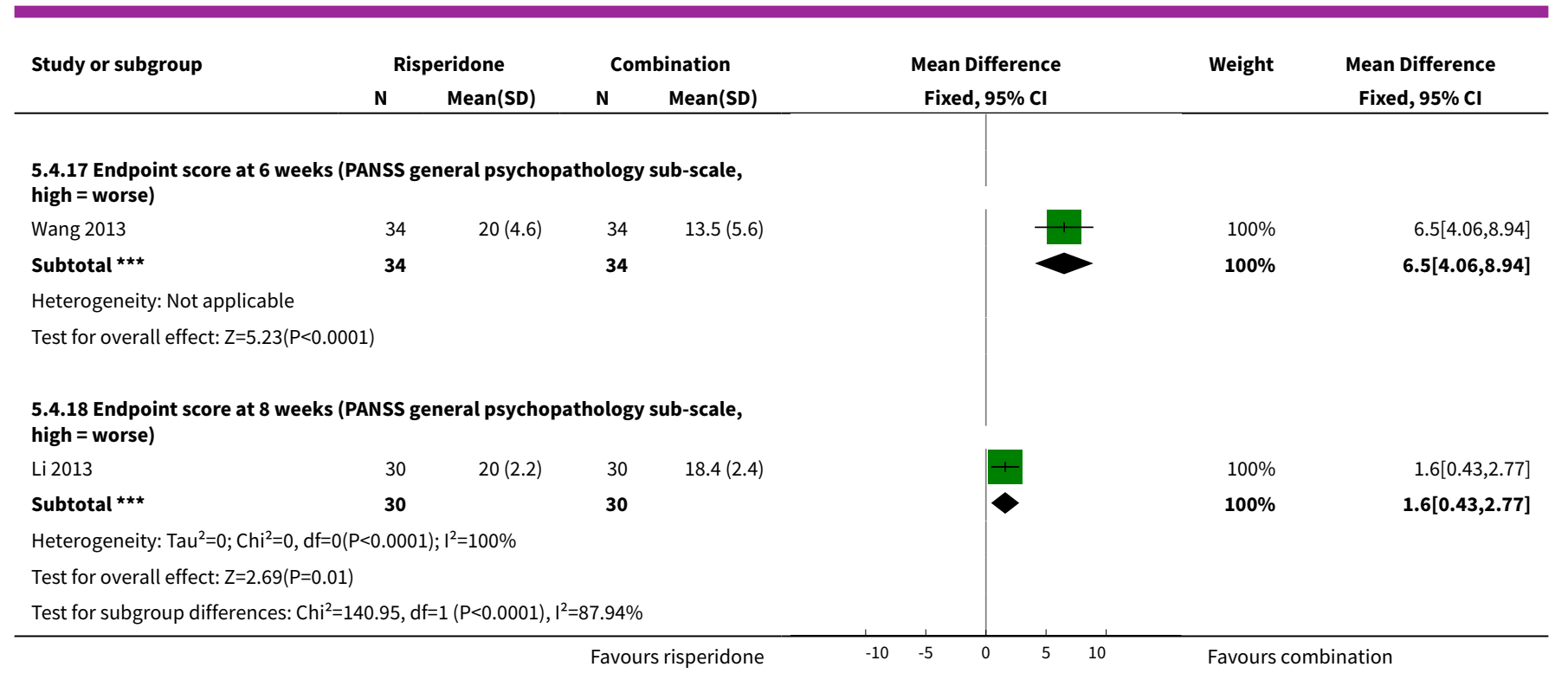

Analysis 5.5. Comparison 5 RISPERIDONE vs COMBINATION: b. RISPERIDONE + VALPROIC ACID, Outcome 5 Adverse effects: 1a. General - Total number of AEs.

\begin{tabular}{llllll} 
& & \multicolumn{4}{c}{ Adverse effects: 1a. General - Total number of AEs } \\
Study & & AEs $(\boldsymbol{n})$, risperidone & patients $(\boldsymbol{n})$, risperidone & AEs $(\boldsymbol{n})$, combination & patients $(\boldsymbol{n})$, combination \\
\hline Wang 2012 & 16 & 27 & 20 & 27 & \\
\hline
\end{tabular}

Analysis 5.6. Comparison 5 RISPERIDONE vs COMBINATION: b. RISPERIDONE + VALPROIC ACID, Outcome 6 Adverse effects: 1b. General - Serious.

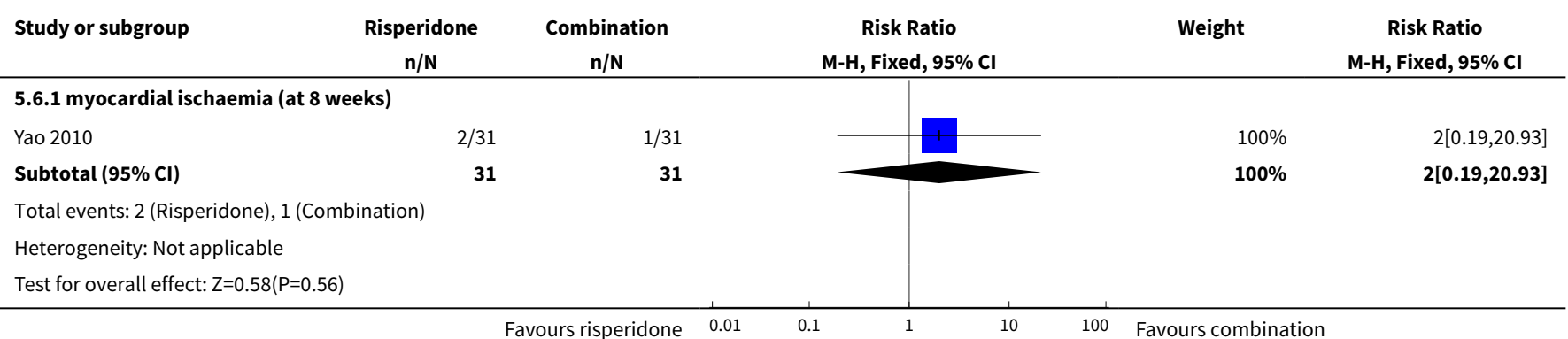

Analysis 5.7. Comparison 5 RISPERIDONE vs COMBINATION: b. RISPERIDONE + VALPROIC ACID, Outcome 7 Adverse effects: 2a. Specific - Anticholinergic.

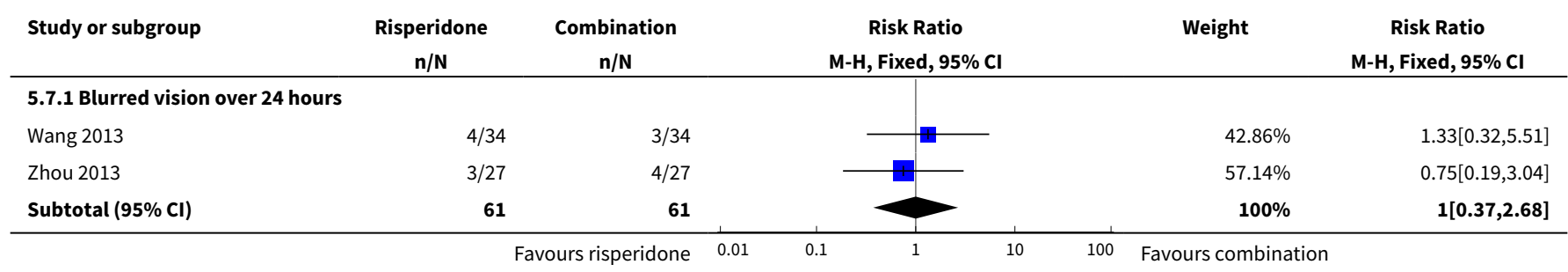




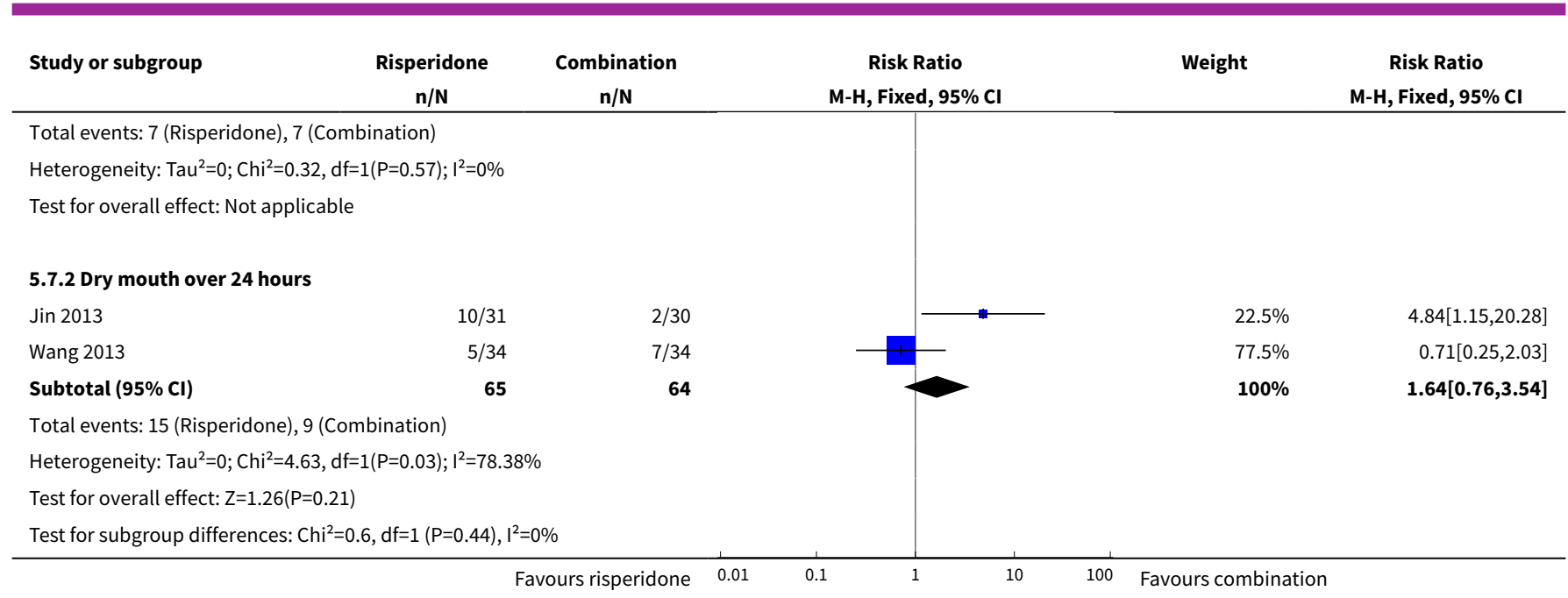

Analysis 5.8. Comparison 5 RISPERIDONE vs COMBINATION: b. RISPERIDONE + VALPROIC ACID, Outcome 8 Adverse effects: 2 b. Specific - Arousal.

\begin{tabular}{|c|c|c|c|c|c|}
\hline Study or subgroup & $\begin{array}{c}\text { Risperidone } \\
\mathrm{n} / \mathrm{N}\end{array}$ & $\begin{array}{c}\text { Combination } \\
\mathrm{n} / \mathrm{N}\end{array}$ & $\begin{array}{c}\text { Risk Ratio } \\
\text { M-H, Fixed, 95\% Cl }\end{array}$ & Weight & $\begin{array}{c}\text { Risk Ratio } \\
\text { M-H, Fixed, 95\% Cl }\end{array}$ \\
\hline \multicolumn{6}{|c|}{ 5.8.1 Insomnia over 24 hours } \\
\hline Zhou 2013 & $2 / 27$ & $1 / 27$ & & $100 \%$ & $2[0.19,20.77]$ \\
\hline Subtotal $(95 \% \mathrm{Cl})$ & 27 & 27 & & $100 \%$ & $2[0.19,20.77]$ \\
\hline \multicolumn{6}{|c|}{ Total events: 2 (Risperidone), 1 (Combination) } \\
\hline \multicolumn{6}{|c|}{ Heterogeneity: Not applicable } \\
\hline \multicolumn{6}{|c|}{ 5.8.2 Somnolence over 24 hours } \\
\hline Jin 2013 & $9 / 31$ & $8 / 30$ & 1 & $53.74 \%$ & $1.09[0.48,2.45]$ \\
\hline Li 2013 & $4 / 30$ & $7 / 30$ & & $46.26 \%$ & $0.57[0.19,1.75]$ \\
\hline Subtotal $(95 \% \mathrm{Cl})$ & 61 & 60 & & $100 \%$ & $0.85[0.44,1.63]$ \\
\hline \multicolumn{6}{|c|}{ Total events: 13 (Risperidone), 15 (Combination) } \\
\hline \multicolumn{6}{|c|}{ Test for overall effect: $Z=0.49(P=0.62)$} \\
\hline Test for subgroup dif & $48, d f=1(P=0.49)$, & & & & \\
\hline
\end{tabular}

Analysis 5.9. Comparison 5 RISPERIDONE vs COMBINATION: b. RISPERIDONE + VALPROIC ACID, Outcome 9 Adverse effects: 2c. Specific - Cardiovascular.

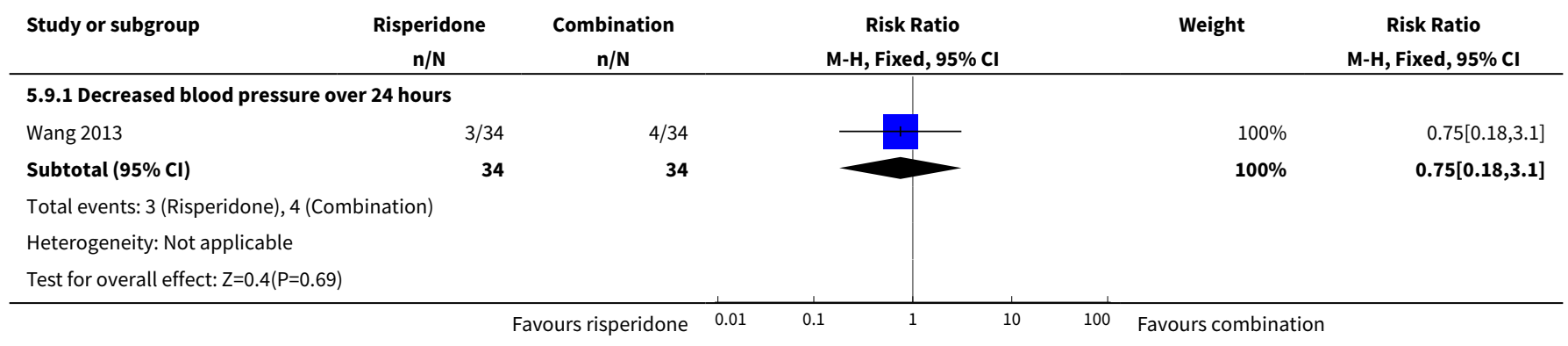




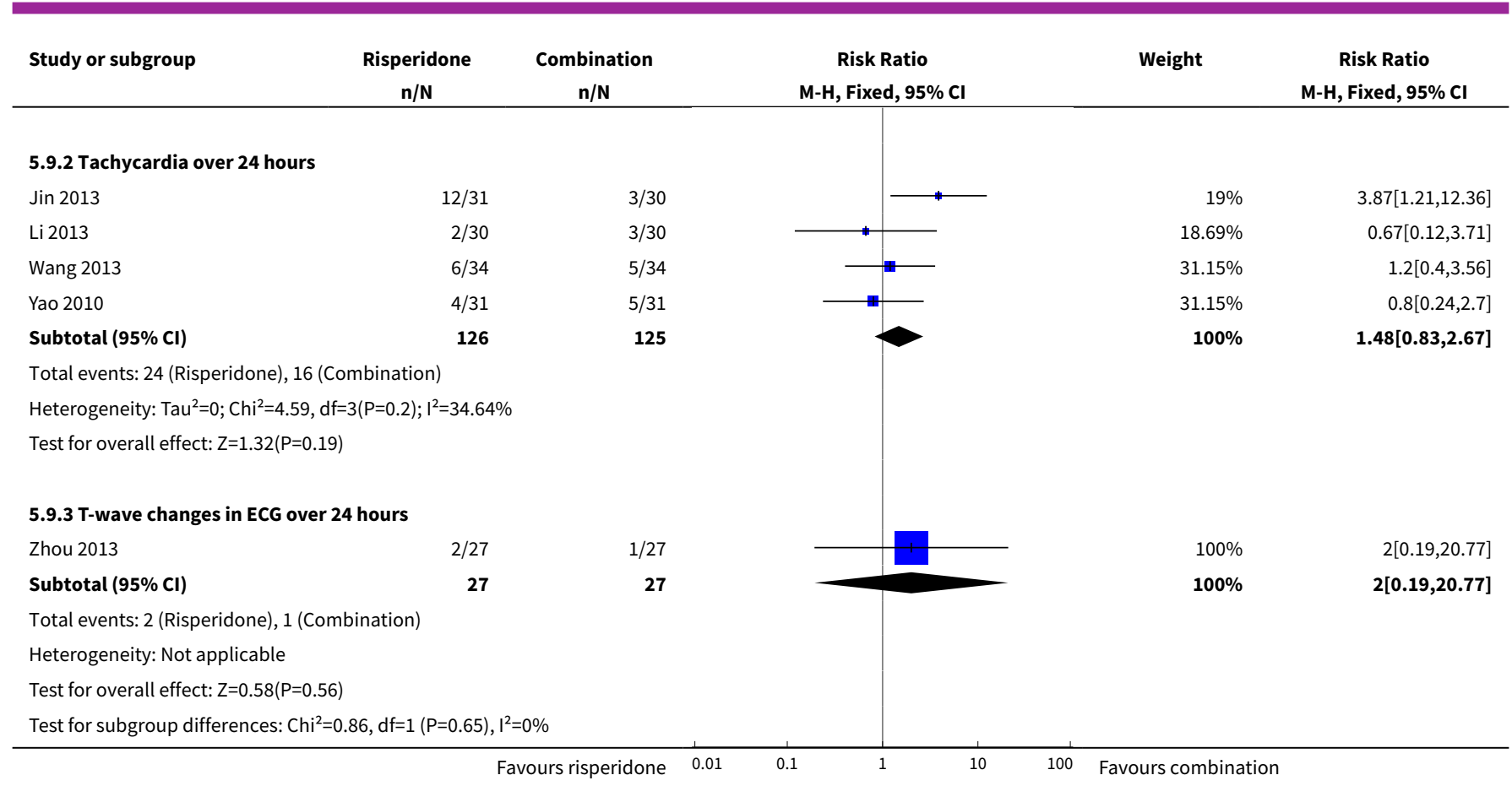

Analysis 5.10. Comparison 5 RISPERIDONE vs COMBINATION: b. RISPERIDONE + VALPROIC ACID, Outcome 10 Adverse effects: 2 d. Specific - Gastrointestinal.

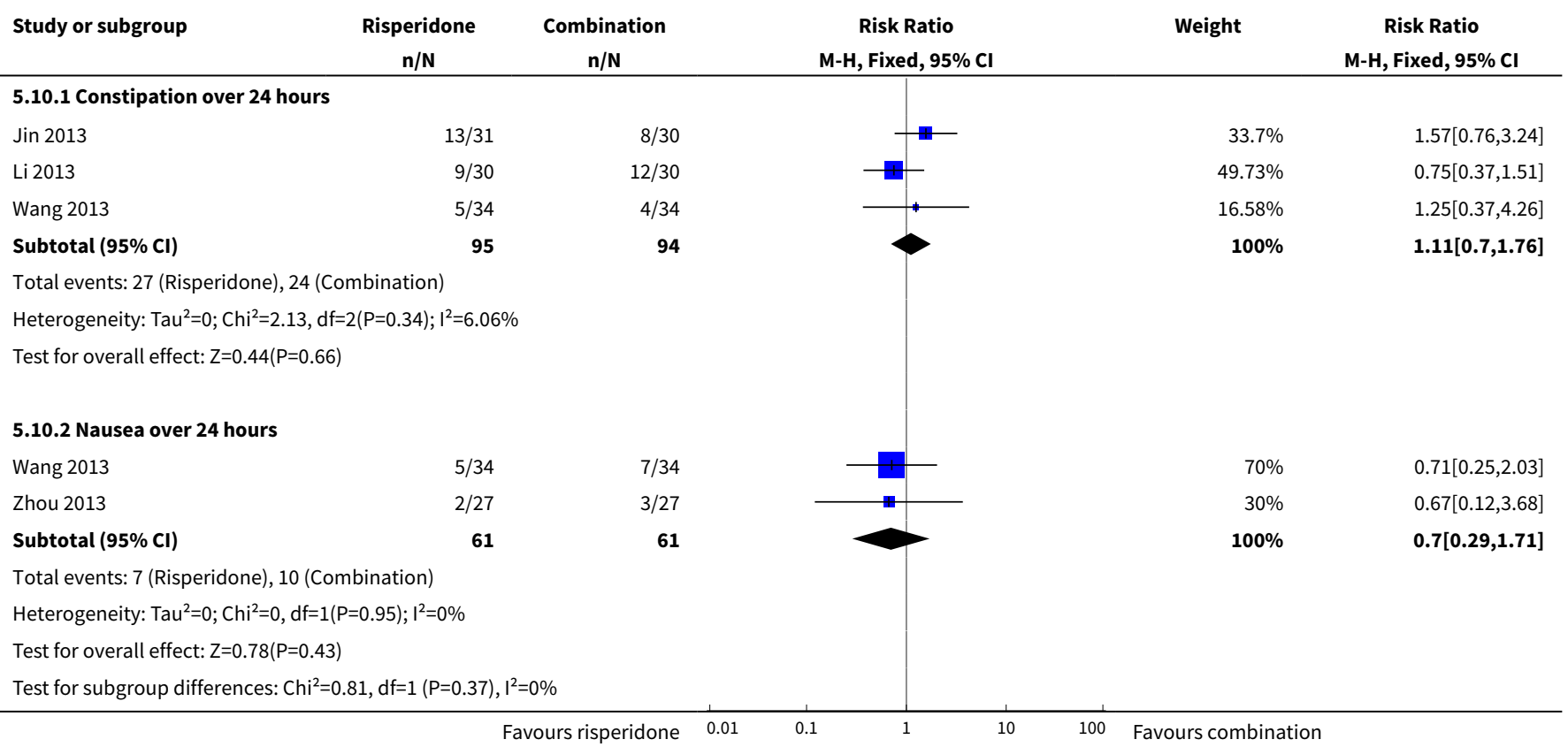


Analysis 5.11. Comparison 5 RISPERIDONE vs COMBINATION: b. RISPERIDONE + VALPROIC ACID, Outcome 11 Adverse effects: 2e. Specific - Movement disorders.

\begin{tabular}{|c|c|c|c|c|c|}
\hline Study or subgroup & $\begin{array}{c}\text { Risperidone } \\
\mathrm{n} / \mathrm{N} \\
\end{array}$ & $\begin{array}{c}\text { Combination } \\
n / N\end{array}$ & $\begin{array}{c}\text { Risk Ratio } \\
\text { M-H, Fixed, 95\% CI }\end{array}$ & Weight & $\begin{array}{c}\text { Risk Ratio } \\
\text { M-H, Fixed, 95\% Cl }\end{array}$ \\
\hline \multicolumn{6}{|c|}{ 5.11.1 EPS over 24 hours } \\
\hline Jin 2013 & $17 / 31$ & $4 / 30$ & $\longrightarrow$ & $25.31 \%$ & $4.11[1.56,10.81]$ \\
\hline Li 2013 & $5 / 30$ & $12 / 30$ & & $74.69 \%$ & $0.42[0.17,1.04]$ \\
\hline Subtotal $(95 \% \mathrm{Cl})$ & 61 & 60 & & $100 \%$ & $1.35[0.76,2.39]$ \\
\hline \multicolumn{6}{|c|}{ Total events: 22 (Risperidone), 16 (Combination) } \\
\hline \multicolumn{6}{|c|}{ Heterogeneity: $\operatorname{Tau}^{2}=0 ; \mathrm{Chi}^{2}=11.48, \mathrm{df}=1(\mathrm{P}=0) ; \mathrm{I}^{2}=91.29 \%$} \\
\hline \multicolumn{6}{|c|}{ Test for overall effect: $\mathrm{Z}=1.04(\mathrm{P}=0.3)$} \\
\hline \multicolumn{6}{|c|}{ 5.11.2 Akathisia over 24 hours } \\
\hline Wang 2013 & $3 / 34$ & $4 / 34$ & & $50 \%$ & $0.75[0.18,3.1]$ \\
\hline Zhou 2013 & $3 / 27$ & $4 / 27$ & & $50 \%$ & $0.75[0.19,3.04]$ \\
\hline Subtotal $(95 \% \mathrm{Cl})$ & 61 & 61 & & $100 \%$ & $0.75[0.28,2.03]$ \\
\hline \multicolumn{6}{|c|}{ Heterogeneity: $\operatorname{Tau}^{2}=0 ; \mathrm{Chi}^{2}=0, \mathrm{df}=1(\mathrm{P}=1) ; \mathrm{I}^{2}=0 \%$} \\
\hline \multicolumn{6}{|c|}{ Test for overall effect: $\mathrm{Z}=0.57(\mathrm{P}=0.57)$} \\
\hline \multicolumn{6}{|c|}{ 5.11.3 Tremor over 24 hours } \\
\hline Wang 2013 & $6 / 34$ & $5 / 34$ & & $100 \%$ & $1.2[0.4,3.56]$ \\
\hline Subtotal $(95 \% \mathrm{CI})$ & 34 & 34 & & $100 \%$ & $1.2[0.4,3.56]$ \\
\hline \multicolumn{6}{|c|}{ Total events: 6 (Risperidone), 5 (Combination) } \\
\hline \multicolumn{6}{|c|}{ Heterogeneity: Not applicable } \\
\hline \multicolumn{6}{|c|}{ Test for overall effect: $Z=0.33(P=0.74)$} \\
\hline Test for subgroup dif & $01, d f=1(P=0.6), I$ & & & & \\
\hline
\end{tabular}

Analysis 5.12. Comparison 5 RISPERIDONE vs COMBINATION: b. RISPERIDONE + VALPROIC ACID, Outcome 12 Adverse effects: 2f. Specific - Movement disorders - Average scores - i. Over 24 hours.

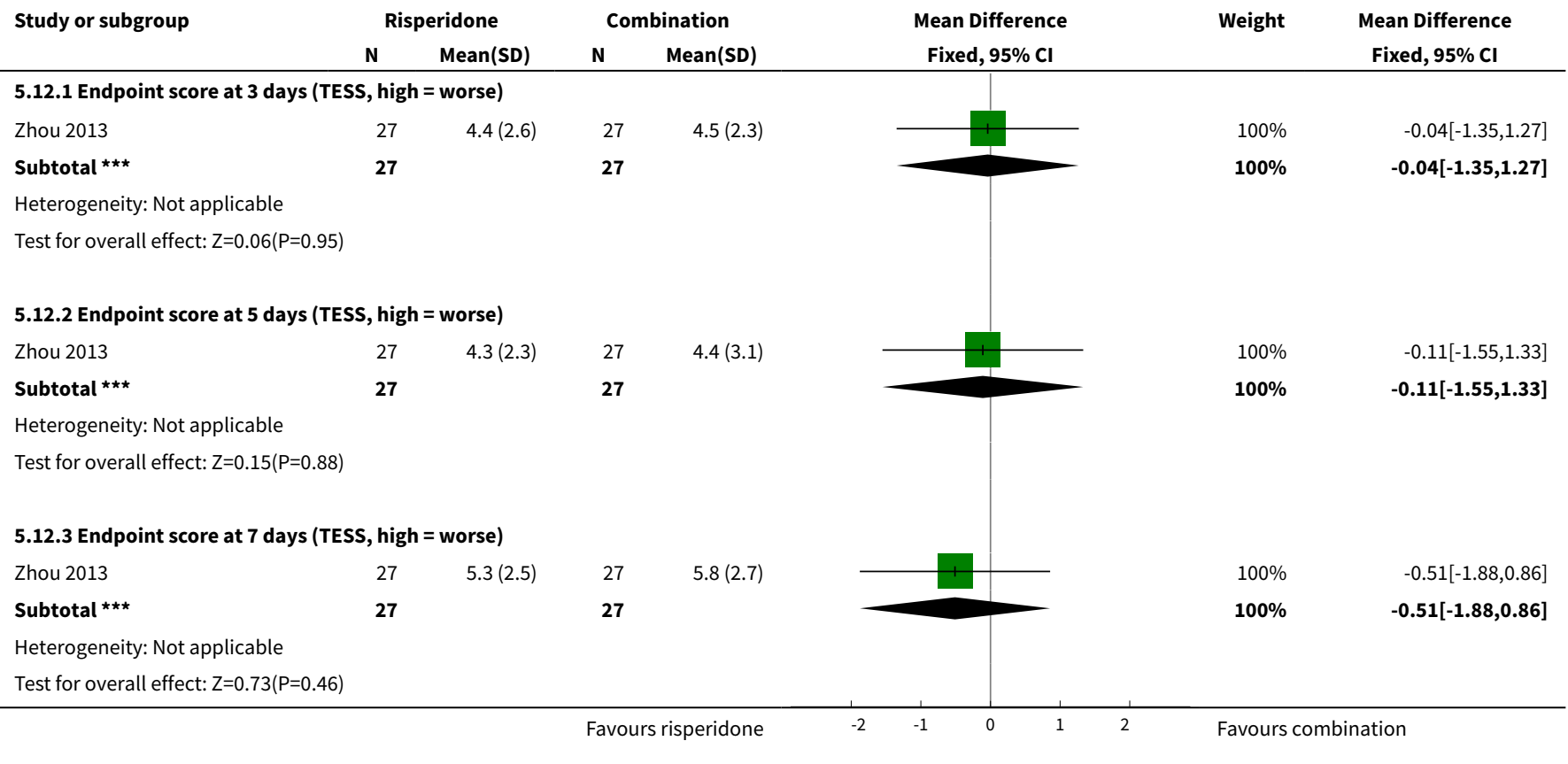




\begin{tabular}{|c|c|c|c|c|c|c|c|}
\hline \multirow[t]{2}{*}{ Study or subgroup } & Risperidone & Combination & \multirow{2}{*}{\multicolumn{3}{|c|}{$\begin{array}{c}\text { Mean Difference } \\
\text { Fixed, } 95 \% \mathrm{Cl}\end{array}$}} & \multirow[t]{2}{*}{ Weight } & \multirow{2}{*}{$\begin{array}{c}\text { Mean Difference } \\
\text { Fixed, } 95 \% \mathrm{Cl}\end{array}$} \\
\hline & Mean(SD) & $\operatorname{Mean}(S D)$ & & & & & \\
\hline \multicolumn{8}{|c|}{ Test for subgroup differences: $\mathrm{Chi}^{2}=0.27, \mathrm{df}=1(\mathrm{P}=0.87), \mathrm{I}^{2}=0 \%$} \\
\hline
\end{tabular}

\section{Analysis 5.13. Comparison 5 RISPERIDONE vs COMBINATION: b. RISPERIDONE + VALPROIC ACID, Outcome 13 Adverse effects: $2 \mathrm{~g}$. Specific - Miscellaneous.}

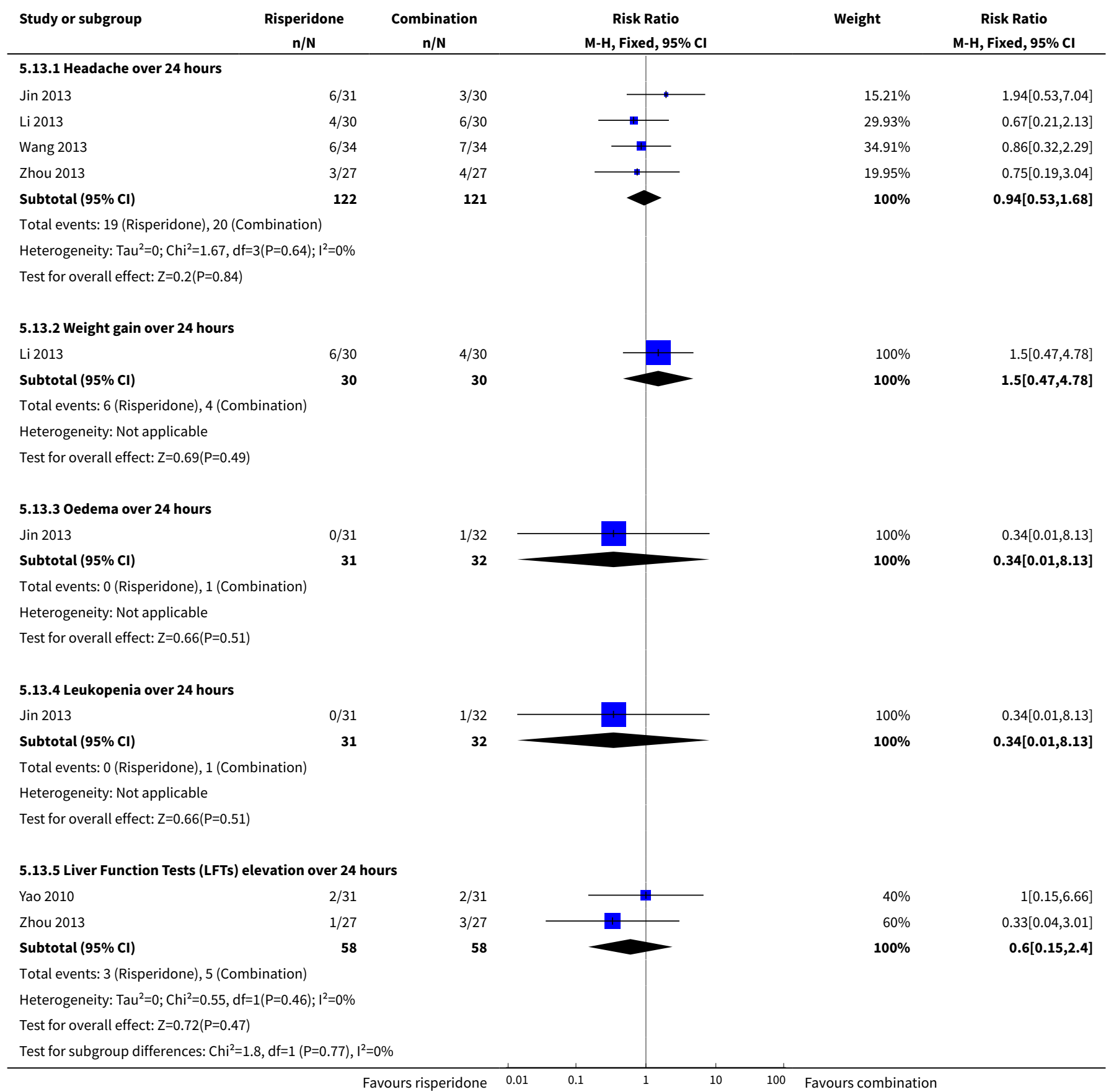


Analysis 5.14. Comparison 5 RISPERIDONE vs COMBINATION: b. RISPERIDONE + VALPROIC ACID, Outcome 14 Leaving the study early.

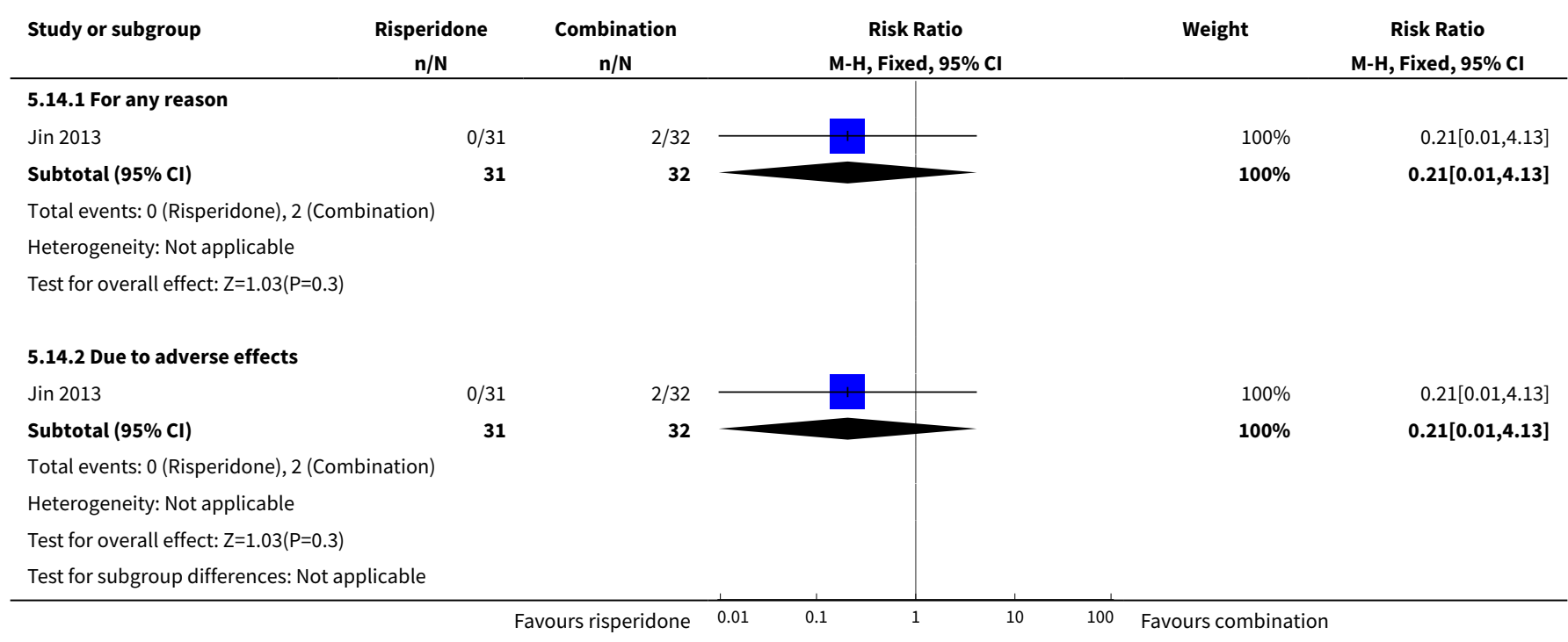

\section{ADDITIONAL TABLES}

Table 1. Linked reviews

\begin{tabular}{|c|c|}
\hline Focus of review & Reference \\
\hline \multicolumn{2}{|l|}{ Completed and maintained reviews } \\
\hline Aripiprazole (intramuscular) for psychosis-induced aggression or agitation (rapid tranquillisation) & Ostinelli 2018 \\
\hline Benzodiazepines for psychosis-induced aggression or agitation & Zaman 2017 \\
\hline Chlorpromazine for psychosis-induced aggression or agitation & Ahmed 2010 \\
\hline Containment strategies for people with serious mental illness & Muralidharan 2006 \\
\hline De-escalation techniques for psychosis-induced aggression or agitation & Du 2017 \\
\hline Droperidol for psychosis-induced aggression or agitation & Khokhar 2016 \\
\hline Haloperidol for psychosis-induced aggression or agitation (rapid tranquillisation) & Ostinelli 2017 \\
\hline Haloperidol plus promethazine for psychosis-induced aggression & Huf 2016 \\
\hline $\begin{array}{l}\text { Olanzapine IM or velotab for acutely disturbed/agitated people with suspected serious mental ill- } \\
\text { nesses }\end{array}$ & Belgamwar 2005 \\
\hline Zuclopenthixol acetate for acute schizophrenia and similar serious mental illnesses & Jayakody 2012 \\
\hline \multicolumn{2}{|l|}{ Reviews in the process of being completed } \\
\hline Loxapine inhaler for psychosis-induced aggression & Vangala 2012 \\
\hline
\end{tabular}


Table 1. Linked reviews (Continued)

Table 2. Suggested design for a trial

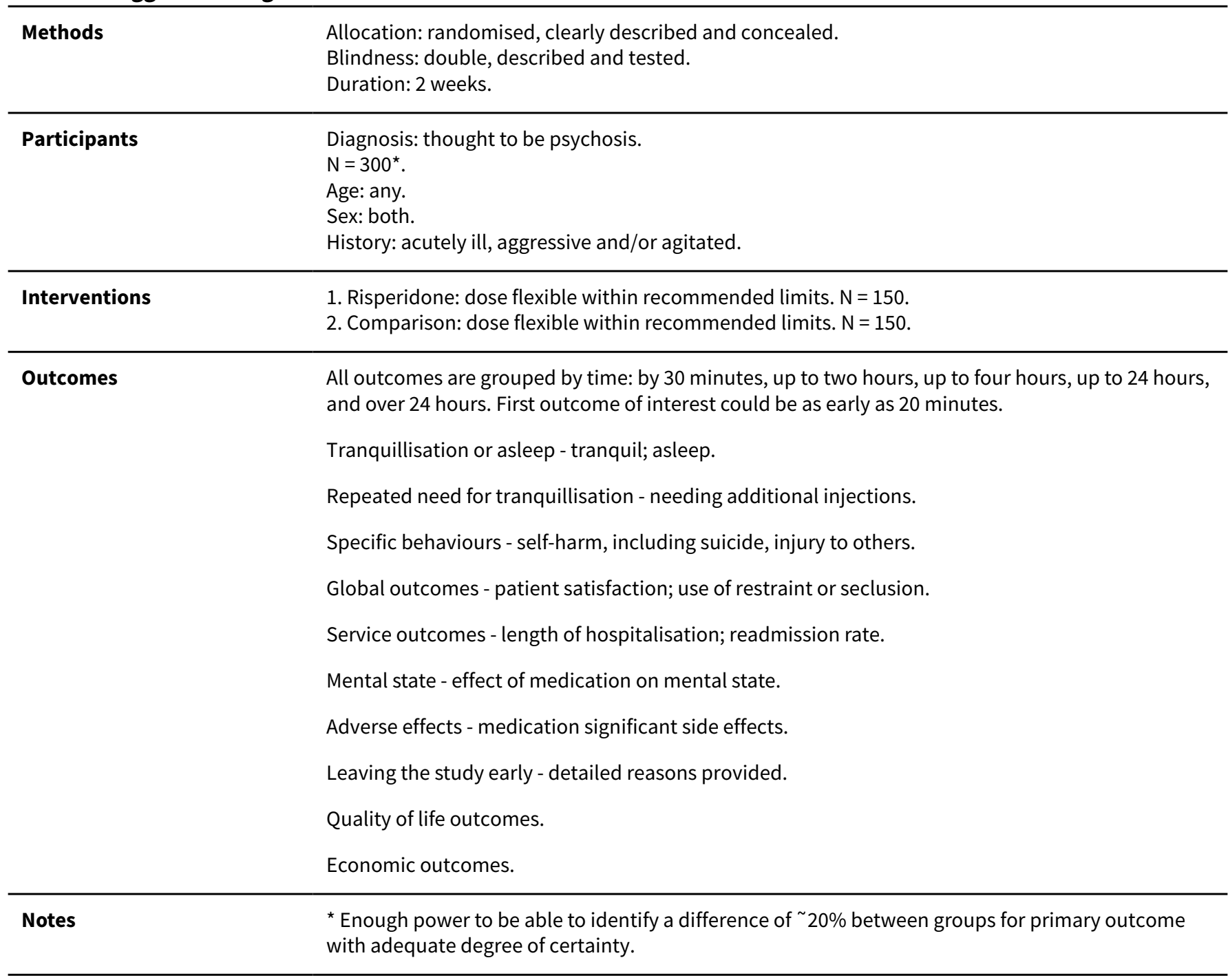

\section{H I S T O R Y}

Protocol first published: Issue 11, 2011

Review first published: Issue 4, 2018

\begin{tabular}{lll}
\hline Date & Event & Description \\
\hline 12 April 2017 & Amended & $\begin{array}{l}\text { Search re-run and 14 Studies were added to Studies awaiting } \\
\text { classification section of the review. }\end{array}$ \\
\hline 19 June 2015 & Amended & $\begin{array}{l}\text { Search re-run and two studies (three references) were added to } \\
\text { 'Studies awaiting assessment' section of the review. }\end{array}$ \\
\hline
\end{tabular}




\begin{tabular}{lll}
\hline Date & Event & Description \\
\hline 1 November 2013 & Amended & $\begin{array}{l}\text { Search re-run in November 2013, and 56 studies were added to } \\
\text { 'Studies awaiting assessment' section of the review. }\end{array}$ \\
\hline 1 December 2011 & Amended & Original search in December 2011. \\
\hline
\end{tabular}

\section{CONTRIBUTIONS OF AUTHORS}

Edoardo G Ostinelli - screened and retrieved papers (2017 search, checking again studies from previous searches) against eligibility criteria, appraised quality of papers, extracted data from papers, entered data into RevMan and analysed data, interpreted data and took the lead in writing the review.

Mohsin Hussein - screened and retrieved papers (2017 search, checking again studies from previous searches) against eligibility criteria, appraised quality of papers, extracted data from papers, entered data into RevMan and analysed data, interpreted data and helped in writing the review.

Uzair Ahmed - (2011 and 2013 searches) screened and retrieved papers against eligibility criteria, extracted data from papers, helped writing the protocol and review.

Fair-ur Rehman - (2011 and 2013 searches) screened and retrieved papers against eligibility criteria, extracted data from papers, helped writing the protocol and review.

Miramontes - extracted data from papers, helped writing the review (2015 search).

Clive E Adams - helped writing and provided advice for the protocol and all review versions.

\section{DECLARATIONS OF INTEREST}

Edoardo G Ostinelli: none known.

Mohsin Hussein: none known.

Uzair Ahmed: none known.

Faiz-ur Rehman: none known.

Krista Miramontes: none known.

Clive E Adams: none known.

\section{SOURCES OF SUPPORT}

\section{Internal sources}

- Università degli Studi di Milano, Milan, Italy.

Employs lead author Edoardo G Ostinelli.

- Queens Medical Centre, The University of Nottingham, UK.

Employs review author Mohsin Hussein.

- Rotherham, Doncaster and South Humber NHS Foundation Trust, Doncaster, UK.

Employed review author Uzair Ahmed at the time of writing the review.

- Buxton Health Centre, Buxton, UK.

Employed review author Faiz-ur Rehman at time of writing review.

- Cochrane Schizophrenia Group, The University of Nottingham, UK.

Employs review author Clive E Adams. 


\section{External sources}

- No sources of support supplied

\section{DIFFERENCES BETWEEN PROTOCOLANDREVIEW}

As the latest searches were conducted some time after protocol publication, we used the latest Cochrane methods for each search and updated the methods section with the Cochrane Schizophrenia Methods template.

In addition, in order to conform this systematic review to the family of 'rapid tranquillisation' ones, the 'methods' section was amended as follows.

\section{Title amendment}

Title is now Risperidone for psychosis-induced aggression or agitation (rapid tranquillisation), the previous title was Risperidone for psychosis induced aggression or agitation (rapid tranquillisation)

\section{Types of interventions}

The 'risperidone in combination with other drugs' potential comparisons were not taken in consideration, in order to have 'risperidone alone' as a common comparator.

Types of outcome measures - primary outcomes

The primary outcome 'not tranquil or asleep' has been specified with a relevant time point indication: 'by up to 30 minutes'.

\section{Types of outcome measures - secondary outcomes}

A list of secondary outcomes within the 'tranquillisation or asleep' subgroup was added.

\section{Data extraction and management - extraction}

A reference for data extraction from figures was added.

Data extraction and management - 'Summary of findings' table

The list of included outcomes was improved and listed within the 'type of outcome measures' section.

\section{Data synthesis}

We preferred to use a fixed-effect model; please note that this change was done before data extraction and studies analyses.

\section{N DEX TERMS}

\section{Medical Subject Headings (MeSH)}

Administration, Oral; Aggression [ ${ }^{\star}$ drug effects] [psychology]; Antipsychotic Agents [adverse effects] [ ${ }^{\star}$ therapeutic use]; Carbamazepine [analogs \& derivatives] [therapeutic use]; Oxcarbazepine; Psychomotor Agitation [ ${ }^{\star}$ drug therapy]; Psychotic Disorders [*complications] [drug therapy] [psychology]; Quetiapine Fumarate [therapeutic use]; Randomized Controlled Trials as Topic; Risperidone [adverse effects] [ ${ }^{\star}$ therapeutic use]; Tranquilizing Agents [therapeutic use]; Valproic Acid [therapeutic use]

\section{MeSH check words}

Humans 